XVI.

\title{
Psychogene Störungen des Auges und des Gehörs.
}

Von

\author{
Privatdozent Dr. F. Kehrer - Freiburg i. B. \\ zurzeit Chefarzt eines Reservelazaretts.
}

(Mit 9 Abbildungen und sechriftproben.)

Je intensiver wir uns nnit der Analyse der Kriegsneurosen beschäftigen, am so mehr nehmen die lokalen Hysterien oder weiter gefasst die lokalisierten psychogenen Störungen theoretisch und praktisch unser Interesse in Anspruch. In meinem vorjährigen Vortrage ${ }^{1}$ ) über , die Entstehung und Behandlung der Kriegsneurosen" bin ich der Frage nach den Bedingungen der „Ortswahl" der körperlichen Symptome und insbesondere der lateralisierten Reiz- und Lähmungserscheinungen nähergetreten. Was ich damals als die Regel aufstellte, dass nahezu in jedem Falle bei eindringlicher Untersuchung das Befallenwerden eines bestimmten Körperteils oder -abschnitts aus kausalem oder verständlichem Zusammenhange heraus eindeutig zu bestimmen sei, hat sich auf Grund aller weiteren Erfahrungen nur noch weiter erhärten lassen. Wenn in einer Reihe von Fällen die psychische bzw. reaktive Ueberwertigkeit der befallenen Körperteile etwa nach einer Granatexplosion oder Verschüttung im Stadium der Restitntion der traumatischen Bewusstlosigkeit ausschlaggebend ist, so ist es in einer anderen eime irgendwie geartete, nervöse oder nicht nervöse, alte oder frische dynamische Minderwertigkeit des psychogen betroffenen Körperteils, und in einer dritten wiederum die ideale Konkurrenz beider Reihen, die die „Ortswahl" befriedigend erkiärt. Als komplizierend treten bei den Experimenten, die sich Natur und Kultur mit den Neurosen des Krieges leisten, nun noch eine ganze Reihe seliundärer Folgen im Seelischen und im Körperlichen bestimmend zu jenen Faktoren hinzu und erzeugen einen Circulus vitiosus, dessen Anfang sich oft nur schwer entwirren lässt. Aus diesem Tatbestande scheint mir za

1) Wanderversammlung der südwestdeutschen Neurologen und Irrenärzte Baden-Baden 3. 6. 1916 und Archiv f. Psych. Bd. 57. H. 1. 
folgen, dass wir, um eine tiefere Einsicht in Entstehung und Wesen dieser lokalen Störungen zu gewinnen, versuchen müssen, zugleich von der psychologischen wie von der physiologischen Seite her diagnostisch alle Möglichkeiten zu erschöpfen. Denn nur so werden wir der Gefahr entrinnen, einseitig alles für ideo- oder thymogen zu halten oder andererseits die Bedeutung der mechanischen Genese zu überschätzen.

Wenn die hier kurz wiedergegebenen Grundsätze, welche aus den Erfahrungen bei den seelisch bedingten Störungen der Extremitäten und des Stammes sich ergeben haben, allgemein richtig sind, so lässt sich erwarten, dass sie im grossen und ganzen auch für die psychogenen Störungen der höheren Sinnesorgane zutreffen und hier nur solche Modifikationen erfahren, welche sich aus Bau und Funktion dieser Sinneswerkzeuge von selbst ergeben.

Aus einer grösseren Reihe von einschlägigen Beobachtungen, welche uns durch liebenswürdiges Entgegenkommen der entsprechenden Fachärzte ${ }^{1}$ ) zur Behandlung zugewiesen wurden, und nach Erschöpfung der diagnostischen Hilfsmittel ihre, wenn man so sagen darf, ,diagnostische Schlussweihe" durch den positiven Erfolg der Psychotherapie erfahren haben, will ich versuchen, in die Pathologie dieser im Frieden so seltenen Erscheinungen einzudringen.

In einer ersten Gruppe von Beobachtungen sollen die psychogenen Störungen der Augenbewegungen behandelt werden, in der zweiten der sehr viel kleinere Kreis seelisch bzw. hysterisch bedingter Blindheit oder anderweitiger Sehstörungen.

An die Spitze der seelisch bedingten Hörausfälle stelle ich die psychogene Aufpropfung auf chronische Schwerhörigkeit; ihnen folgen die hysterischen Taubheiten und die Simulation von Hörschwäche; am Schluss die Gruppe der Taubheit bzw. Taubstummheit nach Explosion und Verschüttung.

\section{Psychogene Störungen der Augenbewegungen.}

Beobachtung 1. S., geb. 1882, Buchdrucker, keine Bleierkrankung.

Als Kind schwächlich, ängstlich; 1 Jahr zu spät zur Schule. Aktiv 1904-06; 1. Manöver bai Bagage. 2 Uebungen, einmal schlapp gemacht. 6. 8. 1914 ins Feld. Anfang 1915 dureh Unterstandleben nervös, schlaflos, fuhr zusammen vor Vorgesetzten usw.

28. 2. Sturm auf F. Im Elan bemerkte er einen dabei erlittenen Streifsehuss der 2. linken Zehe nicht, erst bei kurzem Rückgang vor schwerem Artilleriefeuer beim Liegen auf dem Boden in Deckung; in dieser Situation Granateinschlag links schräg hinten, verspürte „warmen Luftdruck“, wurde in den vor ihm liegenden

1) Ich gedenke dankbar an dieser Stelle besonders der Herren Prof. $K$ ü $m \mathrm{~m} e \mathrm{l}$, Geh. Rat Axenfeld und Prof. vonszily, Privatdozent Dr. Ha uptmann, Prof. Bloch und Dr. Dorff. 
Sprengtrichter geschleudert: bewusstlos; nach spätestens einer Stunde wieder „,bei sich"; sofort Kopfschmerzen, Stechen, Ohrensausen links; ging allein zum Verbandplatz, unterwegs wiederholt schwindlig, Zucken im linken Gesicht. Erst am nächsten Tag im Krriegslazarett merkte er Zittern im rechten Arm, einige Tage später im linken Bein und Gesicht.

2. 3. Heimatlazarett: Apathie, Sehreckträume, sehr starke Kopfschmerzen links hinten und in der Ohrgegend. Hinterkopf druckempfindlich (Contusio).

11. 4. Dauernd starke Kopfschmerzen links, Augenzwinkern.

10. 5. Fachlazarett: Dauernd tikartige Zuckungen des linken Augenlides, der Wangengegend und Mundwinkel. Rechter Mundwinkel bleibt beim Zähnezeigen zurïck. Kniehackenversuch links ungeschickt; sonst, auch otologisch o. B. Allgemeine Schreckhaftigkeit.

12. 5. Nervenbehandlungslazarett: Subj.: Beständig Rauschen, Kopischmerzen links, Konzentrationsschwäche; Sprechen rege auf. Obj.: Missmutig, mürrisch; psych. bedingte Sprechhemmung. Augenfusschluss: Nach Sekunde Lidflattern, rücksichtsloses Körperpendeln nach links, auch trotz brüsker Zurechtweisung; es bleibt aber aus, wenn er zugleich Fingernasenversuch machen muss, wobei er regelmässig mit dem rechten Zeigefinger auf die linke Wange zeigt. Trigeminus 1 links druckempfindlich. Tic abwechselnd mehr in Orbic. oculi, Orbic. oris und 2. Fazialisast links, selten in Kaumuskeln und Platysma; bald mehr kurz, bald mehr wogend. Aktives Verziehen des Munds nach rechts auf Aufforderung nicht zu erzielen. Linke Nasolabialfalte undeutlicher. Zunge feinschlägig tremolierend; dazu Hemispasmus nach rechts. Feuchte, zyanotische Hände. Dermographie stark. Bei statischer Innervation mittelfeines Handzittern rechts (ProSupination). Zuweilen beim Sitzen grobes Zitterwackeln des linken Fusses. Links Patell.-Re. psychisch verstärkt, wie alles andere auch.

28. 5. Am Vortage noch ausgesprochener Hemispasmus glosso-facialis; heute bei Untersuchung wegen Angina (Temp. 38,8), die überrumpelt, streckt er bei Inspektion des Rachens die Zunge gerade heraus, ,vergisst sich", und von da ab bleibt der Hemispasmus aus. Im Gespräch mit der Krankenschwester äussert er sehr typische nosophile Ideen, als diese u. a. fragt: „Sie wollen doch gesund werden?" "Was heisst gesund werden - jetzt, was braucht man gesund zu sein, um sich totschiessen zu lassen."

10. 5. Charakteristisch für den noch restierenden Tic in der linken oberen Gesichtshälfte, besonders der Lider, ist, dass er unbeachtet im. Gleichgewicht des Gemüts sistiert, bei der Untersuchung sehr stark ist, aber auch bei starker Konzentrierung der Aufmerksamkeit beim Schachspiel, wobei er sich sicher nicht beobachtet wähnen kann (zufällige Beobachtıng durchs Schlüsselloch), gelegentlich auftritt. Auch hierbei hält er fast dauernd den linken Kopf etwas gestützt.

Also körperliche und ideogene Schädigung auf der linken Körperseite vornehmlich des Kopfes. Primär: Glaubhafte neuralgische Irradiation und Sensationen (Ohr) vom Trigeminus aus. Sekundär entwickeln sich zunächst reflektorisch als Schmerzabwehrbewegung Augenzwinkern, allmählich ausgreifend zum Tic der Augenschliesser, dann auch der Wangengegend, 
alternierend mit neur- oder psyehalgogener Schonung der Willkürbewegungen der gleichen Seite (Scheinparese: Nasolabialfalte!). Interessant ist auch das Hervortreten einer Ueberwertigkeit der linken Gesichtshälfte im Bewusstsein der Körperlichkeit beim Finger-Nasen-Versuch. Als Krönung des Bildes kompensatorisch-reziproker Hemispasmus glossolabialis der Gegenseite. Also ,hysterische Entartung ${ }^{66}$ einer ursprünglich besonderen Art von „Reflexkrampf".

Nach der äusserst charakteristischen Bemerkung gegenüber der Krankenschwester ist an dem „Defekt des Gesundheitsgewissens" bei dem Manne nicht zu zweifeln. Ebensowenig kann bestritten werden, dass der ganze Symptomenkomplex recht locker sitzen muss, wenn Ueberrumpelung und intensive Ablenkung der Aufmerksamkeit in anderer Richtung ihn vorübergehend seine Symptome "vergessen" lassen. Dennoch aber glaube ich, dass die gegebene Darstellung der neuro-psychischen Entwicklung der Symptome, welche sich aus der ursprünglich nicht von Fachärzten niedergelegten, aber auch später nicht von irgendeinem diagnostischen Neurologenvorurteil beeinflussten Krankengeschichte so ergibt, der Wirklichkeit näher kommt, als etwa die restlose Erklärung aus Krankheitseinbildung. Das pathogene „Rezept": Uebertragung des „Bildes der Untätigkeit einer Gesichtshälfte, wie es sich der Laie vorstellt" (Lewandowsky-Mann) in die Wirklichkeit, spielt hier wohl sicher nur eine Nebenrolle.

Beobachtnng 2. Sch., Unteroffizier, Formermeister.

Als Kind Hydrocephalus, Diphtherie, Scharlach, oft Gefühl, als wenn grosse Massen auf ihn gewälzt würden. 1897-99 aktiv.

3. 9.1915 eingezogen. 12. 2. 1916 ins Ffld, Verdun. 3. 4. Volltreffer im Graben; 4 Nebenmänner tot, er selbst hatte, wie cinen Schlag vor den Kopf, dumpfes Gefühl", Erdmassen ins Gesicht, geringes Zucken, nicht bewusstios; tagsüber benommen. 13. 4. wegen Filzläuse krank gemeldet; bekam dafür Einreibungen mit graner Salbe; danach Gingivitis. Ende April Ohrenschmerzen. 4. 5. deswegen ins Feldlazarett: Nur Otitis externa hämorrhag. 8.-10.5. beiderseits Blepharospasmus, Tränenträufeln, Konjunktiven stark gerötet, sezernierend, Schmerzen und schlechtes Sehen bei Abend. Lichtscheu, Gefühl, ,als ziehe von hinten jemand die Augenlider". 15. 5. Blepharospasmus danernd beiderseits, besonders bei Blick nach oben. Gibt sich ausserordentlich theatralisch als Leidender; unter entsprechender Beachtung nimmt der tonische Blepharospasmus noch zu und zeigt dann daneben noch einige zwinkernde Zusatzkloni; ebenso theatralisch bewegt er sich wie ein fast Blinder im Raum. Grobschlägiger Tremor der ausgestreckten Zunge und Hände. Pseudo-Romberg +; leichte Konjunktivis; Zahntleischbelag.

20. 5. Nervenbehandlungslazarett B.: Psychogene Sprachhemmung und -pressung. Blick nach dem Boden. Konjunk ti va leicht gereizt. Lidspalte wird fast nur zur Orientierung geöffnet, danach um so fester zusammen- 
gepresst. Sugg.-Heilnng durch Androhung an die Krankenschwester, wenn er bis nach 5 Tagen den Blepharospasmus nicht verloren, werde er auf die Abteilung für aktive Therapie verlegt. Meldung am 4. Tag morgens: „Durch die kolossalen Bemühungen der Schwester bin ich von meinem Leiden befreit.". Trifft zu. (Exerzirrübungen bei sonst absoluter Bettruhe.)

Ich führe den Fall nur an, weil er in besonders durchsichtiger Weise die hysterische Fixierung des ursprünglichen Reflexkrampfes oder, wie es Lewandowsky ausdrückt, ,die Permanenzerklärung eines organischen Leidens" zeigt. Cessante cause non cessit effectus. Sonstige körperliche Stigmata der Hysterie fehlten ganz, dafür war die hysterische Darstellungsweise seines ursprünglich rein nervös-unhysterischen lokalisierten Muskelkrampfes um so theatralischer. Der kindliche Entstehungsmechanismus desselben bei einem intelligenten Unteroffizier, das Hineingeraten in denselben nach einer ganz zufallsmässig - durch Intoxikation mit Quecksilber, das gegen Filzläuse verabreicht war - erworbenen beiderseitigen Konjunktivitis ist doch ungewöhnlich. Die hysterische Fixierung als pathologische schlechte Gewöhnung an eine ursprünglich zweckmässige Reflexabwebrbewegung bzw. Abwehrautomatismus zeigt sich hier in einfachster Weise. „Psychisches Austreiben" gelang glatt durch einfachste Aufklärung über diesen Mechanismus-in Form heimlicher Drohung mit unsanfter Kur.

Ich bin überzeugt, dass in fast allen Fällen isolierten, d. h. nur auf die Lider beschränkten Monospasmus diese hier so durchsichtige Entstehungsweise sich bei Erhebung einer eingehenden Anamnese nachweisen lässt. Der entscheidende Ausgangspunkt des Monospasmus der Lider wird also immer in irgendeiner länger-anhaltenden lästigen Sensation entweder im Bereich des 1. Trigeminusastes vorweg des äusseren Auges oder des Bulbus, in Fremdkörper- oder Blendungsgefühl, zu finden sein. Anders liegt der ursächliche Zusammenhang in denjenigen Fällen (Binswanger), in denen der Blepharospasmus nur die Teilerscheinung einer allgemeinen krankhaften Anlage oder Tendenz zu Krampf- oder Kontrakturbildung darstellt.

Theoretisch lässt sich am Beispiel des Blepharospasmus besonders einleuchtend der Punkt angeben, von dem ab ein höherer Reflex bzw. niederer Automatismus zur hysterischen Bewegungsstörung wird. Tch sehe keinen Finwand gegen die These: Die Bewegung ist hysterisch, wenn die chromische Erregung des zentripetalen Schenkels in diesem Falle der sensiblen oder sensorischen Bahn wegfällt oder sich ein Missverbältnis einstellt zwischen der Stärke dieser Erregung und dem Ausmass und Bestehen der Bewegung. Sobald die Bewegung nicht mehr aus der in psychologischem Sinne reinen Dauerempfindung erklärbar ist, muss sie hysterisch genannt werden. Es lrommen dann zwei Möglichkeiten in Betracht: die Bewegung erfolgt entweder auf 
Grund der Reproduktion der primären Empfindung, im Prinzip also infolge einer niederen Halluzination: durch Psychalgien usf., oder aber allein aus psychomotorischer Gewohnheit. Vom genetischen Standpunkte ist also der reine nicht hysterische Reflexkrampf sehr wohl rom Reflexkrampfe zu trennen, der die hysterische Abwandlung eines Bedingungsreflexes darstellt. Wir hätten dann als Unterformen des hysterischen Monospasmus den reproduzierten Reflex von der psychomotorischen Gewöhnung zu scheiden. Natürlich wird es im Einzelfalle echten hysterischen Blepharospasmus meist schwer zu entscheiden sein, welche dieser beiden Möglichkeiten verwirklicht ist.

Trotz der grossen äusseren Aehnlichkeit ist von dem hysterischen Blepharospasmus, für den der durchaus überflüssige und verwirrende Ausdruck Ptosis spastica s. pseudo-paralytica aufgekommen ist, die funktionelle echte $\mathbf{P}$ tosis zu trennen. Dass es eine solche gibt, kann nach den neueren Erfahrungen nicht mehr bestritten werden. Lew andowsky ${ }^{1}$ ), vermag sich zwar nicht zu überzeugen", dass eine wirklich schlaffe einseitige Ptosis hysterischen Ursprungs vorkommt, für die einwandfrei erwiesenen Fälle derart ist aber gerade jener Faktor zur Erklärung geeignet, den er selbst in fruchtbarer Weise in die Hysterieerklärung hereingezogen hat: die individuelle Dissoziationsfähigkeit der Muskulatur.

Den besonderen anatomischen und physiologischen Verhältnissen entsprechend liegen in dieser Beziehung am Auge die Dinge komplizierter als am Stamm und den Extremitäten, und auch am. Auge sind die Bedingungen der Dissoziierbarkeit für die reinen Blickmuskeln andere als für die Lidbeweger. Die Blickwender nehmen hierin eine Mittelstellung zwischen Skelett- und Lidmuskulatur ein. Wie an den Extremitäten hängt hier die Dissoziierbarkeit zunächst von dem Ineinanderspielen der Innervationen von quergestreiften Agonisten, Synergisten und Antagonisten ab. $\mathrm{Zu}$ der zentripetalen Kontrolle des Muskelsinns tritt am Auge komplizierend noch in jedem Angenblick die sensorische Kontrolle hinzu. Abweichungen in der Veränderlichkeit des Bewegungsablaufs lassen sich also allein schon aus solchen der optischen Fusion ableiten. Andererseits aber sind Variationen des Bewegungsspiels möglich, welche einfach eine Steigerung der durchschnittlichen Willkürbeeinflussung quergestreifter Muskeln bedeuten. Sie sind bei richtigem Erlernen jederzeit willkürlich bis zu einem übernormalen Ausmass darzustellen. Theoretisch ist es sehr wohl denkbar, dass dies Erlernen um so leichter erfolgt, wenn bei dem betreffenden Individuum Störungen der Sehfunktion vorliegen, insonderheit wenn die optische Projektion, die Fusion oder die zentrale Sehschärfe zu wünschen übrig lässt. Es ist also wohl möglich, dass auch gewisse Refraktionsanomalien stärkeren

1) Die Hysterie. Springer. 1914. 
Grades der Erlernbarkeit derartiger ,Ueberbewegungen“" erheblich Vorschub leisten.

Für die wichtigste der abnormen Blickbewegungen, den Nystagmus, hat in einer anregenden Studie Igersheimer ${ }^{1}$ ) nahezu alle Möglichkeiten seiner optischen Verursachung aufgewiesen. Insbesondere hat er gezeigt, dass nicht bloss die Amblyopie, sondern eine Reihe von zirkumskripten Störungen der Retinalfunktion, die nicht zu gröberen Sehstörungen Anlass geben, wie die Retinitis pigmentosa, der albinotische Defekt der Macula lutea, partielle Farbenblindheit usf. als ursächliches Moment von Augenwackeln in Betracht kommt. Er hat aber mit Recht hervorgehoben, dass auch bei diesen rein optisch bedingten Nystagmusformen die sensorischen Störungen für sich allein nicht die nystagmischen Augenbewegungen auslösen können, vielmehr die Beteiligung des Grosshirns im Sinne der zentralen Regulierung nicht zu umgehen ist. Für die Frage des funktionellen Nystagmus ist dies von entscheidender Bedeutung. Genereller gibt sich daraus der Wahrscheinlichkeitsschluss, dass zentrale Einflüsse um so leichter zu Nystagmus führen können, wenn latente sensorische Anomalien vorhanden sind. Dies gilt für die willkürliche Darstellbarkeit ebenso wie für das hysterische Ingangsetzen. Igersheimer führt einen in dieser Beziehung klassischen Fall von Ra e hlmann an. Ein Arzt litt in der Kindheit an Nystagmus, der besonders unter Gemütsaffektionen in Erscheinung trat, gegen das 15. Lebensjahr aber verschwand. Der Betreffende konnte von da ab stets willkürlich Augenwackeln hervorrufen. Ueber gröbere Sehstörungen wurde nichts angegeben; dennoch fand sich analog den Fällen von Igersheimer partielle Farbenblindheit.

In jedem Falle von willkürlicher Erzeugung von Nystagmus muss an solche Hilfsursachen gedacht werden. In der Literatur gilt das willkürliche Augenwackeln als Kuriosum. Dass es vorkommt, ist aber danach nicht zu bestreiten. Die Besonderheit des Symptoms bringt es mit sich, dass es sich meist $\mathrm{um}$ Aerzte oder ärztlich gebildete Menschen handelt, die, sei es aus Sport, sei es aus negativen Begehrungsvorstellungen, darauf kommen, sich auf die Erlernung desselben zu werfen.

Wenn schon der Grundsatz nicht bestritten wird, dass das Gros der sinnfälligen hysterischen Symptome unter Umständen willkürlich nachgeahmt werden kann, zwingt uns umgekehrt die in seltenen Fällen mögliche Erlernbarkeit von Augenwackeln das Vorkommen eines - im weitesten Sinne des Wortes - funktionellen Nystagmus anzuerkennen.

Nach den Erfahrungen über die Hypermotilitätserscheinungen an der Skelettmuskulatur lassen sich von vornherein zwei verschiedene Typen funk-

1) Klin. Monatsbl. f. Augenheilkde. 
tionellen Nystagmus ableitell: ein as then is cher und ein hypersthen ischer Typ. Die Entstehungsbedingungen dieser versehiedenen Formen werden deutlich, wenn wir die naheliegende Analogie zu Reizerscheinungen heranziehen, die bei den physiologisch prinzipiell gleichgearteten "freihändigen" Bewegungen der Hände auftreten. Rein kinetisch betrachtet unterscheiden sich, wie Pelnar näher ausgeführt hat, die funktionellen Zitterformen nach der Art der zugrundeliegenden Bewegung ziemlich seharf voneinander. Der psychophysiologische Akt des Objektdeutens geradeaus ist ein anderer als das Festhalten von gekünstelten Stellungen, wie beispielsweise der gespreizt vorgestreckten Finger (,statische Innervation") oder bei der exkursiv weitläufigsten Bewegung im Finger-Finger- und Finger-Nasenversuch. Dementsprechend sind funktionelle Zitterbewegungen, die monosymptomatisch nur oder ausschliesslich bei einen dieser drei Akte auftreten, verschieden zu bowerten. Wie die Exfahrung lehrt, entspringen diese drei modalen Kategorien trotz mancher Uebergänge im Einzelfall grundsätzlich verschiedenen klinischen Ursachen. Auf die Verhältuisse am Auge übertragen, würden wir - normalen Visus vorausgesetzt - auch hier das statische Zittern oder Wackeln der Bulbi, das bei scharfem Fixieren geradeaus auftritt, zu tremnen haben sowohl vom Wackeln des ziellos geradeaus gestellten und dem natürlichen Gleichgewichtszustande seiner Muskelkräfte überlassenen Augapfel, wie von dem Tremor des Bulbus, der in gleichmässiger Kurve einem nach der äussersten Peripherie seines Gesichtsfeld wandernden Objekt folgt. Ganz wie an den Händen, wäre also am Bulbus mehr oder minder scharf das statische Wackeln vom Waekeln in Ruhe und dem eigentlichen Einstellungswackeln zu scheiden. In ganzen wird der "statische Tremor" der Bulbi feinschlägiger und nicht unter allen Umständen so rhythmisch in scharf auseinanderzuhaltenden Phasen ablaufen als das Intentionswackeln der Bulbi bei der multiplen Sklerose. Demgegenüber ist der hypersthenische Nystagmus äusserlich nach Form und Ablauf von diesem nicht schärfer zu unterscheiden, als eine „spastische Pseudoparese mit Tremor" von der echten spastischen Schwäche mit Klonus, wie wir sie bei der Sklerosis multiplex zu sehen bekommen. Die rein bewegungsphysiologische Analyse der wohl allgemein als hysterisch geltenden spastischen $\mathbf{P}_{\text {seudoparese mit Tremor lehrt }}$ uns, dass der Kern dieses Symptomenbildes einem Uebermass zeitlich falsch gewählter und dosierter Innervationen für die Agonisten, Synergisten und Antagonisten entspringt. Wie schon der Selbstversuch lehrt, tritt sekundär mit jeder maximalen oder ungewöhnlichen willkürlichen Dauerspannung, subjektiv als Ermüdungsphänomen, ein grobschlägiges Zittern auf, das sich dann weiterhin im Wechselspiel mit der Fortdauer der zentralen Innervation meist noch verstärkt. Dieser willkürliche Mechanismus kann auch einseitig mehr oder minder unbewusst, $d$. h. echt hysteriseh, in Gang gesetzt werden. 
Das Vorkommen einer halbseitigen spastischen Pseudoparese mit Tremor ist nach unseren Kriegserfahrungen nicht zu bezweifeln. Die Differentialdiagnose gegen multiple Sklerose bereitet naturgemäss die allergrössten Schwierigkeiten dann, wenn das halbseitige Krampfwackeln sich auch auf die Augäpfel erstreckt. Dies lag der folgenden Beobachtung zugrunde.

Beobachtung 3. Sch., geb. 1886, Weissbinder, verheiratet, 2 Kinder, 1 Bruder geistesschwach. Als Kind schwächlich und ängstlich, viel Kopfschmerzen; Bettnässen bis zum 6. Jahr, auf Schule einmal sitzen geblieben. Keine Pb-Vergiftung. Seit vielen Jahren sehr leicht aufgeregt und gereizt.

Norember 1914 zu Landsturm; während Ausbildung Krankmeldung wegen Schwindel, Schmerzen über den Angen, auf der linken Brust und im linken Bein, Magenschmerzen nach dem Essen.

2. 2. bis 26. 3. 1915 Lazarett wegen seit 3 Wochen auftretender Schmerzen in der Magen-Herzgegend, besonders meter Einflüssen der Nahrmgsaufnahme. Obj.: Hautfarbe blass; beide Augen beim Blick geradeaus und bei seitlichen Bewegungen dauernd in zitternder Bewegung (Nystagmus), Zunge zitternd herausgestreckt. Herz leicht erregbar. Leib, besonders Magengrubs, allgemein gespannt, druckempfindlich. Kniem und Achillesreflex beiderseits gleichstark gesteigert, Fussklonus, Bauchdeckenreflex herabgesetzt. Urin: Eiweiss Spur, vereinzelt Zylinder. Neurasthenische Klagen. Verdacht auf epigastrische Hernie. Verdacht auf chronische Bleivergiftung.

17. 3. Macht ausserordentlich gedrückten und gequälten Eindruck.

26. 3. Da das Leiden durch Lazarettbehandlung nicht gebessert wird, eher eine weitere Zunahme der nervösen Erscheinungen festzustellen ist, ins Revier entlassen. Daranf vom 19.--22. 5. 1915 wieder ins Lazarett. Subj.: Kopfschmerzen, Absterben der ganzen linken Seite, Zuckungen im ganzen Körper, Appetitlosigkeit, häufiges Frostgefühl, gestörter Schlaf, Stullverhaltung, Augenflimmern. Obj.: Bleich, verdrossener Gesichtsansdruck. Sprache langsam, nicht leicht verständlich, etwas absotzend, Gang leicht schwankend; beim Stehen mit geschlossenen Augen Schwanken. Pupillen reagieren, Kniephänomene beiderseits gesteigert. $\mathrm{D}$. $\mathrm{u}$. entlassen.

$\mathrm{Zu}$ Hause konnte er angeblich wegen Schwindel bei Blick in die Höhe nicht mohr so arbeiten wie früher. September 1916 wieder eingezogen. Im November stellten sich zu den bisherigen Beschwerden Schwäche in den Beinen, besonders links ein. 5. 11. Nervenstation Kriegslazarett, A.: Klagen über Schwindelanfälle, Gliederlähmung beim Marschieren; deprimierter Gesichtsausdruck; fibrilläre Zuckungen im Orbikularisgebiet; Hyperhidrosis während der Untersuchung, Periostreflex l. > r., Bauchdeckenreflex 0, Kremastarr flex, kaum merkbare, wurmförmige Kontraktionen. Patellarreflex 1. > r. Links starker FusskIonus schon beim Anheben des Fusses. Achillesreflex rechts sehr lebhaft, links kurzdarnernder Knizklonus. Sehr starker Dermographismus. Pupillen r. etwas $>1$. leicht entrundet, sonst 0 . B. In der Ruhe Nystagmus rotatorius nach rechts, der in Endstellungen sich verstärkt, beim Blick nach links wesentlich schneller wird; geringe 
Unsicherheit bei Fingernasenversuch. Sprache etwas schleppend, aber nicht skandierend.

Augenstation: Beiderseits Nystagmus rotatorius, stärker bei äusserer Blickwendung, bei Blick nach rechts langsamer, bei Blick nach links schneller.

Fundus o. B. S. R. ${ }^{4} / 14-1,0$ D. $1 / 8$ p.

L. $4 / 24-0$. V.d. Gl.

Ueber Vereinslazarett 0 . und E. T. T. 20. 12. 1916 Nervenbeobachtungsstation F. (Privatdoz. Dr. Hauptmann): Pupillen o. B., Nystagmus rotatorius, der sich beim Blick nach den Seiten verstärkt und auch horizontal sich bemerkbar macht. Bei Blick geradeaus häufig Strabismus convergens.

Befund der Augenklinik (Prof. v. Szily): „Ein Grund für Nystagmus liegt von seiten der Augen nicht vor. Insbesondere hat er mindestens auf einem Augo volle Sehschärfe, was eine ruhige Stellung der Augen gewährleisten müsste. Der Nystagmus besteht auch beim Blick geradeaus, nimmt bei seitlicher Endstellung allerdings etwas zu; er hat normale Papille; alles spricht also gegen multiple sklerose: jedenfalls fällt der Befund aus den Bahnen der üblichen Augensymptome bei mult. Sklerose heraus. Es ist nichts vermerkt, ob er seit Jugend an Nystagmus leidet, was bei kongenitaler Sehstörung als Ursache des Nystagmus eigentlich Voraussetzung wäre. Nach ganzem Habitus: Hysterie.

Befund der Ohrenklinik: Weder der Nystagmus, noch die statischen Störungen können auf Labyrintherkrankung zurückgeführt werden. 'Auf kalor. Reize reagieren beide Labyrinthe mit einem. Nystagmus (horizontal bzw. gemischt horizontalrotatorisch) nach der Gegenseite. Bei der Reizung des rechten Labyrinths tritt eine Verstärkung des auch sonst bestehenden Nystagmus ein. Schwindel in normalen Grenzen. Gehör o. B. Sprache: heisser, in eigenartiger Klangfarbe; nach Befund der Halsklinik: ,funktionelle Stimmstörung geringen Grades".

Gang etwas unsicher, halb ataktisch, halb spastisch, das linke Bein streift häufig am Boden. Sämtliche Sehnenperiostreflexe äusserst lebhaft 1 . $<$ r.; beiderseits Fuss- und Patellarklonus, I. viel >r.; kein Oppenheim, kein Babinski; Hautreflexe an sich sehr schwach, Bauchdeckenreflex links noch schwächer wie rechts. Ataktische Unsicherheit in Armen und Beinen. Hypästhesie an linker Hand und Fuss, linkes Bein vielleicht etwas schlechtere Stereognosie. Blut: Wassermann negativ.

2. 1. 1917. Die Gehstörung wechselt bei längerer Beobachtung sowohl nach Art wie Intensität, scheint ganz entschieden von psychogenen Momenten, besonders in Anwesenheit des Arztes, abhängig zu sein: bisweilen völlig geschwunden, zu anderen Zeiten viel mehr in funktionellem Charakter bemerkbar, bisweilen mit einer etwas nach Aggravation aussehenden Komponente. Sehr auffallend... ein unregelmässiges Zittern der ganzen Extremität, das entschieden keinen organischen Eindruck macht. Ebenso auffallend ist das Wechseln der Augenstörungen; bisweilen besteht nicht nur kein Nystagmus bei Blick nach der Seite, sondern auch der rotatorische fehlt vollständig.

25. 1. Die funktionelle Komponente macht sich deutlich bei jeder Untersuchung bemerkbar. Die Art des Nystagmus wechselt ständig, in letzter Zeit horizontaler Nystagmus nur bei Blick nach links. 
Schlussurteil: Organische und funktionelle Symptome innig miteinander verbunden; die organischen sprechen am ehesten für multiple Sklerose (Klonus, Hyperreflexie, Schwäche des Bauchreflexes, Nystagmus, vielleicht auch die Sprache); funktionell muten an das Zittern, das dauernde Wechseln der organischen Symptome hinsichtlich ihrer Intensität und Ausdehnung; keine eigentlichen Spasmen, kein „Oppenheim" oder „Babinski", ferner Entstehungsgeschichte: emotionelle Erregungen für Ausbruch der Erkrankung entschieden massgebend. Da Versuch der Behandlung der funktionellen Momente angezeigt, Nervenbehandlungslazarett H.: Gelegentlich Strabismus convergens concomitans. Bei Blick geradeaus, Fixieren eines Punktes in $20 \mathrm{~cm}$ usw. geht manchmal der Nystagmus rotatorius in feinwelligem Nystagmus horizontalis über: Zittern der Hände, zuweilen bei statischer Innervation, zuweilen bei Intention. Gelegentliches Zitterwackeln im linken Bein in Horizontallage macht durchaus psychogenen Eindruck. Linkes Bein beim Gehen spastisch nachgeschleift.

13. 2. In Hypnose Beseitigung der Gehstörung; in ihr ist nur geringer Nystagmus nach links vorhanden. 20. 2. Nimmt täglich eine Stunde am Exerzieren (Freiübungen usw.) teil; dabei keine Störung, vor allem nichts von Spasmus oder Kloni, speziell kein Fussklonus in den Uebergangsstellungen bei langsamen , Knie hebt" ( $=$ - dem Uebergang aus der Stellung: Kniebeuge und Fersenhebung zum Strammstehen), d. h. in Stellungen, die vorübergehend für Augenblicke einem unbewussten Auslösen von Fussklonus entsprechen. In Horizontallage ist dabei der Flussklonus noch immer scheinbar unerschöpflich.

Seine ,organische Unechtheit" lässt sich aber durch folgende Versuchsanordnung erweisen: ,Schleicht" sich der Untersucher aus der brüsken passiven Dossalflexion der Fussspitze ganz allmählich bei anderweitiger Ablenkung des Patienten in für ihn unmerklicher Weise aus, so dass zuletzt die Hand des Untersuchers nur mehr scheinbar dossalflektiert, in Wirklichkeit aber nur sich ohne jede Kraft an die Fussohle anlehnt, so tritt nicht die geringste Abnahme des Fussklonus aus. Lenkt man den Patienten nunmehr weiter ab und sagt ihm suggestiv, das Wackeln werde weitergehen, so bleibt der Fussklonus auch dann noch in bezug auf Stärke, Form und Kurve völlig unverändert, wenn das Bein von der Unterlage wie üblich am Knie aufgehoben in der Luft steht; d. h. also, der Fussklonus besteht unter suggestiver Einwirkung völlig unverändert auch dann fort, wenn die mechanischen Bedingungen der Auslösung von echtem organischen Fussklonus längst weggefallen sind. In ungezwungenem Verkehr nie Gehstörung. In Wochen trat nur einmal rein unter negativ affektiven Momenten Zitterwackeln des linken Beines auf. In wochenlanger Beobachtung nicht der geringste Anhaltspunkt für ein Skandieren. Nachdem die Unechtheit der als organisch verdächtigen und verwerteten objektiven Symptome erwiesen ist, kann an dem funktionellen Charakter des neurologisch sehr interessanten Gesamtbildes wohl nicht mehr gezweifelt werden. 
Nach der zusammenfassenden Darstellung, die er über den Nystagmus bei Hysterie gibt, scheint Wissmann ${ }^{1}$ ) als hysterisch nur oder ausschliesslich diejenigen Formen von Augenwackeln oder BulbuskJonus anzuerkennen, die als Folge- ev. Begleiterscheinung einwandfrei hysterischer Spasmen bzw. Kontraktur der inneren Augenmuskeln voran der Lider auftreten. Die experimentelle Erzeugung eines (,assozilerten") Nystagmus, welchen Stransky bei neuropathischen aber sonst gesunden Soldaten mit dem forcierten Versuch des Lidschlusses bei passiver Fixierung des Oberlids auftreten sah, scheint dafür zu sprechen. Wissmann betont dabei den grob ruckartigen Charakter dieses hysterischen Angenwackelns, und er ist geneigt, ihn durch schnell sich unterbrechende Spasmen der Antagonisten zu erlklären. Der vorliegende Fall belelnt uns aber nun, dass ausser der wohl sicher häufigsten Form: der als Begleiterscheinung krampfartiger Dauerinnervationen im Bereich der übrigen äusseren Augenmuskeln auftretenden Form ein hysterischer Nystagmus vorkommt, der im Grunde das Analogon der spastischen Pseudoparese der Extremitäten darstellt und wie diese sich ausschliesslich halbseitig auf die konjugierten Augenmuskeln derselben Seite beschränken kann. Ich lasse dabei offen, inwieweit der relativen Sehschwäche, die anf der Seite, nach der auch der Nystagmus stärker war, besonders hervortrat, die Bedeutung einer Hilfsursache zukommt. In bezug auf Auftreten und Stärke dieser Reizerscheinungen bestand in unserem Falle zwischen Blick- und Extremitätenmuskeln eine weitgehende Kongruenz. Wie eine immer wiederholte Beobachtung des scheinbar sehr organisch anmutenden Fussklonus doch zum Nachweis gelegentlicher zentraler Innervationszwischenschaltungen und weiterhin zum Nachweis seiner ideagenen Bedingtheit führte, so verhält es sich auch mit dem unter analogen physiologischen Bedingungen - der gleichmässigen Fortdaner einer ungewöhnlichen zentripetalen Erregung in extremer Endstellung des betreffenden Körperteils - entstehenden Augenklomus, dem Nystagmus. Man konnte daher direkt sagen, dass hier der Nystagmus Teilerscheinung einer allgemeinen Tendenz zu (halbseitigem) Intentionsspasmus mit Tremor gewesen ist, wobei wie in fast allen Fällen die Herabsetzung der Sehschärfe unterstützend mitgewirkt hat.

Damit sind die Formen und Arten funktionellen Nystagmus aber nicht erschöpft. Aus den folgenden Beobachtungen geht hervor, dass es seltene Abarten gibt, in denen der Nystagmus ebenfalls Teilerscheinung einer allgemeinen Tendenz zum Zitterwackeln ist, nach Form und Ablauf aber wesentlich durch abnorme Bewegungsabwandlungen an den Augen oder

1) Die Beurteilung von Augensymptomen bei Hysterie. Sammlung zwangl. Abhandl. a. d. Geb. d. Augenheilkde. 1916. Bd. 10. H. 1/2. I 
durch bestimmte Innervationseinflüsse auf die konjugierten Augenmuskeln bestimmt wird. Wir haben es hier mit einem funktionellen Gegenstück zu den organischen Nystagmusformen zu tun, welche Barany als Begleiterscheinung von peripheren Augenmuskellähmungen bzw. im Rückbildungsstadium echter Blicklähmungen gefunden hat. An dem funktionellen Charakter unserer Fälle besteht angesichts der psychotherapeutischen Beseitigung kein Zweifel. Die Untersuchung des Einflusses vestibularer Reizung auf diesen Nystagmus erübrigt sich daher.

Beobachtung 4. W., geb. 1893. Mutter hyst. Krämpfe. Auf Schule einmal sitzen geblieben: sonst Kindheit 0 . B. Steinbrucharbeiter.

Oktober 1913 eingezogen, nie krank. Mit Mobilmachung ins Feld, bis April 1915 ganz frei; ohne Angstsymptome usw. Damals von Granatluftdruck hingeworfen, nicht bewusstlos, nur einige Zeit schwindlig, so dass er beim Aufstehen gegen die Brustwehr fiel und zitterte. Wegen Kopfschmerzen nach 2 Tagen krank gemeldet, nach 4 Tagen wieder ,,vorn"; von da ab gewisse Unruhe im Fener, im Trommelfeuer verwirrt, ohne eigentliche Angstgefühle oder Herzklopfen; dann müde, matt; bekam Schmerzen in den Beinen, die dem Willen nicht recht gehorchten.

19. 1.1916 krank gemeldet. Lazarett Sedan bis April, dann Heimatlazarett.

Befund: Guter Ernährungszustand, leichtes Zittern der ausgestreckten Hände, zitternde Bewegung des Kopfes in horizontaler Richtung. Die Augäpfel treten glasig hervor, ohne dass aber Protrusio vorhanden ist, oder sonst ein BasedowSymptom. Es scheint sich eher um einen angeboren grossen Bulbus zu handeln. Nystagmus, jedoch nicht regelmässig, besonders bei Blick nach beiden Seiten.

Pupillen: Re. prompt, beiderseits gleich. Sehnenreflexe lebhaft, besonders Patellarreflex; kein Fussklonus. Hautreflexe schwach, Fussohlenreflex nicht deutlich anclösbar. Kremasterreflex vorhanden. Banchdeckenreflex sehr schwach. Stehen bei geschlossenen Augen ein paar Augenblicke ohne Schwanken möglich, dann fällt Pat. plötzlich in vollständig gestreckter, steifer Haltung nach rückwärts nm; dagegen Gehen mit geschlossenen Augen ohne Schwanken gut ausführbar. Innere Organe frei.

Therapeutisch: Ruhe, $2 \times$ pro die $1 \mathrm{~g}$ Natr. bromat.

20. 4. Unverändert. 28. 4. Im allgemeinen etwas ruhiger, Nystagmus geringer. Hautreflexe sämtlich + , mit Ausnahme der nicht deutlich auslösbaren Sohlenreflexe. Fallen nach rückwärts bei geschlossenen Augen wie früher.

6. 5. Zur Labyrinthuntersuchung in die Ohrenklinik geschickt.

Befund: Undulierender Spontannystagmus nach rechts. Bei Reizung des Labyrinths (Wasser von $27^{\circ}-30^{\circ}$ in den linken Gehörgang) tritt ein typischer Vestibularnystagmus mit langer und kurzer Komponente auf. Bei Reizung des rechten Labyrinths in derselben Weise physiologischer Nystagmus (nach links). „Der Spontannystagmus ist als nicht-labyrinthärer aufzufassen."

Mitte Mai Besserung: Abnahme des Pseudo-Romberg; Nystagmus unregelmässiger. (Privatdoz. Dr. Hauptmann): „Tch halte alles für Erschöpfungssymptome." 18. 5. Nervenbehandlungslazarett B.: Subj.: Zeitweise heftige Kopf- 
schmerzen über den Augen, Bein- und Rückenschmerzen. Obj.: Gesichtsasymmetrie, starker Nystagmus horizontalis, bei Konvergenz sistierend. Bei Augenschluss nur geringes Lidflattern, geringes Pendeln. Starker Tremor manuum et linguae. Hände feucht, Puls 54-60, Blutdruck (Riva-Rocei) $120 \mathrm{~mm}$ Hg. Neuralgie des linken Tibialis, sonst neurologisch negativ.

19. 5. Nystagmus wechselt ausserordentlich, bald tritt er fast nur bei Fixieren, bald nur bei Seitwärtsblicken auf, bald ist er mehr pendelnd, bald ruckartig stossend. Univ.-Augenklinils H.: 21. 5. R. S. $={ }^{5} / 20$; L. S. $={ }^{5} / 15$. Skiosk: R. - I D.; L. = I D. Abducensparese links in Verbindung mit Nystagmus auftretend. Wassermann negativ. "Zentrale Affektion".

21. 6. Augenstation. R. (Dr. Dorff): „Freie Bewegung der Augen nach allen Richtungen bis auf eine geringe Einschränkung beim Blick nach aussen. Esbesteht zeitweise bei binokularer Fixation in die Ferne kleinschlägiger, horizontaler Rucknystagmus, der bei Nahfixation im allgemeinen wieder verschwindet, bei seitlicher Blickrichtung bedeutend an Frequenz und Amplitude zunimmt, dagegen bei Konvergenz und Blick nach oben geringer wird. Mit Hilfe von Maddoxscheibe und roten Gläsern lassen sich für die Ferne ungekreuzte Doppelbilder mit einer Seitenablenkung von $8-10^{\circ}$ nachweisen. Der Abstand der Doppelbilder verändert sich nicht bei seitlicher Blickrichtung, wie bei Hebung und Senkung.

Sehprüfung ergibt dauernd schwankende Befunde. Bei monokularer Prüfung tritt meist ein verstärkter Nystagmus auf, das Sehvermögen sinkt auf Finger $4-6 \mathrm{~m}$. Bei binokularer Fixation erreicht man schwankende Werte von $6 / 15-6 / 30$; bei gelähmter Akkomodation und weiter Pupille nimmt der Nystagmus ab. Kleinster Druck wird binokular in der Nähe fliessend gelesen, monokular mit Schwierigkeit.

Objektive Refraktion unter Mydriasis ergibt rechts einen geringen Astigmatismus, links eine geringe Uebersichtigkeit.

Binokulares, stereoskopisches Sehen kann mit Sicherheit nïht nachgewiesen werden. Wenn während der Untersuchung die Aufmerksamkeit stark angespornt wird, so tritt deutlich wahrnehmbares Zittern des ganzen Kopfes ein. Befund am Augapfel selbst beiderseits normal, brechende Medien klar, Augenhintergrund keine Veränderung, Pupillen gleichgross, RL (direkt und konsensuell) und RC normal. Angabe des Feldtruppenteils: „Schiess- bzw. Sehleistungen gut."

30. 6. 1916. Schlussbefund: Beiderseits findet sich eine latente Divergenzschwäche. Es handelt sich um keine Abducensparese, da sich der Seitenabstand der Doppelbilder bei seitlicher Blickrichtung nicht verändert. Vielleicht lässt sich aber auf diese Schwäche der Seitenwender die starke Zunahme des Nystagmus bei seitlicher Blickrichtung zuriückführen. Entsprechend verringert sich der Nystagmus bei Konvergenz, um bei Nahakkommodation meistens ganz zu verschwinden. Der übrige Augenbefund ist normal. Die wechselnde Herabsetzung des Sehvermögens für die Ferne ist Folge der in wechselnder Stärke auftretenden nystagmischen Zuckungen. Da bei Naheinstellungen der Nystagmus verschwindet, ist die Sehschärfe für die Nähe bei binokularer Fixation normal.

Als Ursache des Nystagmus können wir die Abducensschwäche nicht heranziehen; sie beeinflusst allein den Verlauf des Nystagmus; denn sonst müsste bei rein monokularem Sehen unter Ausschaltung der Seitenwender der Nystagmus 
verschwinden; im allgemeinen tritt aber das Gegenteil auf: die nystagmischen Zuckungen nehmen bei Abdecken eines Auges bedeutend an Intensität zu. Das äusserst wechselnde Verhalten des Augenzitterns und die Vergesellschaftung mit zeitweiligem Auftreten von Zittern des Kopfes und der Extremitäten macht es sehr wahrscheinlich, dass die Ursache des Nystagmus keine organische Erkrankung ist, sondern dass das Augenzittern dem Zittern der anderen Extremitäten gleichzustellen ist, nur dass es durch die Abducensschwäche einer gewissen Beeintlussung unterworfen ist."

15. 8. Nystagmus, sehr gering im Prinzip aber wie früher; kein PseudoRomberg mehr.

Den bindenden Folgerungen des Ophthalmologen, die sich auf eine minutiöse Untersuchungstechnik aufbauen, ist wohl nichts hinzuzufügen. Ueber die funktionelle Natur des hier vorliegenden Nystagmus kann kein Zweifel obwalten. Dagegen bestehen doch mancherlei Bedenken, ihn nun ohne weiteres hysterisch zu nennen. Positiv dafür zu verwerten sind auf Grund wochenlanger Beobachtung und den eingehenden Untersuchungen allein die merkwürdig schwankenden Angaben bei der Sehprüfung, die mit der Feststellung seines Feldtruppenteils (Infanterie), dass er in $11 / 2$ jährigem Frontdienst gute Seh- und Schiessleistungen aufgewiesen hat, ebenso in Widerspruch stehen, wie mit der Annahme einer ,optischen Erschöpfung". Alles übrige aber weist in dieser Richtung. Der Verlauf der nervösen Reizerscheinungen einschliesslich des Nystagmus, die fast an Heilung heranreichende Besserung durch einfache Ruhe- und Beruhigungsbehandlung usf. führen am ehesten zu der Annahme einer schweren allgemeinen nervösen Erschöpfung. Unter Berufung auf die früheren Auseinandersetzungen hätten wir den Nystagmus als einen asthenischen zu bezeichnen. Nach den Bedingungen seines Auftretens und nach seiner Form war er als statischer Tremor oder Bulbi aufzufassen, der von dem ihn analogen asthenischen Zittern von Kopf and Extremitäten sich nur durch die Intensität oder Exkursionsbreite unterschied. Dieser Unterschied war aber offenbar allein durch ineinander wirkende Hilfsursachen: die latenten Störungen der Abduktion und der Refraktion der Augen bedingt.

Im Grunde ist also auch hier der Nystagmus als Teilerschein ung neurasthenischen Zitterns aufzufassen.

Theoretisch ebenso interessant ist die Erscheinung des Angenwackelns in dem folgenden Falle:

Beobachtung 5. M., geb. 1893, Polsterer.

Mutter und Schwester hochgradig nervös. Als Kind ängstlich, kränklich; Bettnässen gelegentlich bis heute. Wegen Schwäche 1 Jahr zu spät zur Schule; einmal sitzengeblieben; immer kränklich, deswegen wiederholt Berufswechsel. Seit 1910 , d. h. seit einem Schreck über Geriusteinsturz, bei dem er meinte, er werde erschlagen, bemerkte er, dass in der Verlegenheit im Bett es ihm plötzlich 
„warm nach dem Kopf zieht, als ob einer draufschlüge:". Stets leicht jähzornig, erregbar, geräuschüberempfindlich. Oktober 1914 eingezogen, März 1915 ins Feld: Stets schreckhaft, ängstlich, zittri;: August 1915 wegen universellen Zitterns krank gemeldet. Oktober 1915 zum E. T. T. Am Tage der Entlassung fing das Zittern wieder an. 7. 10. 1916 ins Lazarett: Zittern am ganzen Körper, Zucken der Gesichtsmuskulatur. Subj.: Nach Schrecken krampfen sich die Finger (Uebererregbarkeitszeichen!). Reaktionen auf jede besondere psych. Einwirkung sind: Algemeines Zittern, Schweissausbrnch, besonders stark im Gesicht, Puls bis 130, Eindruck der Hinfälligkeit.

11. 10. Nervenbehandlungslazarett B.: Algemeine vibratorische Unruhe fast am ganzen Körper, auch beim. Gehen, bis zu Schlottern sich steigend. Nicht der geringste Anhaltspunkt einer organischen Hirn- oder Rückenmarksaffektion. Augenbefund (Dr. Dorff): Geringe Lebersichtigkeit. ,Sehr interessante Motilitätsstörung": Zuerst kein Nystagmus; dann bei Naheakkommodation auftretend in Form eines sehr schnellen, wellenförmigen, klainschlägigen Nystagmus; zum Teil im Zusammenhang mit dem Akkommodations- und Konvergensimpuls. Durch Vorsetzen von korrigierenden Konvexgläsern ist Nystagmus überhaupt nicht oder nur sehr schwer auszulösen. 24. 10. Beseitigung aller Reizerscheinungen durch Hypnose und Gewaltexerzieren. 15. 11. Dieselben bleiben aus, treten auch nicht mehr im Affekt (z. B. Verweis) auf.

In mehrfacher Beziehung bildet diese Beobachtung das Gegenstück zu den vorhergehenden.

Anch hier wieder finden wir Nystagmus als Teilersoheinung einer monosymptomatischen Zitterneurose, diesmal aber nach Entstehen, Form und Ausgang von einwandfrei hysterischem Charakter. Im Gegensatz zu den vorigen Falle handelt es sich um einen hypersthenischen Nystagmus von besonderer Art, insofern ei allein bei der Innervation der inneren Augenmuskeln, nur konkommittierend mit dem Akt der Nahfixation sich einstellte. Ausbleiben desselben nach Beseitigung der Zittererscheinungen am übrigen Körper durch hypnotische Suggestion, die sich aber nur auf die letztere bezog.

In den Kreis unserer Beobachtungen reiht sich an dieser Stelle der in anderem Zusammenhang behandelte Fall G. (Beobachtung 13) ein. Bei ihm lag ähnlich wie in Beobachtung 3 das Bild der pseudospastischen Parese bzw. Paralyse vor, die sich gleichmässig auf beide Beine erstreckte und zu vollkommener Astasie-Abasie geführt hatte. Hier fehlte Tremor ganz. Ein schwer rubrizierbarer Ruck-Pendel-Nystagmus trat konkommittierend mit einer spastischen Blickparese auf, die ihrerseits auf eingebildete Blindheit des einen Auges zurückzuführen war und sich entsprechend nur beim Blick nach der Seite dieser Blindheit geltend machte. Begünstigend wirkte offenbar die fehlerhafte Ueberkorrektion einer mit Astigmatismus verbundenen Kurzsichtigkeit mittleren Grades. 
Das Charakteristische des ganzen Zustandsbildes war die ausserordentliche Promptheit, mit der sich eingebildete Krankheitszustände in dick aufgetragene Totalausfälle umsetzten und ebenso leicht psychotherapeutisch wieder ,wegblasen" liessen: Ein Schulfall jener Hysteriegruppe, in der alle körperlichen Symptome restlos auf einfache Bremssperrung der grossen symmetrischen Gemeinschaftsbewegungen zurückzuführen war, wie sie willkürlich, aber nur nicht mit gleicher Tiefenwirkung und "pathologischer" Eleganz erzeugt werden kann. Ohne diese Tiefenwirkung der zentralen Innervationen auf die konjugierten Bewegungen, ohne eine abnorme psychomotorische Fertigkeit für künstliche Gemeinschaftsbewegungen, die nicht der Praxie dienen, ist der flüchtige Nystagmus des Falles nicht zu erklären. Die psychomotorischen Fertigkeiten abnormer „Bewegungskünstler" der geschilderten Art werfen ein interessantes Licht auf die Frage der "Simulationshysterie", die auf Grund ähnlicher Beobachtungen aus der Bewegungspathologie der Hysterie uns andernorts beschäftigen soll. In diesem Zusammenhang interessiert uns nur das Vorkommen eines funktionellen Nystagmus, der aus der endogenen Bewegungsformel des betreffenden Individuums abzuleiten ist und daher nicht erlernt zu werden braucht. Es wäre von Wichtigkeit, zu wissen, bis zu welcher Form von Augenwackeln Personelı mit solch abnormer Begabung es bringen können, wenn sie es zum Gegenstand der Eigendressur machen würden.

Wir sind mit den Erörterungen über den vorliegenden Fall an der Grenze dessen angelangt, was als sicher abnorm zu gelten hat. Stellt sich diese eingeborene Bewegungsfähigkeit um wenige Grade geringer dar, so bedarf es schon einer Höehstleistung von Dressur, um eine gleiche Exkursionsbreite des Nystagmus zu erzielen. Damit sind wir zum Ausgangspunkte unserer Betrachtungen über den funktionellen Nystagmus zurückgekehrt.

Beim Ueberblick über die Ergebnisse unserer und früherer Beobachtungen scheint sich als gesetzmässig folgendes zu ergeben:

Neben dem vestibularen Nystagmus, der durch experimentelle oder organische Reizung irgendeines Punktes des zuleitenden Schenkels des vestibulo-okulären Reflexbogens (Neumann) hervorgerufen wird, gibt es zentral bedingte Nystagmusformen ausgleichbaren Charakters, die wir daher als funktionellen Nystagmus zusammenfassen können.

I. Funktioneller Nystagmus in diesem Sinne kommt vor:

1. Als Teilerscheinung einer allgemeinen oder spezifischen Neigung zu Zittererscheinungen, welche sich dann auch auf die Blickmuskeln, voran die assoziierten Seitwärtswender der Augen erstreckt, wenn an irgendwelchen Teilen des Sehapparats, vor allem den übrigen AugenArchiv f. Psychiatrie. Bd. 58 . 
muskeln, eine latente oder deutliche Invalidität schon besteht.

2. Als Begleit- oder Folgeerscheinung mehr oder weniger isoliert auf die äusseren Augenmuskeln beschränkter funktionell-spastischer Zustände. Es bleibt dahingestellt, wie weit auch hierbei derartige latente Invaliditäten mitwirken.

3. Nicht jeder als funktionell sich erweisende Nystagmus ist hysterisch. Es gibt einen asthenischen Typ infolge nervöser Erschöpfung, deren Reizerscheinungen sich meist auch infolge irgendwelcher von früher her bestehender Störungen am Sehapparat auf die Blickwender ausdehnen.

4. Als sicher hysterisch kann nur jener Nystagmus gelten, der auf anderweitige hysterische Zustände am Auge zurückzuführen ist oder mit solchen am übrigen Körper in einem tieferen Zusammenhange steht.

II. Als der Hysterie nicht zugehörig sind, wie einst schon Siemerling betont hat, wohl alle angeborenen oder in frühester Kindheit erworbenen Nystagmusformen anzusehen, welche sich allein aus organischen Veränderungen der Sehbahn (Igersheimer), des Gleichgewichtsapparats oder der motorischen Blickbahn von selbst ergeben.

In den Fällen, in denen, oft latent, ein Nystagmus als Stigma degenerationis imponiert (Oppenheim), dürfte nur die Ermittlung solcher Veränderungen nicht gelingen. In einem Teil dieser Fälle kommt die relative Persistenz des physiologisch postfötalen Augenwackelns in Frage, die trotz annähernd normaler Sehleistung auf pathologische Gewöhnung zurïckzuführen ist (Reste des sog. „Spasmus nutans"). Recht häufig ist, wie Igersheim gezeigt hat, der Nystagmus im jugendlichen Alter bei negativem ophthalmologischen Befund und sonst normalen Verhalten der Augen auf kongenitale Lues (chronische Meningitis?) zurüickzuführen.

Als ein „Stigma degenerations" ist vielleicht ein rudimentärer Nystagmus anzusehen, der bei der Kombination von angeboren abnormer Grösse der Bulbus, leichtem Buphthalmos oder grossem „Glanzauge" mit latenten Störungen am Auge bei Neuropathen nicht gar zu selten ist.

Gegenüber dem funktionellen Nystagmus treten die übrigen Hypermotilitätserscheinungen der Blickmuskeln, was ihre Häufigkeit anbetrifft, zurück. Im einzelnen aber breten sich hier differentialdiagnostisch und theoretisch recht interessante Zusammenhänge.

Beobachtung 6. D., geb. 1894, Schlosser. Früher angeblich gesund.

November 1914 eingezogen. Januar 1915 ins Feld (Inf.). Von Anfang sehr 
ängstlich, im Feuer zittrig. April 1915 Abschuss der beiden Endphalagen 1./2. Fịnger; nach Wundheilung zur Firma Krupp. August 1916 wieder eingezogen (Feld-Art.).

19. 8. In Garnison Huftrift gegen Mund. Sofort ins Lazarett. Öbj.: Unterlippe aussen und innen quer durchtrennt. Verlust der Schneidezähne im Oberkiefer, aus den Alveolen frisches Blut, kein Defekt am knöchernen Schädel. Leichte Benommenheit (zeitweise richtige Antworten, aber sehr langsam). Puls o. B. Kein Erbrechen.

20. 8. Nachts unruhig. Temp. 38,8, Puls o. B. Abends Blutungen aus dem. Mund. Pupillen reagieren sehr träge.

21. 8. Starke Benommenheit. Kornealreflex: 0. Der Blick beider Augen ist meist nach links oben gerichtet. L. Pupille $>$ r.; Zunge gerade. Kein Druckpuls.

26. 8. Immer leicht benommen, Arm-, Beinbewegungen frei. Keine Inkontinenz. Subj.: ständig dumpfer Kopfschmerz. Blick öfters nach links oben.

3. 9. Linke Nasolabialfalte verstrichen. Mimische Muskulatur des linken Gesichts etwas beeinträchtigt. Grobe Kraft r. Hand $>$ l.; Bauch-, Kremaster-, Kniereflex links herabgesetzt. Babinski links zweifelhaft.

21. 9. Hier und da noch leicht benommen. Linke Nasolabialfalte wieder deutlich, Bauchreflex links noch stark herabgesetzt. Babinski links noch zweifelhaft (?). Augen meist, ,nach innen einwärts gedreht gehalten".

28. 9. Unwillkürliche Zuckungen im linken Arm und Bein. „Linksseitige Abducenslähmung, rechts Schwächung des Abducens." (?)

4. 10. Morgens ein Anfall: Gänzlich ohne Besinnung, Pupillen reagieren; kurze Zuckungen der ganzen linken Körperhälfte. Dauer 5 Minuten.

5. 10. „Es häufen sich die Anfälle."

28. 10. Psychiatr. Klinik: Nach einmaliger Belichtung verharren die Pupillen auffallend lang in Kontraktion; leicht entrundet. Gang mit eigentümlich taumelnden Schritten, als ob er auf Eiern ginge.

Augenbefund (Augenklinik): Ausgesprochene Spasmen im Berejch des Rectus internus (Spastisches Konvergenzschielen wechselnden Grades) unter gleichzeitiger Spannung der Akkommodation. Infolgedessen wechselnde Spannungsmyopie. Assoziierte seitliche Bewegungen werden zumeist nicht ausgefüht, doch wohl nur wegen der willkürlichen Spasmen (Bild des hysterischen Schielens, resp. hysterischer Lähmung). Pupillen o. B. Fundus: Hellerfärbung der temporalen Hälften nicht sicher pathologisch (exzentr. physiolog. Exkavation).

7. 11. Nervenbehandlungslazarett B.: Debil.-schüchtern-mädchenhaftes Wesen (spielt mit den Fingern usw.); Chlorose; untersetzt graziler Bau; sehr labile Gesichtsvasomotoren. Kleiner Schädel. Extreme Augenbewegungen (s. oben) werden, weil angeblich schmerzhaft, nicht ausgeführt. Zugleich wird aktiv erst auf energische Aufforderung die Stirn etwas gerunzelt (,,so viel Schmerzen über den Augen"). Starkes Lidflattern bei A.-F.-Schluss. Herabsetzung der rohen Kraft im linken Bein bei Widerstandsbewegungen. Gang: Wie bei pseudospastischer Parese mit Tremor links, tritt links nur auf die Fusspitze auf, wippt mit dem linken Bein, Babinski 0. Rechtes Bein o. B. 
Nachtrag zur Vorgeschichte nach eigener Angabe: Beim 1. Aufstehen im 1. Lazarett war es so flimmrig vor den Augen. Die Gehstörung rühre daher, dass er infolge Schreck bei feindlichem. Fliegerangriff im November hingefallen sei.

Heilung: In Hypnose, in die er sehr leicht verfällt, im Abstand von 2 Wochen, zweizeitig, Beseitigung erst der Geh-, dann der Augenbewegungsstörungen.

Epikrise: Charakteristisch die ganz allmähliche Heranbildung der Symptome, zweifellos unter iatrogener Komponente.

Das Interessante des Falles liegt in der Entwicklung eines einwandfrei hysterischen Schielens mit Abduktionsschonung ans einer 4-5 Wochen bestehenden konjugierten Deviation nach einem Trauma, dessen Folgen auf Anhieb sehr wohl den Verdacht der Commotio cerebri erwecken konnten. Der Umschlag von der konjugierten Ablenkung zum Einwärtsschielen erfolgte offenbar ziemlich plötzlich. Zweifellos hat eine starke Gewalteinwirkung gegen den Kiefer stattgefunden (Hufschlag mit Ausstossen der Schneidezähne, aber ohne Fraktur) und unmittelbar wohl eine leichteste Commotio cerebri hervorgerufen. Die Entwicklung der lokalisierten körperlichen Symptome kann nur auf zwei Wegen erfolgt sein. Entweder hat das Trauma meehanisch zu leichten organischen Läsionen geführt. War der in den ersten Tagen danach erhobene neurologische Befund einwandfrei, so wäre der Sitz der ausgleichbaren Veränderungen (Blutung od. dģL.) in die rechte Brückengegend zu verlegen (Deviation nach der dem Herde entgegengesetzten Seite). In diesem. Falle wäre das organische Symptomenbild ganz schleichend unter hysterische „Regie" getreten; es hätte also eine hysterische „Automimesis" (Ziehen) der gröberen Herdsymptome von erstaunlicher Exaktheit mit geradezu "photographischer Treue" Platz gegriffen. Oder aber die halbseitigen Reflexanomalien waren nur das Produkt einer Deutung der Untersuchungsergebnisse, welche autosuggestiv durch die Schwere der Kopfverletzung bestimmt wurde. In diesem Falle könnte sehr wohl von Anfang an die konjugierte Augenablenkung sensorisch-psychogen, nämlich durch Blickscheu nach einer Seite, bedingt gewesen seï, die aus Ueberemplindlichkeit gegen Licht oder aus dunklen Sensationen in der StirnAugengegend abzuleiten ist. Der mehr minder plötzliche Umschlag von der Ablenkung nach links in ein spastisches Konvergenzschielen ist aus organischen Regeln nicht abzuleiten. Der Umschlag einer organisch bedingten Déviation conjugée in ein - wie der restlose Erfolg der Hypnotherapie ergab - sicher hysterisches Konvergenzschielen, dürfte wohl aus keiner neurologischen Erfahrung heraus zu erklären oder wahrscheinlich zu machen sein.

In der Literatur finde ich keinen Fall, der dem hier gesehilderten gleicht. In einer ihm am meisten ähnelnden Beobachtung von $\mathrm{Manz}^{1}$ ), in dem eben-

1) Berliner klin. Wochenschr. 1880. 2, u. 3. 
falls einer Deviation conjugée ein Strabismus convergens spasticus folgte, fand sich daneben noch hysterische Blindheit. Die Schwierigkeiten der Unterscheidung zwischen Lähmung der Agonisten und Spasmus der Antagonisten offenbaren sich hier bei den Gemeinschaftsbewegungen des Seitwärtsblickens in besonderem Masse deshalb, weil kein Kriterium zur Verfügung steht, aus der Art der Bewegungsstörung an sich festzustellen, ob Blicklähmung nach der einen oder Blickkrampf nach der entgegengesetzten Seite vorliegt. Während bei Fällen mit sicher organischen Halbseitenerscheinungen, wie „Babinski" usw., und mit Indizien eines suprapontinen oder pontinen Herdes diese Entscheidung mit einiger Sicherheit getroffen werden kann, ist beim Mangel solcher Kriterien die Frage: hysterischer Krampf bzw. Kontraktur oder Lähmung der Seitwärtsblicker? wohl kaum zu entscheiden. Wemn auch die Mehrzahl hysterischer Blickabweichungen auf einer aktiven Dauerspannung der gleichseitigen Seitwärtswender beruhen, so ist doch prinzipiell die Möglichkeit einer hysterischen Entspannung der andersseitigen Bliekwender, also einer primären Blickparese, die erst sekundär zum Uebergewicht ihrer Antagonisten und so zum Blickkrampf nach der Gegenseite führt, nicht zu bestreiten. Während der hysterische Blickkrampf einfach in der Richtung der willkürlichen Einstellungsbewegungen der Angen liegt, die wie Schwarz gezeigt hat, schon normaliter derartig $\mathrm{zu}$ steigern sind, dass bei bestimmten Graden von Konvergenz noch assoziierte Blickwendungen ausgeführt werden können, kann diese primäre Entspannung der assoziierten Augenmuskeln willkürlich nur da erreicht werden, wo schon eine abnorme individuelle Innervationsformel für Gemeinschaftsbewegungen der Augenmuskeln zugrunde liegt. Einwandfreier noch, ja geradezu in einem klassischen Beispiel stellte sich die hysterische Automimesis organischer Herdsymptome, vermöge deren ein unmerklicher Regiewechsel der gleichen Symptome vom Organischen zum Hysterischen eintrat, in der

Be obachtung 7 dar: L., geb. 1891, ländlicher Lehrer.

Von jeher sehr schwächlich und besonders ängstlich: Z. B. als Schuljunge hatte er täglich eine Stunde zu gehen, aus Angst ging er nie den Weg allein. Die Eltern nannten ihn stets sehr aufgeregt, nervös. Im Beruf musste er einmal ${ }^{1} / 4 \mathrm{Jahr}$ „wegen. Ueberanstrengung“" aussetzen. Litt viel an Rachenkatarrh. Wegen allgemeiner Körperschwäche nicht aktiv. Reklamiert, daher erst 9. 8. 1916 eingezogen. - Hörfähigkeit beiderseits $5 \mathrm{~m}$. Keine Fehler. September ins Feld. Von Anfang hier sehr ängstlich, im Artilleriefener zittrig, nach Bericht der Kameraden plötzlich blass im Gesicht. 11. 12. auf Posten Granatsplitter-Streifschuss linkes Hinterhaupt. Dann totale Amnesie: Sei erst 4 Tage später im Lazarett zu sich gekommen. Obj. (Befundschein): „Verletzung der Kopfschwarte, Knochenvarletzung nicht festgestellt." 13. 12. Hemianopsie. 13. 12. Feldlazarett: Gibt an, dass er 12 Uhr 30 Min. verwundet, dann zum Sanitätsunterstand zurückgeführt wurde. In ejnem 
Eigenbericht, den er 4 Woehen später machte, berichtet er selbst, im Sanitätsunterstand sei ihm Tetanusserum eingespritzt worden (obj.: richtig). Im Feldlazarett teilnahmlos, Bewusstsein, Erinnerungsvermögen klar, Gehörvermögen stark herabgesetzt. Auf laute Frage vorständige Antworten. Beide Augen nach links gerichtet. Beiderseits Gesichtsfeld ausserordentlich eingeschränkt. Augenbewegungen frei, auch wird in der Nähe mit beiden Augen etwas fixiert. Links besteht Hemianopie der inneren, rechts der äusseren Seite. Bei genauerer Untersuchung ergibt sich, dass das Gesichtsfeld beiderseits nur auf den linken oberen Quadranten beschränkt ist (? Ref.), linke Pupille > r., $7 \mathrm{~cm}$ lange, senkrechte Narbe über die linke Koronarnaht. 14. 12. Temp. 38,4. Galea stark aufgeschwollen, Perdiost wird freigelegt. Knochen nicht imprimiert oder frakturiert, nicht klopfempfindlich. 16. 12. Kopf in der Ruhe nach rechts gewendet, beide Augen nach links. Es ist jedoch Bewegung auch über die Mittellinie hinaus möglich. Beide Augen werden immer gleichsinnig nach rechts oder links gewandt, aber niemals konvergent eingestellt. Keine Fixation in der Nähe, etwas beim Ansehen. Bewegung nach oben/unten möglich. Pupillen über-mittelweit, auf Lichteinfall gut ansprechend. L. S. $=0,5 / 24$, nur mit der linken Angapfelhälfte, das Auge ganz nach links gewandt. R. S. $=0,25 / 30$, Auge auch nach links, sehr beschränktes Gesichtsfeld, in ${ }^{1 / 2} \mathrm{~m}$ Entfernung 10-15 cm breit. Gibt an, die Worte zu hören, aber ohne Klangfarbe, versteht aber bei lautem Sprechen gut. Leichte Unterschiede beim Zähnezeigen r. $>$ l., linke Gesichtshälfte leicht herabhängend, Extremitäten nicht gelähmt.

Diagnose: Konvergenzlähmung, konjugierte Blicklähmung nach links; rechtsseitige Hemianopie, auch linksseitig konzentrisehe Gesichtsfeldeinschränkung auf $10 \mathrm{~cm}$ im Umkreis, bei $1 / 2 \mathrm{~m}$ Entfernung. Herabsetzung der Sehschärfe $\mathrm{r} .>1$. 17. 12. Beiderseits $S .=0,5 / 20$, nur wenn die Leseproben ganz nach aussen links gehalten werden, Farben beiderseits richtig erkannt. 20. 12. R. S. $=0,5 / 24$ bei ganz nach links gestellten Angen. L. S. $=2 / 30$. Augen können nach rechts gewandt werden, aber nicht bis in die Endstellungen, Kopf meist nach der rechten Seite gewandt, mit ganz nach links gerichteten Augen. Konvergenz unmöglich. Sehschärfe links wesentlich besser als rechts. Sehen sei in der Mitte wie abgeschnitten. Beiderseits nur ein kleines Gesichtsfeld, unmittelbar im Zentrum. Grösse $10 \mathrm{~cm}$ in $30 \mathrm{~cm}$ Entfernung. 2. 1. 1917 . Meist teilnahmlos daliegend in der charakterischen Kopf- und Augenstellung. Richtige Antworten. Schwindelgefühl. Rechte Pupille scharf begrenzt. Links geschlängelter Verlauf der Gefässe (? Ref.). Pupille l. >r. wesentliche Beschränkung des Gesichtsfelds. Sehachse an der inneren. Seite des gelben Flecks mit ganz nach links gerichtetem Auge S. L. $=2 / 20$ R. ${ }^{2} / 24$. 9. 1. Linke Papille nicht ganz so scharf begrenzt wie rechts (? Ref.), Gefässe ein wenig stärker gefüllt wie rechts. 13. 1. Im Sitzen Augenbewegung nach allen Seiten möglich. Konvergenzsehen unmöglich. Gesichtsfeld links $2 \mathrm{~cm}^{2}$, rechts $18 \mathrm{~cm}^{2}$ in $1 \mathrm{~m}$ Entfernung. Stilling gut, nur schwierige Zahlen nicht erkannt, ermüdet sehr leicht. 15. 1. Wunde schliesst sich unter Granulationen; nach Aufrichten im Bett sinkt er unter Schwindelgefühl zurück. "Augenärztlicherseits kommt Operation an der Fissura calcarina in Frage, da bisher Besserung nicht eingetreten ist." 16. 1. Heimat: Mit der Sonde 
fühlt man, dass in der Wunde rauher Knochen freiliegt, Babinski/Fussklonus in geringem Masse, ausgeprägt. 6. 2. Beide Augen ständig nach links; es ist ihm nicht möglich, die Augen nach rechts, oben und unten zu drehen. Nur mit allergrösster Mühe gelingt ihm eine kleine Bewegung der Augen. Den Kopf hält er nach rechts gedreht. Das Gesichtsfeld ist auf den linken oberen Quadranten beschränkt (? Ref.). Er liest nur sehr groben Druck mit jedem Auge, und auch das nur mit grösster Yühe, Sprache flüsternd und stotternd, laute Sprache auf 1/2 m Entfernung 24. 2. Ohrenstation H.: Starker Tremor des Kopfes und der Extremitäten, Kopf krampfhaft nach rechts gehalten, beide Augen ständig nach links. Nicht imstande, zu sprechen, macht hierzu krampfhalte Versuche: ein Ton wird nicht gebildet. Verständigung mit ihm nur schriftlich möglich, auf lautestes Schreien keine Reaktion. Bei Wiederholung gibt or zu erkennen, dass er lauteste Fragen versteht. Rechtes Ohr leichte, strichförmige Trübung hinten oben, linkes leichte, allgemeine Trübung.

$\begin{array}{ccc}\text { R. } & 0 & \text { L. } \\ & \text { c l } & \\ 40^{\prime \prime} & \text { c W } & 40^{\prime \prime} \\ 70^{\prime \prime} & \text { c L } & 80^{\prime \prime} \\ 0 & \text { Fl } & 0\end{array}$

Heftiges Zusammenzucken beim Berühren der Kopfnarbe.

Röntgenbefund: 4--5 cm oberhalb der Spina occipit. post. an der Innen fläche des Schädeldaches eine leichte, nur einen mässigen Schatten verursachend七 Eindrückung, die $4-5 \mathrm{~mm}$ ins Schädelinnere vordringt.

Neurol. Untersuchung (Prof. H.): ,L. macht mir durchaus den Eindruck nur psychisch bedingter Störungen."

Augenbefund: Fundus o. B. S. beiderseits $5 / 3$ Gesichtsfeldaufnahme unmöglich (? Ref.), keine Hemianopsie (? Ref.). Die Jinkskonvergenz dürfte funktioneller Natur sein."

Prof. Kümmel: ,Die durch organische Erkrankung unerklärbare Abweichung der Blickrichtung nach links, mit gleichzeitiger Drehung des Kopfes in entgegengesetztem Sinne besteht nicht dauernd. 'Wenn der Mann unbeobachtet ist, hält er meist den Kopf geradeaus und dreht ihn erst in demMoment, wo er sich beobachtet fühlt, mit einem Ruck nach rechts. Mehrfach wurde auch beobachtet, dass er, wenn er beim Abtreten eine militärische Haltung einnahm, auch Kopf und Augen geradeaus richtete. Die Störung ist also sicher psychogen. Dann ist es aber auch mindestens äusserst wahrscheinlich, dass die Hör- und Sprachstörung psychogen ist, ganz abgesehen davon, dass auch das allgemeine Verhalten durchaus nicht das eines Tauben ist; offenbar sehr schwer psychisch eingenommen."

Jetzige Angaben des Mannes zur Anamnese: Am 4. Tage sei er im Feldlazarett wieder zu sich gekommen unter Schmerzen am Hinterkopf, Schwindel, Hörstörung, so dass er nur lautes Schreien am Ohr, aber ,keine Töne und Worte“ hören konnte, und Sehstörung. Als er an diesem Tage erstmals cine Postkarte vorleget bekam, bemerkte er beim Leseversuch, dass die rechte Hälfte wie abgeschnitten war. Als er später aufstehen durfte, musste er den Kopf nach rechts drehen und gedreht halten, um zu sehen, was vor ihm lag, ,sonst wäre er über alles hinweg- 
gefallen“. Er musste alle Gegenstände, die er sehen wollte, ,auf die linke Seite des Gesichts halten:. In der Folge trat noch fortwïhrendes Zischen, Sausen und und Brausen in den Ohren auf, bei starken Geräuschen (Türzuschlagen) hörte er dann für einen Augenblick gar nichts mehr. Bei der geringsten Anstrengung fuhr es ihm wie ein elektrischer Strom vom Hinterkopf zur Stirn. „Die Nachteile im Sprechen" stellten sich erst nach und nach, unter zeitweiligen Schmerzen im Hals, ein; zuletzt und beim Transport in die Heimat konnte er gar nichts mehr herausbringen. Die Hörschwäche an sich blieb völlig konstant; das Gedächtnis nahm sehr ab.

6. 3. Behält die Kopf-Augenhaltung, soweit festzustellen, in allen Situationen bei. Drehung des Kopfes nach rechts um 40, mit leichter Hebung des Kinns, Augen konjugiert nach links und Spur oben abgewichen, im ganzen so, dass die Augenaxen annähernd auf einen Punkt eingestellt sind, der in der Medianebene des Körpers $30 \mathrm{~cm}$ vor den Augen liegt. Reagiert auf bzw. versteht nur lautesten Anruf dicht am Ohr. Keinerlei Sprachinnervation; nicht einmal Versuch, zu sprechen. Mimische Aeusserungen seitens der Augen, des Gesichts und der Arme bleiben ganz aus. Nur wenn er visuell merkt, dass man sich mit ihm in Verbindung setzen will, macht er Einstellungsbewegungen von Augen und Kopf in der Weise, dass er die habituellen Abweichungen derselben noch steigert. Fr macht den Eindruck, als ob er dieselben ausfiuhrt, nicht um akustisch, sondern nur um visuell besser wahrnehmen zu können. Auf die Möglichkeit akustischer Verständigung lässt er sich gar nicht ein, er zieht sofort ein Papier aus der Tasche, um aufzuschraiben oder sich aufschreiben zu lassen. Es fehlen dabei fast ganz Züge von sensorischer Rat- oder' Hilflosigkeit.

Das Gesamtbild entspricht annähernd dem eines apathischen Taubstummen, der zugleich höchst schwachsichtig ist, ja beinahe dem eines unerregbar-stumpfen Idioten. Beseitigung aller Erscheinungen in 10 minutiger Sitzung durch ,Elektrosuggestion:" Anode am. Skrotum, Kathode (kuxze galvanische Schläge) auf Kieferwinkel und herausgestreckte Zunge: Wiederherstellung zuerst des Sprechvermögens, der dam spontan diejenige des Gehörs und fast gleichzeitig der normalen Augenund Kopfeinstellung folgte. Weint aus Rührung über den Erfolg. Nach Beseitigung der hysterosomatischen Erscheinungen kommt ein zaghaft-weichliches, psychasthenisches Wesen zur Schau, das er selbst als konstitutionell charakterisiert. Daneben treten noch einige knabenhaft hysterische Züge hervor. Z. B. viele Tage nach der Heilung meint er in kindlicher Weise, ob von einem Schuss nicht ein Zungeanstossen zurückbleibe, das er tatsächlich in dem gleichen Augenblick gerade erkennbar hervortreten lässt, sofort aber unterdrückt, als man ihm diese Idee energisch austreibt.

Epikrise: Die Ergebnisse der ziemlich eingehenden Untersuchung im Feldlazarett unmittelbar nach der Verletzung sind nicht ganz klar und frei von Widerspruch. Mit Sicherheit geht aber so viel daraus hervor, dass von Anfang an die Störungen seitens der Augen im Vordergrund standen. Sie sind so unmittelbar nach der Verletzung am linken Hinterhaupt im Stadium der Bewusstseinsstörung hervorgetreten, dass ihnen zweifellos ursprünglich eine organische Ursache zugrunde gelegen hat. Es ist später röntgenologisch 
sichergestellt worden, dass eine erhebliche bis 5 nm tiefe Eindrückung der Tabula interna bei (scheinbarer?) Intaktheit der Externa des Schädeldachs in der Gegend des linken Hinterhauptlappens durch den Streifschuss erfolgt ist. Eine ausgleichbare Schädigung des Hinterhauptlappens durch Blutung, Druck der Splitter od. dgl. hat also vorgèlegen. Die ersten Angaben über den Gesichtsfeldausfall in den ersten Tagen sind nicht ganz eindeutig. Wenn uns aber Patient selbst darüber spontan berichtet, wie er auf die Wahrnehmung desselben im Stadium der Bewusstseinsaufhellung gekommen ist - eine vorgelegte Karte kam ihm wie rechts abgeschnitten vor - , so muss man annehmen, dass es sich mehr minder scharf um eine homonyme bilatarale rechtsseitige Hemianopie gehandelt hat: bei dem Sitz der Knochenläsion also um ein reines Herdsymptom des linken Sehzentrums. Es ist danach höchst wahrscheinlich, dass die sehr bald nach der diagnostizierten Hemianopie zutage getretene konjugierte Dauerwendung des Blicks nach links eine Folge derselben, also ein sekundäres funktionelles, besser gesagt dynamisches Herdsymptom gewesen ist, das seinerseits wieder die Abweichung des Kopfes nach der rechten Seite nach sich gezogen hat. Die Ergebnisse der ursprünglichen Sehprüfungen, speziell der zentralen Sehschärfe und der Farbsinnprüfung stimmen mit den bisherigen Annahmen überein. Offen gelassen muss werden, ob die weiterhin berichtete Beschränkung der Konvergenzbewegung absolut oder ebenfalls nur eine dynamische, durch stärkste Innervation überwindbare Erscheinung gewesen ist. Offen bleibt ferner, ob die im weiteren Verlauf an die Stelle der (mehr minder reinen) Hemianopie tretende konzentrische Gesichtsfeldeinschränkung ein rein organisches Rückbildungssymptom oder eine Ermüdungsherderscheinung oder aber schon den Ansatz der hysterischen Umbildung der Symptome bedeutet hat. Wenn aber auch, was nach der Eleganz hysterischer Darstellungsfähigkeit überhaupt sich eigentlich von selbst versteht, mit Präzision der Punkt nicht zu bestimmen ist, wo im Verlauf des Krankheitsbildes das Organische ins Funktionelle übergeht, so tritt doch um so einleuchtender hervor, wie sich allmählich die psychomotorische Folgeerscheinung der ursprünglichen Hemianopsie - nach der Hysterieregel: cessante cause non cassit effectus nach deren Schwinden zum Eigensymptom verselbständigt, fixiert und schliesslich zur grotesken hysterischen Gewohnheit verdichtet hat.

Während wir die Genese der ophthalmologischen Hysterie in unserem Falle recht genau verfolgen können, ist die Entstehung der Hysterie des Hör-Sprachapparats nicht so durchsichtig, obwohl sie sich aus schwachen Anfängen zum eigentlichen Vordergrundsymptom der Taubstummheit ,,angereichert" hat. Nach der Krankheitsgeschichte verlieren sich ihre Anfänge in dem Dunkel des psychischen Choks und der darnach eintretenden Bewusstseinsveränderung. Vermutlich haben wir in den besonderen primären 
Störungen der akustischen Auffassung und der Sprachexekution den psychologischen Kern dieser traumatischen Bewusstseinsveränderung zu erblicken. Sicherlich ist die spätere Angabe, dass er Worte hören konnte, aber ohne Klangfarbe ein rein hysterisches Symptom, jedenfalls handelt es sich dabei um ein recht eigenartiges Phänomen, das ich bisher so nirgends erwähnt finde. Es ist interessant, wie hier eine (funktionelle) Spaltungsrichtung innerhalb des akustischen Wahrnehmungsvorgangs ,statuiert" wird, die sich gerade dadurch, dass sie nur an den psychologischen Aufbau der Wahrnehmung anknüpft und sozusagen allen organisehen Spaltungsmöglichkeiten zuwiderläuft, sich als rein psychogen charakterisiert. Hören und Verstehen, aber ohne die spezifische Klangfarbe; diese entfernt an die Primitivität der Aphonie erinnernde Störung kann nur die Hysterie zu Wege bringen, wie auch nur die Hysterie daraus den Ausfall im Exekutivteil des entsprechenden sensomotorischen Apparats - in diesem Falle Stummheit - ableiten kann. Für den inneren Zusammenhang der hysterischen sensomotorischen Ausfallerseheinungen in unserem Falle bemerkenswert ist der Verlauf der suggestiven Heilung. Von Seite der Stummheit, hinter der allein die suggestive Therapie ,einhakte", liessen sich alle übrigen Symptome geradezu automatisch aufrollen.

Einen bemerkenswerten Beitrag zur vielerörterten Frage: Spasmus der Konvergenz oder Lähmung der Abduktion? liefert die nachfolgende Beobachtung.

Beobachtung 8. H., geb. 1885, Schweizer.

Vater in Irrenanstalt gest. Er von jeher leicht aufgeregt, reizbar. In der Schule sehr schwer gelernt. Will nie eine Sehstörung und anch nie einen Unterschied in der Sehkraft beider Augen bemerkt haben. Juni 1915 als Grenadier eingezogen. Habe immer gut mit rechtem Auge schiessen können. Im August 1915 angeblich Erkältungsschädlichkeit: Nach dem Baden habe er eine Stunde zur Geschlechtskrankheitsuntersuchung nackt in der Kälte stehen müssen; am Tage danach sei es wie ein Schleier oder eine „Jalousie" vor und wie ein Fremdkörper im rechten Auge gewesen, so dass er wegen des Stechens und Drückens am Ange immer reiben musste (Fremdkörpergefühl); es sei eine Augenentzündung gewesen, und dann habe er noch vom Sanitätspersonal zu viel Atropin eingeträufelt bekommen. In der Folge habe das Sehvermögen immer mehr abgenommen. Zurzeit sehe er rechts von nahe ans Auge gebrachten Gegenständen nur den Schatten. Sobald er sich aufrege, sehe er überhaupt nichts. Infolge solcher Blindheit sei er eines Tages auf Vorgesetzten gerannt, habe sich sehr erregt, sei tätlich geworden; wurde später zu 11 Jahren Gefängnis verurteilt, aber nach $\$ 51$ freigesprochen und im September 1915 entlassen. Ein Augenarzt habe ihm gesagt, er müsse entlassen werden, weil er sonst das Augenlicht ganz verliere (? Ref.). Wegen Sehstörung konnte er angeblich nur Tagelohnarbeiten machen.

Januar 1917 als Armierungssoldat wieder eingezogen. 3. 2. wegen Erregungs- 
zustand im Revier: Hier Augenbefund: S. R. $-10,0 \mathrm{D}=$ Fingerzählen in $1 \mathrm{~m}$, L. $-9,0 \mathrm{D}=5 / 12$. Rechts schwere Maculadegeneration.

27. 2. Nervenbeobachtungsstation: Rechtes Auge: Blick maximal nasal gewendet, kann nicht nach aussen gewendet werden, da die Pupille immer wieder hinter dem Lid verschwindet, Reflex nicht zuverlässig zu prüfen. $H$. ist nicht imstande, dem vorgehaltenen Finger nach links oder rechts aussen zu folgen. Auswärtsdrehung links nur unvollkommen auf kurze Zeit, rechts scheinbar überhaupt nicht möglich. Beim Fixieren Doppelbilder angegeben. Bei allen Hantierungen (Suchen usw.) offenbart sich die ausgesprochene Sehschwäche. Er führt alle Gegenstände bis auf $10 \mathrm{~cm}$ an die Augen heran. (Privatdor. Hauptmann): Durch passive Drehbewegung des Kopfes unter Fixierung eines bestimmten Punktes gelingt es mitunter, eine kurze Auswärtsbewegung des linken Auges zu erzielen. Das gleiche gelingt, wenn man passiv ruckartig dem Kopf plötzlich eine Seitwärtswendung zuteil werden lässt. Spricht sehr interessiert von seiner Augenlähmung eher in der Art eines Hysterikers, der durch seine Beschwerden kaum gehindert ist, und sie nur benutzt, um seine Person in den Mittelpunkt des Interesses zu rücken. Es handelt sich wohl weniger um Lähmung des Externus, als um psychogene Kontraktur des Internus."

Augenbefund (Prof. v. Szilly): Beiderseits Myopie höhieren Grades. Rechts etwa - 12,0 D., links etwa-10,0 D. Es bestehen auf beiden Augen myopische Hintergrundsveränderungen in Form eines breiten myopischen Konus. Ausserdem sind rechts auch ausgedehnte atrophische Aderhautveränderungen in der Foveagegend vorhanden, welche die Sehherabsetzung erklären. Die Sehschärfe beträgt: Rechts angeblich (mit - 10,0) nur Finger in $1 \mathrm{~m}$, links (mit - - 10,0) $=5 / 36$. Pupillen 0. B. Doppelbilder werden (infolge der Schwachsichtigkeit des rechten Auges?) nicht angegeben. Strabismus convergens wechselnden Grades. Der Grad des Einwärtsschielens ist wechselnd und nimmt deutlich zu, wenn man sich mit dem Pat. beschäftigt. Verdeckt man das eine Auge, so geht es unter der deckenden Hand in noch stärkere Konvergenz. Bei seitlichen Bewegungen zeigt das eine Auge nicht unerhebliche Ueberbewegung nach innen, während das andere zumeist in der Mittellinie stehen bleibt. Es entsteht dadurch das Bild einer doppelseitigen Abduzenslähmung.

Gelegentlich erreicht man es aber, dass die Augen sich ruckweise auch über die Mittellinie hinaus bewegen, und man erhält auch bei Kopfdrehungen und Fixation von seiten der Augen durchaus den Eindruck, dass die Motilität der Externi nicht vollständig fehlt, sondern in erster Linie durch eine krampfhafte Kontraktion der Interni behindert ist. Es sei jedoeh bemerkt, dass ein mit der Internuskontraktion einhergehender Akkommodationskrampf skioskopisch (wohl infolge der Myopie) nicht bestimmt nachzuweisen ist. Lähmung der Akkommodation (Kokain und Homatropin, bis zur maximalen Pupillenerweiterung) ist ohne Einfluss auf den Zustand der äusseren Augenmuskeln. Sensibilität der Hornhaut und Bindehaut normal. Nach meinem Dafürhalten handelt es sich um eine hysterische Internuskontraktur, welche in diesem seltenen Falle mit einer scheinbaren Lähmung der Externi vergesellschaftet ist."

9. 3. Nervenbehandlungslazarett H.: Kleine, etwas tiefliegende Bulbi. An- 
gaben über Sehvermögen rechts wechselnd. Finmal will er von den vor Augen bewegten Fingern rechts überhaupt nur Schatten sehen, dann werden auf gütliches Zureden Finger in $30 \mathrm{~cm}$ gezählt. Zuerst ist das Gesichtsfeld aussen eingeschränkt, dann wieder auch auf Zureden hin normal. Schliesslich liest er rechts ohne Glas auf Zuspruch in 10-20 $\mathrm{cm}$ grössten Zeitungssdruck (Lebersehrift), links kleinsten Zeitungsdruck in $10 \mathrm{~cm}$. Gesichtsfeld von Anfang an normal angegeben. Rechte Pupille reagiert normal. Strabismus convergens am stärksten bei Blick nach oben, bei natürlichem Geradeausblicken etwa $20^{\circ}$. Von einer absoluten Lähmung der Externi kann nicht die Rede sein, da auf immer erneuten Zuspruch und "Hinwegleiten des Kranken über das Hindernis" der Blick nach links bis zur normalen Exkursion, der Blick nach rechts bis $45^{\circ}$ gebracht werden kann, allerdings

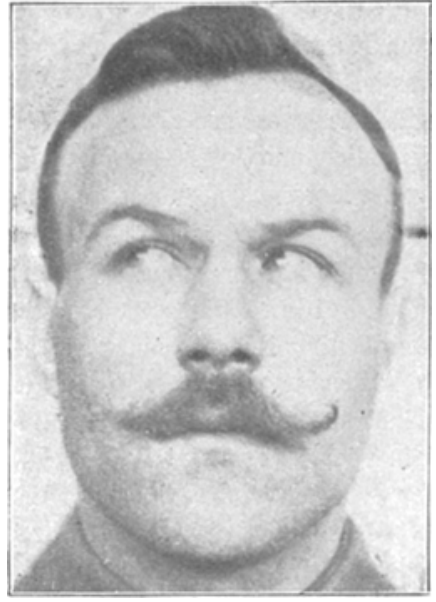

Fig. 1. um sofort nach Nachlassen des Zuspruchs. bzw. seiner langsam einsetzenden Innervation, zur Blickwendung nach aussen in stärkere Konvergenzstellung wie vorher ,zurückzuschnellen". Dies erfolgt überhaupt nach jeder verlangten, nicht ganz gewöhnlichen Blickeinstellung als Begleiterscheinung; als annähernd objektiver Masstab überdurchschnittlicher Augeninnervationen stellt sich regelmässig ein ziemlich starkes, annähernd reguläres Blinzeln ein.

10.3. Beseitigung der Abducenslähmung usw. durch starke Verbalsuggestion, mit kurzen galvanischen Strömen (s. Fig. 1, aktive Einstellung nach rechts oben).

15. 3. Völlig freie Beweglichkeit jedes Auges für sich und beider Augen bei konjugierten Bewegungen. Nur wenn man ihn überraschend etwas fragt, tritt für Augenblicke ein Konvergenzschielen von $10-20^{\circ}$ auf, das aber beim ungenierten Blick geradeaus, in der Unterhaltung usf., nicht besteht. Binokulares Lesen ohne Brille in $40-50 \mathrm{~cm}$. Bei Abdeckung des linken Auges liest er z. B. Druek, der kleiner ist wie Reklamedruck, rechts in $5-10 \mathrm{~cm}$, links in $25 \mathrm{~cm}$. 24. 3. Nach 14 tägiger Arbeit in der Munitionsindustrie während Urlaub weiter völlig freie Beweglichkeit der Augen.

Nachträgliche Feststellungen (durch den Truppenarzt im Westen): „Wegen hochgradiger Kurzsichtigkeit zum Landsturm ausgemustert. 20. 6. 1915 eingezogen, schon in der Garnison niemals zum Schiessen herangezogen. Am 28. 7. nach dem Westen; wieder zurück, da er im Schiessdienst völlig versagte. Fachärztliche Untersuchung: Hochgradige angeborene Schwachsichtigkeit bei hoher Kurzsichtigkeit, mit Netz- und Aderhantveränderungen r. $>$ I. Ausgesprochenes Innenschielen. S.: r. - 10,0 sphär. Handbewegungen in $1 \mathrm{~m}, 1 .{ }^{1} /{ }_{10}$ sphär. (Bestätigung durch Prof. D.). Nur g. oder a. v. in die Heimat. 22. 10. 1915 wegen Strabismus convergens, exzessiver Myopie, Aderhautveränderungen d. u. gemeldet. Vom 
E. T. T. am 8. 11. wieder ins Lazarett: Hier gab er an, dass sich seit seiner Einberufung (!) ein Augenleiden eingestellt habe, das sich sehr bald verschlimmerte (!); gab zu, dass er früher durchschnittlich 8-10 Glas Bier trank. Objektiv fand sich ,fibrilläres Muskelzucken an Armen, Händen, Beinen und Rumpf, Schwanken, Reflexsteigerung, Gangbehinderung. „Das Tageslicht blendet erheblich die Augen, daher trägt er blaue Schutzbrille“ (? Ref.). „Es besteht Lähmung beider (? Ref.) Augenmuskeln, erhebliche Herabsetzung des Sehvermögens rechts." „Allgemeiner Nervosität" (Alkoholmissbrauch). Mehrfach wegen. Nichtgrïssens mit Arrest bestraft. H. führt das auf Schlechtsehen zurück.

Epikrise: Es ist in diesem Falle nicht der geringste Zweifel, dass von Kindheit auf erhebliche Schwachsichtigkeit und Konvergenzsehielen des rechten Auges bestanden hat. Erst der Wunsch nach einer ursächlichen Dienstbeschädigung hat den Mann bewusst oder hysterisch auf die überwertige Idee geführt, dass er früher nie Sehstörungen gehabt und erst seit einer - phantastischen - Erkältung rechts sehwachsichtig sei. Dabei ist festgestellt, dass er schon seinerzeit wegen Schwachsichtigkeit zum Landsturm angemustert war, und als er doch in die rückwärtige Frontstellung (nicht nach vorn!) kam, sofort beim Schiessen gänzlich versagte. Durch vielfache augenärztliche Cntersuchungen hat der Mann ein sehr lebhaftes Interesse für seine Störung bekommen und recht geschickt Vorteile aus dieser gezogen; aber er hat sich doch nie verleiten lassen, objektive Krankheitsdarstellungen zu machen, die nicht vollkommen in der Richtung der organischen Fehler seiner Augen gelegen hätten. Alle Erscheinungen, die selbst nicht aus der Stärke der (anatomischen) Organveränderungen erklärbar bzw. durch den Erfolg der Psychotherapie als solche zu erhärten waren: die Sehschwäche ebenso wie die Augenbewegungsstörungen stellten mit einer so auffälligen „Präzision“ prozentual gleiche Verstärkungen dieser organisch bedingten Funktionsausfälle dar, dass danach der Verdacht der bewussten Aggravation sich vordrängen musste. Dass eine systematisierte Gesichtsfeldeinschränkung, die nach den Erfahrungen über Hysteriefähigkeit an diesen Augen unbedingt programmässig war, vermisst und statt dessen in zeitlich weit auseinanderliegenden (Juli 1915, Januar 1917) augenärztlichen Prüfungen nur eine gleich hohe Verschlechterung des zentralen Sehens angetroffen wurde, schien noch in gleiche Richtung zu weisen. Dagegen hat sich nun bei unmerklicher Beobachtung der unwillkürlichen Augenbewegungen im freien Verkehr der beiderseitige Konvergenzkrampf als eine so konstante Erscheinung erwiesen, dass die Annahme einer bewussten Vortäuschung - wogegen im übrigen auch noch das psychische Verhalten bei der Heilung sprach - nicht mehr zu halten war. Der Zusammenhang liegt hier also so, dass die habituelle latente Einwärtsschielstellung des rechten Auges, die seit Kindheit als Folgeerscheinung angeborener Sehschwäche bestanden hat, auf 
ideogenem Wege zu einer so ausgesprochenen Kontraktur beider Interni gefïhrt hat, dass daneben noch das Bild der Divergenzlähmung vorgetäuscht wurde. Als ein eindeutiges hysterisches Zeichen anzusehen und als solches recht charakteristisch ist es, dass nach der restlos gelungenen Psychotherapie die endogene Labilität im Gleichgewicht der Horizontalmuskeln des rechten Auges nur unter überraschenden affektiven Einwirkungen gelegentlich noch im Sinne einer angedeuteten Schieltendenz zum Durchbruch kam.

Aus dem Nachweis der hysterischen Bedingtheit der Blickstörungen ergibt sich für den nicht organischen Teil der Sehschwäche wohl der Rückschluss, dass auch dieser hysterisch bedingt war. Es steht fest, dass die Idee des rechtsseitigen Schlecht- oder Nichtsehenkönnens tatsächlich sich stark fixiert hatte. Für diese Fixierung muss wohl massgebend gewesen sein, dass die Aufmerksamkeit infolge irgendeiner stark affektbetonten Sensation an diesem Auge überwertig auf die bis dahin im Bewusstsein mehr minder unterdrückte Sehschwäche eingestellt wurde und blieb. Auf den Zusammenhang zwischen Idee des Nichtsehenkönnens und Gesichtsfeldeinschränkung wird weiter unten (Beobachtung 13) eingegangen. Aus der vorliegenden Beobachtung scheint mir zu folgen, dass diese negative Vorstellung auf hysterischem Wege nicht in allen Fällen zum konzentrischen Gesichtsfeldausfall führt.

Den reinsten Fall synkinetischen Dauerkrampfes der homologen Augenmuskeln beider Seiten - zugleich auch um des Mangels jeder organischen Grundlage willen die reinste Hysterie symmetrischer Augenstörungen - stellt

Beobachtung 9 dar: B., geb. 1883, Aufseher.

Vater soll an Anfällen gelitten haben, eine Schwester im 10. Jahre blind gestorben sein. Leidet seit 9.-10. Jahr an Anfällen von Bewusstlosigkeit, die alle 1/2 Jahr auftraten, angeblich öfters mit Zungenbiss und Einnässen, nachher Kopfschmerzen. Schule o. B. Nur habe ihn damals schon der Vater öfters berufen und beschimpft, dass er schiele, er habe gesagt, er kömne nicht dafür; ein Arzt habe gesagt, da sei nicht viel zu machen. Später Krankenwärter. 1904 07 Dragoner, im Einstellungsbefund wird S. beiderseits $5 / 5$ angegeben. Im Verlauf der Dienstzeit nur unerhebliche Krankheiten. Im 1. Jahr sei er vom Sehiessen zurückgestellt und abkommandiert worden, weil er in die Ferne besonders mit dem rechten Auge gar nichts sah. In späterer Zeit habe er einmal eine vom Optiker verschriebene Brille getragen, die inm aber nicht gepasst habe. Mit Mobilmachung ins Feld. War auch hier abkommandiert; keine K. D. B.; von 1915 ab hatte er öfters Sehbeschwerden, z. B. beim Pferdeputzen, beim Lesen, konnte Feineres nicht unterscheiden: Obj. ist das aber nicht aufgefallen. 29. 10. 1916 wegen Incontinentia urinae und Pollakiurie ins Lazarett. Hier ständig nass. Neurolog. o. B. Pupillen auch boi starker Abblendung stecknadelkopfgross, reagieren nur schwach, Bewegungen der oberen Lider sind sehr träge. Er hält die Lider so geschlossen, 
dass nur ein kleiner Spalt bleibt. Strabis mu s convergens. 2,-8. 12. Entzündung am rechten oberen Augenlid. Januar 1917 zum E. T. T. hier 3 Anfälle.

Nervenbeobachtungsstation F.: Pupillen sehr eng, daher scheinbar fast lichtstarr, R. L. tatsächlich prompt; sonst alles o. B. Wassermann negativ. Ein Anfall fraglicher Natur. Augenklinik: Hysterische, spastische Akkommodation und Konvergenz auf Grund eines von früher bestehenden Schielens. Myopie $4-5$ D. wechselnd vorgetäuscht durch den Akkommedationskrampt. Nach Kokain-Homatropin keine Myopie mehr. Auch die Pupillenenge kommt von dem Konvergenzspasmus. Fundi o. B. S. wird $\mathrm{mit}^{5} / 60$ gewiss ganz unrichtig angegeben, typisches Röhrengesichtsfeld. Aggravation psychisch motiviert, nicht mala voluntas. 20. 3. Nervenbehandlungslazarett H.: Ausser Konvergenzkrampf etwas Pseudoptosis (s. Fig. 2). Lesen bei

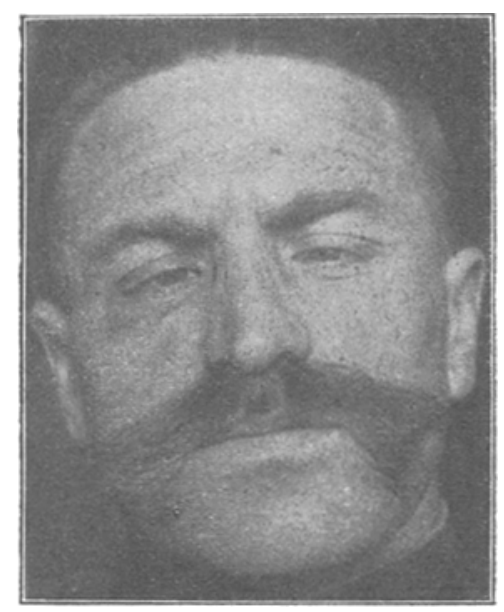

Fig. 2. Annäherung des Objekts bis $10 \mathrm{~cm}$ sehr langsam. Bei Prüfung mit den Nagel'schen Farbproben geht er änsserst langsam suchend vor; zahlreiche Verwechslungen sowohl beim Zeigen als beim Benennen der Farben. Aus seinem Verhalten geht nicht klar hervor, wieviel bewusstes und

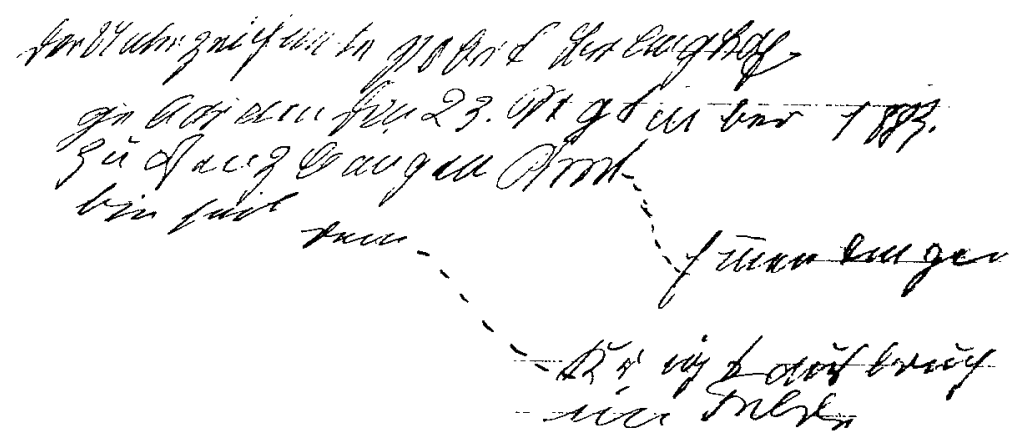

Schriftprobe 1.

unbewusstes Nichtkönnenwollen vorliegt, benimmt sich jedenfalls nicht wie ein organisch Farbenblinder. Das gilt auch für die eigenartige Schriftprobe (s. No. 1). Hierbei behauptet er, wenn er eine Zeitlang geschrieben habe, sehe er so viele Linien, dass er dann die richtige, in der er fortfahren müsse, wenn er die Feder mal abgesetzt habe, nieht mehr finde. 
Macht einen etwas misstrauischen, scheuen Eindruck; zeigt dauernd eine gewisse Renitenz bei äusserlich korrektem Benehmen. Lässt durchblicken, dass man ihm doch nicht helfen könne, weil an den Augen nichts mehr zu machen sei. 25. 3. Unter der Einwirkung der psychischen Atmosphäre und vor allem der positiven Suggestion, die durch 2 Kameraden dargestellt wird, die nach monate- bzw. jahrelanger anderweitiger Lazarettbehandlung hier geheilt wurden, hat er psychisch zum Guten ,umgesattelt"; zeigt nunmehr Hoffnungsfreude auf Heilung. Diese gelingt am 27. 3. innerhalb 15 Minuten durch Suggest-Spritzen, Verbalsuggestion, Streichen mit der ,faradischen Hand", Exerzieren der Augen unter Eigenkontrolle der Bewegungen im Spiegel usw. Danach (s. Fig. 3) auch Beseitigung der Seh-

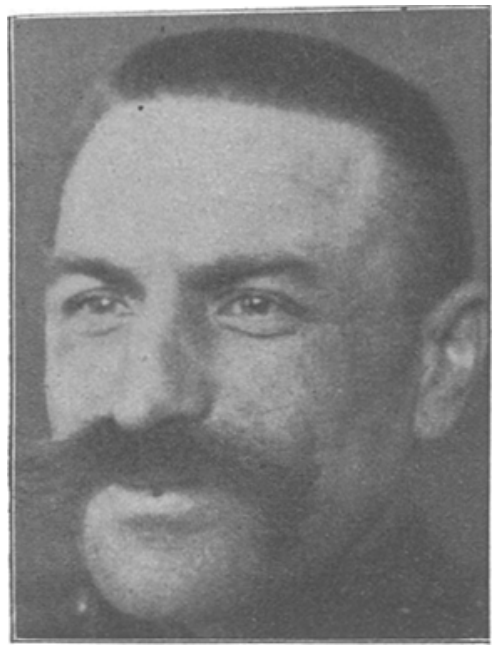

Fig. 3. störung: Nageltafeln prompt, liest gewöhnlichen Druck beiderseits monokular in $20 \mathrm{~cm}$.

Auf mein Bitten schreibt in liebenswürdiger Weise Professor v. Szyli:

„Für die hysterische Natur des Schielens spricht, dass zugleich mit dem Konvergenzspasmus die $\mathrm{Ab}$ kommodation innerviert wird (was beim gewöhnlichen konkomittierenden Schielen nicht der Fall ist). Der Umstand, dass er schon als Kind geschielt hat, spricht nicht dagegen, denn er kann entweder schon damals vorübergehende Spasmen gehabt haben, oder aber die Sache verhält sich so, wie wir annahmen, dass er einen gewissen Grad von (vielleicht periodischem) Schielen hatte, den er aber willkürlich vergrössert und hervorruft.

Da Konvergenz und Naheinstellung (Akkommodation) parallel gehen, wird während des spastischen Anteils des Sehielaktes auch die Akkommodation von ihm innerviert, daher die Myopie, welche im Ruhezustande ganz fehlt. Durch den Akkommodationsspasmus wird natürlich auch die Fernsehschärfe beeinflusst, deren voller Umfang erst im akkomodationsfreien Stadium wird beurteilt werden können, falls der Patient richtig angibt."

Epikrise: Zugrunde liegt eine von Jugend auf bestehende Disposition zu Schielen, welche bei dem Mangel jedwelcher Veränderungen an den bestehenden Medien und am Augenhintergrund in diesem merkwürdigen Falle sich offenbar als eine rein spieltriebartige Gewohnheit fixiert hat. Er selbst gibt uns wenigstens diese sehr plausible und allein aufweisbare Er- 
klärung der Entstehung. Das Fehlen der Erscheinung bei seinen verschiedenen militärischen Einstellungen anch vor vielen Jahren beweist den episodischen Charakter des habituellen Schielens, das früher von ihm selbst offenbar nie richtig als Krankheitssymptom ausgewertet worden ist, sondern unter bestimmten psychischen Einflüssen besonders der darauf gelenkten Aufmerksamkeit als eine besondere Art von psychischem Einstellungsspasmus aufgetreten ist. Aus welchen Gründen sich ursprünglich die Fixierung vollzogen hat, $o b$ rein ideogen oder unter Hinzutritt von erschöpfenden Momenten, lässt sich nicht mehr entscheiden. Der eindrucksvolle Umschlag im ganzen Wesen des Mannes - vom misstrauisch-morosen und hypochondriseh gefärbten Seelenzustande zur gesundheitsfreudigen Jovialität - unter dem Einflusse der Heilkur, der sich, wie die Abbildungen zeigen, besonders auch in den Gesichtszügen ausdrückt, lässt mit Sicherheit darauf schliessen, dass zuletzt ein aus der Unheilbarkeitsidee heraus entwickelter, dunkel bewusster Stolz auf die Symptome fixierend gewirkt hat.

Mit dem Nangel einer organischen Veränderung an und in den Augäpfeln im Sinne einer früheren Invalidität oder einer frischen Läsion hängt wohl die ausserordentliche Symmetrie der Krampfzustände derjenigen äusseren und inneren Augenmuskeln zusammen, welche durch die Gleichheit der Bewegungsrichtung konkommittierender Akte eine physiophysiologische Einheit bilden. Die Intensität des Krampfes jeder einzelnen Gruppe der konjugierten Augenmuskeln entspricht so vollkommen derjenigen aller übrigen, wie sie nur die intensivste Verwirklichung der HauptbewegungsZielvorstellung: Blick auf die Nasenspitze, herbeiführen kann. Konvergenz, Senkung der Oberlider, Verengerung der Pupillen erfolgen also im gleichen Ausmasse wie bei der bewussten Verwirklichung dieser Zielvorstellung. Was die Summe dieser Bewegungen hysterisch macht, ist das Moment der Dauer: Die Persistenz all dieser Bewegungen im Krampf, welche bewusst willkürlich ebensowenig erreicht werden kann, wie der Tiefgang, $d$. h. die Tiefenwirkung der zentralen Innervation, die sich in einem so starken Akkomodationsspasmus äussert, dass dadurch eine scheinbare Myopie erzeugt wird.

Im Gegensatz zu den Beobachtungen Bartels ${ }^{1}$ ) ist hier sichtlich nicht das „Unzweckmässige der Akkommodationsanstrengung" das Wesentliche, sondern die Myopie - wenn auch subjektiv am eindruckvollsten zum Bewusstsein kommend - lediglich Folgeerscheinung der Neigung zum Krampf der verschiedenen einer einheitlichen Richtungsvorstellung dienenden Augenmuskeln. Dabei handelt es sich hier zweifellos um einen in doppeltem sinne primären Krampf: Einmal bestehen keinerlei Anhaltspunkte, den Krampf auf eine Parese des Antagonisten zurückzuführen, des weiteren aber spricht

1) Zeitschr. f. Augenheilk. 1907. 18. Zit. nach Wissmann.

Archiv f. Psychiatrie. Bd. 58. 
nichts dafür, dass der Spasmus dieser einer einheitlichen Praxie zugehörigen Muskeln auf subjektive optische Phänomene, etwa auf Sensationen oder auf Einbildungen sensorischer Störungen, zurückzuführen und in diesem Sinne einfühlend als zweckgemässe Abhilfe- oder sonstwie als Reflexbewegung aufzufassen ist. Sehr viel wahrscheinlicher ist demgegenüber die auch durch die retrospektiven Angaben des Kranken gestützte Auffassung, dass für die Fixierung des Einstellungskrampfes neben der endogenen Neigung zum Schielen die Muskelermüdung in der Weise eine Rolle gespielt hat, dass beim Versuch, diese zu überwinden, jene Disposition sich noch zu dauernden Intentionsspasmen gesteigert hat. Es würde so am leichtesten zu erklären sein, dass mit der Beseitigung des Konvergenzkrampfes durch die Psychotherapie, d. h. der Aufrollung des Symptomenkomplex von dieser psychomotorischen Seite her alle übrigen Erscheinungen ron selbst verschwunden sind.

Vergleichen wir die beiden Beobachtungen miteinander, so ergibt sich nur noch die Frage, ob in jedem Falle doppelseitigen Konvergenzkrampfs eindeutige Beziehungen zwischen diesem und der Stärke des Akkommodationsspasmus und damit auch der spastischen Myopie anzunehmen sind mit anderen Worten, ob die Kurve der Innervationsstärke für Konvergenz und Akkommodation in jedem Falle parallel laufen oder ob auch hier die Innervation des sympathischen Muskelapparats erst bei einer gewissen Stärke der Innervation der im gleichen Akte innervierten quergestreiften Augenmuskeln erfolgt. Sicherlich bestehen auch in dieser Beziehung individuelle Differenzen. Die Erfahrung zeigt, dass physiologischerweise der willkürliche Krampf der Konvergenz nicht von einem Krampf der Akkommodation gefolgt ist. Im Zusammenhang mit allen sonstigen Erfahrungen können wir daher aus der Parallelität zwischen Schiel- und Akkommodationskrampf auf die hysterische Natur des letzteren schliessen. Leider lässt sich in solchen Fällen das pharmakologische Experimentum crucis nicht oder schwer ansführen. Wem wir nach der experimentellen Beseitigung des Aklkommodationskrampfes durch Lähmung der Akkommodation mittels KokainHomatropin den Konvergenzspasmus unverändert weiter bestehen sehen, so beweist dies freilich die Unabhängigkeit des letzteren von allen optisehen Einflüssen, an und für sich aber nichts für die Kongruenz und Abhängigkeit zwischen Schielen und Myopie. Hierüber könnte vielmehr erst der praktisch wohl kaum ausführbare Gegenversuch einer Lähmung der Interni etwa durch Kurarisierung entscheiden.

Die folgende Beobachtung gibt Anlass, auf die wiederholt gestreiften Beziehungen zwischen hysterischen Hypermotilitätsstörungen des Auges und der individuellen Anlage der Psychomotilität einzugehen. Es handelt sich um einen Fall sicherer Hysterie, die sich fast nur in einer Fülle eigenartiger 
motorischer Reizerscheinungen im Bereiche des Kopfes und besonders seitens der mimischen Muskulatur in hysterischer Hypermimie dokumentierte.

Beobachtung 10. Sch., geb. 1892, Dreber.

Auf Schule 2 mal sitzengeblieben. Mai 1915 eingezogen. 18. 6. bis 6. 8. 1915 rechts parenchymatöse Hornhautentzündung (total) (Augenstation Prof. L.) interkurrent Ekzem der Lider infolge warmer Aufschläge.

1. 1. 1916. Front. Von Anfang Zusammenzucken bei Artilleriefeuer. 29. 4. krank gemeldet, müde, matt, Kopfsehmerzen. 30. 4. Lazarett M.: „Apathisch beschränkt", nurinitMühe über Vorgeschichte befragbar. Etwas tremormanuum usw.

16. 5. Lazarett F.: Hält Kopf sehr ruhig; weinerlich. Schweres Gefühl im Kopf. Schwindel beim Gehen. 30. 5. Nach Streit mit Kameraden grosser hysterischer Anfall; reagiert dabei auf Antwort, weint.

9. 6. Nervenbehandlungslazarett: Gespannter Ausdruck, grosse Augen; habituelles Gleichgewichtssehwanken in der Innervation der äussern Augenmuskeln meist so, dass einmal beim Blick geradeaus auf den Untersucher die Sehachse jeweils des einen Auges einige Grad abweicht, was unmittelbar danach oder wenige Minuten später bei gleicher Innervation nicht der Fall ist. Rechte Lidspalte Spur <l. Bei der ersten Untersuchung treten im rechten Frontalis, sobald man sich ihm zuwendet, kurze Zuckungen auf; als er dann wegen Kleinigkeit zurechtgewiesen wird, spielt er den Erregten; gerät in grossen Tränenausbruch, ausgesprochene Tachypnoe, Stöhnen und allerhand undefinierbare Kopfwackelbewegungen.

Im übrigen Gang, Sprache, Kopfbewegungen schlaff, träge, tonlos, schleppend breit. Bei Augenschluss kein Lidflattern, dagegen nach einiger Zeit Tremor capitis horizontalis und Frontalis-Tic. Allgemeine Analgesie. Der Tie sistiert unter Ueberrumpelung. Bei waiterer Untersuchung wird die Kurve des Ties langgezogen, und zwar nur, sobald er wähnt, direkt beobachtet zu werden, nicht z. B., wenn man ihn unauffällig beobachtet, indem man z. B. vor ihm das Krankenblatt liest und durch dieses die Augen sich und ihm so verdeckt, dass man über dessen Rand nur seinen Frontalis beobachten kann. Puls 92, 1. Ton Spitze unrein. Sehr kühle, feuchte Hände. B.-D. $142 \mathrm{~mm} \mathrm{Hg.}$

25. 6. Getragenes Wesen, deutlich hysterisch posiert. Akrobat in allen möglichen Verziehungen der oberen Gesichtshälfte (r. >l.), die der Form und Geschwindigkeit nach alle möglichen $Z$ wischenarten $z$ wischen Athetose und Tic zeigen. Aufgefordert, das linke Auge isoliert zu schliessen, wie zum Schiessen geht er mehrere Sekunden drum herum (Umgebungsbewegungen), als ob er die richtige Innervation suchen müsste, bis sie schliesslich ruckartig eintritt; dabëi ausgesprochene Rücksicht auf die Wirkung des Manövers. Es kommt ihm die habituelle Labilität im Gleichgewicht der Augenmuskeln und die Ueberfälligkeit isolierter Halbseiteninnervation besonders zugut. Beseitigung der Störungen durch ,psychische Isolirung“".

Die beschriebene funktionelle Augenbewegungsstörung steht am nächsten der Gruppe von Erscheinungen, die Kunn als „Dissoziation der Augen- 
bewegungen" bezeichnet hat. Die Augen werden dabei nicht in einer bestimmten Stellung festgehalten, sondern wandern, ohne dass Lähmungen oder Krämpfe bestehen, regellos, dom. Willen nicht gehorchend, wie im tiefen Koma, eines unabhängig vom anderen umher. Im Gegensatz dazu handelt es sich hier aber nicht ohne weiteres um einen Verfall von assoziierten Leistungen, sondern um eine Art Können; aber auch dies Können entspricht nicht geradewegs einer von Haus aus bestehenden oder schon unter geringer Uebung sehr weitgreifenden ,individuellen Dissoziationsfähigkeit", wie sie ja Lewandowsky als bestimmendes Moment ,individueller Gestaltung “ hysterischer Bewegungsstörungen annimmt. Die besondere Art hysterischer Disposition, die hier zugrunde liegt, ist nicht allein etwas Uebernormales, sondern zugleich auch etwas Unternormales. Der Gleichgewichtszustand des Tonus der reziproken Muskeln, die zu einem. System höherer, vorweg assoziierter Muskelleistungen zusammengehören, ist unternormal labiler als durchschnittlich. Diese Leute müssen daher eine überdurchschnittliche Innervationskraft anwenden, um das Normale zu leisten. Andererseits befähigt sie diese Labilität wohl zu Leistungen, die der Normale nicht ohne weiteres fertig bringt. Es besteht aber keine eindeutige Beziehung zwischen dem, was sie mebr können und dem, was sie weniger haben, als der Durchschnitt. Wer z. B. eine besondere Fähigkeit zur Innervation einzelner äusserer Augenmuskeln besitzt, hat andererseits nicht notwendigerweise die Fähigkeit, Entspannungen bzw. eine mehr minder dauernde Herabsetzung des Durchschnittstonus der Angennuskeln so herbeizuführen, dass die Augen in den verschiedensten Richtungen nicht mehr ,zweispännig" fahren, sondern jedes in seiner ,ihm beliebenden" Richtung spazieren geht. Normalerweise erstreckt sich eben die Uebungsfähigkeit auf die möglichst richtige und prompte Dosierung und Verteilung der Innervation auf die Agonisten und Synergisten bei gleichzeitiger (innervatorischer) Entspannung der Antagonisten, nicht aber auf die gleichzeitige Entspannung dieser drei Systeme, durch welche annähernd alle ihrem physikalischen Gleichgewichtszustand zugeführt werden. Dabei leisten im angefïhrten Beisplele die Augenmuskeln, wenn es darauf ankommt, anch assoziiert im Verband das Erforderte. Es bedarf dazu aber, soweit sich durch Einfïhlung aus dem Verhalten der Leute schliessen lässt, einer besonderen Heranziehung der entsprechenden Bewegungsvorstellungen oder des Handlungsentwurfs. Hysterisch mag sich in solchen Fällen direkt eine gewisse Lässigkeit in der Mobilisation dieser kinetischen Vorstellungen eingestellt haben, die sich aber leicht psyehotherapeutisch überwinden lässt. Die hier angestellte Erörterung über die „Beziehung der hysterischen Phänomene zu den willkürlichen Vorgängen", die die Kehrseite der von Le wandowsky allein herangezogenen individuellen 
Dissoziationsfähigkeit der Muskulatur im Auge hat, lässt sich von dem Spezialfall der Augeumuskeln auf zahlreiche andere hysterische Phänomene übertragen.

Es werden dadurch manche Erscheinungen unserem Verständnis näher gerückt, als durch die einseitige Betrachtung unter dem Gesichtswinkel: Kontraktur oder Lähmung? bzw. die Annahme besonders naher Beziehungen zwischen Lähmung und Kontrakturbildung (Kombinationen u. dgl.). Sehr mit Recht hat Lewandowsky die unberechtigte Rolle, die man der Alternative: Lähmung oder Spasmus? zuschob, zurïckgewiesen. Auch wenn es uns in jedem Falle monosymptomatischer Bewegungsstörungen gelänge, sie restlos als einfache Lähmung oder als einfachen Spasmus bzw. Kontraktur zu charakterisieren, würde damit an sich noch nicht die organische Bedingtheit oder der funktionelle Charakter erwiesen sein.

Das Interesse der Frage beginnt erst bei der Analyse des Anteils der verschiedenen wirksamen Muskelkräfte und ihrer Beziehung zu den innervatorischen bzw. willkürlichen Möglichkeiten. Dann erhebt sich noch die weitere Frage, ob und inwieweit ein latentes nervöses Degenerationszeichen oder sonst eine dynamische Sonderdisposition in Latenz vorhanden gewesen ist, das durch irgendeinen psychogenen Anlass zum hysterischen Symptom qualifiziert wurde. Denn es unterliegt wohl keinem Zweifel, dass solche "dynamischen Degenerationszeichen", die wir sicher noch nicht alle kennen und besonders in ihrer Bedeutung noch nicht genügend einschätzen, an sich (noch) nicht hysterisch sind. Was sie aus ihrer Latenz heraushebt, können wir auf psychischem Wege wieder therapeutisch beseitigen, indem wir das Individnum dahin bringen, es ans eigenem Willen und Bewusstsein zu unterdrücken. Diesen Anteil dürfen wir daher als das hysterische Moment ansprechen. Unausrottbar bleibt aber dennoch die Grundlage, die lokalisierte neuropathische Symptomdisposition. Ich glaube, dass von dieser Auffassung aus am leichtesten die Frage generell sich entscheiden lässt, wamn wir eine gegebene Bewegungsstörung, der wir es nach Form und Ablauf ohne weiteres nicht ansehen können, hysteriseh ist oder nicht. Im Brennpunkt des Interesses steht ja die Diskussion bezüglich des Stotterns, des Zitterns und der Ties. Als hysterisch qualifiziert sich von diesen mehr oder minder monosymptomatisch auftretenden Reizerscheinungen nur das, was als irgendwie psychogen friseher Ausbau solcher ,dynamischen Degenerationsstigmata“" erwiesen wird.

Wie oben ausgeführt, sind die Bedingungen der Dissoziierbarkeit der Mnskulatur für die Blickwender andere als für die Lidmuskeln. Sie liegen für diese insofern komplizierter als hier in höchst zweekmässiger Weise 
das Zusammenspiel durch glatte, durchschnittlich also willkürlich nicht direkt beeinflussbare Muskelfasern hergestellt wird.

Nur in ganz seltenen Fällen reichen bei vollem Bewusstsein willkürliche Impulse bis ins Gebiet sympathischer Innervation hinab und hinein. Der typischste Vertreter dieser "Sympathikuskünstler" ist jener vor Jahren in Krankenhäusern herumziehende Mann, der angeblich nach Typhus an sich die Fertigkeit bemerkte und ausbildete, u. a. isoliert sein Zwerchfell zu bewegen und vor allem seine Pupillenweite in durchaus willkürlicher Innervation zu verändern.

Die conditio sine qua non dafür ist psychophysiologisch nicht allein die Stärke und Nachhaltigkeit der „Wollung“", als vielmehr eine spezifische "Reizsamkeit" bestimmter Kategorien sympathischer Muskeleinheiten. Ausdruck dieser Reizsamkeit ist die durchschnittliche Ansprechbarkeit dieser Gebilde für zentrale, zerebrospinale Einflüsse verschiedener Art und Herkunft. Es besteht aller Grund zu der Annahme, dass es von Haus aus bestehende individuelle Sonderdispositionen gibt, die sich nicht auf die sympathische Reizsamkeit üb e r ha u p t beschränken, sondern darüber hinaus noch elektiv auf die besondere Reizsamkeit e in z eln er Gebiete des autonomen Systems erstrecken. Lewandowsky hat sich dahin ausgesprochen, es schienen fast alle hysterischen Erscheinungen insbesondere am sympathischen Nervensystem vor allem durch hypnotische Suggestion bei geeigneten Personen erzeugbar. Diese spezifische Eignung bestimmter Personen kann sich bei dem einen auf die (physiologisch rein) autonomen Systeme des Vasomotoriums, der Trophik, bestimmter Sekretionen usf., bei einer weiteren Gruppe auf die nervösen Verschlussapparate der Körperhöhlen oder -öffnungen beschränken. Die Erfahrungen der Hypnose sprechen nur ganz allgemein davon, dass sympathische Vorgänge sich in ,abnormem" Masse beeinflussen lassen. Es ist aber wohl mit Sicherheit anzunehmen, dass auch die hypnotische Erzeugung ungewöhnlicher sympathischer Erscheinungen nur bei dem Vorliegen solcher Sondereignung möglich ist. Es scheint z. B. nicht nur nicht erwiesen, sondern höchst unwahrscheinlich, dass bei den gleichen Individuen, bei denen sich hypnotisch blutige Schweisse hervorrufen liessen, ohne weiteres etwa Fieber oder hypnotische Pupillenstarre mit Mydriasis auf diese Weise sich müssten erzielen lassen. Dagegen drängt alles zu der Annahme hin, dass eine Person, der durch hypnotischen Befehl z. B. eine Mydriasis beigebracht werden kann, ebenso in der Lage ist, durch Eigendressur die Beeinflussung seines Pupillenspiels bis zu der Fertigkeit des oben erwähnten „Sympathikuskünstlers" zu steigern, wie bei ihr durch hysterogene Ursachen hysterische Zustände auftreten können, in denen die Mydriasis ein Hauptsymptom darstellt. In diesem Zusammenhang kommt der Feststellung von Bettmann und Lewontin, dass bei einer Patientin, 
deren „hysterische" Hautgangrän als artefiziell erkannt wurde, trotzdem die Reizbarkeit ihrer Haut in ganz abnormer Weise gesteigert war ${ }^{\mathbf{1}}$ ), eine grundlegende Bedeutung zu. Es lässt sich also die These aufstellen, dass ein und derselbe motorische Effekt bei entsprechender Sonderanlage ebenso erzeugt werden kann 1. durch die höchste Steigerung des Wollens der Verwirklichung einer bestimmten Bewegungsvorstellung infolge Dressur; diese Dressur kann artistischen wie rein nosophilen Motiven entspringen; 2. durch die überbewusste Vorstellung des schon eingetretenen Erfolgs (ideogen-autosuggestiv, nicht hysterisch); 3. durch die höchste Suggestion dieses Erfolgs mittels hypnotischer Eingebung und 4. durch die Fülle komplizierter psychogener Faktoren, welche als hysterieschaffend bekannt sind (ideo-thymogen, thymogen usf.).

Durch eine spezifische Ansprechbarkeit sympathischer Muskelelemente kann am Auge die Bewegungsformel der Lidmuskeln in besonderer Weise abgewandelt werden. Für die Erklärung funktioneller schlaffer Ptosis dürfte dies von ausschlaggebender Bedeutung sein. Die habituelle Stellung des oberen Lids ist die Resultante des Tonus des glatten Teils des Levator, der in der oberen Kante des Tarsus inseriert und der quergestreiften Fasern, die in der Haut des oberen Lids ansetzen. Die spontane willkürliche Erzeugung von schlaffer Ptosis ohne Orbikulariskrampf bei im übrigen vollständig gesunden Mensehen, wie sie Binswanger und Bartels beobachtet haben, stellt den niedrigsten Grad individueller Dissoziationsfähigkeit dar, auf den diese Lente wohl sicher hysterisch rekurrieren, wenn ein Anlass zum Krank- oder Patientsein vorliegt. Sie sind wohl sicher die „Kandidaten“" hysterischer Ptosis, wenn hysterische Motive in Frage kommen. Ich beobachte zurzeit gerade einen solchen Patienten mit schlüssellochartiger Gesichtsfeldeinschränkung beider Augen, der in stets wachsendem Masse jeweils nach dem Grade der darauf gelenkten Aufmerksamkeit isoliert die Innervation der oberen Lider symmetrisch so dosieren kann, dass jeder beliebige Grad schlaffer Ptosis ohne Lidkrampf vorgetäuscht wird. Bei ihm hat man unmittelbar den Eindruck, als ob es sich um die Lider einer Kinderpuppe handelt, die antomatisch in beliebigen Stellungen festgehalten werden können. Ein höherer Grad derselben liegt offenbar da vor, wo genau der gleiche Effekt als Dauerzustand auftritt. Ein dauerndes Herabhängen des oberen Lids bei normaler Beweglichkeit ist funktionell nur so denkbar, dass der Tonus des sympathischen und des quergestreiften Anteils herabgesetzt ist. Eine dauernde Herabsetzung des Okulomotoriumanteils allein kann nur

1) Lewandowsky, S. 62: 20proc. Lysollösung bewirkte bei ihr schon nach 2 Tagen die Nekrose, während Lewontin bei sich selbst erst bei einer 100 proc. Lösung eine ähnliche Reaktion erzielen konnte. 
durch organische Läsion desselben hervorgerufen werden. Eine isolierte Hypotonie der glatten Lidmuskelfasern setzt ebenfalls eine organische Läsion des Hals- oder anderer Teile des Sympathikus roraus. Dagegen kann die Kombination beider ohne organische Schädigung ein Danerhängen des Oberlids funktionell dann zustande bringen, wenn der zentrale Einfluss auf den Tonus seines zerebralen und sympathischen Muskelanteils im Prinzip tiefer reicht als normal. In diesem Falle muss es zur hysterischen echten Ptosis kommen.

Differentialdiagnostisch entscheidend ist für sie die vollkommen normale Aktivität und Kraft des Levator palpebrae und der negative Ausfall der gebräuchlichen Sympathikusproben. Bewegungsphysiologisch steht diese hysterische Ptosis sehr nahe oder ist identisch mit dem angeborenen oder in frühester Jugend erworbenen Tiefstand eines Oberlides, welches wir oft als einseitiges „Stigma hereditatis seu degenerationis" ebenfalls ohne sonstige nachweisbare Ausfälle des Sympathikus recht häufig bei im übrigen gesunden Menschen zu Gesicht bekommen. Von diesem unterscheidbar ist die hysterische Form also nur durch den Nachweis des psychogenen Entstehens oder Verschwindens. In dieser Beziehung besonders bemerkenswert ist der folgende Fall:

Beobachtung 11. W., geb. 1890, Arbeiter.

Als Kind zart, Lungenentzündung; 2mal sitzen geblieben; 1911-12 aktiv, d. ur. mit Rente wegen Fussbruch. Februar 1915 zur Armierung. September ins ins Feld (Infant.). 18. März 1916 morgens 10 Uhr Verschüttung: Stand auf Posten, weiss noch, dass er sich Zigarette anzündete, dann bis abends 9 Uhr „weg" (Angaben schon damals wie heute). 23. 3. Feldlazarett 2. Rechtes Trommelfell gerötet, Hammergriff kleine zentrale Perforation, trocken. Linkes Trommelfell zum grossen Teil zentral perforiert. Wundränder an die knöcherne Wand angedrückt, Rest gerötet. 24. 3. Rechts Trommelfell etwas blasser, Blutung längs des Hammers nach unten über das Trommelfell links wie früher. Keine Sekretion. T'emp. 38. 26. 3. Feldlazarett; Rechts 2 verschorfte kleine Trommelfellrisse am unteren Hammerende und am vorderen Rand. Linkes Trommelfell gerötet, stark iniziert, v. u. rundes Loch, mässige Absonderung. Flspr. $1.3, \mathrm{r} .{ }^{1} / 2 \mathrm{~m}$. (Mittelohrentzündung (?), ob infolge Trommelfellzerreissung?) 3. 4. Zurück: Befund derselbe. Weber nach links R. Luft- und Knochenleitung verkürzt, Rinne negativ; L. Luft und Knochenleitung sehr stark verkürzt. Ohrtrompete gut durchgängig. 29. 4. Sekretion noch stark, bis 3. 5. sistierend. Schwellung hinter Ohr zugenommen. Operation: zirkul. Sehnitt hinter linkem Ohransatz bis anf Knochen: Reichlich Eiterentleerung. Warzenzellen stark mit Blut gefüllt, teilweise mit Eiter, der bis zum Antrum reicht: Glättung des Antrum. 17. 6. Normaler Verlauf. 1. 7. Wunde abgeheilt. Trommelfell blass. Flspr. r. 5, 1. 1 m. 18. 7. Trommelfelle getrübt, eingezogen. Flspr. r. 7, 1. 2,5. 2. 5. Zum Ersatztruppenteil: Hier immer starke Kopfschmerzen. 30. 9. Ohnmachtsanfall, darauf ins Lazarett: Obj. Puls 69. Ohrbefund wie früher. Beim. Gehen Schwanken nach beiden Seiten, Gefühl, als ob alles an seiner linken Seite 
sich vorbeidreht. 16. 10. Ohrenklinik Freiburg: Trommelfell rechts o. B.; links verdichtet. Schwanken nach links, schraubt sich durch Drehung ums linke Bein weiter, stösst nicht an. Flspr. beiderseits mehr als 5 m, Romberg: Neigung nach hinten, kein Fallen, Balanzieren. Kalor. Nystagmus o. B.: „Hysterie“. Nach Faradisation hysterische Anfall. Nachher will er nicht gehen können, Fallen durchaus gekïnstelt. Keine otogen bedingte Störung der Statik. Angenklinik: Ptosis links, links Pupille enger als rechts, Kokainversueh +: Sympathikusparese. Nervenbeobachtungsstation: Kein Nystagmus, Augenbewegungen frei. Bei mehrfachen Untersuchungen fällt eine schlechtere Innervation der ganzen linken Gesichtshälfte, spez. der Mundpartien auf (Operationsschädigung des Fazialis), dagegen sonst nur gelegentlich erschöpfbare nystagmusartige Zuckungen. Gangstörung immer dieselbe: unsichere, schwankende, wacklige Schritte, „Romberg" nach hinten, mitunter beim Gehen und sonstigen Körpor-bewegungen aus dem Stehen heraus Schwanken nach links. Psychogene Ataxie beim Kniehakenversuch (willk. Mitbewegungen). Angelernte Halte- und Stützbewegungen mit der linken Hand, die auf energisches Anfassen sistieren. 14. 11. Urteil: Die ganze Art der Gangstörung macht trotz des absolut negativen Befunds der Ohrenklinik anfangs doch den Eindruck des Organischen: Kleinhirn- oder Labyrinthaffektion. Die Sympathikusparese vermehrte den Verdacht. Wenn auch jetzt die Möglichkeit einer solchen nicht fallen gelassen werden kann, so scheint doch mit Rücksicht auf das völlige Fehlen sonstiger organischer Symptome usw. das Vorliegen einer psychogenen Störung nicht ausgeschlossen. Daher Nerv,-Laz. B.: Befund: wie früher: links Bulbus Spur vorgetrieben. Linkes oberes

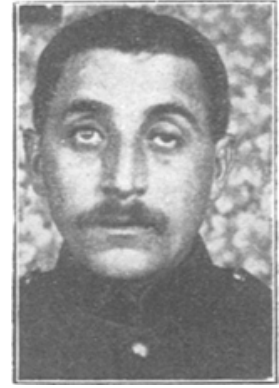

Fig. 4. Lid hängt herab, $3 \mathrm{~mm}$ tiefer wie rechts, zujleich steht die Augenbrane etwas tiefer. Keine Beschränkung der Exkursion und Kraft der aktiven Bewegungen des Lids, auch gegen Widerstand nicht. Romberg: Rücksichtsloses Rückwärtstaumeln: würde, wenn nicht gehalten, sich sicher verletzen. Operationsnarbe hinter der Ohrmuschel von der Höhe der Ohrspitze bis zur Spitze des Warzenfortsatzes. 20. 11. Hypnose: Auch in dieser fällt er rückwärts, als er Freiübungen der Arme macht; Suggestion, danach Rückwärtsfallen nur bei „Arme rückwärtsund aufwärtsstrecken". Suggestion, dass, wenn einmal mit dem elektrischen Strom die Oberschenkelmuskeln zur Kontraktion gebracht würden, er nicht mehr fallen könne. Nach Erwachen überstürztes Exerzieren. Darnach völlig frei von jeder Gang- und Gleichgewichtsstörung.

7. 2. 1917. Hat 4 Wochen anstandslos in der Maurerei gearbeitet. Nie eine sekretorische oder vasomotorische Differenz zwischen rechter oder linker Gesichtsoder Kopthälfte beobachtet. Kein Romberg mehr, tadelloser Gang. Keine Spur von. Gleichgewichtsstörung. Linke Ptosis schlaff um $3 \mathrm{~mm}$ (s. Fig. 4). Linker Frontalis zeigt Spur ausgeprägtere Querfalte wie rechts, die linke Augenbraue steht vielleicht etwas höher wie die rechte, doch könnte dies immerhin durch eine leichte Gesichtsasymmetrie von früher her bedingt sein. Auch bei extremem Aufwärtsblicken, das 
links wie rechts gleich gut erfolgt, sowie bei Fixieren unter Kopf-, passivem Vor- oder aktivem Rüekwärtsneigen des Kopfes ist die Ptosis konstant (,Landolt" negativ). Fazialis $\mathrm{r} .=1$, elektrisch frei. Trigeminus 1 links deutlich druckempfindlich. Sensibilität o. B. Mechanische Erregbarkeit im Gesicht (auch Stirn) sehr lebhaft, r. $=1$. Pupillen annähernd gleichweit, links vielleicht Spur $<r$. Keine Spur mehr von Vortreibung des Bulbus. Beim passiven Lidheben nichts von Muskelspannung oder von Lidwulstung. Er selbst gibt spontan an, dass seine Frau ihn bei seinem ersten Urlaub nach der Verschüttung anf die Differenz der Augenweite aufmerksam gemacht habe. Er klagt noch über häufige linksseitige Kopfschmerzen.

Dauernd vollkommen unhysterisches Wesen und in Monaten kein einziges hysterisches Symptom.

Es muss dahingestellt bleiben, in welcher Weise hier die traumatische Schädigung des Sympathikus zustande gekommen ist, ob durch stumpfe Gewalteinwirkung auf die Hals-Ohrengegend durch die Versehüttung, welche so stark war, dass fast das ganze Trommelfell zerriss, oder infolge einer Operationsschädigung sympathischer Fasern, welche durch den N. caroticotympanicus inferior und den Plexus caroticus internus-radices sympath. gangl. cillar. zum Ganglion ciliare ziehen. Wahrscheinlicher ist das letztere um so mehr, als früher neurologisch einwandfrei auch eine allein durch Operationsschädigung bedingte ausgleichende Facialisschwäche auf dieser Seite festgestellt war. Damals wurde auch das okulopupilläre Symptomenbild der Sympathikumparese durch den Kokainversuch sichergestellt. Geblieben ist davon nur eine echte sympathische Ptosis; selbst die Pupillendifferenz ist nicht mehr einwandfrei vorhanden.

Für die Frage der hysterischen echten Ptosis eines Auges ist der Fall besonders lehrreich deshalb, weil er zeigt, dass sich isolierte einseitige Ptosis als letzter Rest einer sicher nachgewiesenen frischen Schädigung des Sympathikus durch Trauma längere Zeit erhalten kann. Ohne den anamnestischen Hinweis ihrer Entstehung wäre sie wohl sicher als echte hysterische Ptosis aufgefasst worden. Neben der Anamnese brachte differentialdiagnostisch den Entscheid das Ergebnis der Hypnose. Die Gleichgewichtsstörungen, die nur die zeitliche Fixierung von objektiven und subjektiven Funktionsstörungen infolge einer ausgleichbaren organisch-traumatischen Schädigung bedeutet haben, haben sich durch Hypnotherapie beseitigen lassen: die Ptosis erwies sich ihr gegenüber völlig refraktär. Darüber hinaus aber hat sie auch sonst ihren ,mikroorganischen Charakter" erwiesen.

Ich habe die Möglichkeiten hysterischer Bewegungsstörungen der Lider eingehend deshalb erörtert, weil in den einschlägigen Abhandlungen darïber der praktische Kernpunkt verschoben erscheint. Bei allem theoretischen Interesse, das diesen Dingen zukommt, liegt die praktische Wichtigkeit doch nicht so sehr in der viel erörterten Unterscheidung von Orbikulariskrampf 
oder Schwäche der Lidheber. Die Brauchbarkeit des Charcot'schen „Augenbrauenzeichens" und der übrigen differentialdiagnostischen Zeichen von Wilbrandt und Sänger, Landolt, Oppenheim u. a. ${ }^{1}$ ), auf welche in der folgenden Beobachtung noch kurz eingegangen werden soll, ist nicht zu. bezweifeln, auch wenn es nicht immer möglich ist, mit ihrer Hilfe eine scharfe Trennung zwischen Blepharospasmus und Ptosis in ihren verschiedenen Arten durchzuführen (Wissmann). Praktisch bedeutsamer ist demgegenüber entweder der Erfolg der Psychotherapie - wenn er positiv ist ${ }^{2}$ ) - oder die minutiöse Feststellung, dass im gegebenen Falle auch jede feinere organische Schwächë, vor allem eine lähmungsartige Schwäche des Sympathikus ausgeschlossen werden kann.

Beobachtung 12. Br., geb. 1882, Landwirt.

Als Kind Pavor nocturnus, Bettnässen bis in die Schulzeit. Angeblich wegen abnormer Kupfform nicht aktiv gedient; sonst 0 . B.

28. 10. 1914. Armierungssoldat. 11. 11. entlassen. 6. 2. 1915 wieder eingezogen, militärisch ausgebildat. Juli ins Feld; schoss immer mit dem linken Auge, weil er mit dem rechten trotz Bemühung nur ganz unscharf sah and schlecht schoss. Februar 1916 nach Belgien. Wachdienst; im November während Marsch Ohnmacht, einige Tage Revier. Im Dezember 1916 beriefen ihn seine Kameraden öfters abends nach dem Dienst: „Du hast auch wieder genug", womit sie meinten, dass er die Angen so verdrehe. Dabei tat ihm der Kopf weh, und er fühlte sich sehr matt. 3. 1. 1917. Wiihrend Exerzieren an der Front heftige Atemnot, bekam schwarze Ringe vor den Augen, die Umwelt drehte sich nach rechts; war dann ,weg:". Als er nach $1 / 4$ Stunde wieder zu sich kam, konnte er die Augen nicht mehr nach der Seite und aufwärts drehen, weil sie beide krampfhaft im Blick nach vorn und das rechte beinahe geschlossen festgestellt waren. Als er versuchte, sie zu drehen, trat unangenehme Spannung über den Branen ein. Das linke Auge stand weit heraus. Am nächsten Tage wieder Dienst. Am 5. 1. wieder nach $2 \mathrm{~km}$ Marseh Schwächeanfall: musste sich setzen, hatte Flimmern vor den Augen und Doppeloilder, letzteres schwand nach 14 Tagen. 7. 1. You der Front zurück wegen Nervenbeschwerden. 1. Augenärztliche Untersuchung Etappenlazarett: „Nebeneinanderstehende, gekreuzte Doppelbilder, Ophthalmoskopisch 0." Rechte Lidspalte schmal: Aktiv gelingt nur geringe Erweiterung; beide Bulbi anseheinend etwas vorgetrieben, deutlich nach abwärts gekehrt, Blick nach oben beschränkt, sonst Augenbewegungen frei. Bei Konvergenz weicht der rechte Augapfel nach anfänglicher Einstellung nach aussen ab. Pupillen: Exzentrisch, R. L. prompt, Konvergenz- und Akkommodationsbewegungen der Pupillen fehlen. Stirnrunzeln r. $=1$. ; im übrigen genau erhobener neurologischer Befund völlig negativ, ausser

1) Wis mann s. 13 .

2) Anm. bei der Korrektur: Inzwischen habe ich einen Fall zur Beobachtung bekommen, in dem eine seit Kindheit bestehende familiäre Ptosis mit sekundärer Frontaliskontraktur durch Psychoterapie beseitigen liess. Darüber Näheres an anderer Stelle. 
Hyperalgesie. Temp. o. B. Puls 68. Wassermann-; Beschwerden: Schmerzen bein Kauen, in Nacken und Hinterkopf ausstrahlend; Knacken in den obereu Halswirbeln beim Druck, als wenn es auseinandergehen wollte. Aeusserste Druckschmerzhaftigkeit der linken Stim- und Schläfengegend, besonders $3 \mathrm{~cm}$ oberhalb der linken Augenbraue (rom Elektrisieren!). 23. 1. Fazialis r. $>1$. innerviert. 14. 2. Augenstation 0 .: Steht für gewöhnlich mit vorgeneigtem Kopf da; dabei hängt das rechte obere Lid herab, so dass von der Lidspalte nur 3-4 mm frei sind, während die linke Augenspalte stark erweitert $(12 \mathrm{~mm})$ aussieht. Dieser Eindruck wird noch verstärkt dadurch, dass man oberhalb des Auges ein kleines Stück der weissen Lederhaut sieht; $1 / 5$ der Hormhaut steht hinter dem unteren Lid. Beide

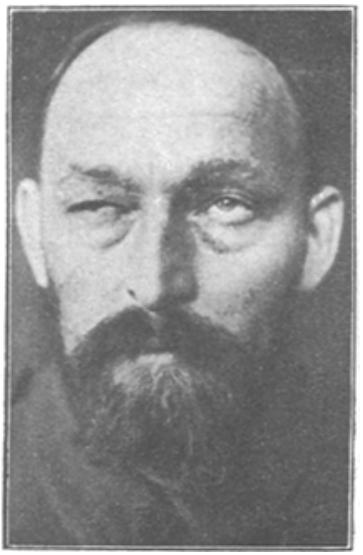

Fig. 5 . Brlbi ständig etwas nach unten gedreht gehalten. Bei Versuch passiver Lidhebung krampfartiger Widerstand. Furchen der Stirn rechts fast verstrichen. Der Stirnhautmuskel wird bei Hebung des Jids nicht stärker benutzt. Beweglichkeit des rechten Bulbus bei Beginn der Prüfung nach oben/unten behindert, nach einiger Zeit ohne Beschränkung, man hat den Eindruck, als ob eine krampfartige Hemmung zu überwinden wäre. Am linken Auge dieselben Erscheinungen, jedoch bleibt das linke Auge baim Blick nach unten stets etwas zurück. R. Pupille Spur > I. R. L. vielleicht etwas träge R. C. + . Bei Nahblick Abweichen des rechten Auges nach aussen. 21.2. Der wagrechte Stirnmuskel wird rechts viel weniger zusammengezogen als links. Stirnfurchen rechts verstrichen. Keine Ataxie. 22. 2. Beim heutigen Elektrisieren erscheinen die Furchen auch rechts ausgeprägt. Am.

Lid Furchen. Nachher das alte Bild. Die obere Lidhaut hängt als Wulst über den unteren Teil herab. Der Rand des unteren Lids steht höher wie links. Linke Lidspalte enger. Rechte Augenbraue steht tiefer, Stirnfalten rechts verstrichen, Lidrand hat $\sim$ Form. Bei Fixieren und Senken des Kopfes Anheben des oberen Lids nicht sicher nachweisbar. 19. 3. 1917 Nervenbehandlungslazarett H.: Derselbe Befund. Bei monokulärem Blick ist die Beweglichkeit jeden Auges nach allen Richtungen frei, von den binokulären Blickbewegungen ist nur die Konvergenz gestört, indem das rechte Auge beim. Fixieren und auch beim freien Blick nach vorn wechselnd um 5-200 nach aussen abweicht (Fig. 5), dabei krampfartige konjugierte Bewegungen nach oben. Bei Vor- und Rückwärtsneigen des Kopfes unter gleichzeitig energischer Fixierung eines feststehenden Objekts, nimmt der Lidschluss so zn, dass von der Lidspalte überhaupt nichts mehr zu sehen ist; dies zeigt sich beim Rückwärtsneigen noch deutlicher als beim Vorwärtsneigen. Bei maxisaalem, isoliertem Stirnrunzeln wird der rechte Frontal stärker innerviert wie der linke, so, dass die unteren Horizontalfalten stärker nach oben konvex werden wie links. Beim Versuch, die Stirn in Vertikalfalten zu legen, tritt leichter Korrugatorkrampf ein (Fig. 6); in diesen Augenblicken sind die Horizontalfurchen rechts 
schwächer wie links ausgeprägt. Gleichzeitig tritt infolge leichten Krampfs des linken Frontalis die linke Augenbraue $1 \mathrm{~cm}$ höher wie rechts. Als Mitbewegungen treten starke Einstellungsbewegungen der Bulbi nach oben auf. Beim Versuch, das linke Auge möglichst weit isoliert zu öffnen, nimmt, wio fast bei allen übrigen monound binokulären Bewegungen, der Blepharospasmus noch zu. Dabei ist von einer nennenswerten Differenz im Tonus der bəiden Lider nichts zu tasten oder zu sehen. Zwischen den gelegentlichen krampfhaften Bewegungen des Korrugator und Frontalis besteht kein reziprokes Verhältnis. Ebenso wechseind ist die Divergenz des rechten Auges, welche nicht bloss bei Konvergenz, sondern auch bei ungezwungenem

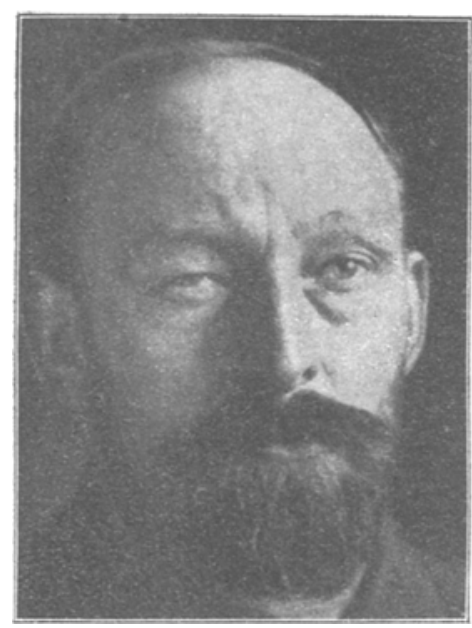

Fig. 6.

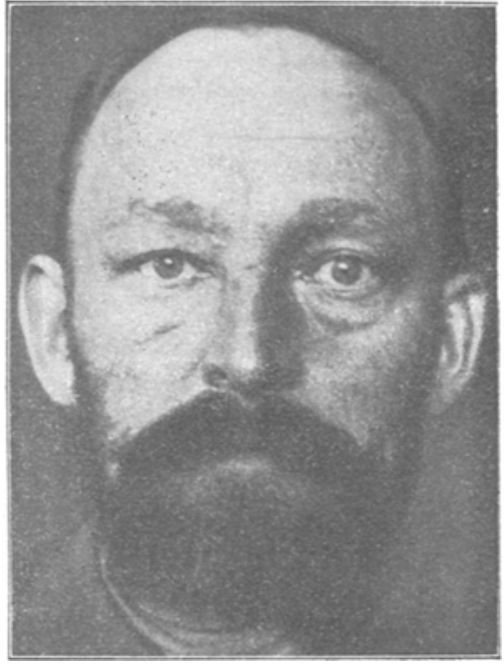

Fig. 7.

Biick geradeaus besteht; sie steht zweifellos in letzter Linie mit der Intensität des Blepharospasmus in innervatorischem Zusammenhang.

27. 3. Heilung (s. Fig. 7) durch Feldhilfsarzt Hoock (Suggestivspritze in die Stirngegend, starke Verbalsuggestion, Streichen mit der "faradischen Hand", Exerzieren der Augen unter Eigenkontrolle des Kranken im Spiegel usw.).

Epikrise: Das Primäre ist hier ein echter Blepharospasmus. Durch den Krampf ist die vertikale Konvexität des oberen Lids so verstärkt, dass der freie Lidrand nach einwärts gerollt ist und die Lidhaut dachförmig vornüberhängt, ähnlich wie es Wilbrandt und Sänger beschrieben haben. Damit mag zusammenhängen, dass von der Hypertonie der Muskulatur selbst nichts zu sehen oder zu tasten ist. Neben dem Mangel der Frontaliskontraktur und dem Tieferstehen der Augenbraue der kranken Seite ist hier der Gegensatz von Hyperkinese dieses Frontalis bei symmetrischer Frontalisinnervation und der übermässigen Erschlaffung desselben bei allen übrigen 
Bewegungskombinationen an der Stirn (bei der Innervation beider Korrugator usf.) und weiterhin die synkinetische Krampfneigung des Korrugators dieser Seite besonders charakteristisch.

Diagnostisch bemerkenswert ist ferner, dass das Landolt'sche Zeichen nicht nur fehlt, sondern im Gegenteil beim Aufwärtswandern des fixierenden Augapfels infolge Vornüberbeugen des Kopfes das Lid sich bis zum völligen Lidschluss senkt und dass andererseits beim Rückwärtsneigen des Kopfes die Pseudoptosis sich nicht nur nicht verringert $\left(, 0\right.$ p pen hei $\left.\mathrm{m}^{6}\right)$, sondern ebenfalls noch zunimmt. Zweifellos ist diese Zunahme des Lidkrampfes bei Vor- und Rückwärtsneigen des Kopfes in gleicher Weise auf eine reaktive Verstärkung des Lidkrampfes zurückzuführen. Das Eigenartigste der Beobachtung ist aber die habituelle Divergenzstellung auf der kranken Seite, die bei gleichmässigem Wechsel des Horizontalstands beider Augen stets in gleichem Masse vorhanden ist. Da sie bei der Konvergenz absolut, d. $h$. nicht bloss scheinbar und relativ, sich steigert, im übrigen aber von der Stärke des Lidkrampfes unbeeinflusst bleibt, so müsste daraus gefolgert werden, dass dieser funktionelle Divergenzkrampf, auch wenn er nicht einfach sekundäre Folge einer Konvergenzschwäche ist, irgendwie mit dem Impuls und überhaupt mit den innervatorischen Zuflüssen zu den Recti interni in innerem Zusammenhang steht. Schwer zu erklären ist dann aber die Tatsache, dass dieser Blickkrampf nach aussen von selbst verschwand, als der Blepharospasmus durch die suggestive Kur beseitigt war. Der psychogene Zusammenhang mit letzterem scheint also ebenso wichtig zu sein. Wie dieser denkbar ist, muss offen bleiben. Es ist also nur eine - wenn auch vielleicht die bildhafteste - Umschreibung des Tatbestands, wenn wir sagen: es handelt sich um die isolierte Innervationsentgleisung eines Krampfes in den reinen Antagonisten. Ueber die Ursachen dieser Entgleisung können wir uns keine rechte Vorstellung machen und uns nur an die ophthalmologisch nicht weiter fassbare Angabe des llannes halten, dass die Leistungen seines rechten Auges nicht so gut waren, wie die des linken, so dass er feineren Ansprüchen wie z. B. Schiessen mit diesem Auge nicht gewachsen war. $^{\mathbf{1}}$ )

Als die wesentlichen Punkte unserer Erörterungen über die psychogenen Störungeu der Augenbewegungen können wir zusammenfassend folgende bezeichnen:

Eine psychogene bzw. hysterische Lähmung wurde nicht

1) Anm. bei der Korrektur: Der nachträgliche erhobene Augenbefund lautet: r. kaum nennenswerte Stabsichtigkeit trotzdem S nur $5 / 29$; Gl. b. n. In der Nähe nur Jäger No. 6 mittl. Druck. Ophtalmoskop. negativ. 
beobachtet. Das Vorkommen echter funktioneller Lähmungen am Auge muss nach allen theoretischen und praktischen Erfahrungen überhaupt bestritten werden. Auch wo das Bild einer solchen primär vorgetäuscht wird, dürfte es sich um Entgleisungen von krampfartigen Innervationen in den oder die betreffenden Antagonisten handeln.

Nur ganz ausnahmsweise lässt sich bei gründlicher Erforschung der Anamnese und des Organbefundes ein ursächlicher oder zeitlicher Zusammenhang der funktionellen Störungen der Augenbewegungen mit irgendwie anatomisch begründeten optischen Störungen nicht nachweisen. In dem einzigen Falle, in dem dies nicht gelang, handelte es sich um die Fixierung eines seit Kindheit episodisch bzw. periodisch auftretenden Schielens, das offenbar eine aus spieltrieb erworbene psychomotorische Fertigkeit darstellte.

Für die besondere Gestaltung der Blickstörung sind individuelle Differenzierungen der Bewegungsformel der konjugierten Augenmuskeln oder eine abnorme Dissoziationsfähigkeit der Muskulatur (Lewandowski) heranzuziehen, die vielfach den Charakter "dynamischer Degenerationszeichen“" bzw. lokalisierter Symptomdispositionen haben. Häufig entsteht aus ihnen das hysterische symptom aus ganz verschiedenen psychogenen Motiven einfach durch Vertiefung und Fixierung. der abnormen bzw. übernormalen psychomotorischen Fertigkeit. Zweifellos spielt auf dem Gebiet der Augenbewegungsstörungen Simulation eine verschwindende Rolle.

Für die Lidmuskulatur gelten die gleichen Regeln. Als ein komplizierendes Moment kommt die individuelle Tiefenwirkung willkürlicher Innervation auf die sympathischen Muskelelemente hinzu. Das Vorkommen echter hysterischer Ptosis scheint sichergestellt.

Das beste Diagnostikum der komplizierteren Störungen der Bewegung der äusseren und noeh mehr der inneren Augenmuskeln bildet auch hier der Erfolg einer souveränen Psychotherapie.

\section{Psychogene Sehstörungen.}

Beobach tung 13. E., geb. 1888, Landwirt.

Erste Angaben: Als Kind schwächlich, aber nie beim Arzt, immer gut gesehen (wiederholte Angaben auch in früheren Lazaretten); nur Augenzittern. Erst eingehend befragt gibt er an, ausser Augenzittern seit ssinem 7. Jahr auch Schielen 
zu haben. Daraufhin befragt, gibt das Bürgermeisteramt scines Dorfes an: „Er leidet, das ist offenkundig, seit seinem. 7. Lebensjahr an Angenzittern und Schielen.:

Februar 1915 eingezogen. April ins Feld.

25. 5. 1915. Bei Loretto verschüttet. Weiss nichts mehr, ausser dass er im Trommelfener bewusstlos wurde; erst im Quartier zu sich kam; mit Brennen in den Augen, Schwindelgefïhl, Stechen im Kopf, Zittrigkeit, Blindheit. Nach 6 Tagen allmähliche Aufhellung derselben.

9. 6. Korpsaugenstation Bomn: Subj.: Durch Verschüttung habe sich sein Augenzittern sehr varschlimmert. Obj.: Beiderseits grobschlägiger Nystagmus horicontalis; im Dunkeln bedeutend stärker. Strabismus convergens. Rechtes Auge reizfrei, hyperopischer Bau. S. 8/36 mit 2,0 8/18. Linkes Auge Ptosis palpebrae, Strabismus convergens, Amblyopie, Sehkraft hell dunkel. Brille R. = L. 2,0 sph. convex.

7. 7. R. $-8 / 1.5$ mit Glas. gv.

19. 8. Untersuchung Univ.-Augenklinik H.: R. 1,0 S. -1/2. L. Jichtschein für höchste Lampe. Wegen Nystagmus kein deutliches Fundusbild.

23.9. Aufnahme Univ.-Augenklinik: Schielwinksl etwa 150\%. S. r. $+2,0$ D. $5 / 35$ Linkes Handbewegungen schwach; niederste bis mittlere Lampe keine Projektion. Ophthalmoskop o. B.

Gesichtsfeld $R$. nach oben und unten auf $20^{\circ}$, nach innen auf $23^{\circ}$, nach aussen auf $18^{\circ}$ eingeengt.

30. 9. a. v. entlassen. Bis August 1916 Arbeitsdienst, dann bis Mitte September in Feld; krank gemeldet; 13. 101916 Augenstation R. (Dr. Dorff): Befund zunächst wie früher: N'ystagmus, der bei starker Fixation des rechten Auges zeitweise beinahe ganz verschwindet, bei Herabsetzung der Beleuchtung zunimmt, ebenso bəi Erregung, wobei das Gesicht orrötet. Pat. geht meist mit dem Kopf nach links gedreht und geneigt, weil er so besser sehen könne. Tatsächlich nimmt der Nystagmus in dieser Lage ab, um zeitweise ganz zut verschwinden, ebenso bei angespanriter Nahfixation. Das linke Auge steht auch eine Kleinigkeit tiefer wie das rechte. Sonst alles frei beweglich. Pupillen, Medien, Fundus bis auf physiolog. temporale Abblassung 0. B. S. rechts ${ }^{6} / 18^{-6} / 15$, links Amaurose.

15. 10. Ausschaltung dex Akkommodation durch Atropin, ohne Einfluss auf Nystagmus.

17. 10. Zur Prüfung der Amaurose wird das rechte Auge lichtdicht verbunden. Das Verhalten E.'s entspricht nicht dem eines wirklich Blinden. Dazu Widerspruch seiner Angaben. Jetzige Angabe: Nie geschielt usw. zu haben (Einstellungsbefund der Truppe existiert nicht).

26. 10. Bei wiederholter Untersuchung, unter Abdeckung des rechten Auges, immer Angabe völliger Amaurose.

3. 11. Beim Vorsetzen eines stark verdunkelnden roten Glases rechts und eines grünen links im Dunkelzimmer gibt er beiderseits Farbenwahrnehmungen an, und zwar beim Hincinleuchten in das bewaffnete rechte Auge rot und ins linke grün; auch bei Wiederholung. „Damit bestätigt, dass Angaben völliger Blindheit falsch sind. Gesamtverhalten spricht mehr dafür, dass es sich um eine funktionelle hysterische Störung handelt und Simulation auszuschliessen ist.: Rechts 
Konzentr.-Einschränkung wie früher, bei sehr hellem Wetter für blau und rot $30^{\circ}$ : für grün etwas enger.

7. 11. Versuch suggestiver Behandlung mit Strychnineinspritzung ohne Ergebnis.

19. 11. „Es bestand mit Sicherheit vor der Verletzung hochgradige Schwachsichtigkeit links mit Schielablenkung."

Bärenstein: Sehr ruhig, ganz unhysterisches Wesen, eher stumpf. Widerstreit früherer Angaben sicher nur aus leichter Schwachsinnigkeit erfolgt. Gesichtsassymetrie. Oberflächliche Exkoriationen auf dem Scheite], Kopfhaltung zwecks Ausglich des Schielwinkels und besserer Apperzeption (Mitte des rechten Angapfels fällt beinahe in die Körpermittellinie). Linke Augenaxe berührt beim ungezwungenen „Geradeausblicken" beinahe die Nasenspitze. Vermehrter Lidschlag. Lidbewegungen 0. B. Keine Ptosis. Nystagmus unter psychischer Ablenkung fast verschwindend, durch Erregung verstärkbar. Bei extremem Blick nach links bleibt. der linke Bulbus etwas zurück, bei extremem Blick nach rechts verschwindet er bis zur Hälfte im innern Augenwinkel. Konjunkti valreflex + . Ausser vasomot. Erregbarkeit neurol. o. B. Auch extremster Lichtschein ins Auge wird links nicht als solcher angegeben; ausser Pupillenreflex keine Reaktion auf Lichteinfall.

3. 12. Beseitigung der Amaurose durch galvanische Ströme (5 M.-A.) zwischen Supra-Infraoroitalgegend und Verbalsuggestion: Zuerst Wahrnehmung von Handbewegungen in nächster Nähe, dann $5 \mathrm{~cm}$ Druckschrift in $4 \mathrm{~cm}$ teilweise gelesen; erneut Strom: erkennt Gegenstände, zuletzt Farbensinn, liest Zeitungen mühselig in $10 \mathrm{~cm}$; nun Visus angeblich wie stets. Neue Suggestion und Strom bei starker elektrischer Beleuchtung: kleine Schrift gelesen. Alle Leseleistungen zeigen kindlichen Typ, d. h., er kann nur buchstabierend lesen und verhält sich dabei bis in alle Einzelheiten wie ein Abc-Schüler.

1. 1. 1917. Bewegungsstörungen wie früher: Pendelnystagmus $(6 \times 24$ pro Minite) am stärksten bei extremerem Seitwärtsblicken, nach links < rechts; gering beim Blick nach oben, geringer nach unten. Bei Konvergenz beträgt Frequenz und Anschlag $1 / 3$ bzw. $1 / 2$ des seitlichen Nystagmus: N'ystagmus sistiert bei Gleichgewicht des Gemüts, sowie ungezwungenem Blick geradeaus und in die Ferne; unter psychischer Hinlenkung stärker. Nach einigen Sekunden Prüfung jeweils durch Ermüdung zunehmend (starkes Augentränen), Gesichtsfeld beiderseits vollkommen normal.

Epikrise: Es steht fest, dass seit frühester Kindheit erhebliches Schielen und Nystagmus, sicher auch ziemlich hochgradige Schwachsichtigkeit besteht. Alles Interesse konzentriert sich auf die Frage, wie ist aus letzterer das Bild der totalen Amaurose entstanden. Es ist infolge Yangels erreichbarer Feststellungen aus der vortraumatischen (Verschüttung!) Zeit nicht widerlegbar, dass möglicherweise seit der Jugend infolge der hochgradigen Schielablenkung das linke Auge gar nicht beim Sehakt selbst, sondern nur als Lichtsignalapparat gebraucht wurde. Der Befund der ersten fachärztlichen Sehprüfung (1915) würde dann tatsächlich dem habituellen Verhalten in Gebrauch und Funktion des linken Auges entsprechen, wie es seit Jahr- 
zehnten bestanden hat. Diese Annahme wird durch die Tatsache gestützt, dass durch die elektrische Suggestivtherapie auf diesem Auge doch nur Sehleistungen erzielt wurden, wie sie etwa denen eines fortgerückten AbcSchülers entsprechen. Durch die Therapie wurde also der Status wieder hergestellt, der in der Kindheit zu einer Zeit bestanden hat, als (nach der Anamnese) Augenzittern und Schielen deutlich in die Erscheinung traten. Die praktisch auf Blindheit hinauslaufende Sehstörung würde dann also durch diese Augenbewegungsstörungen bedingt gewesen sein, d. h. ans chronischem Mangel an äquivalenten sensorischen Anregungen (Amaurosis ex anopsia) entspringen und damit etwa in eine gewisse Analogie zur Taubstummheit zu setzen sein. Gegen diese Auffassung scheinen 2 Einwände möglich. Die Tatsache der psychotherapeutischen Beseitigung der Blindheit bzw. ihre Zurückführung bis zu einem mässigen Grad von Schwachsichtigkeit, d. h. bis zu einer Sehfähigkeit, welche angesichts des seit Jahren bestehenden Schielens und Augenwackelns als die höchstmöglichste Leistung der Sehbahn überhaupt zu betrachten ist, könnte als Beweis für Hysterie angesehen werden. Mancherlei Erfahrungen über die Beeinflussbarkeit gleichgearteter funktioneller Erscheinungen sonst bringen jedoch dies Pathognomonikum ins Wanken. Ich erinnere vor allem an die ,metaparalytische psychogene Akinesie" (Tobby Cohn), welche auch nicht hysterisch in der Kindheit entstanden selbst nach ausserordentlich langem Bestand sich eklatanter Besserung durch den elektrischen Strom zugänglich erwiesen hat. Wenn Tobby Cohn in ansprechender Weise den Vorgang so deutet, dass hierbei der jahrelange Wegfall der Bewegungsempfindungen eines Körperabschnitts bei den im kindlichen Alter stehenden Patienten sekundär eine gewisse Verkümmerung der Bewegungsvorstellungen nach sich zieht, so ergeben sich dadurch weitgehende Analogien zu unserer Auffassung der psychogenen Ambloyopie. Die Analogie würde sich darüber hinaus auch auf den Mangel jeglicher Hysteriesymptome am übrigen Körper erstrecken, mit der bedeutsamen Ausnahme, dass auf dem anderen ,gesunden", d. h. nur mit mässiger Schwachsichtigkeit behafteten "Auge der Wahl" gleichzeitig eine konzentrische Gesichtsfeldeinengung nachgewiesen wurde, die sich ausserordentlich konstant erhalten hat und erst nach über einjährigem Bestehen mit der Beseitigung der Blindheit und der Herstellung eines normalen Gesichtsfelds auf dem „,kranken“ Auge verschwunden ist. Sicher also hat auf dem besseren Auge die Vorstellung des Nichtsehenkömnens bestanden. Man mag sich das direkt so erklären, dass das konstitutionell stark schwachsichtige Auge das bessere psychisch infiziert hat. Eines ist dann aber jedenfalls sehr interessant, dass die Vorstellung des Nichtsehenkönnens in einer geradezu originellen, vom raffiniertesten Fachsimulanten wohl nicht ausdenkbaren Weise genau so viel Apperzeption ausgeschaltet hat, als dem konstitutio- 
nellen Sehvermögen entsprach. Mit der psychotherapeutischen Beseitigung der unmerkliehen Yorstellung des Niehtsehenkönnens ist auf beiden Augen dasjenige Sehvermögen zurückgekehrt, das nach der ophthalmologischen Erfahrung besonders aus den Indizien des seit Kindheit bestehenden Schielens und Augenwackelns von vornherein zu erwarten war. Damit allein schon ist die billige Auffassung entkräftet, welche einfach erklären könnte: ,,Die Angabe des Mannes, dass er nicht einmal starken Lichtschein empfindet bzw. wahrnimmt, beweist allein schon Simulation; nichts einfacher als glatt jeden Lichtschein abzuleugnen!" Des weiteren sieht man daraus, welch komplizierte seelische Störung sich hier auf dem Boden einer konstitutionellen Schwäche des Sehapparats entwickelt hat. Natürlich gibt bei diesem Ineinanderarbeiten von ,körperlichem Entgegenkommen " und seelischer Funktion diese den entscheidenden Faktor $a b$, d. $h$. das Psychogene, richtiger Psychische, gibt den Ausschlag. Dennoch dürfen wir uns nicht verhehlen, dass mit der Zugrundelegung der Vorstellung des Nichtsehenkönnens für unser einfühlendes Verständnis nicht sehr viel gewonnen ist. Ganz besonders will es mir bei dieser Hypothese unerklärlich erscheinen, warum wir eben bei der Hysterie nicht bloss die berühmte konzentrische Gesichtsfeldeinschränkung erleben, sondern - wenn auch seltener - mehr minder totale Amaurose. Hier bestehen nur zwei Alternativen. Entweder entspringt die vollkommene Blindheit einer anderen Art von ,Vorstellung des Nichtsehenkönnens", als wie sie bei der Gesichtsfeldeinengung wirksam ist, oder die Entstehung einer hysterischen Blindheit setzt ein reziprokes Verhältnis zwisehen der Vorstellung des Nichtsehenkönnens und dem Grad dauernder oder vorübergehender materieller Veränderungen irgendwo an dem „Augenorgan" - im Sinne des ,kï̈rperlichen Entgegenkommens" - voraus. Zweifellos gehört unser Fall der zweiten Kategorie an: die generelle Vorstellung des Nichtsehenkönnens erzeugt hier je nach dem ganz unbemerkten - unbewussten Maasse konstitutioneller Invalidität des einzelnen Auges auf dem einen konzentrische Einschränkung, auf dem anderen Blindheit. Es setzt dieser Modus voraus, dass bei dem psychischen Akt Sehen noch der naive Zustand geherrscht hat, in dem das monokulare Sehenkönnen noch gar nicht zum Erlebnis geworden ist, in dem Sehen den selbstverständlichen primär ungeteilten einheitlichen Erlebnisakt des binokularen Sehens bedeutet. Wie steht es aber prinzipiell mit jenen Fällen, in denen wirklich eine irgendwie geartete körperliche Grundlage ausgeschlossen werden kann? So viel ich sehe, bietet die Literatur keinen Fall jahrelang bestehender hysterischer Amaurose, in dem das Nichtvorliegen einer retrobulbären oder noch weiter rückwärts gelegenen organischen Affektion der Sehbahn als des körperlichen Anteils der Blindheit etwa durch den Erfolg der Psychotherapie tatsächlich erwiesen worden ist. Besonders wichtig in diesem Zusammenhang ist die 
Tatsache, dass Willbrand und Sänger in 12 hysterisch verdächtigen Fällen partieller wie totaler Amanrose mit völlig ne gativem Augenbefund ausgedehnte Erweichungen im Hinterhauptslappen fanden. Wie einzig und allein auf psychischen Wege bei vollkommen intakter Funktion aller Teile des Sehorgans hysterische Totalamaurose, d. h. eine echte nicht auf Unterdrückung aller Lichtreaktionen oder glatte Ableugnung des Sehens beruhende Blindheit entstehen kann, ist auch durch eine noch so intensive Steigerung der Vorstellung des Nichtsehenkömnens nicht einfühlbar. Die Selbstbeobachtung lehrt, dass keine noch so angestrengte Vorstellung und Wollung des Nichtsehenkönnens selbst bei geschlossenen Augen den Zustand eines Ausfalls sogar der Perzeption starker Belichtung unter alltäglichen Bedingungen produzieren kann, derart, dass überhaupt uur im Dunkelzimmer die Kontrastbelichtung mit leuchtenden Grundfarben richtig perzipiert wird. Demgegenüber erscheint die Einengung des Gesichtsfeldes selbst bis zum ,röhrenförmigen" ebenso psychologisch aus dem Gegensatz ron deutlichem und reinem Bewegungssehen wie psychologisch aus der Einengung des Aufmerksamkeitsfelds beim Fixieren z. B. aus der einfachen Versunkenheit im Augenblick eines ,fesselnden" Objekts klar vorstellbar und verständlich.

Yir scheint sich daraus zu ergeben, dass die Vorstellung des Nichtsehenkönnens nicht imstande ist, generell und allein alle Arten von hysterischer Sehstörung zu erklären. Mindestens in den Fällell, wo eine Differenz des ophthalmologischen Habitus beider Augen nicht vorhanden ist, d. h. bei normalem Wettstreit beider Sehfelder kann es nur von der Verschiedenheit der entscheidenden patho-psychologischen Vorgänge abhängen, ob eine totale Amaurose oder nur eine konzentrische Gesichtsfeldeinengung entsteht. Nach Klien sind 3 Faktoren für das Zustandekommen der Gesichtsfeldeinengung ausschlaggebend: 1. Störungen der Aufmerksamkeit, 2. die Vorstellung des Schlechtsehens, 3. eine Untererregbarkeit der Sehsphären. Mit der Einführung des Faktors 3 ist der wunde Punkt im System der Ursachen der Gesichtsfeldeinengung aufgedeckt. Herabsetzung der Erregbarkeit einer Sinnessphäre kann sehr wohl ohne jeden psychogenen Einschlag zu Störungen der betreffenden Simnesleistung führen. Dabei ist von vornherein nicht gesagt, dass die Folge derselben etwa in einer Herabsetzung der einfachen Empfindung zu bestehen braucht. Die psychischen Folgeerscheinungen könnten sich auch in viel komplizierteren Störungen der einzelsinnlichen seelischen Funktionen äussern. Auch ohne das Hineinspielen eines mehr minder bewussten Willens zur Verdrängung bestimmter Funktionen (i. e. ideogener Motive) kann die bewusste Funktion des deutlichen bzw. des papillomakulären Sehens eines Auges durch jalurelangen Ausfalls einer spezifischen Sinneserregungen völlig ausgeschaltet und so der Gebrauch des Anges verlernt werden. Wir werden hier auf die analoge Deutung geführt, die 
Le ber bei Kindern mit der (von A. v. Graefe zuerst besehriebenen) „Amanrose nach Blepharospasmus" dieser Erscheinung gegeben hat ${ }^{1}$ ).

Es handelt sich also um psychogene Erscheinungen nicht hysterischen Charakters. Der länger dauernde Abschluss jeder Sinneserregung setzt die Ansprechbarkeit der Sinnessphäre so herab, dass sich diese auch nach dem Wegfall der Ursache dieses Abschlusses bzw. der Bildunterdrückung erst ganz allmählich wiederherstellt. Die optıschen Erimnerungsbilder sind natürlich nicht ,vergessen", sondern nur vorübergehend verlernt worden. Es handelt sich also im Prinzip um einen alltäglichen mnestischen Vorgang. Diesen Mechanismus hysterisch zu nennen, geht deshalb nicht an, weil dann die einfache "Amblyopia ex anopsia" infolge starker Schielablenkung auch so bezeichnet werden müsste. Dass in diesem Falle die Netzhaut wegen mangelnder Uebung, je nachdem das Schielen in frühester oder späterer Kindheit einsetzt, entweder nicht jene Feinheit der Funktion erreicht, welche normalen Augen zukommt, oder die bereits erworbene Funktionstüehtigkeit wieder verliert, ist ja nur eine sekundäre Erscheinung.

Die weitläufigen Erwägungen über das reziproke Verhältnis zwischen funktionellem und organischem Anteil der Sehstörung jedes Auges bei von Haus aus bestehender Differenz der Sehschwäche zwischen beiden Augen lassen sich mutatis mutandis auch auf die folgende Beobachtung übertragen.

Beobachtung 14. N., geb. 1879 .

Kam mit Zange zur Welt. Als Kind schwächlich; wegen allgemeiner Körperschwäche auch nicht gedient. Auf der Schule sehr gut mitgekommen. Nachher Näher in einer Zelttuchfabrik. Nie krank. Bei eingehender Befragung gibt er an, dass er in den Jünglingsjahren zufällig, als ein Kreis von Kameraden beim Spiel sich im einäugigen Sehen prüfte bzw. übte, entdeckt habe, dass er, wenn er das linke Auge abschloss, mit dem rechten Auge nur ganz verschwommen sehen konnte, z. B. konnte er einäugigrechts seinen Vater nicht erkennen, wenn dieser einige Schritte von ihm entfernt stand. Brille trug er nie, das andere Auge war so gut, dass er auch nicht in der vordersten Bank sitzen brauchte, und später beim Militär gut schiessen konnte, z. B. auf $150 \mathrm{~m}$ mit 5 Schuss 49 Ringe.

Eingezogen 14. 10. 1915 als Füsilier. Einstellungsbefund: „S. links normal, rechts $4 / 6$. . Augen?" 2. 3. 1916 ins Feld. 31. 3. ins Feldlazarett, weil er am Abend zuvor Gasvergiftung erlitten hatte. Heute (1917) gibt er darüber an, er habe nur wenig eingeatmet, unmittelbar danach keine Reizerscheinungen gehabt, habe

1) In der Auffassung dieses Krankheitsbildes gehen scheinbar die Meinungen anseinander. Gegenüber Leber haben Schirmer und Wilbrand-Sänger die ursprüngliche Graefe'sche These verteidigt, wonach durch den Blepharospasmus anf mechanischem Wege eine so beträchtliche ,"Lnterwertigkeit der Sehsubstanzen“" erzeugt werde, dass man von Blindheit sprechen könne. Beweisbar ist keine der beiden Hypothesen. Wie fast überall, stehen sich mechanistische und rein psychogene Theorie gegenuiber. 
sich aber sehr schwach gefühlt, dann ,weg“" gewesen und erst am 7.4 . im Etappen1. lazarett zu sich gekommen. Obj.: 31. 3. rasche Atmung, über den Lungen sehr viel schleimiger Auswurf. Herz o. B. Medikation: Atropin 0,001, Kodein, Sauerstoffinhalation usw. Abends im Kriegslazarett starkes Nachlassen der Herztätigkeit, Puls nicht mehr fühlbar, viel Atemnot; 1. 4. Temp. 380, Atemnot, Hustenreiz, sehr kleiner Puls (abnormer Verlauf der Radialis). Ist äusserst schwach. 3. 4. Puls nicht zu fühlen. 4. 4. Macht verwirrten Eindruck, reagiert nur auf lautes Anrufen, kann oft Gegenstände, die ihm gezeigt werden, nicht erkennen, lässt Urin, nachts auch Stuhl unter sich. Temp. ab 5. 4. normal. 5. 4. Dasselbe. 6. 4. Erscheinungen von Gasvergiftung bestehen noch. 9. 4. Metz: Liegt den ganzen Tag schlafend, reagiert nur auf Anruf, lässt sich füttern, Stuhl/Urin ins Bett, lässt Speichel aus Mund fliessen. Auf Befragen nach Befinden antwortet er: ,sauwohl". Rechter Arm und Bein wie gelähmt, wird nachgeschleppt: völlig apathisch, regungslos. 11. 4. Eindruck, als könne er sich des Schlafes nicht erwehren. Es scheint, als ob er an Gegenständen vorbeisieht. Reagiert auf alles. Von körperlicher und neurologischer Unt rsuchung muss bei der Schwäche des N. abgesehen werden. 20. 4. In letzten Tagen munterer; subj.: weiter .,sanwohl". Bewegung der rechten Extremitäten jetzt besser, richtet sich im Bett mïhelos auf. 26. 4. Von Tag zu Tag besser; sieht bedeutend besser, noch gewisse Schwäche im rechten Arm und Bein, und geringes Taumeln beim Gehen. Seit $1 \frac{1}{2}$ Wochen sauber. 27. 4. Blass; Herz 0. B. Allgemeine Hyperästhesie-algesie. Patellarreflex gesteigert $\mathrm{r} .=1$. Babinski usw. 0. Pupillen gleich-weit, links etwas verzogen. Reflex sehr schwach, starkes Lidflattern; ,leich te Insuffizienz der mm. recti interni." (?) Rechte Papille verwaschen, keine Staung. Starke Einengung des Gesichtsfeldes, beiderseits konzentrisch. S. rechts stark herabgesetzt. Starker Tremor der Hände/Zunge.

6. 5. 1916 bis 4. 1. 1917 (!) Ver-Lazarett W.: Keine Lähmungserscheinungen am Bein. Lesen noch unmöglich. 1. 9. Beim Schreiben wird häufig in der Mitte der Zeile angefangen; Lesen geht zur Not; Allgemeinbefinden gut.

11. 9. „Merkliche Besserung im Sehvermögen.“ 21. 10. Es kann gelesen werden. 15. 11. Sieht alles deutlich, kann jedoch die richtige Entfernung nicht abschätzen. 28. 12. "Eine gewisse Schwäche des rechten Armes besteht noch." 4. 1. 1917. Zur Einleitung des D. U.-Verfahrens zum E. T. T.

Ende Februar 1917 (Dr. Dorff): ,Augen äusserlich reizlos, brechende Medien klar, Pupillen scharf begrenzt, Gefässe annähernd normale Durchmesser. An der rechten Papille einige geringe myopische Aderhautveränderungen. Beiderseits isolierte kleine, schwarze Pigmentherde, dünn verstreut, besonders in der Peripherie. Rechtes Auge nach aussen abgewichen, nimmt am binokularen Sehakt nicht teil. Rechts Myopie mittleren Grades, links geringeren Grades, mit Astigmatismu: myopicus inversus. Zentrale Sehschärfe rechts $6 / 12-8,0$ D., links $6 / 6-1,0$ cyl. - $0,75 \mathrm{D}$., Achse $90^{\circ}$. Gesichtsfeld hochgradig eingeschränkt für Weiss und Farben (s. Fig. 8).

Blinder Fleck, nicht vergrössert. Sichtbare Schwierigkeiten in der Orientierung i m Raum, typisches Röhrengesichtsfeld (gleiche Gesichtsfeldgrenzen in verschiedener Entfernung vom Schirm). 
Epikrise (Dr. Dorff): „Es handelt sich hier um sehr verwickelte Verhältnisse, da ein Teil des klinischen Befundes mit grosser Sicherheit auf funktionelle Störung hinweist und andererseits auch anatomische Veränderungen im Augenhintergrund bestehen. Das Schielen rechts führe ich nicht auf die Kriegsschädigung zurück. Das Auge ist durch Nichtgebrauch in Schielstellung abgelenkt worden. Die Veränderungen im Augrenhintergrund bedingen sicher eine gewisse Nachtblindheit, genügen aber nicht allein, den schweren Gesichtsfeldausfall zu erklären. Dem entspricht auch der negative Sehnervenbefund. Dass ein Teil rein funktioneller Natur ist, dafür spricht speziell das hier nachgewiesene Röhrengesichtsfeld. Ebenso spricht die Form des Gesichtsfeldausfalls für Weiss und Farbe auch für eine funktionelle Störung."

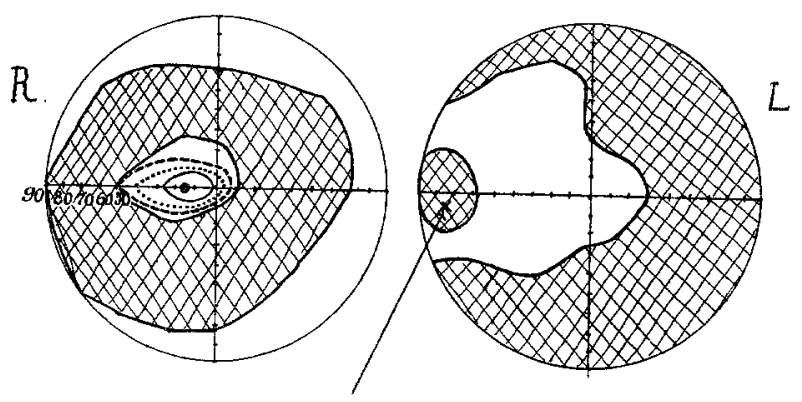

Fig. 8.

1. 3. Nervenbehandlungslazarett H.: Subj.: Er sehe die Gegenstände nicht an richtiger Stelle; früher hatte er ,ein enges Gesichtsfeld, wie wemn er durch ein Astloch sehe". Wenn er durch den Wald gehe, ,,vermute er die Bäume immer mehr links, als sie in Wirklichkeit stehen".

Obj.: Sehr stark gewinkelter Schädel, kleiner Bitemporaldurchmesser. Gesichtsassymmetrie. Rechtshänder. Bei Blick geradeaus und bei Konvergenz bleibt der rechte Bulbus etwas zurück; S chielwinkel e twa $15^{\circ} ;$ Funktion des rech ten Internus an sich völlig frei; bei extremem Blick nach links verschwindet die Iris grösstenteils im inneren Augenwinkel. Bei Blick nach den Seiten hemmt Pat. in der Weise, dass er nur mit 3-4 gleichstarken Rucken von annähernd gloichem Exkursionsmass die Bulbi in die Endstellung bringt. Erst auf energische Aufforderung erfolgt die seitliche Einstellung in normal fortlaufender Bewegung. Bei geöffneten beiden Augen greift er nach der Spitze des vorgehaltenen Bleistifts mit der linken Hand stets anf Anhieb richtig, mit der rechten dagegen immer zu hoch und tastet sich erst sekundär zum Gegenstand vor. Beim Zeigeversuch unter verschlossenem linken Auge greift er in gleichem Sinne sowohl mit der rechten wie mit der linken vorbei. Auf energische Zurechtweisung wird das Zeigen korrekt. Schriftprobe: Siehe 2. (er habe seit 1 Jahr überhaupt nichts mehr geschrieben). Leseprüfung rechts: Nur allergrösster Druck. Beim Gehen 
fühlt er mit den Händen vor, geht vorsichtig, etwas unsicher, wie ein beiderseits stark Schwachsichtiger, Kopf leicht gebeugt. Gesichtsłeld in der Breite wie früher, in bezug auf Höhe besser wie früher. Äusserst ruhiges, sachliches Benehmen; keine Spur von hysterischem Wesen; berichtet über seine Sehstörung in einer für seinen Eildungsstand äusserst verständigen, klaren und vor allem höchst objektiven Weise. Neurologisch keine Abweichung. Rechter Arm normale Bewreglichkeit.
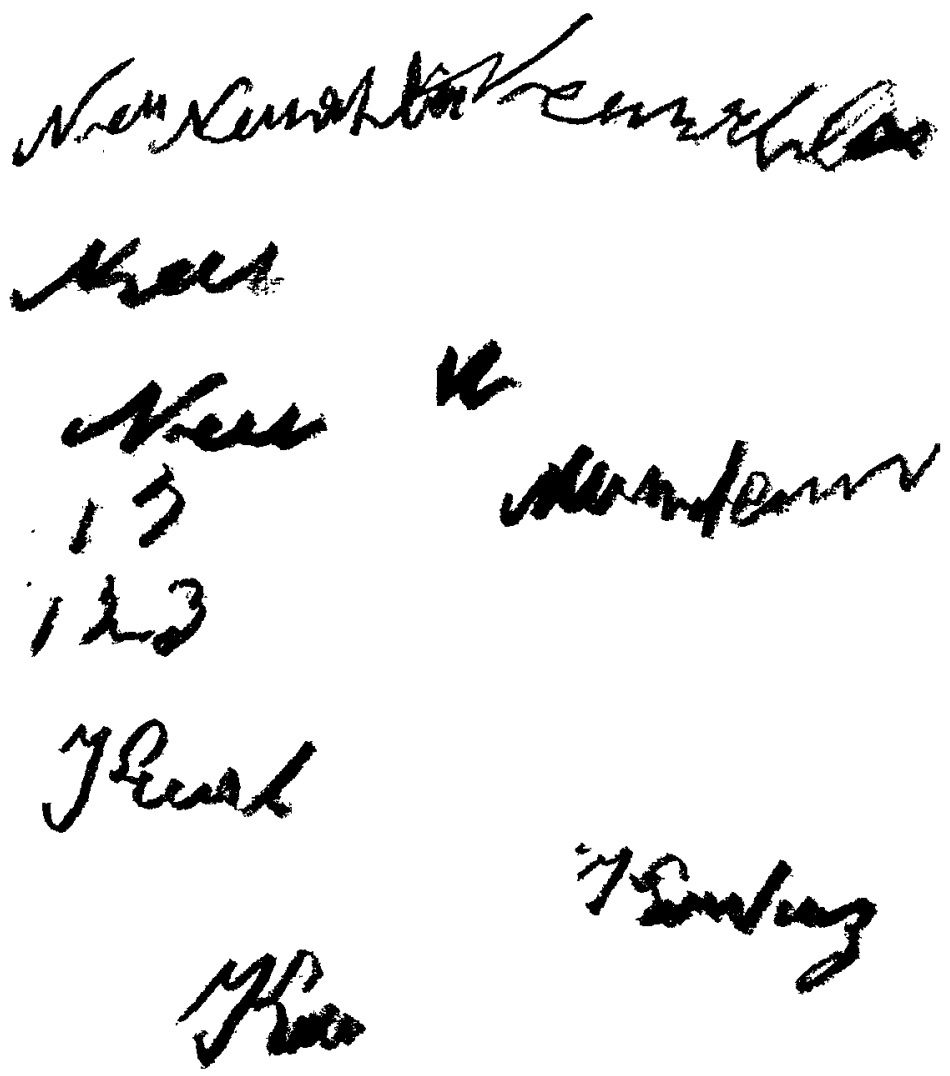

Schriftproben 2.

Psychot herapie: In 7 Touren, die jeweils 3-6 Minuten dauern, und zwischen denen jeweils eine nicht ganz so lange Pause eingeschaltet wird, Heilnng. Das linke Auge wird verbunden. Mit allerschwächsten galvanischen „Blitzen“, unter entsprechender Verbalsuggestion und suggestiven Embarras, werden 1. normale Perimeterwerte herbeigeführt. 2. Normale Greifbewegungen. 3. Lesen feiner Schrift in 10-15 cm. 4. Wird erzielt, dass Pat., der auf einem Stühlchen steht, vor dem in einer Entfernung von je $25 \mathrm{~cm} 4$ verschiedenfarbige Bleistifte liegen, prompt auf Auffordernng bald mit der rechten, bald mit der linken Hand ein bezeichnetes be- 
rïhren kann. ó. Springen über Schemel und Stuhl. 6. Treppensteigen mit Stufeüberspringen: erfolgt zunächst unter Hemmungen (,ich muss das erst erlernen, habe schon seit 15 Monaten das nicht mehr machen können"). 7. Schreiben binokular: Zunächst treten sehr bald schreibkrampfartige Zitterbewegungen auf,

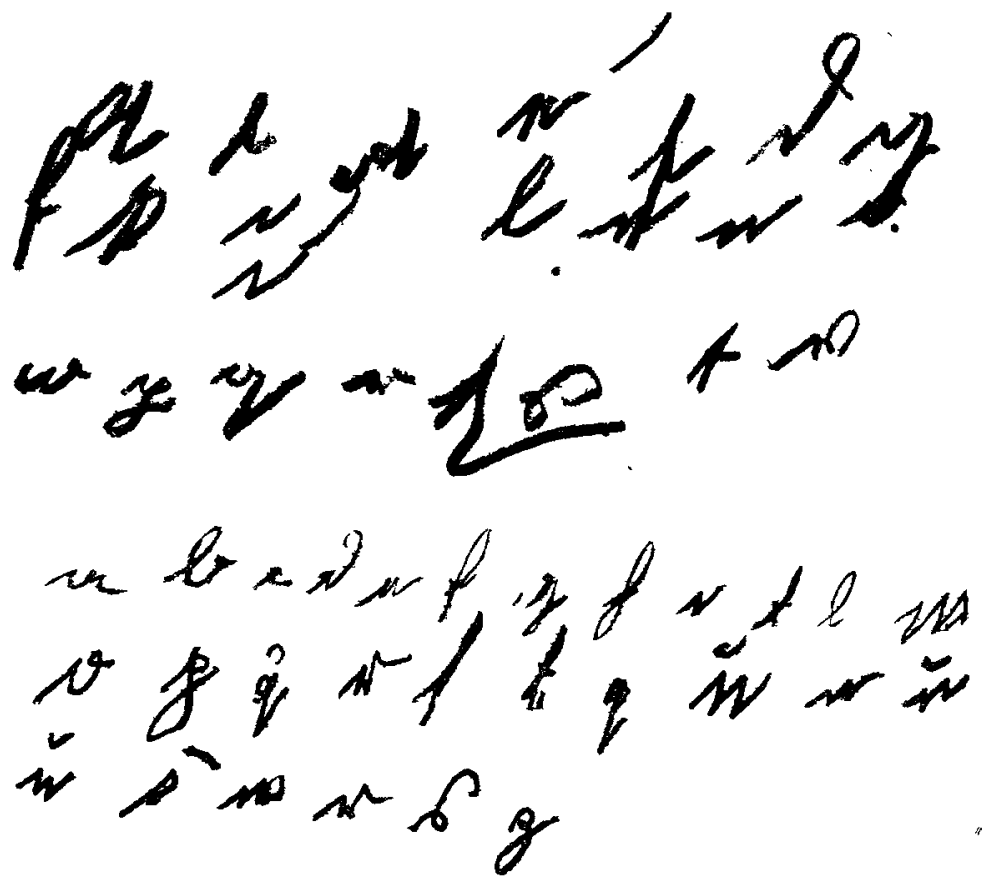

Schriftproben 3.

abce fghiklm Schriftprobe 4 .

später siehe Schriftproben 3. Schrift monokular rechts am nächsten Tage (siehe Schriftproben 4 u. 5).

10.3. Schrift wird weiter gebessert; nummehr, so gut, als nach seinem Bildungsgang nur erwartet werden kann: nichts von Zittrigkeit. Schielablenkung des rechten Auges nach anssen, bei ungezwungenem Geradeausblicken, 10-15 .

Epikrise: Die Differenz der organischen Sehschwäche reicht bis in die früheste Kindheit, offenbar bis auf die Folgen eines Geburtstraumas (Zange), 
die auch sonst am Schädel hervortreten, zurück. Befund und eigene Angaben des Patienten, die ebenso offenherzig wie präzis erfolgen, weisen daraufhin, dass das rechte Auge infolge infantiler Veränderungen der Retina und entsprechender Sehuntüchtigkeit nach aussen abgewichen und ans dem binokularen Sehakt stets ausgeschaltet gewesen ist.

Durch zweckmässige Verdrängung hat er effektiv den relatir erheblichen Ansprüchen, die sein Beruf (Zeltnäher) an seine Sehleistung stellte, genügen können. Es ist sehr bemerkenswert, dass schon in dem Rückbildungsstadium des tagelangen toxischen Koma, das durch die Gasvergiftung im Felde verursacht wurde (trotz des Mangels einer genaueren Anamnese) eine sehr erhebliche Sehschwäche des rechten Auges und vor allem beiderseits konzentrische Gesichtsfeldeinschränkung aufgefallen ist. Da das Vorliegen

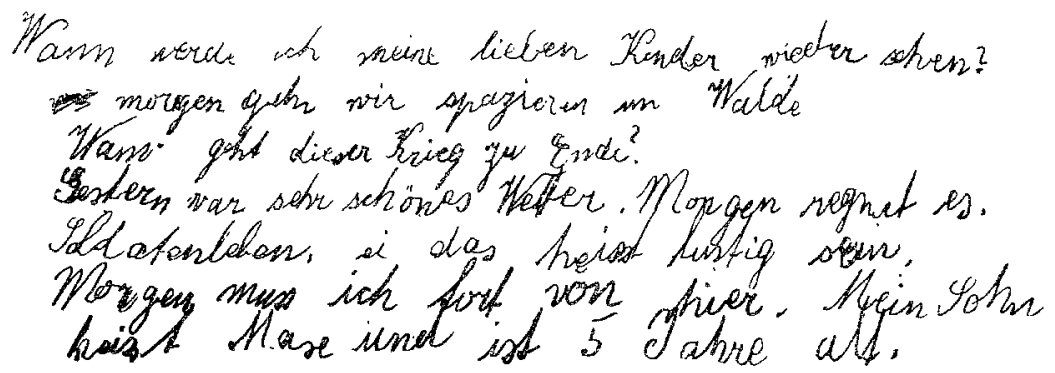

Schriftprobe 5 .

einer gröberen organischen Hirnläsion ausgeschlossen ist, scheint die prinäre Schwäche der rechtsseitigen Extremitäten nicht minder merkwürdig.

Man könnte versucht sein, sich den Zusammenhang hier so zu denken, dass infolge des Gesamtausfalls der "transkortikalen Steuerung" - und für die Dauer desselben - eine konstitutionelle Minderwertigkeit der rechten Körperseite zutage trat. Die vorübergehenden rechtsseitigen Ausfälle würden wir also dann weder als organisch noch als hysterisch, sondern als dynamisch bedingt ansprechen dürfen.

An dem Vorkommen solcher ,dynamischer" Störungen, die weder grob organisch noch an sich in irgendeinem Sinne hysterisch sind, sondem vielmehr etwas durchaus Spezifisches darstellen, ist ja nicht zu zweifeln. Insbesondere können ganz gleichmässig und symmetriseh auf bestimmte Teile des Zentralnervensystems sich erstreckende molekulare oder chemische Schädigungen der funktionstragenden nervösen Elemente habituelle Verschiebungen der Apparate im Hirn oder Rückenmark manifest machen. Wie wir sehen, dașs zerebrale Symptome, denen gemeinhin Herdcharakter zugesprochen wird, unter Umständen erst bei entsprechender Ermüdung 
oder Erschöpfung der Hirnfunktionen überhaupt zutage treten (Pick), so erscheint es nicht wunderbar, dass eine Herabsetzung des zerebralen Tonus etwa durch eine Vergiftung Schwäche- oder Ausfallsymptome auf derjenigen Seite besonders deutlich werden lässt, deren kortikale Vertretung von Haus ans minderwertig ist. Es handelt sich hier um Vorgänge, die vielleicht als ,dynamische Herderscheinungen" bezeichnet werden könnten.

Wenn ich in unserem Falle von dieser Erklärung Abstand nehme, so geschieht es deshalb, weil hier von einer Linkshändigkeit oder -beinigkeit des Mannes nichts ermittelt werden konnte. Es bleibt, also doch nichts übrig, als hier die Idee der rechtsseitigen Insuffizienz der Körperfunktionen zugrunde zu legen. Der einfühlbare Zusammenhang weist dabei auf das Bewusstwerden der Invalidität des rechten Auges nach und infolge der traumatischen Einwirkung als den Ausgangspunkt der Erscheinungen zurück. Versetzt man sich psychologisch recht eindringlich in die innere Situation des Marnes, so wird es begreiffbar, dass dem sich aus dem Koma restituierenden Bewusstsein das seit Jahrzehnten gewusste und nur aus sozialen Grïnden unterdrückte Phänomen der Ausschaltung des, rechten Auges aus dem Sehakt sich am stärksten aufgedrängt und damit für die Folge eine überwertige Bedeutung als beherrschendes Krankheitsmotiv gewomnen hat. Auf die fast vollkommene Parallele, die in bezug auf die Verteilung, der psychogenen Komponente auf jedes Auge nach Yassigabe seiner konstitutionellen Schwäche zwischen diesem und dem vorhergehenden Falle besteht, habe ich schoil hingewiesen. Die Vorstellung des Nichtsehens hat hier genau wie dort ais dem Gesichtsfeld jeden Auges sozusagen genan so viel „herausgeschnitten“ als dem Grad des organisch möglichen Sehenkönnens entsprach und so hier auf dem rechten Auge - praktisch genommen - Blindheit, auf dem linken Auge die gewöhnliche konzentrische Einschränkung erzeugt.

Sehr schön ist nun aber noch zu sehen, wie bei dem gegenüber dem vorhergehenden Patienten wesentlich intelligenteren im übrigen als ganz unhysterisch imponierenden Manne aus dem Bestehen der Gesamtsehsehwäche unterbewusst die psychologischen Konsequenzen gezogen wurden. Dass die Idee der Unheilbarkeit, die ,,iatrogen“ - vom Arzte selbst unbemerkt sich notwendigerweise infolge und während eines nutzlosen achtmonatigen Lazarettaufenthaltes bei dem Manne notwendigerweise entwickeln musste, unterstätzend gewirkt hat, klingt wohl selbstverständlich. Die psychologischen Folgen erstrecken sich in nachweisbarem Zusammenhang im Einzelnen sowohl auf die Orientierung im Raume wie aufs Schreiben. Aus der Idee der Unfähigkeit der optischen Projektion entwickelte sich die Unfähigkeit der Orientierung im Raume und aus der Vorstellung, nicht lesen zu können, eine so ausgesprochene Schreibunfähigkeit, dass nach der psychotherapeu- 
tischen Beseitigung dieser Idee die ersten Schreibversuche zum richtigen Schreibkrampf führten. Für den psychologischen Zusammenhang war seine spontane Aeusserung, dass er erst alles wieder erlemen müsse, nachdem er ein Jahr lang die entsprechenden Bewegungen nicht ausgeführt habe, recht charakteristisch.

Nach der Art der Auslösung des Zustandsbilds, dem Mangel irgendwelcher hysterischer Zeichen im übrigen und vor allem dem durchaus einfühlbaren Zusammenhange der Phänomene kann man bei beiden Fällen trotz der Tatsache der psychotherapeutischen Heilung unsicher sein, wo die Grenze des psychogen nicht Hysterischen sowohl in qualitativer Beziehung wie im zeitlichen Verlauf des ganzen Krankheitsbildes zu ziehen ist. Ich glaube aber, dass diese Unsicherheit mehr aus dem Mangel einer konventionellen Emigung in der Terminologie als aus der Möglichkeit wesentlicher Unterschiede der physiologisch-psychologischen Deutbarkeit erwächst. Sehr viel eindeutiger ist in dieser Hinsicht die folgende Beobachtung:

Beobachtung 15. G., geb. 1897, Bureangehilfe.

Als Kind zart. Auf Schule einmal sitzen geblieben wegen Ohrleiden. Später Lungenentzündung Im März 1916 bemerkte er erstmals, dass er mit dem linken Auge nichts sah (vorher schon trug er Brille); als er "hinfühlte", war Blut da, am nächsten Tage schon sei er von Geh. R. F. operiert worden, seitdem nur Schimmer uder Blindheit!

28. 8. 1916 eingezogen. Rekrut. Ausbildung fiel ihm schwer, ,weil er seit 14. Jahr nur auf Bureau arbeitete, von Sport nur Radfahren betrieb“. Beim ersten Iarsch schlapp gemacht. Nach wenigen Tagen 1. Anfall in Kaserne: füblte sich schwindlig, hatte unruhige Herztätigkeit, die Beine waren für einen Augenblick steif; ging zu Bett. Später Erbrechen, Durchfall. Nach 2. Anfall ins Revier; nun kamen diese Anfälle immer nur nach strengem Dienst. Einmal habe er sich dabei rechte Hand verstaucht.

14. 9. vor Verdun aber nie ganz vorn; bei Artilleriefeuer sofort Schwindelinfälle mit Bewussstlosigkeit und Beinsteifigkeit: „Das waren Brustkrämpfe“", ein Arzt nannte sie so, als er als Dreizehnjähriger ein einziges Mal denselben bekam, nachdem er zu lange kalt gebadet hatte; auch er nenne sie so, weil es sich um ein Gefühl des Zusammenpressens der Brust handle. Im Felde kamen sie nach längerem Gehen.

19. 9. Zurürk wegen „hysterischer Lähmungen der Arme und Beine“, die in Frscheinung traten als er nach 2stündiger Bewusstlosigkeit, in der er von der marschierenden Truppe dem Ortsarzt übergeben war, wieder zu sich kam.

20. 9. Im Lazarett: Bei Bewusstsein, aber totale steife Lähmung der Extremitäten, verbunden mit Grimassieren. Kein Babinski; Hypäthesie an den distalen Teilen, geometrische Hypalgesie an Vorderarmen und rechtem Unterschenkel. 23. 9. Uebungsbehandlung: Es gelingt, ihn wieder auf die Beine zu bringen. Ganz typisch, hysterisch, zaudernd. Nachts unruhig, Schreien, das auf Beruhigung ausbleibt. Willenloses Wesen. 
5. 10. Nervenbehandlungslazarett B.: Unbeherrscht, unmilitärisch, ticartig: Zuckungen, besonders in Frontalis links und im 2. Fazialisast rechts bei Sprechen. besonders aber bei Augenbewegungen. Augeneinstellungsbewegungen erfolgen erst auf energische Zurechtweisung, nachdem er anfänglich sehr geschickt Blickparese nach links darzustellen versucht hat (weil er blind sei!). Durch die willkürliche falsche Dosierung der Impulse wird neben der Blickparese gelegentlich auch ein unrubrizierbarer Pendelnystagmus vorgetäuscht. Auf Aufforderung kann er in Horizontallage die Beine nur um $10^{\circ}$ von der Unterlage abheben. Das passiv erhobene Bein sinkt unter pseudospastischer Fixierung in Streckstellung in Knie/Fussgelenk brüsk auf die Unterlage zurück. Beiderseits sehr starke Hammerzehe; dadurch wird der Plantarreflex in Pseudo-Babinski umgewandelt. Grad des Spasmus in den Beinen je nach psychischer Einstellung, am stärksten bei der (deshalb nicht möglichen) Reflexprüfung. Auf Aufforderung, auf zustehen, schiebt er den Unterkörper/Rumpf unter maximaler Fixierung aller Gelenke mit den Fersen in theatralischer Weise auf dem Boden hin, ohne zum Stehen/Gehen zu kommen. Aufhebung der Unterschiedsempfindlichleit in manschettenförmiger Weise, rein ideogen.

Körperlich: Stark aufgeschossen; blass; senkrecht abfallendes Hinterhaupt. Turmschädel; sehr breites Gesicht, ausgesprochene Zeichen von Rachitis.

Augenbefund (Dr. Dorff): Als Sehvermögen zuerst angegeben: „R. Finger $1^{1 / 2}$ m., l. =0. Mit Simulat.-Proben S. r. = 1. monokular $6 / 10-6 / 12$ mit $-2,5$ (bisher überkorrigiert). Nach Verhalten keine Simulation. Versuch der Ueberzeugung seiner Sehtüchtigkeit gelingt."

Also offenbar nur reine Einbildung von Blindheit, erwachsen auf der Grundlage medizinischen Laienhochmuts, und geschürt durch die ïberwertige Idee einer seltenen Augenerkrankung, die mit einem Einschlag hypochondrischen Affekts aus miss- oder halbverstandenen, fachärztlichen Bemerkungen sich entwickelte.

7. 10. Heilung gelingt leicht durch Gewaltexerzierkur (galvanischer Strom nachher als ,Denkzettel"), typisch wichtiotuerisches, serviles und doch überlegenes Wesen. Karikiert (unwillkürlich) geradezu die militärische Strammheit und kriecherische Dienstbefliessenheit. 27. 10. Weiter symptomfrei.

Epikrise: Der hysterische Charakter drückt sich hier in typischster Weise sowohl im Seelischen wie im Körperlichen aus: Disposition zu Anfällen hysterischer Färbung von Jugend auf, meist als Reaktionen auf Schreck und andere Emotionen; pseudospastische Lähmung mit Astasie-Abasie als Fixierung zufälliger Findrücke nach subjektiven Schwächeanfällen usf. Die Besonderheiten der motorischen Erscheinungen am Auge sind in früherem. Zusammenhang behandelt worden. Hier interessiert uns nur noch die Art der hysterischen Sehstörung. Als organische Grundlage findet sich beiderseits angeborene oder früh erworbene Brechungssehschwäche. Auf diesem Boden entstand links eine richtige Einbildungsblindheit. Unverkennbar ist das ideogene Moment ihrer Entstehung darauf zurückzuführen, dass die Aufmerksamkeit des Mannes vor kurzem besonders auf dies Auge eingestellt 
war und eine unvorsichtige oder von ihm in seinem nedizinisehen Laienhochmut falsch erfasste Bemerkung eines Augenarztes sofort im Sinne der drohenden Blindheit des Auges umgedeutet wurde. Ungewöhnlich für Hysterie und mit einer noch so gesteigerten spezifischen Suggestibilität nicht vereinbar ist gegenüber allen übrigen Symptomen des Falles nur die Promptheit und Sicherheit, mit der die ration ale Belehrung über die effektive Sehfähigkeit auch dieses Auges zu Beseitigung der Blindheit geführt hat.

Gegenüber den Erfahrungen, die wir mit den zahlreichen psychogenen bzw. hysterischen Schwerhörigkeiten und Taubheiten gemacht haben, fällt in unseren Fällen funktioneller Sehstörungen überhaupt die grössere $\mathrm{Zu}$ gänglichkeit für rationale Belehrung auf. Diese Erscheinung dürfte mit den Unterschieden der Anschanlichkeit und Vorstellbarkeit, die zwischen dem vom Gesicht und dem vom Gehör Vermittelten bestehen, zusammenhängen.

Bei allen Abweichungen, die bei den vorliegenden 3 Beobachtungen im einzelnen bestehen, lässt sich als das allen Gemeinsame herausstellen, dass in jedem Falle irgendeine "Organbegründetheit" vorhanden war, die psychogen ausgewertet oder in den Dienst, hysterischer Motive" gestellt wurde. Besonders bemerkenswert war die prozentual exakte psychogene "Abrundung nach oben", die bei erheblichen anatomischen Differenzen zwischen rechtem und linkem Auge Platz gegriffen hatte. Vermutlich lässt sich dieser gemeinsame Zug zum wenigsten für die chronischen Formen psychogener Schwachsichtigkeit oder Blindheit als die Regel hinstellen.

Insofern dürften unsere Kriegserfahrungen bezïglich psychogener Blindheit über die Friedenserfahrungen hinausweisen, nach denen als chronische hysterische Amaurose zumeist Fälle figuriert haben, die trotz negativem ophthalmoskopischem Befund sich schliesslich doch auf kortikale oder „,transkortikale" Lä̈sionen der Sehsphäre zurückführen liessen (Wilbrandt und Sänger).

\section{Psychogene Hörstörungen.}

\section{A. Psychogene Aufperopfungen.}

Beobachtung 16. R., geb. 1891, südbadischer Landwirtssohn.

Vater leicht erregbar, Mutter fast taub. Tin älterer Bruder schwerhörig. Nach eigner Angabe von frühester Kindheit auf sehr angstlich, zaghaft; nächtliches Weglaufen im Schlaf. Vor Schulzeit schwere Krankheit in Kopf und Hals. Bald danach Ohrlaufen beiderseits, das dann im 10. Lebensjahr und später fast alle Winter, zuletzt 1914/15, rezidiv erte. Dazwischen häufig Ohrschmerzen, Zucken im Ohr und Kopfschmerzen. Der Vater fuhr das erstemal mit ihm nach Tübingen in die Ohrenklinik. Auf der Schule wegen Schwerhörigkeit vom Lehrer meist geschont, lernte kaum Rechnen, Lesen und Schreiben nur einigermassen. Das linke Ohr war „das mindere“. Er war nach eigenen Angaben immer am liebsten 
für sich allein, still, ruhig, ging gern seiner Arbeit nach, hat noch nie sexuelle Regungen gehabt usw. Ein Versuch industrieller Arbeitstätigkeit schlug fehl. Wegen Schwerhörigkeit mehrmals zurückgestellt. 20. 10. 1916 zur Infanterie: Ausbildung fiel ihm schwer, er begriff schlecht, konnte die Kommandos nur sehr schwer verstehen, ,machte es meist den Kameraden nach", tat nur Arbeitsdienst. Inn übrigen hielt er sich auch von jenen zurïck, weil er im Gespräch nicht mitkam oder von ihnen verlacht wurde; wurde eigentlich nur zu niederem Arbeitsdienst herangezogen.

Ende Oktober bis Anfang Dezember wiederholt in der Ohrenklinik F. untersucht: „Am Trommelfell keine, für die angebliche Schwerhörigkeit wesentliche Veränderung. Der Mann verhält sich völlig ablehnend, spricht nicht nach." 30.10. „Lauteste Umgangssprache am Ohr will er nicht hören. Hochgradige Schwerhörigkeit anzunehmen." 9. 11. Status idem; er reagiert auf keinen Befehl, auch dann. nicht, wenn eine Handbewegung denselben verständlich macht. Bei der Faradisation mimt er auf sehr plumpe Weise einen Anfall. Auf alle Falle verhält er sich so, wie es ein wirklich Tauber nie tun wïrde. Die Ortsbehörde gibt befragt an, ..er war schwerhörig, aber so hochgradig nicht, dass er nicht verständlich (!) war". Zur Kompagnie in andere Garnison, hier Februar Ohrenstation: „Bei Intersuchungen hat er sich mehrfach in Widerspruch gesetzt. Auffallend ist ferner, dass er trotz angeblich vieljähriger Taubheit eine durchaus normale Sprache hat, nicht abliest und auch auf Zeichensprache sich vollständig reaktionslos verhält. Verdacht auf Simulation, zum mindesten Aggravation." Dann Ohrenbeobachtungsstation H.: Auffallend stumpfes, ablehnendes Wesen, reagiert auf Anrede wie auf Gebärdensprache wenig und zögernd, wenn er antwortet, nur nach langem Zögern; auch auf schriftliche Fragen, sieht er den Frager lange wie ratlos an. gibt dann kurze, doch nicht immer der Frage entsprechende Antworten in fliessender, gutartikulierter, normaler Sprache. Ablesen kann Pat. gar nicht (? Ref.). Will nur lautestes Schreien am Ohr vereinzelt hören. Beide Trommelfelle getrübt, beiderseits hinten unten je eine kleine Narbe. Untersuchung durch Leiter der Taubstummenanstalt: „Er verhält sich nicht wie ein Tauber; für die lange Zeit, die er taub sein will, müsste er besser ablesen. Fin gewisses Mass von Ablesen scheint zu bestehen. Auffällig ist das falsche Kombinieren. Wenn ihm vielfach Zahlen aus den Zwanzigern vorgesprochen sind, sagt er danach 28-68. Das Wort „Sonnabend“, das ihm offenbar fremd ist (Sïdbadner! Ref.), zwischen anderen Wochentagen vorgesagt, liest er nicht ab, versteht es aber bei Konversationsstimme am Ohr. Diese am Ohr verstanden, wenn es sich nicht um Hörprüfung handelt. Stimmgabel auf keine Weise gehört, Monochord $r$ bis $a^{5}, 1$ bis $g^{5}$. Nachnystagmus (schwer prüfbar) beiderseits + . Durch Zwischenfragen während der Prüfung überführen lässt er sich nicht."

Schlussurteil Ohrenstation Heidelberg: R. zeigt bei allen Prüfungen und Unterhaltungen ein ganz auffälliges, durchaus nicht mit dem von tauben Leuten übereinstimmendes Benehmen. Auf das gesprochene Wort reagiert er gar nicht, zeigt nicht die geringste Aufmerksamkeit dafür, während sich jeder wirklich taube Mensch wenigstens bemüht, durch Absehen wenigstens etwas von dem Sinne des Gesagten zu erraten. Die gleiche ablehnende Gleichgïltigkeit zeigt er auch gegenüber schriftlichen Fragen, einerlei welchen Inhalts. Er tut so, als wenn ihm das Lesen ausserordentliche Mühe machte. Anf die Aufforderung, die Fragen schrift- 
lich zu beantworten, schreibt er aber, sobald er sich dazu herbeilässt, zuzugeben. dass er den Sinn der Anfrage erfasst hat, ganz flott, ohne jedes Zögern, in klaren und verhältnismässig gewandten Schriftzügen die Antwort hin.

Es ist uns trotz aller Aufmerksamkeit nicht gelungen, dem Mann sicher ein Hörvermögen nachzuweisen. Immerhin ist es schon nach seinem ganzen Benehmen so gut wie sicher, dass er die Taubheit zu Unrecht behauptet. Er müsste, wenn er tatsächlich seiner Angabe entsprechend bereits seit der Kindheit nahezu taub gewesen wäre, in der Schule grosse Schwierigkeiten gehabt haben, und es wäre recht unwahrscheinlich, dass er sich schriftlich gewandt auszudrücken gelernt hätte. namentlich da er in einem kleinen Landort aufgewachsen ist; erklärbar wäre das nur. wenn er etwa einen ungewöhnlich hohen Grad von Absehfertigkeit für die Sprache sich angeeignet hätte; er kann aber, soweit ärztlicherseits und durch den in der Beurteilung solcher Gebrechen sehr erfahrenen Leiter der hiesigen Taubstummenanstalt festgestellt werden konnte, gar nicht ablesen: Es handelt sich sicharlich nicht bloss darum, dass der Mann nicht ablesen will, sondern er ist auch unfähig dazu.

Abgesehen ron den Anhaltspunkten, die das Benehmen des Mannes, seine geistige Entwickling und der Mangel der Absehfertigkeit bei ihm ergeben, spricht noch eine direkte Wahrnehmung dafür, dass Hörvermögen bei ihm vorliegt. Wie in der Krankengeschichte angegeben, gibt $R$. beim Ablesen von Zahlen- und Wortreihen, die jeder leidlich intelligente Mensch leicht ablesen lernt, verkehrte Antworten, deren Unnatürlichkeit erkennen lüsst, dass er sie absichtlich verkehrt sagt. Am auffallendsten ist die bei dieser Prüfung am 3. 3. erfolgte Beobachtung mit dem Worte "Sonnabend" (Krankenblatt: ,... Er ist eigentlich der erste, bei dem ich eine bewusste Simulation annehme; aber ich kam den Mann mit aller Mühe nicht überführen").

Nachträgliche Erhebungen bei der Orts- und Schulbehörde der Heimat ergeben: ,Schwerhörigkeit angeboren, ein Erbgut der Mutter. welche hochgradig schwerhörig ist. Leistungen mährend der ganzen Schulzeit hinlänglich, er litt an Schwerhörigkeit, weshalb er in einem unteren Schıljahr wiederholen musste, so dass er nicht alle Schuljahre besuchen konnte."

6. 3. Nervenbehandlungslazarett H.: Bei der Aufnahme scheinbar absolute Taubheit: selbst lautestes Schreien ins Ohr wird nur partiell gehört. Yon Anfang an regt sich auf Grund der Kenntnis der Psychologie des Südbadener Banern der Verdacht, dass neben der otologischen Störung und wahrscheinlich diese beherrschend psychische Abweichungen vorliegen, die im ganzen etwa dem reaktiv-situativen Stupor eines Imbezillen gleichkommen. 7. 3. Beseitigung der „Hörstörung" durch die übliche Aktfolge von Suggestivmanipulationen erst links, dann in sehr viel rascherer Weise rechts. Nach der Kur zunächst noch ganz befangen, apathisch, unzugänglich. Auf Fragen, die er nach dem Ergebnis der Hörprïfung sicher erfasst, nur ein linkisch ratloses Verhalten. Erst nach 2 Tagen unter entsprechendem Zuspruch Lmwandlung des psychischen Bildes: Bringt nun mehr auch einmal ein Lächeln auf. Wird in jeder Beziehung sensorisch ansprechbarer. Aber auch noch nach weiteren Tagen, zurzeit, da er ein über die objektiven Erhebungen der Heimat noch hinausgehendes Hörvermögen besitzt, von dem er selbst sagt, dass es, soweit seine Frinnerung reiche, noch nie so gut gewesen sei 
- nümlich leiseste, hauchende Flüstersprache (mit Exspirationsrest) rechts in 30 . links in $25 \mathrm{~cm}$, mittlere Lmgangssprache rechts in 9, ]inks in $7 \mathrm{~m}$ - bietet er noch immer das Bild erheblichen Schwachsinns: Stumpfes, etwas hilf- und ratloses Yerhalten, sehr geringe Mimik, zahlreiche kindlich-schwachsinnige Aeusserungen der Verlegenheit und Befangenheit (Reiben der Hände auf den Oberschenkeln, Zungenund Fingerschnalzen, Stuhlrutschen; ferrer hilfloses Lächeln, Neigung zu Gesichtsröte, tiefe Inspiration vor der Antwort auf etwas schwierige Frage usw.). Dazu monotone, langsame Sprechweise mit deutlichem Zungenanstossen bei meist leicht geöffnetem Mund. Einfache Verlangsamung aller psychischen Vorgänge, besonders der Auffassung gleichermassen auf allen Sinnesgebieten. Leichte, allgemein psychische Hemmung. Eine Intelligenzprüfung führt,ebenfalls zu dem Ergebnis angeborenen Schwachsinns, der sich gleichmässig aus dem Tiefstand sensorischer Anregbarkeit und assoziativer Leistungsfähigkeit aufbant. Sehr dürftige Schulkenntnisse, nicht umbeträchtliches, aber rein mechanisch auswendig gelerntes Gedächtnismaterial (Kirchenliedstrophen usw.), Mangel jeden eigenen Urteils und der Fähigkeit, auch einfachste, kombinatorische Leistung zustande zu bringen. Dabei nichts von Bauernschläue; kein Einschlag bewusster Falschdarstellung, vielmehr in jeder Beziehung Eindruck des treuherzig-gutmütigen Imbezillen. Dabei hat er ein dunkles Gefühl für seine psychische Insuffizienz, die er treuherzig zum Teil unter Kampf mit Tränenausbruch damit erklärt, dass er , halt immer tür sich gewesen sei, dass der Vater ihn nicht aus dem Dorf wegliess, weil die Brïder in die Fremde zogen: in dem Verkehr mit den Leuten sei er daher halt nicht so bewandert". Retrospektiv gibt er auf Befragen unter vielen Zeichen der Verlegenheit an, er habe früher besonders in der Ohrenklinik, ,halt immer - , ich weiss au itte, warum so eine heimliche Angst gehabt": Der Doktor ,habe ihn so stark angerufen, da sei er so verschrocken ${ }^{\circ}$. Zu Hause ging es mit dem Verständigen; er verstand Eltern und Geschwister, ,weil er sie eben gewöhnt war ${ }^{6}$. Doch habe er von selbst ein bisschen gelernt, den sprechern auf den Mund zu sehen, um abzulesen. Eingehende Prüfung ergibt, dass ex - so weit es bei ihm zu erzielen - im Gleichgewicht des Gemüts, sofern er genau auf den Sprecher eingestellt ist und dieser die Lippenbewegungen beim Sprechen markiert, bis zweistellige Zahlen langsam, aber prompt labial einfachste, zweisilbige Worte teilweise, Sätze gar nicht ablesen kann, z. B. (28) +, (33) +, (Baum) +, (August) Achtnng, (Feder) till, (Lampe) Lamm, (Strauch) Strauss (Gerhard) Gens. Auch ungezwungene spielend in ein Gespräch eingeschaltete Hörprüfungen. geben für die Auffassung des ganzen Falles bemerkenswerte Ergebnisse. Z. B. wird er mitten in gleichmütigster Unterhaltung aufgefordert, zu lauschen, was er gerade in der Umgebung höre: Es bedarf sichtlich eines inneren Antriebs, um von der Gebundenheit auf Ton und Gespräch des Ref. loszukommen und sich auf andere akustische bzw. psychische Inhalte einzustellen. Es schlägt die Kirchenglocke 11 Uhr: 3 Schläge, nachdem er gelauscht hat, gibt er ihre Apperzeption kund. Nun soll er weiter auf ein leiseres Gespräch, sehr leises Knistern des Zimmerofens in $3 \mathrm{~m}$ Entfernung, lauschen - er lauscht lange, sagt schliesslich: ich höre nichts. Nun soll er lauschen, ob er das ,Vogelzwitschern draussen“, das tatsüchlich nicht existiert, hört. Bis in alle Einzelheiten des Minenspiels und den Affekt wie vorher, sagt er wiederum: ich höre es nicht.

Archir f. Psychiatrie, Bd. 58. 
Nachträg]iche Erhebungen: Bei der militärischen Einstellung wurde er ,mit Schwachsinn bezeichnet", in der Kompagnie, der er zugeteilt wurde, mit "grosser Schwerhörigkeit".

Epikrise: Die Beurteilung des Falles von ohrenärztlichem Standpumkt hat Prof. Kümmel prononeiert in den Satz zusammengefasst: ,Er ist eigentlich der Erste, bei dem ich eine bewusste Simulation annehme, aber ich kann den Waun nicht überführen." Die ohrenärzthiche Beurteilung vorher spitzt sich auch immer mehr auf diesen Leitsatz zu. Dennoch ist es der 1. Fall, der von Anfang an und nicht bloss bei den Hörprüfungen ausschliesslich aus diesen psycho-pathologischen Zusammenhängen heraus zu beurteilen war auch wenn nicht nachträglich durch objektive Erhebungen über den Hörbefund der Kindheit einwandfrei festgestellt worden wäre, dass überhaupt aus der Skala willkürlicher Vortäuschung nur Aggravation, nicht Simulation hätte in Frage kommen können. Je mehr man psychologisch sich mit ihm beschäftigt, um so mehr befestigt sieh die Auffasssung, dass der Kern des Zustandes als Reaktion eines hochgradig und vor allem sensorisch Schwachsinnigen auf die besonderen Verhältnisse der militärischen Einstellung anzusehen ist. Der situative Stupor hat durch das Vorliegen einer von Haus aus bestehenden Schwerhörigkeit und ihrei inneren Zusammenhängen mit dem einfachen Schwachsinn nur seine besondere Note erfahren. Es ist recht deutlich, wie gleichgerichtete psychische Einwirkungen, die in Anbetracht seiner seelisehen Gesamtverfassung fiur ihn ganz ungewönliche Erlebnisse bedeutet haben, zu psychogen krankmachenden Faktoren geworden sind. In diesem Sime haben die oft wiederholten Hörexamina den offenbar latenten Versetzungsstupor, der durch die militärische Einstelhung geschaffen war, jeweils zur akuten Exazerbation und vor allem zur fast vollständigen Absperrung der akustischen Apperzeption gebracht, wie andererseits Brüskierung am falschen Ort zur Auslösung von psychogenen Protestanfällen geführt hat. In dem Krankenblatt der Ohrenstation H. ist ja auch dem Nichtpsychiater der Gegensatz zwischen der Hörfähigkeit in freier Konversation und im Hörexamen wenn auch nur mehr eindrucksmässig zum Bewiusstsein gekommen. Und retrospektiv hat der Kranke selbst in eindeutiger Weise die rein psychogenen (nicht eigentlich hysterischen) Motive seiner Scheintaubheit, die ihrem Wesen nach vielleicht am echtesten als affektive Absperrungstaubheit bezeichnet werden könnte, aufgedeckt. Ich stehe nicht an, in diesem Falle gerade in dem negativen Gefühl der fortgesetzten reinen Simulationsverdächtigung, das dem Kranken aus den Verhalten der Ohrenärzte erwuchs, ein Moment zu erblicken, das negative Suggestionen auslöste und so seinen psychogenen Stupor eher vertiefte.

Sehr bemerkenswert ist die spontane Angabe des Kranken gegenüber 
der Krankenschwester, er höre seit der Kur viel besser, als er je nach seiner Erinnerung gehört habe. Die heutige Hörprüfung bestätigt die Richtigkeit dieser Angabe vollauf. Es ist wohl kein Motiv denkbar, das einen „ehemaligen Vollsimulanten“, unter den gegebenen Umständen zu einer derartigen Aeusserung bestimmen könnte. Dagegen ist dieselbe für die Beurteilung der Art der früheren Schwerhörigkeit bemerkenswert. Sie zeigt, dass offenbar seit der frühen Kindheit der organisch - d. h. durch chronisch rezidivierende Ohreiterung und eventuell dazu noch durch hereditäre Prozesse - bedingte Hörausfall psychogen „,nach oben abgerundet" wurde. Es ist sehr damit zu rechnen, dass sehr viel häufiger als es scheint ja ganz allgemein vielleicht angeborene geistige Schwächezustände mit einfacher ,Affektatrophie" d. h. mit besonderem Daniederliegen der Affektivität organisch bedingte Sinnesausfälle ,psychogen" dadurch verschlimmern, dass es infolge der zu niedrigen Ansprüche, die dauernd an das Hörvermögen gestellt werden, gewohnheitsmässig zur richtigen Ausnützung der Hörreste gar nicht kommt. Im Grunde würde es sich da um einen Vorgang handeln, der entfernt mit der Amblyopie ex anopsia in Analogie zu bringen ist. Gerade im vorliegenden Falle spricht in diesem. Sinne die psychologisch von dem Kranken angesichts seines Schwachsinns nicht weiter analysierbare, dafür aber an sich um so charakteristischere Bemerkung, dass er zu Hause sich ganz leidlich verständigen konnte, weil er ,an Eltern und Geschwister" offenbar nicht bloss rein akustisch - nach Știmmenklang und -färbung - gewöhnt war.

Wohl als erster hat Kraep elin psychogene Zustandsbilder abgegrenzt, die mit chronischer Schwerhörigkeit in ursächlichem Zusammenhang stehen. In einer Untergruppe seiner ,Verkehrspsychosen" schildert er als ,Verfolgungswahn der Schwerhörigen" eine psychogene Erkrankung, die sozusagen nur die pathologische Verzerrung und Systematisierung des verständlichen Misstrauens der durch Hörausfall zum geistigen Krüppel gewordenen und vor allem aus dem durchschnittlichen menschlichen Verkehr ausgeschlossenen Erwachsenen darstellt. Es ist kklar, dass es zu derartigen „Umgangspsychosen" nur dann kommen wird, wenn vor allem die affektiven Antriebe zum menschlichen Verkehr in normaler Weise wahrscheinlich sogar in besonderem Masse vorhanden sind. Wo dieser soziale Trieb aus Gründen, die mehr minder zentral in angeborenem oder früh erworbenem Schwachsimn zu suchen sind, konstitutionell verkümmert ist, ist dem Affekt von vornherein der Boden entzogen. Die psychologische Wirkung der Schwerhörigkeit wird sich in diesen Fällen konstitutionell in einer Vertiefung der mangelhaften geistigen Ansprechbarkeit, episodisch aber bei der Einwirkung eingreifender Aussenweltserlebnisse in der Neigung zum (reaktiven) Stupor geltend machen. Es ist bei der Rangstellung, die der Hauptverkehrssinn Gehör unter den intellektuellen Sinnesorganen einnimmt, in letzterem Falle 
selbstverständlich, dass das Ineinanderwirken geistiger Hilf- und affektiver Ratlosigkeit sich im Wahrnehmungsfeld des organisch gestörten Simnesorgans besonders stark bemerkbar macht. Die psychologisch komplizierten Verhältnisse, die hier sich geltend machen, lassen die Schwierigkeiten begreiflich erscheinen, solch gemischte Scheintaubheit von der simulierten Taubheit zu unterscheiden.

In der folgenden Beobachtung tritt dies in besonderer Weise hervor. Als ein wesentlicher Faktor im Komplex der psychogenen Krankheitsursachen führt sich auch hier ein ,ia trogener" ein: Züge des reaktiven Zustandsbilds, die unmerklich und beiden Teilen unbewusst auf die Eingestelltheit des Kranken auf irgendwelche ärztliche Einwirkungen zurückzuführen sind. Unter den iatrogenen Schädlichkeiten stehen ja meist therapeutische Massnahmen im Vordergrund. Daneben sind aber die negativen ärztlichen Wirkungen nicht zu vergessen, die der Kranke stillschweigend und dem Arzte oft unbewusst ans dem Tenor seines Gesamtverhaltens gerade ihm gegenüber herausliest und nach seinen ganzen Ansehauungen auf seine besondere Art ausdeutet. Bei der Disposition zu Misstrauen, die chronisch Schwerhörigen besonders eigen ist, müssen wir bei den Fällen mit psychogener Pfropfung immer ins Auge fassen, dass der heimliche Verdacht, für einen Simulanten gehalten zu werden, schon aus harmlosen Bemerkungen des Arztes, vor allem aber, wenn dieser tatsächlich an die Möglichkeit der Simulation denkt, aus seinen unbewussten mimischen Aeusserungen vom Kranken „er" schöpft wird. Dass dieser schleichende Verdacht als psychogen krankmachender Faktor wirken kann, und gelegentlich besonders in einer reaktiven Vertiefung der Absperrung des Kranken gegen den Arzt wirkt, ist mir nach diesen Erfahrungen nicht mehr zweifelhaft.

Beobachtung 17. R., geb. 1883, Landwirt.

Anamnese (eigene Angabe jetzt): Angeblich mit 2 Jahren Osteomyelitis am linkenUnterschenkel. Bald danach fing das linke Ohr an ,zu laufen" und Schmerzen zu machen; man habe damals gesagt: es habe sich ",vom Bein ins Ohr geschlagen". Wegen des schlechten Gehörs wurde er in der Schule immer in die vorderste Bank gesetzt; bis dahin habe er, weil er infolge des schlechten Gehörs nicht mitkam, oft Nachsitzen gehabt. Auch zu Hause habe man ihn immer laut anrufen müssen. Oft habe sich seine Frau erstaunt, wenn laut schwätzend Leute am Acker vorübergegangen seien, ohne dass er das geringste bemerkte. Ohrlaufen stellte sich regelmässig im Sommer und Winter öfters im Jahre für mehrere Wochen ein. Vorher hatte er jeweils Schmerzen in der Stirngegend. Es stank scheusslich. Dennoch nie ärztliche Hilfe in Anspruch genommen. Von Gleichgewichtsstörungen könne er nichts angeben. Auf dem linken $\mathrm{Ohr}$ war es auch sonst von jeher, ,als ob alles zu wäre". 1903 von Infanterie nach ${ }^{1 / 2}$ Jahr wegen Knochenhautentzündung und Schwerhörigkeit links d. u. entlassen.

10. 2. 1915. Fingezogen 3. 4. Loretto; stets ängstlich/zittrig im Artilleriefeuer. 
Die Offiziere hätten ihn immer ermahnt, sich wegen des Gehörs krank zu melden. Er wollte aber nicht weg. Seit Januar 1916 wieder Ohrenfluss und Schmerzen über den Augen. Dies verschlimmerte sich. Auf Posten durch Granatexplosion (keine Terwundung) kurze. Zeit ,weg“. Danach gar nichts gehört; deshalb krank gemeldet (Angaben wechseInd). 9. 2. 1916 Kriegslazarett Sedan: Rechtes Ohr trocken, Tronmelfell getrübt, sonst o. B.; linkes Ohr (nach Entfernung eines Cerumenpfropfs) Trommelfell eingezogen, narbig verändert, trocken, Tuben frei. Stimmgabel c durch Luft links nicht, rechts gehört. Rinne negativ. Knochenleitung verkürzt (links 5 Sek., rechts 20 Sak.). Beiderseits Konversationssprache am Ohr. 13. 2. Reservelazarett Heimat. Narbenbildung am linken, Einziehung am rechten Trommelfell. Flïstersprache rechts $30 \mathrm{~cm}$, links 0. Lante Sprache links am Ohr. Luftdusche-, Katheter- usw. Behandlung. 23. 3. Status idem. 20. 6. Immer dasselbe. Nun (!!) Teilnahme am Ablesekurs (!), daher 5. 7. Reservelazarett T.: Hior links mässige Eiterung des Mittelohrs, Perforation die vordere Hälfte des Trommeltells einnehmend.
A ron Scheitel 1 Sek., \} gehört.
Galton r 0,5
alle Töne 10

R. die vorhandenen Stimmgabeln nur ganz kurz,

1. nicht gehört.

Lingangssprache r $5 \mathrm{~cm}$

7. 7. Eiter geringer.

1 ganz laute U.-Spr. nicht gehört.

R. mittellaute Worte: ,,99" in $30 \mathrm{~cm}$

l. $\quad, \quad, 77^{4,}, 5 \quad$,

$\left.\begin{array}{l}\text { Ganz laute Sätze rechts in } 1 \mathrm{~m} \\ \text { lauter Anruf }\end{array}\right\}$ gehört, nicht verstanden.

8. 7. A. v. zum E. T. T. 6. September Ohrenklinik. Ambulanz: Senkung der oberen Gehörswand, fötides Sekret; in der Tiefe Granulom. Starke Schmerzen beim Einsetzen des Ohrtrichters.
Auditus r. $\mathrm{z}$
$\varnothing$ Flst. $\varnothing$
Wenige Sekunden Lw $\varnothing$
$\varnothing \mathrm{cL} \varnothing$
r. Konversationsspracho ad concham.
1. Surditas (auch mit Barany)
Eindruck starker Aggravation.

19. 9. Aufnahme in die Klinik: Rechts Trommelfell trübe, kl. Narben, links etwas fötides Sekret; keine Senkung mehr. Zentral kl. Granulom. Perforation nicht zu sehen.
r. 1 .
$5^{\prime \prime} \mathrm{cm} \varnothing$
$5-10$ e T. $\varnothing$
r. Konversationssprache $20 \mathrm{~cm}$, laute Umgangssprache auf $30-40 \mathrm{~cm}$.
1. $Q$
c $50 \mathrm{~b} \operatorname{Tgr} \varnothing$

Angaben über Hören mit Befund beim Lippenablesen widersprechend. Auf Vorhalt sehr ungehalten. 4. 10. Ohr trocken.

12. 10. Zur Beseitigung der Taubheit Anwendung der Methode PilzeckerKümmel (Injektion von $5 \mathrm{pCt}$. Kochsalzlösung in die Haut vor dem Warzentortsatz beiderseits; danach in Chloräthylrausch Ausfüllung des Gehörgangs mit 
Salbetampons). Danach ganz apathisch; sehr schlechtes Ablesen. 13. 10. Abnahme des Verbands. 14. 10. Hört jetzt angeblich laute Konversationszahlen rechts anf $20-40 \mathrm{~cm}$, links gar nicht, auch nicht bei offenem rechten $O \mathrm{hr}$. Meint aber doch besser zu hören. 15. 10. Rechts Konversationszahlen in $50 \mathrm{~cm}$, links nur ganz laute Zahlen am Ohr; noch sehr apathisch verschlossen. 20. 10. Immer disselben Angaben. Auch auf der Strasse gelang es nicht festzusteilen, dass er sich mit anderen unterhält, trotzdem zweifellos Hörvermögen viel besser. Obj.: Unrichtige Angaben. z. B. mit durchbrochener Olive im rechten $O h r$ dasselbe Resultat rechts wie links; bei Oeffnung und bei Schliessung derselben. Eindruck, dass ein tiefes Misstrauen ihn in seinen Aussagen hemmt, fürchtet Simulationsverdacht usw. 26. 10. Rechts Konversatior $30 \mathrm{~cm}$; räumt nach langem Zureden ein, Flüsterzahlen wenigstens $2 S, 32$ u. dgl. nahe am rechten 0 hr zu hören. Links nur laute Zahlen ganz dicht am Ohr. Bei Einsetzen der offenen Olive ins linke Ohr, bei Oeffnung rechtes $\mathrm{Ohr}$ nichts gehört; bei Einsetzen der offenen ins linke, der verschlossenen ins rechte Ohr ebenfalls nichts; nach Wegnahme der linken hört er wieder laute Zahlen am linken Ohr. Alle Variationen ergeben wieder, dass er auf boiden Ohren hören muss, es ist aber völlig unuöglich, festzustellen, ob das Gehör ganz oder annähernd normal ist, ob wirklich eine gewisse, nicht sehr erhebliche organische Schwerhörigkeit besteht. Kalorische Prüfung rechts: $27^{\circ} \mathrm{C}$ nach $225 \mathrm{ccm}(=1 / 3$ der normalen Erregbarkeit nach Brïnings), erste Andeutung von Nystagmus bei Blick nach links. Links nach $100 \mathrm{ccm}\left(={ }^{3} / 4\right.$ Brünings $)$. .Also eine gewis a organische Schädigung des Vestibularapparats, deshalb wohl anch das Cochlearis wahrscheinlich." „Hörstörung wahrseheinlich zum grössten 'Teil psychogen." „Ich befinde mich hier in einer gewissen Unsicherheit: Wenn ich auch nach unseren. Beobachtungen als sicher annehme, dass er auf beiden Ohren organisch hört, so konnte ich doch keine Sicherheit gewinnen, dass keine organische Schädigung neben der psychogenen Störung vorlag, und erst recht nicht, wie gross der Grad der organischen Hörstörung ist."

27. 10. Nervenbehandlungslazarett B.: Erhebliche körperliche und vor allem geistige Schwerfälligkeit, sehr ungewandt in allen Bewegungen, Handlungen. Gesten; debiler Gesamteindruck, Neigung, sich abzuschliessen. Konversation nur durch lautes Schreien an beiden Ohren möglich, sonst wie früher. 28. 10. Beseitigung dex Hörstörung (durch die Methode wie im vorhergehenden Falle) rechts völlig, links bis zu einem. Grade, welcher nach seiner eigenen spontanen Angabe noch eine Besserung gegenüber der seit Jahrzehnten bestehenden Schwerhörigkeit links bedeutet. Erst widerwillig; nachher sehr dankbar. Retrospektive Angabe über die Heilung: „A uf einmal ein ganz anderes Gefühl im Ohr", dann allmählich Wiederkehr des Gehörs. Für den organischen Charakter der noch restierenden geringen Schwerhürigkeit links spricht auch, dass es Müh kostet, ihm die seit Jahren bestehende habituelle Schiefhaltung des Kopfes im Simne des Zunoigens des besseren rechten Ohres zum Sprecher abzugewöhnen. Nach der Kux Umwandlung des Persönlichkeitsausdrucks zum guten: Hoffnungs-, Arbeitsfreudigkeit, dauernd heitere, joviale Stimmung; aber auch dabei noch alle Zeichen der geistigen Schwerfälligkeit, Umständichkeit in der Sprechweise; ausserordentlich primitive psychische Persönlichkeit. Kombinatorisch äusserst dürftige Ver- 
anlagung. Versucht man ihn durch ,Kreuzfragen" bezüglich scheinbarer oder konstruierter Widersprïche, sowohl solche, die sich auf seine Hörschwäche beziehen, wie anderweitige, ,hereinzulegen", so zeigt er sich äusserst ungewandt und hilflos. Selbst wo man annehmen könnte, er wolle sich ins rechte Licht setzen, wie z. B. durch Versuche, mit äberschwänglichen Dankbarkeitsbezengungen sich beliebt zu machen, benimmt er sich äusserst schwerfällig. Besonders aber im ungezwungenen Verkehr mit Seinesgleichen und mit dem Personal lässt er dauernd jeden Zug vermissen, der in irgendeinem Sinne als bewusst-willkürliche Darstellungstendenz gedeutet werden könnte. Bei dem einzigen Versuch, sich anders zu geben, wie es psychisch seine ,Natur" ist, dem Bemühen, im Gespräch mit Vorgesetzten sich aus seinem nicht leichtverständlichen Dialekt in hochdeutsche Sprechweise ,hinaufzuschrauben:", benimmt er sich so ungeschickt, dass man beim ersten Worte seine Absichten merkt. Seine Dankbarkeitsbezeigungen sind rührend primitir, ,ungeschlacht". Konversationssprache, spiclend" in $3 \mathrm{~m}$, auch unter Ausschlnss der Lippenablesemöglichkeit. Laute Flüstersprache unter scharfer, passiver Einstellung desselben auf den. Hörakt rechts $5 \mathrm{~m}$, links dicht am Ohr; Konversationssprache links in $1 \mathrm{~m}$. 14 Tage E.-U. dann links Umgangssprache bis $4, \mathrm{~m}$, Flïstersprache vor dem Ohr, rechts Konversationssprache annähernd normal, Flüstersprache in 4-5 m. nur ganz selten noch habituelles Vorstrecken des rechten Ohrs. Fortgesetzte unauffällige Beobachtung ergibt nicht den geringsten Anhaltspunkt für eine Gleichgewichtsstörung.

Feststellung auf Nachfrage 1. bei seinem Feldtruppenteil: ,Verschüttung krommt nicht in Frage, da es sich um ein altes Leiden handelt, vor seiner Krankmeldung fiel er schon durch Schwerhörigkeit auf"; 2. beim Bezirkskommando, dass ar 1903 nicht eigentlich wegen Schwerhörigkeit, sondern wegen der mit den Knochen verwachsenen Narbe am linken Schienbein (alte Osteomyelitisnarbe) entlassen wurde.

Epikrise: Nach dem ganzen psychischen Habitus des Yamnes vor und nach seiner Heilung ist bewusste Vortäuschungstendenz geradezu ausgeschlossen. Der Schein der Aggravation seiner Hörschwäche erwuchs hier offenbar aus der Unkenntnis der Vorgeschichte and andererseits aus der ungenügenden Einschätzung des psychischen Faktors. Der einzige Widerspruch zwischen subjektiver Darstellung und objektiver Feststellung des Krankheitszusammenhangs ist vielleicht nur ein scheinbarer. Wenn seinem Feldtruppenteil von seiner Verschüttung nichts bekannt ist, so lassen seine Angaben doch noch die Möglichkeit; ja die Wahrscheínlichkeit zu, dass eine starke Detonation bei dem invaliden Hörapparat vorübergehend doch zu subjektiver Taubheit geführt hat, die dann sekindär fixiert wurde.

Als der bestimmende psychische Faktor ist neben der Herabsetzung der Intelligenz hier weniger allgemeine Stumpfheit als die eigenartige Primitivität und schwerfällige Ungeschlachtheit der psychischen Persönlichkeit anzusehen. Als ein Zeichen seiner Neigung zu relativer Stuporosität dïrfen wir wohl das apathische Verhalten nach der therapeutischen Ohrabschliessung 
und überhaupt die Neigung ansehen, sich seiner chronischen Hörschwäche wegen von jedem Verkehr mit der Umgebung abzuschliessen. und in resignierte Versunkenheit hineinzusteigern. Sichtlich wird diese Tendenz durch das dunkle Gefühl der Insuffizienz unterhalten, dass er infolge seiner verständlichen und psychomotorischen Unbeholfenheit die Folgen seiner Schwerhörigkeit für den menschlichen Verkehr nit seiner Umgebung nur noch verschlimmert. In dem psychogenen Anteil seiner Hörschwäche dürfen wir also die Steigerung einer Gewöhnung an die Folgen seiner akustischen Hilflosigkeit und den apperzeptiven Mindergebranch des Gehörs erblicken, die vielleicht durch die vorübergehende funktionelle Detonationstaubheit noch begünstigt wurde. Zweifellos hat auch der Affekt des Misstranens insofern eine Rolle gespielt, als er unter dem Verdacht, für einen Simulanten gehalten zu werden, gelitten hat. Daher rief die Kur bei ihm nicht nur eine in echtesten Dankbarkeitsbezeigungen sich äussernde Zufriedenheit über den Erfolg, sondern ganz evident einen plötzlichen Wechsel von Depression zu reinster Gesundheitsfreude und echtem Arbeitstrieb hervor.

In anderen Fällen finden wir den Affekt des Misstrauens, auch ohne dass wir den Verdacht der Simulationsgeltung ,erfühlen" können, in einer gerade merklichen Widerstrebigkeit gegen alle Einflüsse der Umwelt zur Geltung kommen. In der folgenden Beobachtung sehen wir einen ganz umschriebenen hypochondrischen Komplex als Motiv in dieser Richtung mitwirken.

Beobachtung 18. H., geb. 1876, Kaiserstuhler Landwirt.

Eigene Angaben: Als Kind schwächlich, kränklich, ängstlich, Bettnässen bis zur Schulzeit. Mit 6 Jahren Fraktur am linken Ellbogen. Wegen des linken Armes nicht aktiv gedient, mit 25 Jahren habe er bemerkt, dass er schlechter höre wie andere (r. $>$ l.), was sich allmählich immer mehr verschlimmerte.

30. 10. 1915 eingezogen. Während der Ausbildung musste er wegen Schwerhörigkeit immer ins 2. Glied. April 1916 Schützengraben. 10. 6. 1916. Yinensplitterverletzung linke Hand und Unterarm, zugleich Verschüttung mit Hautabschärfungen/Brandwunden im Gesicht. In der 1. Woche darnach sei er ganz taub gewesen. 16. 6. Feldlazarett: Leichte Benommenheit, Verbrennung, besonders des linken Gesichts, tiefgehende Wunde vor dem linken Ohrläppchen, sonst Schürfwunden. In beiden Gehörgängen eingetrocknetes Blut, rechts am Hammergriff, links am oberen hinteren Quadranten frisches Blut. Lappige Wunde auf der Streckseite des linken Zeigefingermittelgelenk; radial am Mittelglied oberflächlicher Minensplitter; grosse Anzahl Steckschüsse auf dem linken Handrücken, einer auf dem Unterarmrücken, 2 Schürfwunden linke Schulter. [Motilität?] 17. 6. Frisches Blut an der Spitze des Ohrentampons. 21. 6. Fingerwunde sondert ab. 22. 6. Ohrstation: Rechts Blutspuren am Trommelfoll, links im o. B.; Ohr trocken, links geringe blutige Absonderung und Rötung des Trommelfells. Flüstersprache 0 beiderseits, Ungangssprache dicht am Ohr. Diagnose: Trommelfelliriss 
beiderseits, mit Labyrintherschütterung. Granulationen am linken Zeigefinger. 26. 6. Heimatlazarett: Status idem.

5. 7. [erste Notiz über Motilität!]: Linker Mittelfinger im Metacarpophalanggelenk in stumpfwinklig gebeugter Stellung, passive Streckung frei, aktive aufgehoben. An Streckseite 1. Unterarm/Hand oberfl. Metallsplitter, dazu im Röntgenbild ein länglicher. stiftartiger Metallsplitter $4 \mathrm{~cm}$ oberhalb Handgelenk in Spatium inteross., nahe der Ulna senkrecht die Muskulatur durchbohrend. 12. 7. Entfernung d. sselben. 7. 7. Absonderung an Ohren hört auf.

17. 7. Ohrenstation F.: Rechts und links Blutkrusten an verschiedenen Stellen am und um das Trommelfell. Rechts eine zentrale, links vorne eine Lücke. $e^{1}$ in der Luft nicht, v. Sch. i. d. M. stark verkürzt, Uhr ${ }_{i}^{1}$ knl. beiderseits, v. Sch. i. d. M.; Flüstern $=0$, Umgangssprache beiderseits nur nahe am Ohr. 26. 7. Fängt an abzulesen. 23. 8. Rechts noch Blutkrusten, links T'rommelfell abschilfernd, Schleimhant der Lücke abblassend. $\mathrm{c}^{1}$ nicht gestört.

1. 9. Ungangssprache links $0,4 \sim 0,3 \mathrm{~m}$, rechts $0,25 \sim 0,15$.

19. 9. Chirurgische Abteilung: L. Hand/Unterarm von der Wunde aufwärts blaurot gefärbt. Gefühlsstörungen im Medianusbereich, Faustschluss nicht vollständig infolge Lähmung der kleinen Handmuskeln.

21. 10. Wieder Ohrenstation: Flüstern $\frac{\| 1}{11}$ Ungangssprache rechts 0,2 , links 0,2 . $c^{1}=0$. Uhr 0 beiderseits, a $/ \mathrm{W}$ zf, v. Sch. 0 .

23. 10. Neurologische Untersuchung: ,Nicht hy. Lähmung, sondern wie die Atrophie, die Krallenbandstellung, die sensiblen Störungen und die Bewegungsstörungen zeigen teilweise Läsion des Ulnaris." In den atrophischen Muskeln partielle Ea. R. Die blaurote Verfärbung der Hand grösstenteils auf Schonungsbestreben bzw. Nichtgebrauch zurückzuführen. Nervennaht empfohlen.

10. 11. Operation (Prof. H.): $10 \mathrm{~cm}$-Schnitt Bengeseite am Unterarm: weder am Mediamus, noch Ulnaris eine krankhafte Veränderung; nirgends alte Narben oder Schwielen. 24. 11. Gute Verheilung. Anästhesie 3,-5. Finger (Ulnarisgebiet); Spreizen der Finger 0, Strecken der 3.-5. Finger 0, Faustschluss des Daumens und Zeigefinger gut, der übrigen nicht vollständig. Starke Atrophie der Interossei entsprechend. Ulnarislähmung; am Unterarm farad. Erregbarkeit herabgesetzt.

Urteil: ,NNach Operationsbefiund keine anatomische Verletzung des Ulnaris am Lnterarm. Andererseits spricht Atrophie, elektrischer Befund gegen funktionelle Störung. Es erscheint nicht ausgeschlossen, dass während der ersten Operation, die in Blutleere ausgeführt wurde, die Abschnürbinde dureh Druck auf den Nerv eine Verletzung hervorgerufen hat, die den jetzigen Befund bedingt. Es waren mehrere Monate abzuwarten, ob nicht spontane Besserung eintritt."

28. 11. Nervenuntersuchung: Hysterische Schwerhörigkeit.

5. 12. Nervenbehandlungslazarett: Gewohnheitsmässiges Vorschieben des linken Ohrs. Ex selbst spricht leise. Rechts /links lauteste Umgangssprache $4 \mathrm{~m}$, links lauteste Flüstersprache, links partiell am $\mathrm{Ohr}$, rechts $=0$.

Ohrkitzelreflex: $x .=1$, negativ.

Hände: I. $>$ r. zyanotisch, links bis Unterarm gefleckt, erheblich kühler. 
Umfänge: Dicht unterh. Proc. styloides links $16, \overline{5}$ rechts 17,5

$\begin{array}{lllll}\text { Am Metacarpophal.-Gelenk } & , & 20 & , & 22 \\ \text { Grösster Unterarm-U. } & , & 24,5 & . & 27,5 \\ \text { Kleinster ㄱ, } & , & 21 & , & 24\end{array}$

Dauerstellung links: In Handgelenk Mittelstellung Finger leicht interphalangeal gebeugt. Bei Faustschluss wird der 2. Finger nicht ganz auf den Thenar aufgepresst. Dorsalflektion Handgelenk 0 . Fingerstreckung minus $10^{\circ}$. Opposition 4./5. Finger gegen Daumen 0. Spreizen nur angedeutet. Ea.-R. III-V. Interosseus. Anästhesie links. Unterarm (scharf von Ellbogen Handgelenk) rolar.

7. 12. Kombinierte Suggestivkur der Hörstörung und der Bewegungsstörung links.

Erfolg: Leise Umgangssprache in $3 \mathrm{~m}$. Nur noch Beschränkung der maximalen Dorsalflexion im Handgelenk, durch Angst vor Dehnungsschmerzen in der Operationsnarbe gelingt nur bis $\Varangle 190^{\circ}$, Beschränkung der Spreizung 4. Finger um $5^{0}$. Adduktion des 5. Fingers um 15-20\%. Gegen Widerstand, d. h. Gegendruck von der Radialseite der gespreizten 2.-4. Finger ist letztere fast normal. Ueber Exfolg der Gehörbehandlung durchaus nicht erfreut, versteift sich Mitkranken gegenüber darauf, dass es doch wieder schlechter werde, nachdem er seit seinem 25. Jahre schlecht höre und auch Prof. B. ihm gesagt habe, ganz gut könne es nicht wieder werden.

Nun gibt absolut glaubwürdig die Ehefrau an: Dar Grossvater mütterlicherseits war sehr schwerhörig, seine Mutter im Alter absolut tanb, ein Vetter ist auch schwerhörig. Bei ihm setzte Schwerhörigkeit ohne akute Erscheinungen. (Eiterung usw.) unter subj. Geräuschen im 25. Jahre ganz allmählich ein (einseitig schlimmer). Die Schwerhörigkeit war ortskundig. Durch Fenster/Tür war er ganz unfähig, Sprache zu verstehen. Seit Jahren versteht er dio Ehofraru in mittellauter Umgangssprache in $1 \mathrm{~m}$. In der Ambulanz der Ohrenklinik habe man seinerzeit wohl von erblichem Ohrenleiden gesprochen. Nachträgliche Feststellung durch Entgegenkommen der Ohrenklinik F. ergibt, dass H. 1904 polikliniseh dort wegen „Stapesankylose“ behandelt wurdz, ,unter welcher Diagnose damals die Fälle von Otosklerose gingen".

Der Einstellungsbefund 30. 10. 1915 ergibt, dass er rechts schlecht hörte. Psychischer Habitus eines schwerfälligen, unbeholfenen, nachlässigen, militärisch unerziehbaren Bauerntyps.

Epikrise: Der Fall bietet die nicht so seltene Merkwürdigkeit des zufälligen Zusammentreffens alter trammatischer Invalidität und Kriegsverletzung an einem und demselben Körperabschnitt - hier in ,doppelter Ausfertigung ${ }^{6:}$ An beiden Ohren, die einwandfrei seit Jahren, offenbar einfach durch chronische Prozesse (Otosklerose: erblich?) in der Funktion allmählich geschädigt waren, wird durch schwere trammatische (Explosion!) Trommelfellzerreissung mit lange nachhaltender Blutung die bestehende Hörstörung funktionell bis zur fast vollkommenen Taubheit gesteigert und gleichzeitig an dem infolge ,Ellbogenbruch" seit der Kindheit leicht invaliden linken Unterarm eine im weitesten Sinne traumatogene Bewegungsstörung 
gesetzt. Die Unsicherheit in der früheren Beurteilung der Natur sowohl der Schwerhörigkeit wie auch der Motilitätsstörung des linken Vorderarms ist hier wesentlich durch den Mangel der Anamnese bedingt. Hätte man früher genau subjektive und objektive Anamnesen gegeneinander gehalten, so wäre von Anfang nur die Eventualität in Betracht gezogen worden, daß eine psychogene Aufpfropfung auf eine chronische organische Schwerhörigkeit vorliegt, eine Aufpfropfung, die ihrerseits aus einer sehr schweren traumatischen Einwirkung auf beide Trommelfelle sich ableitete. Es erscheint nicht wunderbar, dass ein durch chronisch-organischen Prozess geschwächtes und richtiger Apperzeption seit Jahrzehnten entwöhntes Gehör in seiner funktionellen Leistungsfähigkeit durch ein schweres mechanisches Trauma (Ruptur usw.) relativ mehr betroffen wird als ein vorher gesundes. Auch ohne die Annahme eines Einschlags von bewusstem „Nichthörenwollen, -können" erscheint das schlechte Hörvermögen aus der chronischen Resignation auf die apperzeptive Unzulänglichkeit und der überwertigen Idee der Unmöglichkeit restloser Restitutio ad integrum, die durch die vorübergehende organische Schädigung gefestigt war, ebenso verständlich wie die Restitutio zum Status quo ante durch die höchste Suggestion des Geheiltwerdenmüssens.

Diese hat sehr grosse innere Widerstände seitens des Mannes überwinden müssen, die nur ganz allmählich durch fortgesetztes Wiederansetzen der Suggestion in schleichender Weise sich überwinden liessen. Er verhielt sich dabei ausserordentlich stumpf und eigentümlich gleichgültig in einer Weise, die am ehesten als "Dickfelligkeit" za bezeichnen wäre. Sein ganzes mimisches Verhalten bei der Kur, bei der alle „Register" zwischen ,sanft" und „,stark" gezogen wurden, war regungslos, geradezu starr, und doch versteckte sich hinter dieser aus Unzugänglichkeit und Unbeeinflussbarkeit durch sensible wie sensorische Reize und motorische Schwerfälligkeit gepaarten Starre eine gewisse Renitenz und Widerstrebigkeit. Hinter der standes- und stammesmässig sehr charakteristisch gefärbten ,widerhaarigen" Indolenz stand- erfühlbar - nun gerade gar.kein bewusstes Nichtwollen, sondern die schleichende Idee der Unheilbarkeit der Hörschwäche, mit der sich sichtlich die geistige Persönlichkeit nicht bloss abgefunden, sondern in überwertiger Weise identifiziert hatte. Anch nach der Wiederherstellung des früheren Hörvermögens durch die Behandlung war diese überwertige Invaliditätsidee - vor Jahrzehnten hat der „Ohrenprofessor" die Unheilbarkeit festgelegt, als 0 (!) wird die Besserung nicht sicher vorhalten! - nicht überwunden, sondern wurde heimlich noch mit einem gewissen hypochondrischen Stolz vorgebracht. Die unauffällige Beobachtung des Mannes im freien Verkehr, besonders mit seiner ihn oft besuchenden Frau nach der Kur ergab, dass all die geschilderten Züge nur die unerbebliche Steigerung seines konstitutio- 
nellen Wesens und Charakters bedeuteten. Auch im sprachlichen Verkehr mit seinen Angehörigen verhielt er sich im Prinzip vor wie nach der Kur, d. h. er bot völlig ungekünstelt das psychische Verhalten des chronisch Schwerhörigen mit seiner monotonen, dabei etwas leisen Sprechweise, mit den reflektorischen Einstellungsbewegungen des Kopfes nach der Seite des hörfähigeren Ohres, den resignierten Gesichtszügen usf. Die psychogene Aufpfropfung war also ausschliesslich, wie nur möglich auf eine Verminderung der Hörweite, vornehmlich unter den Bedingungen der Hörprüfung beschränkt.

Wenn wir die psychogene Aufpfropfung der Hörschwäche in diesem Falle nach ihrer psychologischen Struktur begrifflich kurz umschreiben wollen, so würden wir vielleicht am richtigsten von einer apperzeptiven Untererregbarkeit sprechen und als Ursachen im allgemeinen die konstitutionelle Stumpfheit, im besonderen die hypochondrisch gefärbte Idee der Gehörsinvalidität heranziehen.

Anhangsweise sei hier nur noch erwähnt, dass die ermittelte Anamnese zu einer neuen Auffassung der Armstörung geführt hat: Sehr viel wahrscheinlicher als eine Schädigung des Ulnaris (gerade des Ulnaris!!) durch die Esmarch'sche Schlanchkompression bei der ersten Operation. ja fast erwiesen ist, dass durch die in der Kindheit erlittene Ellbogenfraktur eine geringe Invalidität des Ulnaris hervorgerufen wurde, die aber aus bäuerlicher Indolenz gar nicht in Anrechnung gebracht worden ist. Eine gewisse Zyanose der Hände ist hier physinlogisch, die Gefühlsstörung wurde gar nicht bemerkt, die allein neurogene Beweglichkeitsbeschränkung des 5. Fingers kam praktisch nicht als Ausfall in Betracht. Daher dann die Autopsie in vivo nichts ergab und nur sekundär den negativen Behandlungserfolg zeitigte, dass aus Scheu vor Dehnungsschmerzen in der langen Operationsnarbe eine Schonungsbeschränkung der Strecker eintrat und sich fixierte. Die zweite Möglichkeit ist die, dass trotz negativen, autoptischen Befunds durch den (röntgenologisch seinerzeit in Spatium interosseum antebrachii gefundenen und extrahierten) Splitter mikroskopische Veränderungen am Ulnaris, d. h. der Fasern zn Inteross. 4./5. hervorgerufen wurden. Eine weitere Frage ist es, wie die Erscheinung zu erklären ist, dass die alktive Adduktion des 5 . Fingers nur gelingt, wenn passiver Widerstand in der Adduktionsebene geleistet wird. Sicher ist am Interosseus eine neurogene Läsion. Trotzdem könnte diese Frscheinung ebensowohl neurophysiologisch als ideoggen erklärt werden. Man analysiere an sich die vollkommen verschiedenen Beweglichkeitsemptindungen, die man hat, wenn man den 5 . Finger rein aktiv gegen die ,freihändig" fest einander adduzierten linken 2.--- Finger ebenfalls adduzieren will, und wenn man diese geschlossen mit der rechten Hand in der Adduktionsebene nach dem 5 . Finger hin kraftvoll presst, den $\check{s}$. Finger aber nur mit Nebenkraft adduziert, richtiger sich diesen adduzierend vorstellt.

Eine besondere Nuance gewinnen Zustände reaktiver Stupidität bei leicht debilen Schwerhörigen durch das Hervortreten eines stärkeren affektiven Moments, das sich in verschiedenen Richtungen geltend machen kann. Als wesentlich in dieser Beziehung müssen wir im psychischen Zustande der 
folgenden Beobachtung die Erregungsspannung der Erwartung heranziehen.

Beobachtung 19. Pf., geb. 1878, Steinhauer.

Waisenhäusler. Im 19. Lebensjahre platzte ihm beim Pistolenschiessen das linke Trommelfell (er fiel vor Schreck auf den Kopf). Als er einige Wochen später sich einen Zahn ziehen liess, habe der Arzt, dem er über Ohrschmerzen klagte, dies festgestellt. Von da ab Schwerhörigkeit links.

1900 aktiv. Dezember entlassen wegen Schwerhörigkeit/Kopfschmerzen (Oktober bis Dezember im Lazarett).

12. 9. 1916. Eingezogen. Während der Ausbildung hatte er nach seiner Angabe deswegen viel Schwierigkeiten: Der Feldwebel usw. sagte ihm immer, er solle nicht nach dem Mrnd sehen: Kommandos, die er nicht verstand, vollführte er nur auf dem Wege der Nachahmung der Kameraden usw.

5. 10. Wegen rheumat. Besehwerden im Nacken Krankmeldung. 10. 10. Eriegslazarett J. zur Ohruntersuchung. „Uebertreibt seine Schwerhörigkeit offensichtlich stark. Dieselbe Aufforderung oder Frage mehrmals in gleicher Stärke wiederholt, führt fast immer zn einer Reaktion, anch wenn jegliche Zeichenverständigung streng vermieden wird. Der Kopf wird etwas gebeugt gehalten, passiven Bewegungen starker Widerstand entgegengesetzt. Stumpfer, unbeweglicher Gesichtsausdruck. Spontane Bewegungen ziemlich spärlich." Arterie rigide. Puls 120, gespannt. Aorta o. B.

20. 10. Gesichtsausdruck dauernd depressiv, stumpf. Kopf danernd geneigt, Hörfähigkeit wechselnd. Oft hört er alles, wenn man auch leise spricht. Sobald man ihn zur Rede stellt, wiederholt er immer im glaichen Tom dieselber Erzählungen von seinem früheren Unfall usw.

Versuch nach Kaufmann: ,.. Nach 1/2 Stunde wird er dazu gebracht, den Kopf, wenn auch langsam, nach allen Seiten zu bewegen und anch leisere Befehle zu verstehen. Der Versuch scheitert aber an dem Alter, Schwerfïlligkeit und Mangel jeder militärischen Disziplin des Mannes."

30. 10. Hörstörung nur ganz selten noch in höherem Masse. Zur Truppe zurïck.

10. 11. Wiederaufnahme im Kriegslazarett: Schwerhörigkeit gebessert.

11. 11. Univ.-Ohrenklinik F.: Trommelfelle o. B.; $\mathrm{c}^{1}$ in Luftleitung nur rechts; vom Scheitel 0; Flüstern 0; Umgangssprache: rechts nahe am Ohr, links 0.

Nervenbeobachtungsstation: „Pf. übertreibt seine Schwerhörigkeit nicht nur hysterisch, sondern durchans bewusst. Man kann sich mit ihm auch auf woite Entfernung durch leise Umgangssprache, auch wenn er dabei nicht vom Munde ablesen kann, ganz gut unterhalten."

18. 11. Nervenbehandlungslazarett B.: Kopfhaltung schief, Kopf aufs linke Ohr geneigt (das komme von dem Beruf, indem man mit dem Hammer am rechten Ohr vorbeischlage). Etwas gespannt-vergrämter Gesichtsausdruck.

Hörprüfung: Rechts Flüstersprache bis $2 \mathrm{~m}$, links 0 , nur lautes Sprechen. Zu Anfang der Untersuchung, wobei er sich merkwürdig indifferent und einen auffallenden Mangel an mimischen Enttäuschungen zeigt. scheinbar völlig taub. Auf 
energische Zurechtweisung (Drohung mit Kriegsgericht) gute Verständigung in mittellauter Limgangssprache, allerdings bei der Möglichkeit, dass er sehr viel rom Munde abgelesen hat.

21. 11. Bei heutiger Visite wieder scheinbar taub. Auf Vorhalt der Bestrafungs-

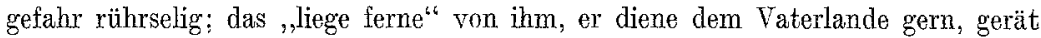
in Weinen (Puls 108!).

Beschwerden: Wenn er was Festes auf dem Kopf habe (Mütze!) drücke es den Kopf aufeinander; ,wenn die Witterung kommt, ist es, wie wenn etwas vor das Ohr gehängt wird ${ }^{: C}$. Mitunter Schwindelanfälle.

Wesentliche Besserung durch Kur (Stichelung der Ohrumgebung mit Nadel, Suggestivspritze und einigen kurzen, galvanischen Strömen), danach sehr dankbar. In den nächsten Tagen gibt er an, er sei so erregt (aus Freude!), dass er so gut höre, es sei ihm ganz merkwürdig, neu im Gefühl" und zumute, es sei besser als jemals seit 1900 . Wenn es nur vorhalte!

9. 12. Hörprüfung (wiederholt): Rechts Flüstersprache für Sätze in $\pm \mathrm{m}$, links, lauteste Umgangssprache wird nur als unbestimmte Schallwirkung empfunden, vielleicht handelt es sich nur um die Lindeutung der Empfindung der Lufterschütterung in Schallempfindungen.

Nachträgliche Ermittlungen: 1. des Laz.-Krankenblatts 1900: Damals eigene Angabe: Seit 1893, seit Sturz auf den Hinterkopf im Steinbruch, Verschlechterung einer vorher schon bestehenden Schwerhörigkeit. Obj. (26. 10. 1900): L. < r. Trommelfell blass, eingezogen, äusserer Gehörgang gerötet. Rechts (? Ref.) Umgangssprache $20 \mathrm{~cm}$, links (? Ref.) $1 / 2 \mathrm{~m}$.

30; 10. 1900. Zweimal ,ertappt", dass er leise Fragen/Aufforderung richtig verstand. 10. 11. Links Trommelfell blass, Membrana flaccida leicht gerötet. 27. 11. Achtet deutlich auf Mundbewegungen des Sprechers; so zu erklären, dass er auch leiseres Sprechen hört. Links Trommelfellbefund dauernd derselbe. Glaubwürdige Hörfähigkeit. Blick etwas unstät. Mundablesen. Umgangssprache rechts 30 , links $60 \mathrm{~cm}$.

Dezember d. u. entlassen nach Anl. 4.21 und C36 Heerordnung. 2. Mannschaftsuntersuchungsliste September 1916: "Taubheit auf dem linken Ohr."

Epikrise: Zweifellos haben wir zunächst diesem Patienten Unrecht getan, wenn wir selbst anfänglich durchaus bewusste Aggravation zugrunde legten, weil seine Reaktionen auf akustische Reize widerspruchsvoll erschienen. Bei eingehender Analyse musste es aber doch für einen Aggravanten ein fast sinnloses Verhalten sein, in leiser Umgangssprache auf weite Entfernung Unterhaltung mit sich führen zu lassen und scheinbar mit einem Schlage nur durch die Drohung mit dem Kriegsgericht von Taubheit zu leichter Schwerhörigkeit überzugehen. Die nachträglichen Erhebungen haben gezeigt, dass er schon 1900 - zu welcher Zeit also die Schwerhörigkeit schon länger bestanden haben muss - während der Lazarettuntersuchung so gut ablesen konnte, dass er auch leise "Fragen und Unterhaltung verstehen konnte. Die schlechten Hörresulate waren also offenbar auf die Indolenz im Ab- 
lesen zurückzuführen, die nach dem psychischen Bilde des Mannes (wie es sich bei eingehender Beobachtung darbot) das Resultat einer eigenartig ratlosen inneren Gespanntheit darstellte. Neben dieser psychischen Abweichung war weiterhin noch eine schwer zu deutende affektive Labilität recht auffällig, deren negativer Einfluss auf die apperzeptive Ansprechbarkeit des Gehörs nicht unberücksichtigt bleiben darf. Das Ergebnis der Suggestivkur, die eine so wesentliche objektive und anch subjektiv so eindrucksvolle Besserung des binaurikulären Hörvermögens, auf dem linken Ohr aber keine nur einigermassen deutliche Veränderung der Funktion erzielte, stimmt mit den nachträglich gemachten objektiven Feststellungen vollkommen überein. Eine chronische Taubheit auf dem linken Ohr hat danach als erwiesen zu gelten. Nach dem Seelenzustande des Mannes drängt sich die Vermutung auf, dass die psychisehe Infektion des gesunden durch das organisch kranke $\mathrm{Ohr}$ auf der Wirkung einer eigenartigen Mischung von ideogenen und affektiven Motiven beruht.

In diesem Zusammenhang scheint mir eine Beobachtung wichtig, welche wir bei denjenigen psychogen Tauben gemacht haben, die seit vielen Jahren oder seit Jahrzehnten in nicht unerheblichem Grade chronisch schwerhörig waren. Einige Tage nach der Heilung ihrer Taubheit traten sie gegenüber dem ihnen vertrauten Pflegepersonale mit der spontanen Bemerkung hervor, dass soweit sie sich rückerinnern könnten ihre Hörfähigkeit noch nie so gut gewesen sei wie nach der Kur. Gerade im Gegensatz zu den übrigen Fällen machte einer unabhängig vom anderen diese subjektive Feststellung so regelmässig, dass wir schliesslich daraus unmittelbar Rückschlüsse auf die Echtheit der chronisehen organisehen Grundlage ihrer Hörstörung ziehen konnten, die dann nachträglich durch die objektiven Erhebungen bei Heimat-, Schulund Militärbehörden usf. voll bestätigt wurden.

In keinem dieser Fälle hatten wir Grund, diese Aeusserung etwa als Pseudologie einer sich vordrängenden Scheindankbarkeit aufzufassen. Noch weniger aber wüsste ich anzugeben, wie eine derartige Aeusserung etwa in den psychologischen Zusammenhang einer bewusst absichtlichen Aggravation - denn nur um solche, nicht um Simulation kann es sich in Anbetracht der zugrunde liegenden organischen Veränderungen handeln - hinein passen könnte. Wenn auch andererseits daran zu denken ist, dass der Affekt der subjektiven Kontrastwirkung zwischen vor kurzem noch bestehender Taubheit und der plötzlich wiedererlangten akustischen Apperzeptionsfähigkeit erinnerungsfälschend wirken kann, so habe ich doch nicht den Eindruck, dass dies subjektive Moment das Entscheidende ist, sondern dass vielmehr ein objektiv zutreffender Zusammenhang von den Leuten aufgedeckt wird. Nach der einfühlenden Analyse der Fälle, in denen ein physisches, sensorisches oder psychisches Trauma zur psychogenen Verschlimme- 
rung einer organischen Dauerschwerhörigkeit bis zur Taubheit geführt hat, ist es mir sehr wahrscheinlich, dass schon vor diesem Trauma der organische Kern einen funktionellen Zuwachs dadurch erfahren hatte, dass diese Leute sich mit der Unheilbarkeit der organischen Ausfälle subjektiv abgefunden und gewohnheitsmässig darauf verzichtet haben, die Reste ihrer Apperzeptionsfähigkeit erschöpfend auszunutzen. Da nun unsere Psychotherapie sie dazu zwingt, verlieren sie nicht bloss die traumatische Aufpefropfung. sondern auch diesen psychogenen Vorschub. Es leistet daher ihr Gehör an Wahmehmungsfähigkeit tatsächlich mehr als jemals vorher. Je weiter bis in jugendliches und kindliches Lebensalter die Ausbildung der organischen Hörstörung zurückreicht, un so mehr tritt dieser Mechanisnus der „Hörverschlechterung aus Nichtgebrauch"i infolge Ausschaltung eines Ohrs aus dem doppelseitigen Hörakt in Analogie zur Amblyopia ex anopsia, - auf die wir ja früher eingegangen sind. -

Als allgemeine psychopathologische Erkenntnis ergibt sich aus derartigen Beobachtungen, dass auf dem Boden des angeborenen Schwachsinns bzw. ,Stumpfsinns" mit in der Kindheit erworbener organischer Schwerhörigkeit reaktiv bzw. situatir voraus unter den besonderen Eindrücken eines Situationswechsels, der bei derartigen Individuen wie ein Chok wirkt, eigentümlich gefärbte Stuporen erwachsen, die sich vor allem in mehr minder vollständiger psychogener Absperrung des Gehörs offenbaren.

Was wir in der vorstehenden Beobachtung als zwar befristeten, dennoch aber über eine längere Zeitstrecke ausgedehnten psychischen Ausnahmezustand kennen gelernt haben, erzeugen wir gelegentlich bei ungebildeten Soldaten mit annähernd gleichen Graden von organischer Schwerhörigkeit aber geringfügigerer Herabsetzung der Intelligenz oder der Affektivität bzw. beider ärztlich unabsichtlich als experimentellen Ausnahmezustand, und zwar mehr minder als „Momentbild“: durch die Hörprüfungen. Wie unsere Erfahrungen lehren, disponieren gerade ländliche Eingesessene des bäuerlichen Standes, die mit rudimentären Schwachsinnsformen behaftet sind, zu solchen Reaktionen. Pathologische Verstärkungen und stammesmässige Differenzen des primitiven Gefühlslebens dieser Nenschenklasse in Verein mit aus abnormer Hirnanlage entspringenden individuellen geistigen Defekten erzeugen mancherlei Nuancen dieses experimentellen Grundvorgangs. Als Beispiel führe ich hier die folgenden Beobachtungen an:

Beobachtung 20. E., geb. 1888. Kaiserstuhler Landwirt.

Mit 6-7 Jahren Ohreiterung auf einem Ohr, wahrscheinlich sei es das rechte gewesen. Der Vater habe ihn deshalb zur Untersuchrng in die Freiburger Ohrenklinik gebracht, weiter sei aber nichts gemacht worden. Nach $^{1 / 4} \mathrm{Jahr}$ sei es spontan 
vergangen. Diesseitige Erhebungen 1. bei der Heimatbehörde bestätigen ,Schwerhörigkeit seit Kindheit rechts, die aber Verständigung mit ihm ermöglichte". Deswegen nicht aktiv gedient. 2. beim einstellenden Armierungsbataillon bestätigen, dass es da ,bekannt war, dass er schon bei Einstellung äusserst schwerhörig war". Nach eigener Aussage habe er in der Kirche nur auf der vordersten Bank hier und da ein Wort verstanden.

3. 2. 1915. Zur Armierung. Befehle seien von Anfang nur so zu ihm gedrungen, dass er sie von seinem Nebenmann abnahm. Seit Anfang 1916 öfters Kopfschmerzen und Schwindel. Nachdem er Angust 1915 nach ärztlicher Angabe links Mittelohrentzündung gehabt habe, die dann Januar 1916 wiederkehrte.

4. 1. 1916. Kriegsbaracke: Hört ganz lautes Sprechen nur, wenn in das Ohr hineingesprochen wird. August 1916 krank gemeldet wegen Darmkatarrh, nach seiner Angabe wegen zunehmender Taubheit rechts, Verschlechterung des Hörvermögens links, im Anschluss an heftigen Schreck durch Granatfener, seit welcher Zeit er auch Beschwerden im Sprechen hatte.

18. 8. Ver.-Lazarett Sch.: ,Links Trommelfell entzündet."

Oktober 1916. Ohrenstation: Rechts Trommelfell fächerartig, links o. B. Rechts lautestes Schreien nicht; links laute Umgangssprache in 3-10 cm. C 128 vom. Scheitel njcht gehört, rechts weder Knochen- noch Luftleitung. Links Rinne bei sehr stark verkürzter Luft- and Knochenleitung. Obere Tongrenze links leicht herabgesetzt, rechts überhaupt 0 . Taubheit rechts, hochgradige Nervenschwerhörigkeit links.

14. 10. 1916. Ohrenklinik H.:

$$
\begin{array}{lll}
\text { R. } & & \text { L. } \\
\varnothing & \text { c W } & \varnothing \\
\varnothing & \text { cL } & \varnothing \\
\varnothing & \text { FI. } & \varnothing
\end{array}
$$

Mit verbundenen Augen c L links $60^{\circ}$ gehört, wahrscheinlich noch erheblich länger, denn wenn die Stimmgabel nur ganz leise angeschlagen wird, hört er sie auch noch. Sowie man die Prüfung jedoch anch bei stark angeschlagener Gabel länger fortsetzt, will er sie nicht mehr hören. Bei Ausschaltung des linken Ohres mit dem „Barany“ werden Fragen in Umgangssprache auf $1 \mathrm{~m}$ prompt beantwortet (Ablesemöglichkeit gering).

Psychiatrische Poliklinik: Hörstörung sicher zum grössten Teil psychogen, die Sprachstörung ganz bestimmt (er könne die Sprache nicht richtig aus dem Hals herausbringen). Spricht aber auch schwere Konsonanten mit Zischlaut im Beginn und der Mitte prompt nach, wenn er sich Miihe gibt. Nach Scheinoperation Angabe, links besser zu hören, objektiv:

$$
\begin{aligned}
& \text { Von L c W } 15^{\prime \prime} \text { auf c W } 50^{*} \\
& " \quad \text { c L } 50^{\prime} \text { " c L } 90^{\circ},
\end{aligned}
$$

Schlussurteil Ohrenstation Heidelberg: „Die Frage, ob die angeblich nahezu vollständige Taubheit durch eine organische Schädigung des Gehörorgans herbeigeführt wird, ist namentlich deshalb schwer zu beantworten, weil er schon früher nicht normal gehört haben will und die Schwerhörigkeit 
nach der heftigen Schallwirkung allmählich zugenommen haben soll. Das stimmt nicht gut zu der Annahme einer rein psychogenen Erkrankung; aber andererseits bestehen alte organischen Veränderungen am Mittelohr und ferner weisen manche gelegentliche Beobachtungen (Unterhaltungen mit Kameraden) darauf hin, dass er die Sprache nicht so ganz schlecht hören kann. Er ist aber offenbar psychischer Beeinflussung nicht leicht zugänglich, so dass die "Scheinoperation" ganz wirkungslos blieb. Doch müssen alle Behandlungsmöglichkeiten erschöpft werden (offenbar ungünstige Einwirkung raffinierter Rentenjäger in $\mathrm{H}$.) daher nach Bärenstein. Die stockende, zuweilen undentliche Aussprache verschiedener Sprachlaute ist kein wohl charakterisiertere Sprachfehler."

4. 12. Nervenbehandlungslazarett B.: Blöder, starrer, hilfloser Gesichtsausdruck. Zu Anfang der Untersuchung fast ständiges Schlucken und Schnalzen mit der Zunge bei forcierter Atmung, Sprache mit nasalem Beiklang, typischer Banerndialekt mit allen Unbeholfenheiten und Schwierigkeiten der Schwachsinnigen dieser Menschenklasse. Auch in der Folge Auffälligkeiten der Sprache aus Mangel an Euarthrie oder der Expressionsfähigkeit aus Gründen der Imbezillität restlos erklärbar, dem psychiatrischen Kenner der Bevölkerung dieser Gegend wohlbekannt. Derselbe Mangel auch an formaler Gebundenheit auch in den Gesten, Mimik, Gang, Haltung, Bewegungen. Allgemeine Schwererregbarkeit anf allen Sinnesgebieten. Gesichtsasymmetrie, linkes Ohr abstehend. Binaurikulär (wobei Neigung, immer das linke Ohr dem Sprecher entgegenzuwenden) nur lauteste Umgangssprache.

Prïfung: Links lauteste Sprache in $5 \mathrm{~m}$, laute Umgangssprache in $1 \mathrm{~m}$. Rechts dasselbe bis $5 \mathrm{~m}$ bzw. am Ohr (offenbar wie links). Bei wiederholter Prüfung gibt er ganz einwandfrei an, dass er so nur via links hört.

Nach einstündiger Kur (Stichelung, Suggestivspritze, galranische Ströme) lauteste Umgangssprache beiderseits (?) in 3-4 m.

Resultate der Hörprüfung vor allém beeinflusst durch die Imbezillität, die apperzeptive Schwäche und Schwerfälligkeit und Examensstuporosität. 7. B. ist es auch durch eingehendste Be- und Umschreibung nicht möglich, ihm klar zu machen, dass er dabei reflektorisch nachsprechen soll; wie er sich verhalten soll, wenn er nur perzipiert, nicht apperzipiert hat usw. Während der mit allen psychologischen Kautelen ausgeführten Prüfung tritt bald mehr das Versinken in ängstliche Frwartungsspannung anf das Reizwort oder auf weitere Therapie oder auf Vorhalten des Arztes hervor; bald mehr steht im Vordergrunde eine ratlose Examensverwirrung oder Verstörtheit mit entsprechenden qui pro quo-Wahlhandlungen, bald mehr Perservieren frïherer Reizworte in bezug auf Inhalt oder Aufgabenart; dazwischen wieder schiebt sich Reiterieren früherer Aufgaben, oder unbewusstes Raten und Zusatzdeuten von unscharf Perzipiertem. Dazu alle möglichen körperlichen Ausdrucksphänomene negativer Gefühlstöne (hochgradige zyanotische Fleckung im Gesicht oder Tachypnoe, Tachycardie), gelegentlich ganz echte Verzweiflung, Schluchzen usw. in kindlicher Art. Aber auch hierbei nichts, was nur einigermassen den Eindruck bewusstwillkürlicher Produktion hervorriefe. Gibt mittags spontan der Schwester an, heute besser zu hören als je seit Kindheit. 11. 12. Ernente Hörprüfung nach mög- 
lichstem suggestiven Zuspruch: Links deutliche Flüstersprache (Zahlen) $10-20 \mathrm{~cm}$, Mittellaute Limgangssprache 2-21/2 m (je nach Geläufigkeit der Worte); rechts lautestes Rufen ins Ohr: "Ich höre nichts." Binaurikuläres Hören besser.

20. 12. Bei allen Prüfungen wie bei Unterhaltnngen mit Vorgesetzten usw. sonst, neigt er ganz unwillkürlich dazu, das linke $\mathrm{Ohr}$ vorzuschieben. Ferner häufig eigenartige, schnalzende Bewegungen und Geräusche mit der Zunge, die am meisten an psychasthenische Verlegenheitsstereotypien erinnern. Als Motiv seiner früheren Tränenausbrüche gibt er in rührend kindlicher Weise an: „Weil er besșer hören müsse und solle als er könne." Unauffällige Beobachtung ergibt, dass er ganz unabhängig von der äusseren Situation stets denselben Grad von Schwerhörigkeit aufweist. Auch im Gebaren, in der Art und Weise des Wiederfragens bietet er psychisch das Bild des echt Sehwerhörigen. 12.1.1917. Rechts taub, bei isolierter Prüfung nur schainbar hier Perzeption. Links Flüstern $20 \mathrm{~cm}$ für Zahlen, $10 \mathrm{~cm}$ für Worte, sonst Weber links. Rinne links negativ.

Eine nachträgliche genaue Exploration seines sehr verständigen und glaubwürdigen Vaters ergibt: Im 1. Lebensjahr hielt man ihn für taubstumm, erst mit 3 Jahren lernte er sprechen; er behielt aber immer einen Sprachfehler. Im 6. Jahr brachte der Vater ihn nach der Ohrenklinik wegen Ohreiterung rechts; es wurde gesagt, es sei nicht riel mehr zu machen. In der Schule wurde er immer, weil sehr schwerhörig, in die vorderste Bank gesetzt, Lehrer und Eltern brachten ihm etwas Ablesen bei. In die Kirche ging er nur, ,weil es der Glaube gebot"; verstehen konnte er nie etwas von der Predigt. Links wurde nie eine Ohreiterung beobachtet. Im Alltag verständigte E. sich mehr durch Ablesen als durch Hören.

Epikrise: Als erwiesen hat zu gelten, dass der Mann seit seiner Kindheit erheblich schwerhörig ist - ganz einerlei ob dies durch den Mittelohrbefund eine Erklärung findet oder -- wie tatsächlich -- nicht. Auf diesseitige Mitteilung meiner Auffassung schreibt mir denn anch Prof. Kümmel, dass es danach ,wohl schliesslich am nächsten liegt, anzunehmen, dass doch eine organische Hörstörung auf dem einen Ohre vorliegt - obwohl er sich dazu sehr schwer entschliessen könne, da keine ausreichende Erklärung für eine solche organische Schädigung vorhanden sei." Die ganze Fragestellung des Falles verschiebt sich somit dahin, wie hoch die Prozentsätze der Schwerhörigkeit anzusetzen sind, die 1. auf seit Jahren bestehenden organischen (mikroskop.?) Veränderungen am Mittel- oder inneren Ohr, 2. auf eventuell im Kriegsdienst erworbener Veränderung gleicher Art, 3. auf psychogener Aufpfropfung beruhen. Zweifellos bietet die Analyse der Art dieses Psychogenen Schwierigkeitell. Von allen Fällen tritt hier der Anteil von Schwachsinn in allgemeinstem Sinne besonders aber eines wenn man so sagen darf, vor allem ,sensorischen" oder ,apperzeptiven Schwachsinns" bei den Resultaten der Hörprülung am deutlichsten hervor. Durch ihn wird die relativ einfache Prüfung zum komplizierten psychologischen Experiment. Sehr richtig sagt Prof. Kümmel: „Es müssen doch komplizierte psychische, einer Psychose verwandte Zustände mitspielen." Affektive Vor- 
gänge der verschiedensten Richtung greifen hier in kompliziertester Weise, wie oben geschildert, in den Wahrnehmungsvorgang hinein und ersehweren oder stören den Verlauf von der Perzeption zur Apperzeption, so dass alle denkbaren ,akustischen (sensomotorischen) Fehlhandlungen“ resultieren. Unter diesen beanspruchen besonderes Interesse die verschiedenen Arten von "Vorbei-nachsprechen". Einzelne Stellen der Prüfungsprotokolle erinnern fast an die Protokolle komplizierter Fälle von sensorischer oder Leitungsaphasie.

Eine ganze Reihe von Möglichkeiten derartiger Fehlleistungen sind hier verwirklicht. Neben der einfachen Perseveration das mnestische Zurückgreifen auf klangassoziativ verwandte Zahlenreihen, dann Umdeuten und zuletzt einfaches Raten; ferner alle Kategorien des nichtwillkürlichen bzw. nicht gedanklichen Vorbeiredens. Schliesslich aber scheint - was bei den Aphatikern gar nicht in Betracht kommt und nur bei differentem Hörvermögen zweier aus verschiedenen Ursachen verschieden schlecht hörender Ohren möglich ist - nicht selten ein einzelnes Fehlergebnis dadurch bedingt zu sein, dass entweder eine psychosensorische Interferenzerscheinung oder ein unwillkürlicher „Aufmerksamkeitssprung" zwischen beiden Hörfeldern das Ergebnis der (monaurikulären) Prüfung des generell schlechteren Ohres stört.

Gehört schon für den Gebildeten eine gewisse Eingestelltheit und psychologisches Verständnis dazu, um in jedem Einzelfalle ein "Wissen" zu ermöglichen, welches zweier different hörfähiger Ohren bei wechselndem Ort der Schallquelle auffasst, so wird es nicht wunder nehmen, wenn bei einem allgemein sensorisch so schwerfälligen und verwirrbaren Menschen (sensorischer Typ des Schwachsinns!) geradezu reflektorisch aus dem erzwungenen Willen, überhaupt ein Resultat herauszubringen, jede Prüfungsmethode (sogar eine solche, welche einen wirklich schalldichten Abschluss des besseren Ohrs ermöglichen könnte) ein besseres Seheinresultat erzeugt als wie es dem wirklichen Hörvermögen des schlechten Ohrs entspricht. Es kommt also unwillkürlich und bona fide ein „Mokel"-Ergebnis heraus, das etwa grob genommen dem Verhalten eines peripher Gelähmten gleicht, der mit seinen Synergisten erzielt, was von dem gerade geprüften Agonisten verlangt wird.

Zu diesen allgemein-psychologischen Faktoren kommt nun bei vorliegendem Falle ein rassenpsychologisehes Moment hinzu. Wer aus örtlichen Gründen mit der Psychologie des nicht direkt schwachsinnigen Bauern dieser Gegend zu tun gehabt hat, weiss, dass die Schwierigkeiten der Verständigung mit den Vertretern dieser Sondermundart schon für einen im verwandten Dialekt Heimischen oft so gross sind, dass es ,zum Verzweifeln ist". Dies fällt in vorliegendem Fälle besonders ins Gewicht. Dieselben „Volksstamm- 
erwägungen" kommen bei der Beurteilung dessen in Betracht, was früher als ,ganz bestimmt psychogene Sprachstörung" aufgefasst worden ist. Zweifellos trifft die Auffassung Kümmel's, dass es sich da ,nicht um einen wohl charakterisierten Sprachfehler" handelte, das Richtigere. Auch hier belehrt uns die Vertrautheit mit der Dialektnuance der Gegend, aus der der Mann stammt, eines Bessern. „Psychogen" im üblichen Sinne trifft die Sache nicht, vielmehr liegt ein dispositioneller Mangel an Euarthrie besonders bezüglich der Lippenlaute zugrunde, der nur durch die vergeblichen Versuche, gegenüber Vorgesetzten usw. sich ins Hochdeutsche zu "schrauben", aus seiner mehr minder ausgesprochenen Latenz gehoben wird. Wenn die Anspannung aller innervatorischen Kräfte durch die militärische Nötigung gerade beim Nachsprechen normale Resultate liefert, so ist das eben damit zu erklären, dass von allen individuellen und generellen Sprechleistungen das Nachsprechen selbst komplizierter Worte das relativ leichteste ist, während gerade ein guter Spontanwille zum Ueberwinden solcher individueller Dysarthrien in der freien Sprache mit Vorgesetzten eher störend auf das Gelingen einer guten Sprechweise wirkt. Zusammenfassend dürfen wir diese Funktionsstörungen also wohl am richtigsten als psychogenen Zusammenhalt organisch fundierter Funktionsabwandlungen unter neuartigen äusseren. Bedingungen charakterisieren. In engerem Sinne dürfen wir sie schon kaum mehr hysterisch nennen, wenn sie auch psychogen in dem anderen Sinne sind, dass sie durch rücksichtsloseste Psychotherapie sich auf ein Jinimum reduzieren liessen.

Beobachtung 21. Kr., geb. 1891, Landarbeiter, verheiratet, 1 Kind.

Kindheit usw. 0. B. In Schulzeit längere Zeit oft Kopfschmerzen mit Erbrechen. Mit 8 Jahren Mittelohrentzündung mit Eiterung bis zum. 11. Jahr rechts, sehr viel stärker wie links. Seitdem schwerhörig. Der Vater („Kgl. Bahnbeamter") schreibt: „Dies wurde uns oft vom Lehrer bestätigt." 19113 Wochen bis August Grenadier, er liess sich gern einstellen, obwohl er schwerhörig war, dann deshalb entlassen.

Febrnar 1915 eingestellt, Juni 1915 ins Feld, einmal Hitzschlag. Januar 1916 wieder ins Feld. 26. 5. 1916 durch Granatplatzen in seiner Nähe zu Boden geschleudert, ohne Bewusstlosigkeit. 27. 5. Kriegslazarett: Diagnose: Linke GesichtsHalsseite zeigt multiple Granatsplitterverletzungen: eine $5 \mathrm{~cm}$ lang in der Tiefe 2 Querfinger vom Kopfnicker, Nasenspitze zerquetscht. Ganze linke Kopiseite mit dicker Schmutzkruste bedeckt, auf dem Boden einer Verbrennung 2. Grades Gehörvermögen aufgehoben.

4. 6. Venöse Blutung aus der Halswunde. 10. 6. Rechtes Trommelfell: Leichte Injektion des Hammergriffs, links starke Eiterung, ,nicht übersichtlich". 16. 6 . Angina, besonders links. 22. 6. Linkes $0 \mathrm{hr}$ trocken.

Chirurgische Station H.: Wunden nicht ganz verheilt. 27. 6. Linksseitiges Erysipel bis über Kopfschwarte, hohes Fieber, delirante Züge. 8. 7. Abgeklungen. 
17. 7. Ohrenambulanz: Beiderseits sehr starke Schwerhörigkeit. „Akustikusaffektion? Funktionell?:"

20. 7. Ohrenstation: Rechtes Trommelfell leicht getrübt, eingezogen. Linkes Trommelfell, sowait sichtbar ohne Entzündungserseheinungen. Links Tonsillitis. Leichte Rhinolalia aperta. Mehrere lange Narben um linkem Ohr herum. Ekzem. Ablesevermögen, trotz Teilnahme am Ablesekurs, gering.

$\mathrm{R}$.

L.

$\begin{array}{ccc} & \text { c S } & \\ 100 & \text { c W } & 40 \\ 120 & \text { c L } & \\ \text { ad conch Flst. } & \varnothing\end{array}$

28. 8. Trommalfell eingezogen, hinten oben verdickt. Tuben frei.

16. 9 .

$\begin{array}{rcr}R . & \text { } & \mathrm{L} . \\ 85 & \mathrm{c} \mathrm{S} & \\ 145 & \mathrm{cW} & 50 \\ \varnothing ? & \mathrm{c} \mathrm{L} & 130 \\ \varnothing ? & \text { Elst. } & \varnothing\end{array}$

Leiseste Konversationssprache beiderseits über $5 \mathrm{~m}$ bei abgewandtem Gesicht durchgeführt.

27.9. Konversationssprache: Rechts 0,6, links ad couch. 14. 10. Rechts $2 \mathrm{~m}$, links $0,5 \mathrm{~m}$.

30. 10. Ohrenklinik: Scheinoperation usw., keine Besserung.

8. 11.

$\begin{array}{rcc}\text { R. } & & \text { L. } \\ & \text { c S } & \\ 100 & \text { c W } & 90 \\ 170 & \text { c L } & 160 \\ \text { ad conch. Flst. } & \varnothing \\ 12 \mathrm{~m} & \text { Konv. } & 12 \mathrm{~m}\end{array}$

17. 11. Nach Behandlung mit starken galvanischen Strömen Flst. beiderseits am $\mathrm{Ohr}$. Konversationssprache rechts $1 \mathrm{~m}$, links $2-3 \mathrm{~m}$.

18. 11. Leise Konversationssprache beiderseits $4 \mathrm{~m}$.

Schlussurteil Ohrenstation Heidelberg: „Zweifellos ist das linke Ohr organisch verletzt worden und hat geeitert, jetzt alles vernarbt. Wenn auf diesem $\mathrm{Ohr}$ eine Ertaubung also auch nicht ganz ausgeschlossen erscheint, so ist es doch wenig wahrscheinlich. Rechts ist offenbar nie eine Trommelfellverletzung dagewesen und eine organische Läsion geràdezu unwahrscheinlich. Anfangs ist offenbar nicht das Nötige der psychischen Beeinflussung geschehen ... so die Krankheitsvorstellung fixiert. Deshalb bisherige Behandlungsmethode erfolglos. Man könnte annehmen, dass ein organisch bedingter Anteil der Schwerhörigkeit schuld sei, wenn psychische Beeinflussung nur so unvollkommenen Erfolg erzielte. Das ganze Verhalten K.'s spricht aber dagegen, dass eine nennenswerte organische Hörstörung überhaupt vorhanden; namentlich steht das gute Gehör für Stimmgabel in gar 
keinem Verhältnis zu dem sehr schlechten für Sprache besonders Flüsterstimme, wenn sich auch durch keine Hörprüfung das Vorhandensein eines besonderen Hörvermögens für Sprache hat nachweisen lassen. (Nachträgliche briefliche Mitteilung [13. 12.] ,feste Ueberzeugung, dass eine organische Störung überhaupt nicht vorliegt").

Nervenbehandlungslazarett B.: Narben wie früher, leichte Zyanose der Hände und Füsse. Puls 80 , nach 10 Kniebeugen 120, sonst neurologisch 0 . B. Hörprüfung: Rechts laute Umgangssprache auf $3 \mathrm{~m}$, Flüstersprache $20 \mathrm{~cm}$; links laute Umgangssprache auf $3 \mathrm{~m}$, Flüstersprache 0, Uhr anf keine Weise gehört (Stirn usw.). Kitzelreflex am $0 \mathrm{hr}$ rechts 0 , links sehwach. Ueberhastete, nasal gefärbte, abgehackte und etwas undeutliche Sprache (angeblich seit Jugend), Gesichtsausdruck starr, etwas hilf- und ratlos, leicht stupide, zuweilen blödes Lächeln. Geringe Mimik, schlaffes Wesen. Keine Intelligenzdefekte an sich. In der Unterhaltung schon tritt deutlich hervor, dass es sich um keine reine Hörstörung, sondern daneben um eine psychisch bedingte Störung der Auffassung und Aufmerksamkeit handelt. Fragen, die ein neues Thema anschneiden, werden im Flusse des Gesprächs meist überhört, auch wenn sie sehr laut gestellt werden, während mitunter ganz leise gestelite die in Zusammenhang mit dem Thema stehen, apperzipiert werden.

6. 12. Behandlung: Stichelung, Einspritzung, galvanischer Strom, Brüskierung und Verbalsuggestion usw. Nach 2 Stunden nur geringe Besserung: Flüstersprache nur dicht am Ohr, Ungangssprache ungleich bis auf $5 \mathrm{~m}$ beiderseits (?).

7. 12. Nachprüfung: Ausgesprochener Angststupor mit innerlicher Erregtheit. Nach tunlicbster suggestiver Ausschaltung dessen: Zahlen in mittellauter Umgangssprache rechts bis $3^{1} / 2$, links bis $3 \mathrm{~m}$, kurze Sätze deutlich schlechter. Vom ersten Augenblick der Prüfung tritt hier Vorbeiantworten in bisher noch selten beobachteter Reinheit hervor. Doch auch dabei macht eingehende Einfühlung in sein ganzes Gebaren es fast zur Sicherheit, dass das wesentliche Motiv dieses Vorbeiredens in der Paarung von Angst mit dem Willen besteht, zu dokumentieren, wenn er überhaupt etwas (Geräusche) perzipiert hat.

11. 12. Bei gleicher Prüfung durch die Krankenschwester untermittellante Lmgangssprache rechts in $3^{1} / 2$, links in $2 \mathrm{~m}$.

20. 12. Kommt, um Weihnachtsurlaub zu erbitten. Bei der Hörprüfung wird gesprächsweise möglichst obenhin der Schwester gesagt, dass vom Ergebnis die Urlaubsgenehmigung abhänge. Links Flüstersprache (leise) Zahlen bis $10 \mathrm{~cm}$. Leiseste Umgangssprache bis $2,5 \mathrm{~m}$.

Bei 2,5 m folgendes Nachsprechen: 95:33, 88: 86, 77:97, 50:15, 23:24, 23: 25, 23:33, 57: 35 . Haus: 4, Baum: 7, Heim: 11 , Bild: 5 , wie lange Soldat?: 37, wiederholt: 35, Beruf?: 35, Urlaub: Kr üger Krüger, Jeserich (Geburtsort): 39, Heidelberg (wiederholt): 34, Ohrenklinik: 94, Bild: 5, Baum; 12, Urlaub: 4, Urlaub: 6 . Im Verlaufe dieser Reihe wird ihm wiederholt vorgehalten, dass er ja immer Zahlen höre, während Worte vorgesprochen seien. Dann werden kurze Fragen gestellt und dabei der Abstand variiert: (Sind Sie verheiratet?) in $1 \mathrm{~m}$. (Haben Sie Kinder?) in $2,5 \mathrm{~m}$. (Wie alt ist Ihr Kind?) 5 mal wiederholt aus Entfernung zwischen 2,5 und $1 \mathrm{~m}$, beim 5 . Male + . Längeres Fragen in $1 \mathrm{~m}$. 
Rechts leise Umgangssprache bis $2,5 \mathrm{~m}$, auf einzelne Fragen wieder Zahlen nachgesprochen, z. B. (wann zuletzt zu Hause?): 64 . Flüstersprache wie links.

Epikrise: Das psychische Bild des K. während der ganzen Untersuchung besteht aus einer Mischung von Versumkenheit in die Aufgabe, die gelegentlich ganz tief bis zu stärkster Scheinunaufmerksamkeit sich steigert, und hochgradiger akustischer Aufmerksamkeitseinengung nit dem Unterton einer gewissen ängstlich gespannten Erwartungsspannung und -erregung. Schon nach einigen Minuten beträgt die unauffällig an der stark hebenden Karotis gezählte Pulsfrequenz 120, das Gesicht ist gerötet, die Augen blicken starr geradeaus, die sonst nur leicht dunkelroten Hände zeigen tiefe Zyanose, die sich auch auf die Unterarme ausdehnt. Besonders auffällig ist, dass die Versuche, ein Maximum von Apperzeption durch psychische Beeinflussung der verschiedensten Art -- von Zureden bis zu starken militärischen „Brustton" zu erzielen - im Seelenzustande und auch in den ,,körperlichen Ausdruckserscheinungen" keinerlei Aenderung hervorrufen. Trotzdem ihm in den versehiedensten Formen zum Bewusstsein gebracht ist, dass er am anderen Tag auf Urlaub nur fahren dürfe, wenn es mit dem Gehör besser gehe, ist das Resultat am 22. doch eher schlechter. Charakteristisch ist bei der heutigen Prüfung, dass er wiederholt, wenn auch nicht ganz richtig nachspricht, als man versehentlich beim Einsprechen in leisester Flüstersprache mit dem Arm leicht an ihn stösst, was er ohne dieses Signal nicht tut. Im übrigen genau dasselbe psychische Bild. Unauffällige Beobachtung ergibt ausser seiner grossen Umständlichkeit Schwerfälligkeit und auch ausser akustischer Auffassungserschwerung im freien Verkehr mit den Kameraden keinerlei hysterische Allüren, oder gar Fingerzeige auf bewussten Krankheitswillen. Auch seine mangelhafte Fähigkeit vom Mund abzulesen, beruht sicher nur auf Nichtkönnen. Alles lässt erkemmen, wie gespannt er sich Mühe gibt, ,dahinterzukommen". Auch sein gelegentliches Verhören in der gewöhnlichen Unterhaltung zeigt das Falschhören des echt Schwerhörigen.

In dem Schlussurteil Prof. Kümmel's wird die Annahme eines nennenswerten organischen Anteils der Hörstörung namentlich durch die Unstimmigkeit zwischen den Resultaten der Stimmgabel- und der Sprachprüfung, besonders mit der Flüsterstimme, entliräftet. Dabei scheint mir der Unterschied zwischen der relativen psychologischen Kompliziertheit des psychischen Vorgangs: Sprachlautapperzeption-Nachsprechen gegenüber der Einfachheit der Empfindung: Klang übersehen, der durch den Schwachsinn an sich schon etwas, durch den geschilderten psychischen Ausnahmezustand der Prüfung aber ganz erheblich gesteigert wird. Eine Diskrepanz zwischen der Reaktion auf Flüsterstimme und auf Umgangssprache ist zudem hier nie hervorgetreten. Entscheidend in der Frage ist aber die nachträgliche Feststellung bei seiner Kompagnie, dass der Mann bei der militärischen 
Einstellung. am 19. 2. $15 \mathrm{Fl}$ x. nur in 1,5 , l. in $1 \mathrm{~m}$ hörte, dass also sicher eine organische Dauerschwerhörigkeit seit vielen Jahren, wohl seit Kindheit besteht. Die Fragestellung verschiebt sich also auch hier dahin, wie die Verschlechterung von $1-1,5 \mathrm{~m}$ auf $5-20 \mathrm{~cm}$ zu erklären ist. Dass die schwere Gewalteinwirkung durch Granatexplosion mit sekundärer Eiterung (Erysipel) am Trommelfell auch ohne jeden psychogenen Einschlag einen mehr minder hohen Prozentsatz dieser Verschlechterung bedingen kann, ist wohl sicher. Der dann bleibende, organisch unerklärte Rest wird wohl ohne Künstelei auf Examensfaktoren zurückgeführt werden dürfen. Der Widerspruch, der darin liegt, dass die Differenz der Hörfähigkeit zwischen rechts und links in keinem Verhältnis steht zu der Tatsache, dass das von Haus aus schlechtere (linke) $\mathrm{Ohr}$ auch das traumatische allein schwer geschädigte ist, wird wohl dadurch gelöst, dass durch die Perzeption des besseren rechten Ohrs trotz möglichst schalldichten Verschlusses das Hörvermögen des schlechteren scheinbar gehoben wird, so dass also die Differenz heute etwa so ist, wie bei seiner Einstellung.

In dem ganzen Bilde hat sich bei eingehender Prüfung darauf nur ein Moment finden lassen, das auf Begehrungsvorstellungen zurückführbar sein könnte. Erst bei wiederholter Exploration gab er anch leichten Ohrenfluss auf dem nicht traumatisch geschädigten $\mathrm{Ohr}$ in der Kindheit an, während er bis dahin immer nur von der Ohreiterung des rechten Ohrs in jener Zeit gesprochen hatte. Bei oberflächlicher Betrachtung konnte es ziemlich bestimmt so klingen, als ob rechts alles von Jugend her bestehe, links alles allein durch die verschiedenen Folgen der Granatexplosion entstanden sei. Aber auch hier bin ich nicht sicher, ob das nicht auf unbewusste Erinnerungsfälschung bzw. unbewusstes erinnerungsmässiges Nichtbeachten einer seiner Zeit nicht sehr eindrucksvollen Erkrankung zurückzuführen ist. Unsere Annahme wird nachträglich durch den glücklich ermittelten früheren Einstellungs- und Entlassungsbefund (Garde-Gren.-Reg. von 16. 10. bzw. 4. 11.) 1911 bestätigt:

Einstellung: $H .=7 \mathrm{~m}$, links Trommelfell glänzend, unübersichtlich, rechts rötlich, nur zum Teil übersichtlicher Hammergriff.

Angabe: Seit 23. 6. 1911 (also vordienstlich!) durch Messerstich an der Stirn gehörleidend za sein.

Entlassung: Beide Trommalfelle trübe, glanzlos. Flsp. beiderseits $1 / 2 \mathrm{~m}$, Tuben fast undurchgänglich; nach Kathetrismus keine Besserung der Hörfähigkeit. Obere Tongrenze R. L. 3,5 (Galtonpfeife), Weber nach rechts (?). Rinné R. + L. +. Untere Tongrenze R. V. 2 h ebenso. Diagnose: „Beiderseitige hochgradige Schwerhörigkeit durch Erkrankung des schallperzipierenden Apparats, d. u., 20 pCt."

Zu den nachträglich von mir gemachten Erhebungen über das Hörvermögen der Fïlle 20 u. 21 zur Zeit der militärischen Einstellung während oder 
vor dem Kriege schreibt mir nachträglich Kümmel: „Sehr interessant ist mir, was Sie mir über den früheren Zustand des Gehörs bei $\mathrm{E}$. und $\mathrm{Kr}$. mitteilen. Die Angabe, dass $\mathrm{Kr}$. auf dem linken Ohr nur $1 \mathrm{~m}$, auf dem rechten $1,5 \mathrm{~m}$ weit Flüsterstimme bei der Einstellung gehört habe, ist sehr wichtig. Eine solche Hörstörung würde vergleichsweise bei unserer Flüsterstimme etwa eine Hörweite von $40-50 \mathrm{~cm}$ auf dem rechten, und $20-30 \mathrm{~cm}$ auf dem linken $\mathrm{Ohr}$ bedeuten. Von Interesse ist jedenfalls auch bei K., dass er im Februar 1912 eine Trommelfellentzündung gehabt haben soll. Anscheinend ist er damals nur revierkrank gewesen; wahrscheinlich ist aber keine wesentliche Hörstörung übriggeblieben. Die Schwerhörigkeit, die bei $\mathrm{E}$. und Kr. zur Zeit der Einstellung vorlag, lässt sich jetzt nachträglich nicht weiter analysieren. Liesse sich bei den Leuten eine zuverlässige Hörprüfung machen, so wüsste man wenigstens, ob die jetzige Schwerhörigkeit auf das Mittelohr oder auf den Gehörnerven zurückgeführt werden muss; danach könnte man dann ja Vermutungen über die Ursache der früheren Störungen entnehmen. Da nun aber eine verlässliche Hörprüfung alssgeschlossen ist, kann ich gar keine Anhaltspunkte für die Lokalisation der Schwerhörigkeit bei den beiden Leuten gewinnen."

Beobachtung 92. B., geb. 1878, Landwirt und Zimmermann.

Vater war geisteskrank. Mit 16 Jahren Sturz vom. Gerüst, mit Bewegungslosigkeit, 2 Monate im Krankenhaus. Man habe von Gehirnerschütterung gesprochen. Seitdem Anfälle.

Dennoch 1898-1900 Grenadier, auch Manöver o. B. 1902 bei der 1. Uebung im Manöver schoss sein Hintermann eine Platzpatrone an seinem linken Ohr vorbei, er hatte sofort Ohrensausen, tat aber Dienst weiter, weil er nicht daran dachte, dass ihm das zum Nachteil werden könne. 1904/05, 1906/07 und später wiederholt (obj. festgestellt) vom Hausarzt wegen ,chronischer Mittelohraffektion, Katarrh und Sklerose" behandelt.

Obj.: Er wurde 30. 8. 1916 eingezogen, wurde am 28. 9. wegen „Klagen über 6 Anfülle von Bewusstlosigkeit, die sich nach 2 Tage anhaltenden Brustschmerzen für die Dauer von $1 / 2$ Stunde einstellten, namhaft gemacht für Eimweisung in die Beobachtungsstation, wo er 27. 10. bis 5. 12. beobachtet wurde. Damals Verständigung nur durch Schreien mit ihm möglich. Psychogene Tachypnoe, demonstrative Aengstlichkeit, Schreckhaftigkeit. Am 1. Tag unter Erwartung der Visite Stupor, dann einfaches Sich-vom-Stuhlfallenlassen mit nachfolgendem Grimmassieren, Armkrampfen: Alles von „durchaus willkürlichem Eindruck“ (Vorsichtigkeit bezüglich Verletzung). ,Trägt auch seine angebliche Schwerhörigkeit weiter in ostentativer Weise zur Schau. So tut er bei jeder Visite, als ob er den Arzt nicht bemerke, auch wenn er schon an dem Benehmen der übrigen Patienten merken muss, dass dieser anwesend ist." Befund der Ohrenklinik: Trommelfelle ohne Besonderheiten. Die von ihm angegebéne Schwerhörigkeit erscheint nicht glaublich. Nach kräftiger Faradisierung auf dem rechten $\mathrm{Ohr}$ wird er veranlasst, Umgangssprache etwa $1 \mathrm{~m}$ weit, wenn auch zögernd, nachzusprechen, links bisher kein Resultat erzielt. 
Bei seiner mangelnden Intelligenz und mangelndem guten Willen ist zu erwarten, dass nur bei öfterer Faradisation die angegebene Schwerhörigkeit überwunden. werden kann. Nachforschungen in der Heimat sehr zweckmässig.

5. 12. Nervenbehandlungslazarett: Zunächst ergibt eingehende Befragung folgende ganz neue Anamnese bezüglich des Gehörs: 2 Jahre nach jener Einwirkung auf dem linken Ohr (Platzpatrone) veranlasste ihn zunehmende Schwerhörigkeit links die Ohrenklinik Strassburg aufzusuchen, wo zuerst eine Trommelfellaffektion festgestellt worden sei. ${ }^{1 / 2} \mathrm{Jahr}$ lang habe er alle $1-2$ Wochen zur Behandlung dorthin gemusst, später zum prakt. Arzt, dann 1906/07 wieder in die Ohrenklinik, wo es hiess, es könne wohl nichts mehr werden. Wegen Ohrleidens links wurde er von der 2. Uebung befreit. In allen folgenden Jahren musste er einmal wegen des Gehörs, Schmerzen im Hinterkopf, Zwitschern im linken Ohr „doktern". Diese Angaben, unter steter Skepsis durch Kreuz- und Querfragen erhoben, machen einen durchaus zutreffenden Eindruck.

Obj. Befund: Andeutung von Turmschädel mit einem Horizontalumfang $52^{1 / 2}$; stereotype Schmalzbewegungen mit der Zunge, stupider Gesichtsausdruck und Lächeln. Grosse Schwerfälligkeit bei annähernd durchschnittlicher Intelligenzleistung. Durchschnittliche Sprache sehr laut. Rinné/Weber negativ.

Hörprüfung: Links Schreien in $10 \mathrm{~cm}$, rechts laute Umgangssprache auf $2-3 \mathrm{~m}$. Die unauffällige Beobachtung ergibt auch im Verkehr mit Kameraden ein entsprechendes Resultat. Flüstersprache beiderseits 0 .

9. 12. Aktive Behandlung (Stichelung am linken Ohr, symbol. Einspritzung in den Arm, Ausspritzung des Ohrs, nach einem galvanischen Schlag von 15 M.-A. für 2 Sek. Dauer) deutlichste Flüstersprache bis $50 \mathrm{~cm}$, nach zwei weiteren Schlägen bis $1^{1 / 2} \mathrm{~m}$, wobei allerdings die Möglichkeit, dass er mit dem der Wand zugewandten besseren rechten $\mathrm{Ohr}$ trotz dessen dichten Verschlusses mit Watte und Finger mit apperzipiert hat, nicht ausgeschlossen ist. Es wird vielfach am richtigen Resultat vorbeigeantwortet (auf , 3 “ $8 \ldots 5$, anf , 23“ . . 100). Es scheint, dass ein Teil dieser Vorbeiantworten einfaches Drauflosreagieren anf nicht scharf Apperzipiertes ist; dass dabei immer doch ein Zahlenresultat herauskommt, hängt wohl damit zusammen, dass er ganz auf Zahlen eingestellt ist; sicher nur in der Minderzahl der Fälle beruht es auf bewusstem Falschsagen. Im weiteren Verlauf der Kur wurden die Resultate wieder schlechter. Es ist aber nicht zu ermitteln, ob das auf Apperzeptionsermüdung odex auf bäuerliche „Dickfelligkeit" zurückzuführen ist. Auch die Wahl der aufeinanderfolgenden psychotherapeutischen „Register", wahlweise zwischen brüskester soldatischer Zurechtweisung und einschmeichelndem Zureden bzw. Belobigung, verändert das Resultat innerhalb eines bestimmten Zeitabschnitts nicht. Als im Verlauf der Kur etwa nach $3 / 4$ Stunde wegen seiner Lässigkeit kurzes Gewaltexerzieren eingeschaltet wird, versucht er zuerst äusserst komische Trippeltänze mit visionärem Minenspiel von absolut hysterischem Gepräge (Flucht in die Krankheit) zu produzieren, was er aber alsbald unterlässt, als er merkt, wie wenig er damit weiterkommt. Nach $1^{1} / 2$ stündiger Kur wird das Resnltat plötzlich wieder infolge einfacher psychischer Sperrung schlechter: Links Flüstersprache am Ohr. Im gewöhnlichen Gespräch Vorbeugen des Oberkörpers/Kopfs. r. = l.

20. 12. Rechts $10-20 \mathrm{~cm}$ Flüstersprache, 2-2,5 m mittlere Umgangssprache. 
Links Optimum am Ohr, in $1 \mathrm{~m}$ Umgangssprache: „,ich ver:tehe es nicht". Habituelles Schnalzgeräusch der Zunge.

Erhebungen bei der Truppe: „B. wurde bei der Uebung in Jahre 1909 (nicht 1904) wegen $1 \mathrm{Z} 31$ (Ohrenleiden) krank befunden." Bei der Einstellung 30. 8. 1916 wurde vermerkt: 1 L 31 links und 32 bds. D. A. Mdf. (,hochgradige Sehwerhörigkeit oder Taubheit auf einem Ohre bei verminderter Gebrauchsfähigkeit des anderen" und ,erhebliche chronische Erkrankung eines Ohres usw."), dazu Erläuterung der Kompagnie: Er war schon z. Z. der Finstellung schwerhörig. Eine Verschlimmerung wurde nicht beobachtet, er hat immer gleich schlecht gehört.

Weitere nachträgliche Erhebungen in der Heimat: Ein Arbeitgeber fand vor 12 Jahren schon seine Schwerhörigkeit so stark, dass man ihn förmlich anschreien musste. Genau dasselbe bestätigt ein Arbeitgeber und ein Nachbar aus der Zeit von 1912 bis 1916. Die Schwerhörigkeit habe bei jeder Gelegenheit und ,ohne Ausnahme" bestanden. Schliesslich bestätigt sein früherer Arzt, „er sei vor dem. Krieg so hochgradig schwerhörig gewesen, dass er nur laute Umgangssprache verstand".

Epikrise: Trotz mangels stärkerer Trommelfellveränderungen ist, wie die geschlossene Anamnese ergibt, sicher die Schwerhörigkeit in der Grundlage organisch und nur die Verschlimmerung auf psychogene Pfropfung zurückzuführen. Reine Simulation kommt nicht in Frage. Bewusst willkürlich ist sicher nur gelegentlich ein akustisches Sichabsperren oder lässiges Sichgehenlassen. Es gelten ähnliche Erwägungen, wie bei vorangehenden Beobachtungen, nux dass hier der Anteil des Schwachsinns quantitativ mehr zurücktritt zugunsten des hysterischen im engern Sinne. Dafür hat er ausser früheren hysterischen Anfällen den schönsten Beweis geliefert durch die rein auf „Flucht in die Krankheit" und Protest zu gleichen Teilen zurückzuführende episodische hysterische Reaktion, die im Verlauf der Kur so überraschend in Erscheinung trat. In der Szene, die er aufführte, als er aus der liegenden Stellung bei der Kur (in seinem unbekleideten Zustande) zum psychotherapeutischen Zwangsexerzieren herangeholt wurde, zeigte er für einige Minuten eine ,Amoktanzpsychose", die gerade um des höchsten Kontrastes zwischen Originalität und Produktivität hysterischer Darstellungsfähigkeit und einer sonst stets so hochgradigen bäuerlichen Schwerfälligkeit in allen Ausdrucksformen von groteskester Komik war. Einen bis in alle Einzelheiten gleichen Zustand habe ich nur einmal bei einem in bezug auf Beruf, Herkunft und Geisteszustand völlig gleichgearteten Soldaten gesehen, der sich angetrunken bei einer grösseren Feier in einem zweifellos veränderten Bewusstseinszustande in gleich komisch wirkender Weise produzierte auch ein interessanter Beitrag zur Hysteriepsychologie, insofern er uns zeigt, wie bei einem selbst schwachsinnigen Bauern eine affektiv besondere Situation durch Beseitigung von psychisehen Hemmungen eine Urwüchsigkeit in eigenartigen gemütsmässigen Ausdrucksformen auslösen kann, die bei einem 
Gebildetẹn oder einem eingeborenen Städter unbedingt den Eindruck willkürlich bewusster Darstellung machen müssten.

Im Anschlusss an diesen Exkurs ist noch eine standespsychologische Bemerkung angebracht. Unsere Erfahrungen bei den Kriegsneurosen lehren uns, dass unter unseren Hysterosomatikern - sogar unabhängig von rassenmässiger Hysteriedisposition - sowohl quantitativ als was die besondere Hartnäckigkeit ihrer hysterischen Fixierungen anlangt, diejenigen obenan stehen, die von landwirtschaftlicher Herkunft an die Peripherie der (Gross-) Städte herangerückt sind und in diese berufsmässig vor allem als Maurer u. dgl. zur Arbeit gehen. Dass sämtliche unserer organisch-psychogenen meist doppelseitig Hörgestörten nur Vollvertreter der Landwirtschaft sind, ist immerhin auffällig. Da drängt sich Einem auf, für diese gewisse Regelmässigkeit irgendeine standespsychologische Ursache heranzuziehen. Zweifellos betätigt sich die relativ höhere bäuerliche Indolenz gegen Kranksein besonders gegenüber chronischen Erkrankungen der animalen Organe, welche nicht mit stärkeren Schmerzen verbunden sind. Je abgeschlossener von Kultur und vor allem ,mediziniseher Kultur", um so selbstverständlicher nimmt die bäuerliche Psyche darauf beruhende Funktionsstörungen hin und findet sich mit ihnen ab. Das geht nicht am wenigsten aus den Schwierigkeiten hervor, die wir haben, um anamnestische Daten über die Störungen aus diesen Leuten herauszuholen. Spontan pflegen sie sich nie darüber zu äussern. Besässen wir über diese Leute psychologisch gesicherte ohrenärztliche Einstellungsbefunde, so zweifle ich nicht, dass wir nur in den seltensten Fällen die Annahme reiner Psychogenität oder willkürlicher Vortäuschung, welche sich meist auf die etwas billige Erwägung stützt, dass der Mann mit diesem Grad von Hörstörung nicht so lange hätte militärischen Dienst machen können, für bindend hielten. Das selbstverständliche Sichabfinden mit derartigen sensorischen Funktionsdefekten, das mit unmerklicher, unbewusster Gewöhnung an ein durchschnittliches apperzeptives Mindermass des betr. Sinnesgebiets Hand in Hand geht, erklärt uns die Hartnäckigkeit solcher psychophysischer Gewöhnung besonders gegen die Einwirkungen der Psychotherapie ebenso wie die zirkumskripte „Hysteriefähigkeit" dieses Sinnesgebietes bei Eintritt ganz neuartiger Lebenseindrücke.

Wenn auch unter den psychogenen Ausnahmezuständen bei Pfropfschwerhörigkeit der Stupor erheblich überwiegt. so lässt sich doch auch bei anderweitigen reaktiv psychotischen Bildern ein tieferer Zusammenhang mit der psychogenen Hörstörung nachweisen. Dies zeigt sich in der folgenden Beobachtung.

Beobachtung 23. G., geb. 1884, unehelich, Gelegenheitsbauarbeiter. Bayer. August 1914 bis Angust 1915 in der Geschossfabrik Z. wurde Schwerhörigkeit beobachtet. 
12. 5. Lazarett Kolmar: Nach seiner Angabe ist am 9. 5. eine feindliche Mine, ohne ihn zu verletzen, neben ihm explodiert. Nach objektiver Angabe eines Kameraden hat er noch einen Befehl seines Kompagnieführers übermittelt, nach einigen Stunden stellten sich Gehstörungen und Taubheit ein. Obj.: A uf Befragen keine Antwort, schreit dann aber plötzlich überlaut, dass er nichts verstehe. Beim Gehen fällt er nach vorn, aber nicht zu Boden, weil er rechtzeitig auf beiden Seiten gestützt wird. Besichtigung der Trommelfelle ergibt keine wesentlichen Anhaltspunkte für die Erscheinungen (keine Blutung, keine Rötung). Narbige Veränderungen daselbst, rühren offenbar von einer früheren $\mathrm{Ohr}$ eiterung her; auf Stimmgabelprüfung und sonstiges Zureden reagiert $G$. nicht. Kein Nystagmus, kein Erbrechen.

13. 5. Nervenbaracke: Gesichtsausdruck heiter; kommt allen Anforderungen, die nur durch Zeichensprache oder schriftlich erfolgen können, prompt nach. Begleitet dieselben mit einem schallenden, dem Inhalt der Aufforderung durchaus nicht entsprechenden Gelächter. Plötzlich und unvermittelt mit sehr lauter Stimme unerwartet von hinten an ihn gerichtete Fragen bleiben ohne jegliche Reaktion. Oertlich-zeitlich ungenau orientiert. Conj.-Cornealreflex herabgesetzt, Gaumenreflex angedeutet, Armreflex nicht erzielbar. Patellarreflex njcht deutlich, links kaum auslösbar. Achillesreflex links nicht auslösbar. Kein Babinski. Kremaster. r. $>$ l. Bauchdecken r. $=1$. Seitlicher ,Romberg". Gang: Auf den Fusspitzen leicht wippend. Tastreize, tiefe Nadelstiche werden mit Ausnahme einiger Streifen am linken Bauch/Rücken nicht empfunden.

Subj.: Abgesehlagenheit, Summen in Kopf/Ohren: "Links gluckst es und rechts ist es wie Glocken". Starkes Frostgefühl auch im warmen Zimmer. Nachts Träume. Witzelt öfters, oft grotesk, im übrigen euphorisch.

10. 10. Achilles- und Patellarreflex links nicht auslösbar. Plantarreflex nur auf tiefe Nadelstiche, links deutlich, rechts kaum merklich. Analgesie beiderseits damenstrumpfförmig an Armen total, am Stamm fleckenweise. Anscheinend völlig taub. Hört dagegen seit einigen Tagen Musik. Als von ihm völlig unbemerkt in $10 \mathrm{~m}$ ein Kamerad Mundharmonika spielt, horcht er auf: ,Wusik das ist schön". Die hohen Töne könne er besonders gut hören. Ein ihm bekanntes Lied, vorgespielt, kann er als solches nicht erkennen. 13. 10. Im Gegensatz zu sonst mürrisch gedrückt.

14. 10. Gibt an: „Ich weiss oft nicht, was ich sage; wenn die Leute hintennach lachen, merke ich, dass ich etwas Dummes gesagt habe. Wenn es doch mal etwas besser würde." Als er draussen mal gearbeitet habe, sei er so müde geworden, dass der Gang war , wie der von einem alten Wagenrad, das kaput ist und hinund herschwankt": (dazu charakteristische Bewegungen). Früher habe er ,durch 10 Paar eiserne Hosen" sehen können, jetzt verschwimme ihm die Schrift, dass er nach kürzester Zeitungslektüre meine, ,es bollere ihm das Hirn heraus". Im Kopf ,saust es, als ob er besoffen wäre". Sonst zahlreiche neurasth. (sexualneurasth.) hypochond. Klagen, die auch in für Aerzte nicht berechneten Briefen zum Ausdruck kommen, z. B. an seine Frau: „Du weisst, dass ich Zeit meines Lebens nichts von kranken Leuten wissen wollte, und jetzt bin ich selbst in der Lage und glaube auch nicht, dass ich mer ein Mensch würde, wie ich war. Das Singen in meinem Kopf 
1. Summen lässt halt gar nicht nach auch von Hören ist noch keine Spur in meinem Kopf sumt (summt) u. brumt (brummt) es den kansen Tag u. das ewige Stecken gibt gar nicht nach, und weiss auch öfter nicht, was ich Du und was ich sage meine Bein wärden nicht me Warm anch die Arme und Beine sind sehr Mat u. schlaf hab ich ganz wennicht, wen es die Nacht viel beträcht höchsten 3 bis 4 Stunden ... Ich denke der Herr Stabsaz glaub mir gar nicht, ich bekom keine Arznei und ka nichts $u$. er dut bloss lagen (lachen) wen Er von mir vorbei geht. Wenn ein Fehler dabei, musst Du verzeihen, denn meine Gedanken sind nicht mehr besammen." Als der Arzt mal nach seinem Schnurrbart greift, schnappt er nach dessen Hand. Sehr stimmungslabil und stimmungsinkontinent. Lachen unter Tränen usw. Züge von Kindlichkeit: Als er kürzlich auf dem Krankenblatt ,Taubheit" gelesen hatte, wurde er weinerlich erregt, weil das in seinem Dialekt „Dummheit" oder "Verrücktheit" bedeute. Geschmack herabgesetzt. 7. 11. Patellarreflex links besser, doch immer noch < r. Bis Januar 1917 keine wesentliche Aenderung: Gelegentliche Verstimmungen, sonst läppisch heiter, oft witzelnd, z. B. redet er den Kameraden, der ihm die Ornamente fürs Stockschnitzen zeichnete, immer mit „Bauherr" an. Oder als er zur Sensib.-Prüfung mit starken Strömen zuletzt an der Nase elektrisiert wird, erklärt er, ,der Schnupftabak tut sich entzünden". Stimmung sehr labil; immer höchst unmilitärisch. Gelegentlich sehr auffällige Handlungen, z. B. wenn er die Fiebertafeln wie Klosettpapier benutzt, oder wenn er wegen seiner unmilitärischen Anrede von Vorgesetzten zur Rede gestellt, erklärt: ,Wenn ich sage ,Dut, wird es doch nicht richtig aufgefasst ${ }^{46}$, und fast unmittelbar danach sagt: ,Sie sollten sich auch einen längeren Schnurr stehen lassen." Kein nennenswerter Intelligenzdefekt. 14. 12. Ohrenbefund: Beiderseits vorn unten etwas Einziehung des Trommelfells, vorn oben und hinten unter Trübung. Links. Tube anscheinend wenig verschwollen. Stimmgabel für Luft und Knochen, Ausfall links total, rechts hohe Töne für Luft erhalten.

22. 1. 1917. Psychiatrische Beobachtungsstation H.: Keine Zeichen organischer Erkrankung. Obj.: Nur allgemeine Hypästhesie; Taumeln beim Gehen von rechts nach links; nicht der Eindruck des Zerebellaren; äusseres Benehmen hanswurstartig; scheint sich um seine Krankheit nicht zu grämen, rühmt seine militärische Tüchtigkeit und behauptet spontan, er sei kein Drückeberger.

Befund der Ohrenklinik: Trommelfelle beiderseits stark getribt, vorne Narbe; auf dem linken Trommelfell hinten oben Borke, darunter Narbe. Er will lautestes. Schreien an beiden Ohren nicht hören, dagegen Umgangssprache ablesen können: Angeblich liest er auch schwierigste Worte ab und auch solche, die man durch $\mathrm{Ab}$ lesen allein nicht unterseheiden Kann, wie ,Frühling" und ,.Jüngling". Ausserdem antwortet er auf Fragen, bei denen der Sprecher die Hand vor den Mund hält. 1. F.-Prüfung rechts Knochenleitung c $40^{\prime}$, Luftleitung c $15^{\circ} 0$, links 00 ; 2. Prüfung rechts do., links (freudestrahlend) c 15". Romberg bei Ablenkung anfänglich 0 , später + . Bei Gehen mit verbundenen Augen wahrte er auffallend gut die Richtung, kam nie ins Fallen, machte gute Kehrtwendungen. Drehumnystagmus normal. Kalor. Nystagmus beiderseits nach $70-80 \mathrm{cem} 20^{\circ}$, dabei offenbar erheblichas Schwindelgefühl, das einige Zeit anhielt. Barany's Zeigeversuch normal. Schiefe Ebene nicht zu prüfen, da er beim Anheben der Standfläche sofort heruntersprang. 
Urteil: „Kein Anhalt für Kleinhirnerkrankung, mit aller Sicherheit bestehen funktionelle Hörstörungen, die vielleicht einer starken, organisch bedingten Schwerhörigkeit aufgepfropft sind."

20. 2. Nervenbehandlungslazarett H.: Psychisch vom ersten Augenblick an recht auffällig bei jedem Verkehr mit seiner Umgebung. Während er sich selbst überlassen, mehr strmpf vor sich hinzuleben scheint, legt er bei Ansprache ein sehr seltzames Verhalten an den Tag, das, abgesehen von dem Mangel jeder militärischen Form, einfühlungsmässig am ehesten als verklärte Stillvergnügtheit oder Euphorie eines höchst naiven Mensehen charakterisiert werden kann. Auf jede Zurechtweisung wird nur mit einer geringen Verstärkung der Züge der absoluten affektiven Indifferenz gegenüber Aussenweltsreizen oder mit dem Ausdruck kindlicher Varsonnenheit reagiert. Nur einmal auf schärfere "Ansprache" hin motorische Unruhe: Fuchtelt mit den Händen in der Luft herum, springt auf, geht im Zimmer schwankend umher, setzt sich plötzlich mit den Worten: „Halt, sonst komm ich wieder ins Narrenhaus." Zunächst versteht er lauteste, allmählich mittlere Umgangssprache, wenn er ablesen kann; sobald man den Kopf abwendet, bittet er: ,Sie müssen auch Ihr Maul (!) sehen lassen." Er selbst spricht eher leiser als normal. Schreien rechts in $30 \mathrm{~cm}$, links 0 .

10. 3. Durch absolute ,psychische Isolierung“" im Bett, die nur durch tägliche brüske Ausführung der Hörprüfung mit entsprechendem verbalsuggestivem Antrieb unterbrochen wird, ist allmählich die Hörfähigkeit rechts auf lauteste Flüstersprache in $4 \mathrm{~m}$, leiseste Hauchsprache, welche von Feinhörigen nur auf $3 \mathrm{~m}$ gehört wird, auf solche in $10 \mathrm{~cm}$ gesteigert worden.

Epikrise: Die psychotische Komponente beherrscht hier von Anfang an und über Monate hinaus Art und Verlauf des posttraumatischen Zustandsbilds. Wenn auch die Störungen seitens des Hör-Gleichgewichtsapparats zeitlich das primär Hervorstechende gewesen sind, so ist doch nach dem ersten Bœfund die Möglichkeit einer organischen Schädigung desselben durch die Explosion ausgeschlossen. Denn selbst wenn man aus dem fast 5 Monate nach derselben erhobenen Nachweise einer „Borke am linken Trommelfell mit darunterliegender Narbe" auf einen durch die Explosion gesetzten Trommelfellriss schliessen wollte, so beweist doch das charakteristische Verhalten drei Tage nach letzterer, dass die damals nachgewiesene Absperrung alles akustischen Verstehens in der Hauptsache psychogen bedingt war. Nach den übereinstimmenden otologischen Feststellungen sowohl unmittelbar wie 5 Monate nach dem. Trauma ist an dem Vorliegen einer vortraumatischen Ohrinvalidität nicht zu zweifeln. ${ }^{1}$ ) Es ist also wohl sicher, dass in dieser der Grund zu suchen ist, warum der psychosensorische Chok, der durch das Schreckerlebnis und die akustische Gewalteinwirkung gesetzt wurde, sich vorweg auf akustischem Gebiet geltend machte. Sehr wahrscheinlich haben

1) Anm. bei der Korrektur: nachträglich durch Erhebungen bei dem früheren Arbeitsgeber bestätigt: „S. hörte schwer, manche Zeiten sogar sehr schwer," 
zahlreiche unlustbetonte akustische Sensationen in gleichem Sinne gewirkt, wobei immerhin offen bleibt, ob die mannigfachen unangenehmen Geräusche durch die nicht in organischem Sinne wirkende Erschütterung des Hörapparats infolge der geringen Invalidität des schalleitenden Teils besonders stark 'um Bewusstsein gebracht worden sind. Der psychologische Zusammenhang der funktionellen Empfindungsstörungen mit der Färbung des psychotischen Bildes, im Simne der "Verursachung" dieser durch jene, ist unverkenubar. Zunächst sind in der nicht auf ärztliche Beachtung zugeschnittenen Darstellung seiner Klagen, die ihrem ganzen Tenor nach in der Richtung hypochondrischer Bewertung liegt, die Sensationen im Ohr und Kopf das Beherrschende. Weiter aber tritt in vielfacher Beziehung die Abhängigkeit seines psychischen Verhaltens von der akustischen Selbstabsperrung zutage, vor allem in der allmählichen psychischen Aufhellung, die durch den unter psychischer Isolierung schleichend fortschreitenden Zwang zur Gewöhnung an die normale akustissche Ansprechbarkeit eintrat.

Im übrigen ist neben den vielen hysterischen Einschlägen, die besonders im Körperlichen hervortreten, in psychischen Bilde mancherlei, was mit Rücksicht auf die psychogene Krankheits-,Lrsache“ ungewöhnlich ist: Die aus äusseren Anlässen nicht verständliche Labilität der Stimmung, die Witzelsucht und die teils clownistischen teils infantilistischen Züge erinnern trotz ihres psychogenen Charakters sehr viel mehr an haftpsychotische Komplexe wie an posttraumatische Ausnahmezustände hysterischen Gepräges.

B.

Während bei allen bisherigen Beobachtungen in irgendeiner Weise psychisch abnorme Vorgänge für die psychogene Pfropfung bestimmend gewesen sind, haben wir es in den folgenden Gruppen mit psychogenen Hörausfällen organisch Schwerhöriger zu tun, welche entweder aus der Normalpsychologie verständlich zu machen sind, oder in die Psychologie der Hysterie im engeren Sinne hineinführen.

Beobachtung 24. Th., geb. 1877, Mechaniker.

Bettnässen bis zum 7. Jahr. 1897-99 aktiv gedient. 1906 Krankenhaus. Angeblich eines Morgens mit Ohrlaufen links erwacht. Kopfschmerzen. Es soll ihm ein Polyp an dem Ohr entfernt worden sein. Es lief $1 / 1$ Jahr lang. Seitdem konnte er, wenn er sich Winters erkältete, links nicht mehr gut hören.

August 1914 nach Belgien. Juli 1915 in Front. August 1915 dureh Erkältung Ohrlaufen links; 8 Tage; machte Dienst, danach als Ordomanz, musste oft $2 \mathrm{mal}$ nach Befehlen nsw. fragen. 25. 10. 1916. Granatexplosion in seiner Nähe, Granaten schlugen rasch hintereinander halb rechts und halb links vor ihm ein. Granatsplitter fügten ihm harmlose Verletzungen am Kinn und dicht vor dem rechten Tragus zu (Narben; o. B.). Nach dem Knall sagte er sofort zu seinen Kạmeraden, er höre 
nichts mehr. Dazu Dumpfheit im Kopf und Schwindligkeit, keine Bewusstlosigkeit. Allmählich rechts wieder Aufhellung des Gehörs.

28. 10. Lazarett F., Ohrenklinik: Rechts Trommelfell verkalkt, narbig verändert, besonders in der Tiefe eine rundliche, tiefe Narbe. Links übelriechender Eiter in der Tiefe des Gehörgangs; Trommelfell bis auf den Stummel des Hammergriffs zerstört. Ambosgegend leer zu sondieren. Schleimhant gewulstet, c Luft nur rechts, v. Sch. a. rechts stark verkürzt.

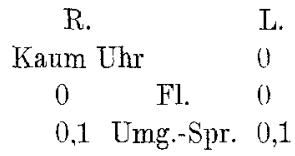

31. 10. Links noch übelriechende Eiterung; Schrapnellschleimhaut granulierend. Kuppelraum eiternde Hautmasse. Links dicke Sekretfetzen an den Kuppelraum angeblasen. Granulationspolypen auf Promontorium geätzt. 4. 11. Polypenreste abgetragen. 6.11. Links geringe Absonderung.

23. 11. Nervenbehandlungslazarett B.: Beschwerden: Stiche, „dumpf: in linker Schläfe, Sausen usw.; Gehör rechts nicht ganz gut, links ausgefallen. Obj.: Sehr ruhig; anständiges, unauffälliges Wesen. Frei von jedem hysterischem Zug: intelligenter Eindruck. Habituelles Vorneigen des rechten Ohrs. Vorbeugen des Oberkörpers (wie zu besserer Auffassung). Umgangssprache annühernd o. $B$. Rechtes Trommelfell glänzend, links Perforation Rinné/Weber, links angeblich negativ, rechts nur Rinné positiv. 2. 12. Besserung des Hörvermögens durch Stichelung, Suggestivspritze, kurzen galvanischen Strom. Nachher Angabe: Rechts/links sei das Gehör wie vor der Einstellung. Obj.: Laute Flüstersprache links in $1-1^{1} / 2 \mathrm{~m}$, rechts in $8 \mathrm{~m}$.

Epikrise: Der psychologischen Dentung bietet dieser Fall die geringsten Schwierigkeiten. Erhebliche Ausfälle der feineren Schallperzeption besonders links erscheinen nach dem Trommelfellbefund und der Anamnese selbstverständlich. Für Simulation, aber auch für Hysterie ergeben sich aus dem körperlichen Befund und ganzen Verhalten und Wesen des psychisch ganz auf dem Niveau seiner Herkunft und Standes stehenden Mannes nicht die geringsten Anhaltspunkte. In allem bot er das Bild des wirklich Schwerhörigen. Dennoch war auch hier durch die Suggestivkur eine Besserung zu erzielen, die fast über das nach dem objektiven Befund erwartete Mass hinausging. Die gleichmässige funktionelle Einschränkung der Hörweite für Klang, Geräusch und Sprache ist offenbar die einfache Fixierung des subjektiven Zustandes nach der Explosion: ,cessante causa non cessit effectus". Abnorm ist hier nur das dauernde Festhalten der psychophysiologischen Komponenten eines starken akustischen Erlebnisses. Jeder, der eine starke Detonation oder Granatexplosion in der Nähe mitgemacht hat, weiss aus eigener Frfahrung, dass dies körperliche Erlebnis unabhängig davon eintritt, ob akustischer Ueberreiz als ein für den Erlebenden ungefährliches Ereignis erwartet wurde oder mit elementarer Wucht über ihn hereinbricht. Das Ent- 
scheidende der traumatisehen Reizwirkung liegt also zunächst unabhängig von der sekundären psychischen Bewertung und Verarbeitung in der körperlichen Sensation, welche der wesentliche Faktor des ganzen traumatischen Vorgangs: die Erschütterung des Hörapparates durch die akustische Wellenbewegung oder die exzessiven Luftdruckschwankungen erzeugt. Bei gleicher psychischer Bereitschaft und gleichem mechanisch-akustisehen Trauma ist wohl als sicher anzunehmen, dass der chronisch Hörschwache gegenüber dem Normalhörigen psychosensorisch stärker gesichert und daher der Schreckwirkung dieses Ereignisses weniger zugänglich ist, dafür aber um so mehr lokalen Schädigungen durch die physikalischen Kräfte des Traumas ansgesetzt sein wird. Ceteris peribus dürfte also beim chronisch Schwerhörigen die physikalische Mehrbelastung des Ohres eher zu subjektiven und objektiven Störungen lokaler Natur führen, als beim Hörgesunden. Ist disee Annahme zutreffend, so ist es ohne weiteres verständlich, dass jede wie immer geartete psychogene Einstellung auf das doppelt betroffene Sinnesorgan sich besonders intensiv und hartnäckig in Störungen und Ausfällen desselben monopolisieren wird. Wenn wir in andern Fällen zum Beispiel eine besonders gefärbte hypochondrische Tendenz als „ideo-" und ,thymogen“ gleich wirksames Motiv solcher Einstellung nachweisen können, so gelingt uns in anderen wie den vorliegenden Fällen dieser Nachweis nicht, ohne dass wir deshalb aus dem ganzen Verhalten der Leute die psychologische Berechtigung ableiten dürften, nun ohne weiteres etwa bestimmte ideogene Faktoren heranzuziehen. Vielmehr können wir dann nur negativ die Tatsache feststellen, dass der Kranke aus eigener seelischer Kraft, der Kraft eines starken Willens zur Apperzeption u. dgl., nicht dazu kommt, den psychogenen Krankheitsfaktor zu überwinden.

Wie und wieweit organische Schwerhörigkeiten sich auf eigenartig psychogenem, aber durchaus unhysterischem Wege auch bei ganz intelligenten Menschen ganz schleichend verschlimmern können, dafür gibt ein interessantes Beispiel die in diesen Zusammenhang gehörige folgende

\section{Beobachtung 25.}

Als eine Klavierlehrerin von den Heilungen psychogener Taubheiten in unserem Lazarett gehört hatte, bat sie, ob bei ihr nicht auch einmal ein entsprechender Behandlungsversuch gemacht werden könne. In ihrer Familie war Schwerhörigkeit erblich; die Idee, dass in vorklimakterischem Alter dieses heriditäre Leiden wie in der Aszendenz alle weiblichen Mitglieder bedrohe und zur Taubheit führe, schwebte seit Jahren als düstere Suggestion über ihr. Mit doppeltem Bangen erwartete auch sie das Leiden, das sie, die auf Musik als ihren Lebensberuf vollkommen angewiesen war, fast in ihrer Existenz bedrohte. Ganz allmählich setzte die Schwerhörigkeit ein; als sie unsere Behandlung aufsuchte, war dieselbe so weit fortgeschritten, dass sie nur mit Hörrohr sich verständigen konnte und schon die grössten Schwierig- 
keiten hatte, ihre Klavierstunden weiter zu geben. Die rein organische Grundlage der Schwerhörigkeit schien absolut sicher. Wie hätte man von Hysterie reden können, da sich die ganze Persönlichkeit seit Jahren gegen das Leiden einsetzte! Und dennoch gelang es, durch die Suggestivkur in der ïblichen Weise (Berthold) eine so wesentliche Besserung herbeizuführen, dass sie das Höhrror aufgeben und nunmehr unbehindert ihrem. Berufe nachgehen konnte. Erst jetzt war die Hörschwäche effektiv auf ihren organischen Kem zurückgeführt.

Wir sehen also in überraschender Weise, wie hier sogar die durchaus begründete und normale Furcht vor dem drohenden Ausfall des Gehörs als negativ psychogener Faktor gewirkt und trotz allen Sträubens des Persönlichkeitsbewusstseins eine psychogene - wir können doch wirklich nicht sagen hysterische! - Aufpropfung ganz schleichend herbeigefïhrt hat.

l.

Wir haben damit die Arten psychogener Aufpropfung organisch bedingter ehronischer Schwerhörigkeiten, soweit es unser Material zulässt, erschöpft und wenden uns nunmehr den rein traumatisch bedingten funktionellen Hörausfällen zu. An Hand einer kleinen Gruppe behandelı wir die psychogenen Fälle von einwandfrei bzw. im engeren Sinne hysterischen Charakter, worauf sich Anlass bieten wird, auf die Simulationsfrage einzugehen. Zum Schlusse werden wir damn noch zum Kapitel der Erschütterungs- und Explosionstaubheit Stellung zu nehmen haben.

Beobachtung 26. M., geb. 1894, Schweiz, Schreiner.

Frühere Anamnese angeblich o. B., auch bezüglich der Ohren. 12.11. 1914 nach Osten. 20. 8. 1915. Kopfschuss durch Gewehr. Krankenblätter über die ersten 4 Wochen nicht aufzubringen.

14. 9. 1915. Reservelazarett Bromberg: 2 Narben reizlos verheilt. Einschuss genau in der Mitte zwischen beiden Angenbrauen. Ausschuss: 10-Pfennigstiuckgross, rund hinter derselben eine leichte Knochendelle, Ausschuss am Rand des rechten Kopfnickers $2^{1} / 2 \mathrm{~cm}$ unterhalb der durch die Spitze des Warzenfortsatzes gelegten Horizontalen, $2 \mathrm{~cm}$ hinter der durch diese gelegten Vertikalen. Rechtes Auge, rechtes Ohr "vollkommen vernichtet". Rechts Trommelfell trïbe und mehrere Verkalkungsstellen; im vorderen Teil eine kleine, rundliche Verkalkung, deren Mitte rot gefärbt ist; oberes rechtes Lid hängt schlaff herab. Auge äusserlich reizlos. Angapfel steht in Abduktion. Gelähmt sind die Abduktoren und Heber. Fundns o. B. Visus gleich 0 . Puppillenreaktion 0. 19.9. Oedem des rechten Ober- und Unter lids, bis 27. 9. geschwunden; Unempfindlichkeit auf der rechten Wangenseite, Schwindelgefühl rechts. 23. 10. Lazarett: Eigene Angabe, dass er rechts (nur rechts!) taub, blind, im Gesicht teilweise gefühllos sei und rechts nicht kauen könne. Bei längerem Gehen Gefühl, als ob der Boden unter den Füssen weggezogen sei. Lider können gut geöffnet/geschlossen werden. Rechtes Auge Schielstellung nach aussen (?); sonst Beweglichkeit; vollkommene Abblassung der Pupille, leichte 
Lähmung der unteren Aeste des Fazialis, Gefühlsstörung im Bereich des Trigeminus II, namentlich Gegend des Unterlids und Nasolabialfurche. Ohrenärztlicher Befund: Rechts Trommelfell leicht getrübt, etwas eingezogen, links etwas eingezogen.

Hörprüfung:
Fl. $\left\{\begin{array}{l}\text { R. nach Lufteinblasung am Ohr } 1 \mathrm{~m}, \\ \text { L. 2, nach Lufteinblasung am Ohr in } 4 \mathrm{~m} \text {. }\end{array}\right.$
St. $\left\{\begin{array}{l}\text { R. } \varnothing \\ \text { L. } \varnothing \text { c }^{2} 64 \text { und folgende }\end{array}\right.$ G. Pf. $\left\{\begin{array}{l}\text { R. } \varnothing \\ \mathrm{L} .1,0\end{array}\right.$
Luftl. $\begin{cases}R . & \cos x \\ \mathrm{I}_{2}, ", & ,\end{cases}$
Rinné $\left\{\begin{array}{l}\text { R. nicht zu prüfen } \\ \text { L. }-5, \text { nicht zu prüfen }\end{array}\right.$
Weber $\left\{\begin{array}{l}\text { \&. } \\ \mathrm{L} .\end{array}\right.$

Romberg: Angedentet bis positiv. Stehen aut ein Bein mit gesehlossenen Augen unmöglich.

Dreh-Pr. $\left\{\begin{array}{ccc}10 & \text { Dr. nach } 1 . & 5 " \\ 10 & \text { ". } & \text { r. } 15^{*}\end{array}\right\}$ Nachnystagmus.

Kalor.-Pr. $\left\{\begin{array}{l}\text { R. nach } 800 \mathrm{~cm}^{3} \text {, kühl W. träger Nystagmus. } \\ \text { L. " } 150, ", \text { deutlicher lebhafter Nystagmus. }\end{array}\right.$

Diagnose: Labyrinthatrophie, Taubheit rechts, leichte Nittelohrschwerhörigkeit (aIt) links.

13. 12. Korps-Ohrenstation: Wie früher. Keine Fazialislähmung. Starke Verdunkelung der rechten Nebenhöhlen, dabei Röntgenbefund negativ. Inochenleitung um 15 "verkürzt. Rinné $1 .+$, r. - Fl. links $1 / 2 \mathrm{~m}$, rechts $4 \mathrm{~m}$. Sp. rechts $1 / 2$ m. Schädigung des schallempfindenden und -leitenden Apparats.

5. 10. bis 5. 12. 1916. Ohrenärztliche Untersuchung Heidelberg: angeblich trüher nie ohrenleidend. Rechtes Ohr Trommelfell leicht getrübt. Im rechten oberen Quadranten, unmittelbar vor dem Hammergriff, eine kleine, strichförmige Trübung, vielleicht Narbe. Linkes Ohr o. B. Grosser Polyp in der linken Nase. 12. 10. extrahiert. Röntgenbefund: Nebenhöhlen frei. Tuben: o. B.

$\begin{array}{ll}\text { Hörprüfung: } & \text { R. } c / \rightarrow \mathrm{L} . \\ & \varnothing \mathrm{cW} \varnothing \\ & \varnothing \mathrm{cL} \varnothing \\ & \varnothing \text { Flst. } \varnothing\end{array}$

Augenbefund (Klinik): R. Visus $0,1 .=5 / 5$. Strabismus divergens. Totale Sehnervenatrophie (ohne Lichtreaktion).

12. 10. Während Spülung nach Polypenextraktion wird $\mathrm{M}$. in eine Unterhaltung rerwickelt, dabei antwortet er prompt auf leise Umgangssprache bei jeweils mit nassem Finger verstopiten einem Ohr.

21. 10. NaCl-Injektionen auf jeden Proc. mastoid. in Chloräthylrausch nach entsprechender suggestiver Vorbereitung (Scheinoperation), nachher Salbentamponwickelverband als schalldichter Verschluss. Nach der Entfernung 23. 10. will or links gut, rechts nichts hören. 
24. 10. Einwandfrei gewöhnliche Umgangssprache beiderseits auf $15 \mathrm{~m}$, druch hartnäckige Behauptung, rechts nichts zu hören.

$$
\begin{aligned}
& \text { R. c } \rightarrow \mathrm{L} \text {. } \\
& 30 \text { c W } 30 \\
& \varnothing \text { c L } \varnothing
\end{aligned}
$$

25. 10. Gibt heute an, durch Luftleitung wieder nichts zu hören. Folgendes Experiment: Bei verbundenen Augen soll er das Hören der angeschlagenen c-Gabel mit , „Ja", das Nichthören mit „Nein" angeben. Durch promptes „Nein"-Antwortell lässt sich mit Sicherheit nachweisen, dass c durch Luftleitung beiderseits ,225": gehört wird.

8.-30. 11. Begutachtung Ohrenstation Heidelberg: Rechts angeblich völlige Taubheit, links Konversationssprache $2-3 \mathrm{~m}$. Flüstersprache 0 . Nach Heissluftdusche links Flüstersprache $30 \mathrm{~cm}$, rechts Taubheit. 13. 11. Rechts nach „Knacken“, Behandlung mit konstantem Strom (Elektroden an den Tragi), links Flüstersprache $20 \mathrm{~cm}$.

Schlussurteil: Schädigung des rechten Mittelohrs durch Schuss nicht ausgeschlossen: Trommelfellveränderungen vielleicht darauf zurückzuführen. Am linken Ohr nichts nachweisbar, was auf Verletzung hinweisen könnte; der Umstand, dass Blutung aus Nase und Mund, keine aber ans dem Ohr eingetreten ist, spricht geradezu gegen Basisfraktur durch die allein die behauptete, nahezu vollständige Erkrankung erklärt werden könnte. Also wohl nur Verletzung der knöchernen Nasenwände einschliesslich Siebbeinzellen. Der Geschossplitter muss auf seinem Wege den Opticus verletzt haben. Ferner hat sich vielleicht infolge der Siebbeinverletzung ein Polyp links entwickelt, der jetzt beseitigt ist. Nebenhöhlenerkrankung: Fremdkörper in keiner Weise nachweisbar. Ob tatsächlich irgendwelche Hörstörung besteht, ist sehr zweifelhaft. Zahlreiche Beobachtungen sprechen dafür, dass sein Hörvermögen wesentlich besser ist; aber bei allen Bemühungen, dies nachzuweisen, hat er sich nie überraschen lassen; deshalb völlig unmöglich, festzustellen, ob eine organische Hörstörung überhaupt vorliegt. Eindruck, dass M. sich gewissermassen in die Vorstellung, nichts zu hören, hineingeredet hat, vielleicht aber keinen anderen Ausweg aus der verfahrenen Situation zu finden weiss, als dass er diesen Grad der Hörstörung hartnäckig behauptet. Wahrscheinlich auch gewisse Beeinflussung durch andere psychogene Hörgestörte (Rentenjäger)."

Tervenbehandlungslazarett B.: 30. 11. 1916. Ruhig, geordnet, etwas kindliches Wesen. Angenstellung habituell: Rechts Bulbus etwas höher wie links. Rechte Augenachse weicht nach aussen oben um $10^{\circ}$ ab. Pupille rechts mittelweit, absolut lichtstarr R. C. + ; konsensuell ist durch Belichtung des linken Auges rechts keine prompte Reaktion, durch Belichtung des rechten Auges links keine Spur von Raflex zu erzielen. Augenbewegung: Nach aussen extrem, $\mathrm{r} .=1$.: rechter Bulbus nach oben und unten je $10^{\circ}$ zurïckbleibend. Auch unter Berücksichtigung der Amaurose rechts. Konvergenzschwäche rechts von $10-20^{\circ}$.

Facialis: Stirn rechts besser wie links. Nosolabialfalte rechts verstrichen. Fazialis II bleibt bei allen Bewegungen und Lachen etwas zurück, besonders bei Mundaufreissen. 
Akustikus: Anfangs kann man sich nur mit lantester Stimme, schliesslich in Umgangssprache mit ihm unterhalten.

Zunge Spur nach rechts. Wangen-Zahn-Gaumenschleimhaut rechts scharf bis Mitte anästhetisch-analgetisch.

2. 12. Durch Suggestivmethode wesentliche Besserung des Hörvermögens, verhält sich willig, nachträglich scheinbar dankbar.

6. 12. Zweifellos infolge Erkältung heute Temp. 40, Puls 150. Pflaumengrosse, pralle, sehr druckschmerzhafte, bucklige Schwellung an der Nasenwurzelnarbe bis $2 \mathrm{~cm}$ oberhalb der Augenbrauen und in die inneren Augenwinkelhinein. Unter Antipyretika und warmen Umschlägen (Eisblase vergrössert zunächst die 'Tumescenz) Rückgang aller Erscheinungen.

9. 12. Fieberfrei. Gleichzeitig mit der Schwellung gelblicher, nicht riechender Eiter aus rechtem Nasenloch und rechtem Mittelohr. Ebenfalls 9. 12. verschwunden, danach weitere Aufhellung des Gehörs.

11. 12. Exakte Hörprüfung:

L.

R.

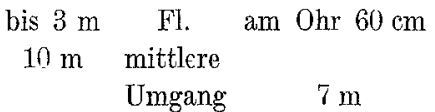

Auf Befragen nachher Angabe, dass er alles mit dem linken Ohr gehört habe, rechts gar nichts (Verschluss des linken bei Prüfung des rechten Ohrs mit Watte and Finger, also nicht absolut schalldicht).

10. 12. Bis gegen 11. 12. unveränderter Hörbefund; wiederholt Klagen über Schmerzen am rechten Ohr und nächtlichen Ohrfluss.

Würgreflex nur durch Berühren der linken Uvula sehr prompt, von rechts überhaupt nicht auslösbar.

Rechts Zunge an Spitze anästhetisch.

Geschmacksprüfung: Rechts nur süss empfunden, übrige Qualitäten alle falsch, gelegentlich auch an der linken hinteren Zungenpartie.

Geruch: Nach Augenschluss wird scharfriechende Zigarette überhaupt nicht, sehr starkes Parfüm richtig, danach Zigarette nur als Rauch empfunden.

Spontane Angabe: Wenn ihm ein Bissen in die rechte Backentasche gelange, bringe er ihn ,,so nicht heraus", ,finde ihn nicht", so dass er ihn mit dem Finger beseitigen müsse. Rechts ermüde ihn das Kauen so. Keine nachweisbare Differenz der Kraft der Masseteren. Anaesthesie-Analgesie rechts über Jochbogen bis $2 \mathrm{~cm}$ oberhalb der Augenbraue und $2 \mathrm{~cm}$ unterhalb Kiefer, nach vorn scharf in der Mitte abschneidend, nach hinten bis 2 Querfinger vor dem $\mathrm{Ohr}$.

Temperatur-E. im Gesicht o. B. Korneal-Konj.-Re.lex rechts schwächer wie links, vielleicht aber mit der Blindheit zusammenhängend.

20. 12. Otitis externa rechts. Er könne das Fleisch so schlecht kauen: obj. begründet; Schmerzen bei Druck auf den Tragus.

Schlussurteil: Läsion der Mehrzahl der ,,vorderen“ Hirnnerven an der Schädelbasis kurz vor oder nach ihrem Austritt. Opticus durchschossen, Oculomotorius ,externus" teilweise, Trochlearis fraglich, Trigeminus II/III, 
Facialis II/III, durchschossen Akustikus?, Glossopharyngeus teilweise? Legt man um die Verbindungslinie Einschuss-Ausschuss als Achse die möglichen Geschossbahnen, so könnte aus der so sich ergebenden Spindel diese Auswahl der Hirnnerven sehr wohl herzuleiten sein.

Möglicherweise ist die Disposition zu Gehör(gangs-)entzündungen auf die Störung des 2. Trig. zurückzuführen. Ob Geruchstörung auf Durchschuss von Olfaktoriusfasern zurückzuführen oder auf die sekundären Nebenhöhlenentzündungen ist fraglich.

Rückverlegung nach der Ohrenklinik wegen der zunehmenden Ohreiterung rechts. 20. 12. 1916. Reichliche Absonderung rechts. 22. 12. Probepunktion der

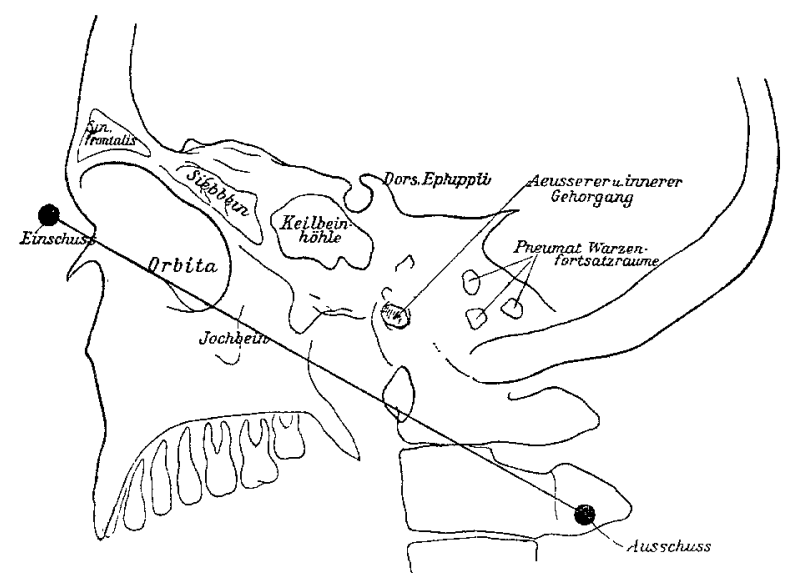

Fig. 9 .

Stirnhöhle: Kein Sekret, rechts Gehörgangwände diffus verdickt (keine Furunkel); Trommelfellbefund daher nicht zu erheben (auch weiterhin nicht erhoben). ,Akute Nittelohrentzündung':

Röntgenaufnahme, bei welcher Ein- und Ausschuss durch Bleikugeln markiert sind, ergibt, dass die gerade Verbindungslinie beider etwa $4 \mathrm{~cm}$ unterhalb des Schläfenbeins verläuft, so dass nach Ansicht Prof. Kümmel's Splitterung desselben nicht gerade wahrscheinlich ist. (Fig. 9.)

Dr. Stekelmacher: .,Beteiligung der Basis cerebri ausserhalb des Schussbereiches. Das Geschoss trifft auf der angegebenen Linie am Boden der rechten Orbita den n. infraorbitalis und die rr. alveolares sup., ferner etwas weiter lateral and in der nächstunteren Schicht etwas unterhalb des Foramen sphenopalatin. den n. masticatorius 1 . Cuccinatorius und den rechten lingualis (und zwar aberhalb der Verbindung mit der Chorda tympani, da der Geschmack an der Zungenspitze angegeben wurde), sowie mittlere Fazialisüstchen. Von dieser durch die Nervenläsionen deutlich gekennzeichneten Schussrichtung aus ist die Surditas am rechten Ohr nicht als neechanjsche T,äsion zu verstehen." 
Immer wiederholte Prüfungen des kalorischen Nystagmus ergaben kein eindentiges Resultat, weil, wie, wie immer das Resultat ausfällt, dasselbe durch Blinzeln bei jeder Aufforderung zum Fixieren und durch allerlei dazwischenkommende willkürliche Bulbusbewegungen gestört wird. Einmal schien der rechte Vestibularis ganz unerregbar, dann wieder fast normal (Brünings 11/2); ausgesprochene subj. Schwindelgefühle bei Ausspülung jederseits. Prüfung auf dem Drehstuhl: Normaler Nystagmus. Bei wiederholter Prüfung des Hörvermögens immer wieder leiseste Flüsterstimme, links $0.5 \mathrm{~m}$, rechts kein Gehör, auch lauteste Sprache nicht. Stimmgabelprüfungen in unregelmässiger Reihenfolge Luftleitung rechts 2 mal 20,2 mal 0 Sek.; links 2 mal 45 Sek.; Knochenleitung rechts 1 mal 25, 1 mal 45; links 2 mal 75 Sek. ,Zufüllig befindet sich auf der Station ein auf einem Ohre tauber Patient, der auf dem anderen Ohr etwa die gleiche Hörweite hat. Es wird M. gezeigt, dass dieser Mann in gewöhnlicher Umgangssprache gesprochene Zahlen ohne weiteres in der Nähe des Ohres hört. Nachdem er das gesehen, gibt er jetzt zu, Zahlen in gewöhnlicher Umgangssprache auf $20 \mathrm{~cm}$ zu verstehen.

5. 2. Schlussurteil Kümmel: „Gegenwartig lässt sich nicht sicher nachweisen, dass rechts überhaupt Gehör vorhanden ist. Aber das Verhalten des II. bei der Prüfung spricht so entschieden für die Willkürlichkeit der Angaben, dass man auf sie keinen Schluss aufbanen kann und nach unserer Ansicht der durch die Prüfung nicht nachweisbaren und nach der Art der Verletzung nicht besonders wahrscheinlichen Annahme einer Zerstörung des rechten Akustikus sehr skeptisch gegenüberstehen muss. Besonders die Tatsache, dass der rechte Vestibularis fast so gut wie der linke und nach Brüning's Otokalorimeter sogar leichter als normal reagierte (?), spricht doch sehr gegen eine mechanische Verletzung des rechten Alzustikus, auch eine isolierte Verletzung der Schnecke ohne die des Vestibularis durch Schläfenbeinfissur ist als eine Folge der Schussverletzung kaum denkbar. Jedenfalls besteht ein für alle praktischen Bedürfnisse ausreichendes Hörvermögen. Es verdient Erwähnung, dass wenig über 3 Wochen nach der Verletzung rechts wie links Verkalkungsstellen am Trommelfell, also zweifellos alte Veränderungen vorhanden gewesen sind. Höchstwahrscheinlich ist dem Mann bei der Lazarettaufnahme (s. oben) bereits die Vorstellung suggeriert worden, dass das rechte Ohr vollständig verloren sei. Auch die Vorstellung der Verstümmelung sitzt bei ihm sehr fest."

Die Beschreibung des Falles habe ich deshalb so ausführlich gestaltet, um zu zeigen, wie unter Umständen alle noch so exakten Erwägungen, die die Dinge von der anatomischen wie von der psychologischen Seite her in Angriff nehmen, doch nicht zu einem bindenden Urteil darüber führen können, ob sicher bestehender Ausfall des Hörens auf der Seite einer Schädelschussverletzung rein organisch ist oder rein auf absolut fixierter und auch durch keinerlei psychotherapeutische Massnahmen zu beseitigender Einbildung des Nichthörenkönnens beruht. Durch die Schussverletzung (Einschuss an der 
Nasenwurzel, Ausschuss hinter und unterhalb der Spitze des Warzenfortsatzes), sind einwandfrei der rechte Optikus zerstört und zahlreiche Einzeläste basaler Hirnnerven schwer getroffen worden. In Diskussion steht topographisch nur noch die Frage, ob der Schusskanal dicht unterhalb der Schädelbasis gelaufen ist oder dicht oberhalb. Nach der geraden Verbindungslinie zwischen markiertem Einschuss und Ausschuss im Röntgenbild würde man den ersteren Fall für vorliegend erachten. Nach der Konstruktion der möglichen Schusslinien am Skelettschädel ist auch die zweite Möglichkeit zuzugeben; ganz besonders wenn man bedenkt, dass der Geschossbahn, die eine Parabel beschreibt, als Schusskanal durch den Schädel nicht die gerade. sondern eine nach oben konvexe Linie zwischen Ein- und Ausschuss entsprechen kann. Mit der Möglichkeit einer Splitterung des Felsenbeins und einer tatsächlichen Schädigung des inneren Ohres ist immerhin zu rechnen, wenn auch diese Möglichkeit nicht wahrscheinlicher ist, wie die erstere.

Beweisbar ist die rein psychogene Natur der rechtsseitigen Schwerhörigkeit deshalb nicht, weil es auch mit „Barany“ nícht gelingt, auszuschliessen, dass alle positiven Ergebnisse der Hörprüfung des rechten Ohres nur scheinbare sind, nämlich auf linksseitiger Apperzeption beruhen und andererseits der Indizienbeweis der Vestibularprüfung nicht einwandfrei Funktion oder Nichtfunktion des rechten Vestibularis erwiesen hat. Nimmt man eine psychogene Einbildungstaubheit rechts an, so kann man sich den psychologischen Zusammenhang nur so erklären, dass in der Hauptsache eine psychische Autoinfektion vom Gesicht auf das Gehör erfolgt ist, wobei körperlich die kurze Zeit nach der Verwundung nachgewiesenen Verkalkungsprozesse an beiden Ohren begünstigend gewirkt haben. Das von dem Augenblick der Verletzung an bestehende sichere Wissen und Erleben der organischen Blindheit rechts hat sofort die Idee der rechtsseitigen Taubheit assoziatiy ausgelöst und befestigt. Primär könnte diese Idee iatrogen (im Krankenblatt lautet 4 Wochen nach der Verletzung der Eintrag; ,,rechtes Ohr vollkommen vernichtet") sekundär durch von früher bestehende Folgen von Mittelohrprozessen (urspriinglich Narbe nur am rechten Trommelfell) befestigt worden sein. Mit der Annahme einer derartigen psychischen Autoinfektion, die im Erlebnischok des schweren Schädelschusses erfolgt ist und in mehr als $1 \frac{1}{2}$ Jahre sich besonders festwurzeln konnte, wäre vielleicht die Unersehütterlichkeit der Taubheitseinbildung gegenüber aller Psychotherapie zu erklären.

Würde die Möglichkeit einer Verletzung des rechten Akustikus ausgeschlossen werden können, so würden wir den ersten Fall aus der Reihe unserer Beobachtungen vor uns haben, in dem der Ausfall der Hörfähigkeit eines Ohres auf „Nichthörenkönnen=wollen“ und in denkbarer Reinheit auf die unerschütterlich festgewurzelte Idee des Nichthörenkönnens zurück- 
zuführen ist. Die psychische Einstellung des Mannes auf seine rechtsseitige Taubheit, die vorübergehend auch das andere Ohr psychisch infiziert hat, ist in durchsichtigster Weise von Rentenbegehrungen diktiert. Der Rentenkampf beherrscht unermüdlich sein ganzes Denken und Wollen und nur die Unsicherheit der Diagnostik stellt die Alternative, ob dieser rein medizinisch begründet ist oder nicht. Vom sozialen Standpunkt bleiben seine Begehrungsvorstellungen auch daun unberechtigt, wenn diese Taubheit voll organisch wäre, da er in seiner beruflichen Leistungsfähigkeit dadurch nicht behindert ist. Die nosophile Grundtendenz ist also auf alle Fälle das Beherrschende. Wenn die Läsion der Akustikus durch Felsenbeinfissur ausgeschlossen werden kann, kommt also allein die hysterische Einbildung des Nichthörenkönnens als Ursache der Taubheit in Frage.

Im Verlauf der bisherigen Darstellungen ist die auffällige Tatsache hervorgetreten, dass die psychogenen Hörausfälle mon o s y m p to mat is ch aufgetreten waren. - Die Beobachtung 18 macht davon nur eine scheinbare Ausnahme, da hier die psychogenen Störungen am Arm eine sehr erhebliche organische Grundlage hatten. - Das Fehlen hysterosomatischer Symptome im übrigen war in den behandelten Fällen einer der Gründe, von psychogener, nicht von hysterischer oder aber von psychogen - nicht hysterischer Pfropftaubheit oder Schwerhörigkeit zu spreehen.

Die nachfolgende Beobachtung macht von dieser Regel eine Ausnahme. Der Grund für diese Ausnahme wird durch die Vorgeschichte offenbar: Von dem vorigen Falle mit seiner in dieser Beziehung besonderen Sachlage abgesehen, ist sie die erste, in der eine alte organische Grundlage im Sinme einer vor der Entwicklung der psychogenen Ausfälle schon jahrelang bestehenden chronischen Schwerhörigkeit sicher ausgeschlossen werden kann.

Beobachtung 97. M., geb. 1878, Möbelpacker.

Auf der Schule sehr schwer gelernt, mehrmals sitzen geblieben. Aktiv gedient 1899-1901 (o. B.) Infanterie. August 1914 ins Feld; ,couragiert".

6. 5. 1915 auf Posten: Als er Minenabschlag hörte, sprang er sofort in ein Deckungsloch; ehe er dahin kam. gab es auch schon einen Krach, er flog hin, momentan ,weg"; kroch zurück, konnte sich dann nicht aufrechthalten ,vor Schwächegefühl"; Sprache frei, war taub, hatte Kopfschmerzen, Schwindel, der Bat-Arzt habe sofort Trommelfellruptur festgestellt: hatte Doppelsehen, ,im Ohr war's wie ein Propeller". Ende 1910 d. u. entlassen mit 100 pCt. Rente, sogar mit Verstümmelungszulage, auf Grund von Zeugnis der Universitätsohrenklinik G., Prof. L.: "Linkes Ohr taub, rechts sehr schwerhörig: links Trommelfell grösstenteils zerstört." Arbeitete dann als Möbelpacker. Dabei merkwürdiger geistiger Eindruck; trotzdem in einem Quartal ununterbrochene Tätigkeit. Fachuntersuchung in H.: 13. 1. 1916. Rechts im hinteren Quadranten unregelnässige streifige Trübung, links zentrale Partien narbig verdünnt, sonst Trommelfell getrübt. 
Hörprüfung: c-Stimmgabel beiderseits weder durch Lưt, noch durch Knochen gehört. Bei nochmaliger Prüfung Stimmgabel für Luftleitung vielleicht auf einige Sekunden gehört. Sichere Hörreste.

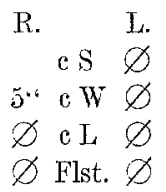

Hat einige Uebung im Ablesen; nur so will er sich verständigen können. Spontannystagmus in Ruhe nach links; starker Nystagmus beim Blick links nach $7 \mathrm{Um}$ drehungen im Uhrzeigersinn, starker Nystagmus bei Blick rechts. Nach 7 Lmdrehungen gegen den Uhrzeiger Andeutung von Nystagmus bei Blick links. Bein Gehen nach der Behandlung auf Drehstuhl läuft M. im Zickzack. Zeigeversuch ohne Drehen: Mit der linken Hand sehr ungeschickt, weist links vorbei, mit der rechten Hand normal. Nach 8 Drehungen im Urzeigersinn mit beiden Händen fast korrekt, jedenfalls viel weniger Vorbeizeigen als vor den Drehungen. Kalorische Prüfung: Wasser $22^{0}$ rechts nach Spülung von $50 \mathrm{~cm}^{3}$ : Nystagmus nach rechts stark, nach links angedeutet. Ziemlich starkes Schwindelgefühl. Links nach $30 \mathrm{~cm}^{3}$ dentlicher Nystagmus nach links, weniger nach rechts: Starkes Schwindelgefühl und ausgesprochen schwankender Gang.

Darüber nachträglich folgende Kritik von Kïmmel: Von den bei mir erhobenen Befunden reicht keiner aus, um zur Annahme einer organischen Erkrankung des Vestibulapparates oder irgendeines Teiles vom Zentralnervensystem zu zwingen. Die Ungleichmässigkeiten in der Erregbarkeit der beiden Vestibularorgane durch die kalorische Reizung und durch den Rotationsreiz liegen durchaus noch innerhalb der Grenzen, die auch bei gesunden Individuen zu beobachten sind: bei der kalorischen Reizung können Verschiedenheiten in der Richtung und Geradheit des Gehörganges schon eine Erklärung abgeben für die kleinen Verschiedenheiten der Nystagmusreaktion. Bei dem Zeigeversuch und dem Nystagmus nach Drehungen kommen ähnliche Verschiedenheiten, wie sie hier gefunden wurden, auch bei Leuten vor, die offenbar ganz normal funktionierende Bogengangsapparate besitzen. Die Gleichgewichts-, bzw. Gehstörungen, die der Mann zeigte, waren alle nicht beweisend für eine organische Vestibularerkrankung, und Herr Prof. Hoffmann war nach eingehender Untersuchung bestimmt davon überzeugt, dass bei dem Mame keine organische Erkrankung des Zentralnervensystems, sondern nur funktionelle Störungen vorliegen; nur bezüglich des Vestibularorgans schob er mir die Verantwortung für die Verwertung der Befunde zu. Alle diese Befunde waren so wenig charakteristisch, wemn sie auch z. T. recht auffallend schienen, dass ich persönlich nur an eine rein funktionelle Störung gedacht hatte und erst durch psychiatrische Untersuchungsbefunde überhaupt. auf die Möglichkeit einer, zunächst ganz unbestimmbaren, organischen Er- 
krankung gekommen bin. Eben wegen der Unmöglichkeit, aus den Symptomen eine bestimmte Erkrankung des Nervensystems zu diagnostizieren. haben wir Herrn Prof. Hoffmann noch um eine Untersuchung gebeten, die aber dann das Bestehen einer organischen Erkrankung als ausgeschlossen erscheinen liess. Doch blieb nach den vielen Untersuchungen und Erwägungen so viel innere Unsicherheit bei mir zurück, dass ich meinerseits nicht mehr mit voller subjektiver Sicherheit an die „Behandlung“ des Mannes herangehen mochte, um so weniger, als dabei hier noch die erwähnten ungünstigen psychischen Einwirkungen als störend in Anschlag zu bringen waren."

Augenbefund (Augenklinik): Ausser Skleralring negativ; „Wassermann": negatir. Befund Prof. Hoffmann: Sehnenreflexe sehr schwer auslösbar; rechter gar nicht sicher, wahrscheinlich fehlt er nicht. Hypäthesie tür Tast-, Schmerz-, Temperatursinn der ganzen rechten Körperseite, mit Herabsetzung des rechten Plantar-, in geringem Grade auch der Bauchreflexe; Skleral-, Nasen-, Rachenreflex stark herabgesetzt. Nichts von sicherem Nystagmus usw. Bei Augenfussschluss, Stehen auf einem Fuss, Gehen auf dem Kreidestrich stets Uebersinken und Uebertreten nach rechts (beim Gehen auf der Strasse weiche er stets nach rechts ab). Die Art und Weise des lenksamen, stets gleichmässigen. Uebersinkens nach rechts macht nicht den Eindruck des Vestibularen oder organisch Bedingten, sondern des Psychogenen.

Auffallend ist folgende Beobachtung: Es werden dem M. die Fragen stets schriftlich vorgelegt. Nachdem er angegeben, dass er auf der Strasse stets nach rechts abweiche, wird ohne stärkere Akzentuation die Frage gestellt: „Was noch?”: keine Antwort. Nun schreibe ich nieder: „Was weiter zu klagen?" Darauf beginnt er seine Antwort mit: "Was sonst noch."

Diagnose: „Sicher psychogene (hysterische) Störung mit Uebertreibung (in welchem Grade?)."

12. 10. Nervenbehandlungslazarett B.: Befund: Rechts Pupille etwas ausgefranst; rechts L/C nicht ganz so gut wie links. Nystagmusartige, rudimentäre Pendelbewegungen bei Seitwärtsblicken, rein als Ermüdungsphänomen. KornealKonjunkt.-Reflex +. Patellarreflex rechts nur mit .,Jendrassik“; auch dann noch schwächer wie der normal auslösbare linke. Achillesreflex schwach r. = l., Plantarreflex rechts sehr undeutlich, links sehwach. Tonus o. B. $\mathrm{r} .=1$. Grosse N.-St. frei. Hört nur lautestes Anschreien unmittelbar ins Ohr hinein; bei der Aufnahme durch den Pol.-U.-Offizier Verhalten wechselnd: Einmal antwortet er dabei auf laute Anrede, wobei er aber vielleicht vom Munde abgelesen hat, dann wieder auf lautestes Türzuknallen keine Reaktion (also hieraus nur Entweder-Oder-Schluss: organisch oder hysterisch taub).

18. 10. Beseitigung der Taubheit: In Horizontallage bei verbundenen Augen Ausspülung des Gehörgangs mit warmer Kochsalzlösung, dann einige Schläge mit der galvanischen Bürste im Ohrbereich, die bis zu schmerzhafter Stärke (6 M.-A.) gesteigert werden unter zunehmender Verbalsuggestion. Bei der Kur widerwillig: nach der Heilung keine Spur von Freude/Dankbarkeit, eher Mürrischkeit. 
25. 10. Hörvermügen weiter tadellos. Unauffällig; lnie etwas, was auf Schwindel deutete, beobachtet. Neurologische Untersuchung: Hemihyp- bis -anästhesie, Hemianalgesie rechts. Grenze scharf in der Mittellinie. Das Frgebnis einer Ueberrumpelungsprüfung gibt zunächst sehr zu denken, ob diese „Empfindungsschwäche " nicht einfach auf willkürlicher Verdrängung der Reaktionen auf diese Empfindungen beruht: Ueberstürzt man nämlich die Nadelstichreize, die am Rücken immer in gleicher Segmenthöhe je $2-3 \mathrm{~cm}$ seitlich der Vittellinie bald von links nach rechts, bald von rechts nach links im Rhythmus von Jambus und Trochäus so gesetzt werden, dass der ,betonte" Stich $(\stackrel{)}{)}$ bald in die normale, der unbetonte ( $)$ ) auf. die anästhetische Körperhälfte fällt und umgekehrt, so ergibt sich nicht der geringste

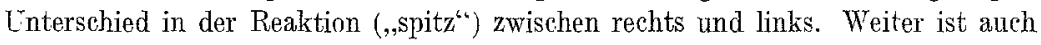
durch Schmerzreize von der rechten Seite die Pupillenerweiterung (unter allen. Kantelen geprüft) genau so, wenn nicht prompter, auszulösen wie von der linken. Unter Ablenkung auf verschiedene Weisen ist heute Plantar- und Achillesreflex genau so prompt auszulösen wie links.

Das neurologisch Interessante des Falls liegt in der Art der Sensibilitätsstörung. Besondere Untersuchungstechnik (die bezeichnete Ueberrumpelungs- bzw. Ueberstürzungsprüfung) kann hier erweisen, dass die Halbseitenhypästhesie-analgesie einzig auf der Unterdrückung der reaktiven Kundgebung der Empfindung beruht, die hier eine sehr merkwürdige Analogie in der unwillkürlichen Unterdrückung der Sehnen- und Hautreflexe findet. Wenn auch mancherlei in dem Charakter des Hannes an den seiner Sache nicht so ganz sicheren Rentenschwindler gemahnt, so ist doch dies Zu- bzw. Nebeneinander von halbseitiger Anästhesie und Hyporeflexie wie immer man diese beiden Erscheinungen aufeinander in psychogene Beziehung: bringen will, selbst psychologiseh-neurophysiologisch viel zu kompliziert, als dass man es selbst einem ausgepichten Simulanten, geschweige denn einem debilen Kopfe als willkürliches Produkt zutrauen könnte. Trotz der Tatsache, dass bei jener Ueberstürzungsprüfung sich keine Differenz zwischen normaler und anästhetischer Körperhälfte ergibt und der Abfluss des Empfindungsreizes in die hochwertigsten reinen, $d$. h. willkürlicher Unterdrückung: durchschnittlich gänzlich entzogenen Reflexbahnen (Psychoreflex der Pupille) von beiden Hälften in gleicher Weise sich vollzieht, mïssen wir diese Erscheinungsreihen doch als hysterisch, d. h. funktionell aber nicht voll bewusst-willkürlich ansprechen. Dennoch möchte ich nicht mit Lewandowsky die Hyporeflexie als ,Begleit- oder Folge- bzw. Teilerscheinung der Sensibilitätsstörung" ${ }^{\text {( }}$ ansehen ${ }^{1}$ ), sondern beide Reihen gleicher Weise jede

1) Ich lasse dabei offen, ob der Fall die Lücke in der Semiologie der hysterischen Reflexanomalien schliesst, die Lewandowsky anführt, wenn er angibt (Hysterie $\therefore$. 11), dass einseitiges Fehlen (in unserem Falle käme nur wesentliche Herabsetzung in Betracht) des Patellarreflexes überhaupt nicht beschrieben ist. 
für sich auf die hysterische Hemmungsfähigkeit zentrifugaler Reflexabsehnitte zurückführen. Der Unterschied zur einfach bewussten, absichtlichen Unterdrückung würde also darin liegen, dass die unabsichtliche (,unbewusste ") Willkürbeeinflussung in solchen Fällen im zerebrospinalen System zwar ,im Prinzip tiefer geht als normal“, andererseits aber nicht tief genug, um auch gleiche Hemmungen in den komplizierten höchstwertigen Reflexbahnen herbeizuführen. Wir dürfen hierin einen Massstab für, wenn man so sagen darf, die Tiefe der Hysterie erblicken. Die schwersten Grade würden dann die Fälle darstellen, in denen die Hemmung auch auf diese Bahnen sich ausdehnen kann. Das würde etwa da vorliegen, wo, wie es Lewandowsky einige Male gesehen haben will, auf kräftige Reizung der anästhetischen Haut auch der Psycho-(Schmerz-)Reflex der Pupille ausbleibt.

Noch von einer anderen Seite lässt sich die Richtigkeit dieses Masstabs erweisen: durch den Grad der Leichtigkeit, mit der diese Hemmungsfähigkeit durch unmerkliche Ablenkung bei zugleich anderweitig starker Inanspruchnahme der Aufmerksamkeit übertrumpft wird.

Es liegt nahe, aus der Gleichmässigkeit der suggestiven Beeinflussbarkeit dieser Halbseitenerscheinungen und der psychogenen Taubheit die psychophysiologisehen Grundbedingungen jener auch bei letzterer für gegeben zu halten. Danach würden wir die Art der psychogenen Taubheit auf die besondere hysterische Fähigkeit der Unterdrücknug aller oder fast aller akustischer Reaktionen mit dem Schein der alkustischen Unerweckbarkeit zurückführen. Im Gegensatz zu der affektiven Form könnte man hier vielleicht von einer ,,ideogenen Absperrungstaubheit“ sprechen. Dass in die ideogenen Motive derselben in diesem Falle Rentenbegehrungsvorstellungen eingehen, ist nach Verlauf und Ausgang und besonders nach der psychologischen Wirkung, die die Heilung auf den Mann ausgeübt hat, ganz unverkennbar. Aber auch in diesem Falle, in dem das ideogene Moment in relativer Reinheit ${ }^{1}$ ) als bestimmend durch das ganze Krankheitsbild hindurchzieht, ist es doch charakteristisch, dass ein ,körperlicher Ausgangspnnkt" bzw. eine körperliche Grundlage für die hysterische Taubheit in Gestalt einer unkomplizierten Explosionszerreissung beider Trommelfelle nicht gefehlt hat.

Mit der vorliegenden Beobachtung ist unsere Kasuistik der ideogenen hysterischen Taubheit bereits erschöpft. Ich lasse dahingestellt, ob dies nur auf zufälligen Ursachen des Materials oder der Materialquellen zurückzu-

1) D. h. in der lsoliertheit, welche für psychologische Elementarvorgänge, die eigentlich nur durch Abstraktion sich gewinnen lassen, im Leben und in der Wirklichkeit überhaupt denkbar ist. 
führen ist. Ist dies nicht der Fall, so dürften wir in dieser zunächst rein statistisch auffallenden Tatsache für die Auffassung der Hysterie und die Stellung der funktionellen Sinnesausfälle im Rahmen der Hysterie wohl doch allgemein wichtige Hinweise erblicken.

Systematisch fortschreitend wenden wir uns nummehr dem psychologisch ebenso schwierigen wie unerfreulichen Kapitel der Simulationshysterie zu. Ich halte die Anwendung dieses zwitterhaften Begriffs, der logisch sowohl die Aufeinanderfolge wie die Mischung beider Vorgänge bedeuten kann, für gerechtfertigt, weil er symboliseh die besonderen psychologischen Schwierigkeiten ausdrückt, die sich beim Aneinandergeraten der naturwissenschaftlichen und juristischen Betrachtungsweise ergeben.

Beobachtung 28. K., geb. 1890, Maurer.

1911 aktiv bei Infanterie. 4. 8. 1914 ins Feld, zurïck am 13. 11. 1914 ins Lazarett (Heimat): hier Angabe, sich Mittelohrentzündung durch den Lnall beim Schiessen zugezogen zu haben. Von Oktober ab verschlimmerte es sich. Obị.: Flüstersprache in nächster Nähe. Lïnziehung des Trommelfelles; ,es ist eine Erschütterung des Labyrinths anzunehmen" (?).

27. 11. 1914. Ohrenstation M.: Angabe: Seit 1908 beiderseits Schwerhörigkeit, im Felde verschlimmert. Obj̣.: Rechts Trommelfell stark gerötet, Perforation im vorderen oberen Quadranten. Mässige Absonderung; verstärkte Flïstersprache am Ohr. Links Trommelfell gerötet. Hochgradig eingezogen, Umgangssprache am Ohr. 5. 12. Frweiterung der Perforation durch Parazentese. 16. 12. Starke Tonsillitis/Pharyngitis. Kieferhöhle frei. 26. 12. Abgelilungen. Hörbefund: Links bei verschlossenem rechten $0 \mathrm{hr}^{2}$ und $\mathrm{c}^{4}$ bei stärkstem Anschlag augenblicklich vernommen. Rechts- Tonreihe ausgefallen bis $\mathrm{c}^{1}$ einschliesslich, $\mathrm{c}^{2}$ bis $\mathrm{c}^{4}$ stark verkürzt. Umgangssprache rechts in $1-1^{1 / 2} \mathrm{~m}$. Unter Aussehluss des rechten Ohrs mit der Barany'schen Lärmtrommel links Umgangssprache an Ohr, Galton 3,5-4,9.

10. 2. Abgangsbefund: Rechts stecknadelkopfgrosse Narbe im vorderen oberen Quadranten. Trommelfell hochgradig eingezogen, auch links T'ube schwer durchgängig, Knochenleitung beiderseits vollständig aufgehoben, Pinné, Weber usw. nicht zu prüfen. D. u. 40 pCt. wegen Tubenstenose links, Terwachsungen und hochgradige Veränderungen beider Mittelohre, die grösstenteils bereits früher bestanden, Sklerose beider Mittelohre, geringe Labyrintherschütterung beiderseits. (?)

Rentennachuntersuchung Juni 1916. Angabe: „Beträchtliche Zunahme der Schwerhörigkeit, Ohrensausen, Schwindel, weil er 191 ó infolge Schwindelanfall: beim Betreten eines Steges das Gleichgewicht verloren habe und in den Bach gestürzt sei. Obj.: Beide Trommelfelle eingezogen 1. > r., links trüb, völlige Taubheit beiderseits; selbst Schreien am Ohr nicht verstanden. Liest alles rom Munde ab. selbst gefliüsterte Worte. Stimmgabel völlig aufgehoben." Urteil: ,"Taubheit, wahrscheinlich verursacht durch fortschreitende Otosklerose, die anch als ursächliches Moment für die subjektiven Beschwerden anzasehen ist." Daraufhin Untersuchung. Begutachtung (Kümmel). Lazarettaufnahme 21. 9. 1916. Angabe: Seit 16 Jahren 
fast jedes Jahr 2--3 mal etwa 14 Tage lang heftige Schmerzen an beiden Ohren; 3 mal deswegen in ärztlicher Behandlung; das Gehör verschlechterte sich dabei immer mehr. Während Dienstzeit 1911/13 angeblich wegen Ohrschmerzen 16 Tage im Lazarett, wegen schlechten Gehörs im 2. Jahr als Ordonanz abkommandiert (!), in Nähe Altkirch Granateinschlag in $1^{1 / 2} \mathrm{~m}$ Entfernung; war schwindlig, hatte Ohrschmerzen, meldete sich aber erst am 11. 11. krank.

Obj.: Rechtes Ohr: Narbe in Gegend des Stapesköpfchens. Uebriger Teil der Pars tensa etwas getrübt, Pars flaccida extrem retrahiert.

Linkes Ohr: Trommelfell im ganzen ge trübt, im hinteren oberen Quadranten länglich dunkle Stelle (Narbe), daneben streifige Trübung. Pars flaccida extrem getrübt. Muschel/Rachen gerötet. Tube o. B.

$\begin{array}{lll}\text { R. } & & \text { L. } \\ \varnothing & \text { c S } & \varnothing \\ \varnothing & \text { c W } & \varnothing \\ \varnothing & \text { c L } & \varnothing \\ \varnothing & \text { Flst. } & \varnothing\end{array}$

Während Stimmgabel nicht gehört wird, antwortet er, abgelenkt, gut auf Fragen, die in Umgangssprache an ihn gerichtet werden, ohne dass er den Mund des Sprechers sieht.

Vorläufiges Urteil: „, Sicher psychogene, hochgradige Schwerhörigkeit, ob daneben mässige organische, nicht ganz klar; ich glaube nicht recht daran." Daneben rein psychogene, angeblich nach früherem Lendenrheumatismus und dem oben erwähnten Sturz (!) aufgetretene Haltungsanomalie: Steht vornüberge beugt, breitbeinig, das Gesäss nach hinten gestreckt, Unfähigkeit, sich aufzurichten, durch suggestive Turnübungen im Nervenbehandlungslazarett beseitigt. Psychiatrische Kontrolluntersuchung: Angabe: Die Ertaubung sei nicht plötzlich bei der GranatExplosion, sondern August/November 1914 allmählich gekommen. Obj.: Hört sicher einiges, denn er liest die unmöglichstenWorte und schnellgesprochene Sätze ohne jedes Versagen ab, auch dann, wenn er den Mund gar nicht von vorn sehen kann. ,Wenn ich ihm laut verspreche, liest er laut, wenn leise, leise ab, und wiederholt sowohl Betonung wie die Silbentrennung." Psych. Gesamtverhalten das des traumatischen Neurotikers. Daneben Struma, Pulsbeschleunigung, feuchte Hände (leichte Thyreotoxikose!).

11. 11. Scheinoperation in Chloräthylrausch (Injektion von $\mathrm{NaCl}$ in Haut am Proc. mast., schalldichter Verband). 13. Abnahme dieses: Hörvermögen unverändert. Beide Irommelfelle stark retrahiert. Liest auffallend gut ab, auch bei halbabgewendetem Gesicht.

22. 11. Behandlung mit starken galvanischen Strömen ohne Erfolg. Liest auch bei schalldicht verschlossenen beiden Ohren gut ab.

Schlussurteil: „Es steht an sich nicht ganz fest, ob organische oder funktionelle Taubheit. Sicher sind organische Veränderungen am rechten Trommelfell, die mit einiger Wahrscheinlichkeit auf die Granatexplosion zurückgeführt werden können und es wäre wohl möglich, dass diese auch eine organische Läsion des inneren Ohres herbeigeführt hätte. Dagegen spricht, dass er Dienst weiter tat, bis eine aknte Mittelohrentzündung mit Eiterung 3 Monate später anftrat. Damit liegt die 
Wahrscheinlichikeit vor, dass die narbigen Veränderungen an beiden Trommelfellen. auf diese Entzündung, nieht die Granatexplosion zurückgeführt werden müssen.

Durch eine solche Mittelohrerkrankung lässt sich eine vollständige Zerstörung des Hörvermögens nicht erklären, zumal keinerlei Erscheinungen des Vestibularapparats im fachärztlichen Krankenblatt berichtet sind ... Der Nachweis, dass K. tatsächlich noch etwas und wieviel hört, ist nicht gelungen. Er hat viel mit einem besonders gerissenen, angeblich tauben, zweifellos Taubheit vortäuschenden Rentenempfänger verkehrt und ist wohl durch diesen beeinflusst... Manche Beobachtungen sprachen dafür, dass er Gesprochenes wirklich hört. $0 b$ er sich einbildet, es nicht zu hören, sondern nur abzulesen, oder ob er das vortäuscht, wage ich nicht zu entscheiden. Um möglichste Klarheit zu schaffen, Verlegung nách Nervenbehandlungslazarett.

30. 11. B.: Angabe: Oktober 1914 schlng eine eigene Granate kurz vor der Schwarmlinie ein; damals nicht krank gemeldet, vielmehr erst am 12. 11., weil er beim Bücken das Gefühl hatte, als ob der Kopf im Feuer wäre und auseinanderfahre. Obj.: Ruhiges, etwas stumpfes Wesen. Bei Unterhaltung Vorschieben abwechselnd des rechten und linken Ohrs und Vorneigen des Oberkörpers, wie, um besser auffassen zu können. Grobe Hörprüfung: Befund: wie früher; Rinné/Weber negativ.

1. 12. Heilung sofort: Bei verbundenen Augen auf Bett gelegt, Stichelung der Ohrumgebung mit feiner Nadel in konzentrischen Ringen, abwechselnd Suggestivspritzen (in Gehörgang warmes Wasser für Bruchteile von Sekunden), ein galvanischer Schlag von $15 \mathrm{M}$.-A. (Elektroden auf Deltoideus und seitliche Halspartie). Gehör nach Zweiminutenkur im Augenblick der Ansetzung der Elektrode "freigegeben ". Nachher Flüstersprache beiderseits in $7 \mathrm{~m}$ !! Weiterhin tadelloses Hörvermögen, ganz einerlei, ob ex zugleich imstande oder vollkommen ausserstande ist, am Munde abzulesen. Dankbarkeit erscheint sehr wenig echt. Vor wie nach der Kur bauernschlaues, iuberlegenes Iächeln.

Epikrise: Dauernde Widersprüche der Angaben über die entscheidende Aetiologie seiner Schwerhörigkeit bzw. Taubheit. Diese sind regelmässigauf den besonderen Zweck der Untersuchung von ihm zugeschnitten. Es besteht nur die Wahl zwischen absichtlich bewusster oder halbbewusster psychogener Verschleierung des Tatbestands. Für die Beurteilung der Qualität der Hörstörung sind sie daher weder positiv noch negativ brauchbar. Sie könnten ebensogut für Vortäuschung wie für hysterische Bedingtheit der Hörstörung ausgewertet werden.

Glaubwürdig erschienen wohl die Angaben, dass er seit Jahren mit den Ohren za tun habe. Dennoch kann von solchem Ohrleiden keine echte organische Hörstörung zurückgeblieben sein, da er nach 2-minutiger Kur laute Flüstersprache bei verbundenen Augen auf mehr als 7 Meter hört. Sehr problematisch erscheint die ohrenärztliche Feststellung, dass er Sätze auch bei schalldicht verschlossenen Ohren vom Munde abgelesen habe. Selbst: wenn man solche Technik im Ablesen bekäme, und auch wenn man zugrunde 
legt, dass (wie Kümmel schreibt), „die psychogen Tauben die Schüler mit den besten Resultaten im Ableseunterricht sind, die leicht auch Wörter ablesen lernen, welche der bestgeschulte organisch Taube nicht ablesen kann, ohne dass darum behauptet werden soll, dass solche Leute ihre Taubheit simulieren", so ist doch selbst bei höchst denkbarer Technik wohl ausgeschlossen, dass èr seiner Zeit unmöglichste Worte und schnell gesprochene Sätze ohne jedes Versagen abliest und nur vermöge Mundablesens laut Vorgesprochenes laut, leise Vorgesprochenes leise nachspricht.

Nachträgliche Feststellungen: 1. des Feldtruppenteils: „Ende September 1914 hat sich K. durch K.-D.-B. ein Ohrleiden zugezogen, so dass er merklich schwerhörig wurde; daher lange Zeit im Revier bis 12. 11. 1914. 2. des Arbeitgebers, dass er 1915/16 im Beruf so schwerhörig gewesen sei, ,dass man sich durch lautes Rufen und Winken" mit ihm verständigen musste. 3. Einstellungsbefund vom 11. 10. 1911: H. $=20 \mathrm{~m}$ beiderseits:

Krankenblattauszug: 2. 12. 1911. Furunkel am linken äusseren Gehörgang. 12. 2. 1912. Trommelfellentzündung beiderseits. 4. 3. 1912. Grippe nach Blasenkatarrh (im Krankenblatt darüber nichts von Schwerhörigkeit), dienstfähig zur Truppe.

Wir müssen also auf Grund seiner systematischen Irreführung der Aerzte bezüglich der Anamnese die fast einzige Zubilligung der Glaubwürdigkeit, die wir ihm früher machen konnten, zurücknehmen. Er hat nicht seit Jabren mit den Ohren zu tun, sondern er hat vor Jahr und Tag einmal mit den Ohren zu tun gehabt. Im Felde hat sich ein Rezidiv eingestellt und später ist einfach die aus Tubenkatarrh und Perforation resultierende Schwerhörigkeit festgehalten worden - ich sage festgehalten, gerade um die Möglichkeit offen zu lassen, dass es sich sowohl um eine hysterische Dauerfixierung als um eine zur Rentenuntersuchung ,wieder hervorgeholte“ Funktionsstörung handeln kann. Wer sich für ersteres entscheidet, wird zugeben müssen, wie ausserordentlich "locker" die hysterische Fixierung sein muss, um es möglich zu machen, dass diese Störung, je nachdem die psychische Atmosphäre mit dem Geist von Rentenjägern gesättigt oder vollkommen frei davon ist, sich psychotherapeutisehen Bemühungen gegenüber äusserst hartnäckig erweist oder spielend in wenigen Augenblicken zum Verschwinden bringen lässt.

Für eine hysterische Bedingtheit in früheren Stadien spricht einzig und allein - wenn man sie für richtig hält -- die Feststellung seines Arbeitgebers, das er bei der Arbeit fast taub gewesen sei, dass also hochgradigste Schwerhörigkeit offenbar aus hysterischer Beachtungstendenz vorgelegen hat. Die Entwicklung der Hörstörung hat sich also hier in drei Stadien abgespielt: aus dem organischen ins hysterische und von da in ein Schlussstadium, das im wesentlichen von wechselnden Verschleierungstendenzen 
beherrscht wird, die sich bald mehr in Pseudologie bezüglich der Vorgeschichte, bald mehr des tatsächlichen Hörenkönnens äussern. Unverkennbar vollzieht sich im Innern des Mannes der Widerstreit der Pflichten chronisch. Je nachdem die subjektive Unsicherheit über die mentale Fähigkeit seines konsequenten Falschwollens oder die psychopathische Beeinflussbarkeit hin und her schwankt, drängt sich der anständige oder der schlechte Wille vor; bis schliesslich der erstere siegt, weil ein ehrenvoller Rückzug unter ärztlicher Nachhilfe als das kleinere von zwei Uebeln imponiert. Dass dies der Simulation recht nahe steht, ist wohl unbestreitbar. Hier etwa vom kranken Simulanten zu sprechen, würde den Tatbestand aber ebensowenig präzise charakterisieren wie einfach alles hysterisch zu nennen. Wenn man sieht, wie solche Leute auch bei zweckmässigster Trennung voneinander immer wieder sich ,agglutinieren", um über ihr Kernthema: Rente zu diskutieren, wird man sie zwar um diese geistige Aermlichkeit und Engbrüstigkeit bemitleiden, aber unabhängig davon ihnen soviel Wissen um das Nichtdürfen ihres mangelhaften Wollens zutrauen, als forensich für das Vorliegen des Dolus zur Vortäuschung gehört. Wenn man solche Individuen etwa als ,kranke Simulanten“ anspricht, so kann es nur den Sinn haben, dass man annimmt, ihre Zugänglichkeit für schlechte Eingebungen ist über durchschnittlich und steht besonders ïber dem, was durchschnittlich von einem wehrfähigen, nicht kriminellen Manne erwartet werden muss. Sie entspricht etwa der Zugänglichkeit für negative moralische Einwirkungen, die ein Kind hat, - in diesem Falle aber analogieweise ein Kind, das sich auch sonst durch Züge moralischer Minderwertigkeit, wie lebhafter Neigung zum Lügen usw. hervortut.

Sehr viel klarer liegt der psychologische Zusammenhang der Vortäuschung in der in übrigen sehr verwandten

Beobachtung 29. Geb. 1881.

Angeblich Kindheit o. B. und anch nie krank. Seit Schulzeit ununterbrochen in einer grossen mechanischen Spinnerei tätig. Dieselbe gibt nun auf Befragen an, dass er (dennoch) nje an Schwerhörigkeit gelitten habe (? Ref.). 1903/05 aktiv Infanterie. 11.8.1914 ins Feld; hier bis 28.12. 1915 angeblich obne Störung; dann Verschüttung durch Granate: Angeblich $1 / 4$ Stunde bewusstlos, hatte nachher Quetschungen der rechten Schulter; will aus beiden Ohren geblutet und auf beiden sofort sehr schwer gehört haben, d. h. ,wenn man mit dem Finger hinfasste, war Blut daran", und 17 Tage Jang soll beim Husten Blut aus dem Mund gekommen sein.

30. 12. Kriegslazarett: Schürfwunden oberhalb und seitlich des linken Auges; dessen Umgebung geschwollen, blau unterlaufen. Auge unversehrt. Auswurf hellen, hellen, roten Bluts. 2./3. Rippe druckempfindlich.

31. 12. Heimat. 12.1.1916. Befund der Ohrenklinik: Beiderseitige frische Mittelohreiterung naeh Trommelfellzerreissung. Ohrenstation: Links Trommelfell gerötet, vorn grössere Lücke trocken, rechts Trommelfell gerötet, vorn unten 
mit Eiter bedeckt. $\mathbf{c}^{1} 0$, Uhr 0, Flüstern 0, laute Sprache 0 (Aggravation?). 18. 1. Feucht belegt. 31. 1. Links völlig reizlos, rechts trocken. 1. 2. Links trocken, rechts noch Krusten. Bei Bewegungen leicht Schwindel, antwortet auf schwache Umgangssprache bequem auf $1 / 2$ m. 3. 2. Links wieder Spur Eiter. Beiderseits c 1, Uhr/Umgangssprache 0. 4. 2. Angeblich laute Sprache nicht gehört; versucht von den Lippen abzulesen und, ,versteht dadurch besser". Antwortet aber auch auf Entfernung bis $1 \mathrm{~m}$, wenn er den Mund nicht sieht.

10. 2. Von Univ.-Ohrenklinik F. mit 50 pCt. und Verstümmelungszulage d. u. gemacht. Schlussbefund: Beide Trommelfelle gerötet, an beiden vorne grössere Lücke; keine Eiterabsonderung. Gehör: Flüster- und laute Umgangssprache nicht gehört. Diagnose: Beiderseitige hochgradige Nervenschwerhörigkeit, entstanden durch Trommelfellzerreissung und Labyrintherschütterung. „Er übertreibt seine Schwerhörigkeit; sie ist jedoch so hochgradig anzunehmen, dass sie eine Verwendung ausschliesst. Heilung ist nicht zu erwarten."

Am 10. 1. 1917 bittet er um Kapitalabfindung, darauf Nachuntersuchung Ohrenklinik H. Er gibt an, in dem abgelaufenen Jahre bape es zwar nie mehr geeitert, doch das Gehör habe sich noch verschlechtert.

Obj.: Rechts Trommelfell retrahiert, im ganzen getrübt und verdickt; vorne unten kleine schartbegrenzte, ovale, atrophische Narbe. An der Peripherie des hinteren Quadranten 2. ausgedehnte Narbe, innerhalb dieser kleine rundliche, scharfrandige Perforation, deren Ränder Epidermisbildung zeigen. Davor I'rommelfell kalkig verdickt. Links Trommelfell retrahiert, getrübt; vorne unten scharfrandige, rundliche Perforation. Mittelohrschleimhaut blass, trocken, hinter dem hinteren Perforationsrand kleines gestieltes Granulom. Will weder Flïster- noch Umgangssprache noch Stimmgabel hören und sich nur durch Ablesen verständigen. können. Bei unverstopften Ohren, ,liest" er anf $5 \mathrm{~m}$ glatt jedes Wort, selbst wenn der Sprecher leise und mit der Zigarre im Mund spricht. Bei verstopften Ohren ist er nicht imstande, auch nur ein Wort abzulesen. Wenn er abgelenkt ist, gelingt es gut anf etwa $1 \mathrm{~m}$ sich mit ihm zu unterhalten, ohne dass er den Mund des Untersuchenden sehen kann. Er starrt krampthaft auf die Augen desselben, nie auf den Mund. Nach seinem Verhalten auf den Vorschlag einer Operation usw. geht hervor, dass er den festen Willen hat, nicht wieder hören zu wollen. Sebliesslich erklärt er sich mit dem Eingriff einverstanden, äussert jedoch immer wieder, er glaube nicht geheilt, bzw. gebessert werden zu können, die Ohren seien nun einmal zerstört.

9. 3. Nervenbehandlungslazarett H.: Hörprüfung:

$$
\begin{array}{ccc}
\text { R. } & & \mathrm{L} . \\
0 & \text { Flsp. } & 0 \\
2-3 \mathrm{~m} \mathrm{cl} & 2-3 \mathrm{~m}
\end{array}
$$

Weber bei verschlossenem Ohr links + , rechts zuerst negativ, auf Anpfiff + . Gibt an, sich nur durch Ablesen zu verständigen, wenn der Sprechende mehr als $2-3 \mathrm{~m}$ von ihm entfernt sei. Dabei versteht er in $2-3 \mathrm{~m}$ auch gut, wenn zwischen dem im Bett befindlichen Manne und dem am Bett stehenden Fragenden das Krankenblatt gerade des letzteren Mund verdeckt. Psychisch nicht auffällig. Intelligenz usw., Herkunft, Alter, Bildung usw. durchaus entsprectend. 13. 3. HEilung der beiderseitigen Schwerhörigkeit durch die übliche Kur erst links, dana rechts innerhalb 
10 Min., spielend Flüstersprache beiderseits in $5 \mathrm{~m}$, Umgangssprache in $8 \mathrm{~m}$. Unmittelbar nach der Heilung stampft er über den Erfolg mit den Füssen aut, heult vor Wut, auch später noch sehr unwillig über den Erfolg.

Epikrise: Ueber die Plumpheit der Schwindelei des Wannes ist nach dem Befund und insbesondere dem Verhalten vor und nach der „Heilung" in diesem Falle kein Wort zu verlieren. Es ist aus der Reihe unserer Beobachtungen der einzige Fall, wo der Nachweis der Simulation so leicht wie möglich und der psychopathologische Befund gänzlich negativ ist. Man kann nur erstens die Frechheit bestaunen, mit der er immer wieder behauptete, nur durch Ablesen sich zu verständigen, während er effektiv kein Wort ablesen konnte, zweitens die Dummheit, dass er so wenig ,im Bilde ${ }^{\text {* }}$ blieb und statt einer geheuchelten Dankbarkeit nach der „Heilung" unmittelbar Gelränktheit und Wut über deren Erfolg an den Tag legte. Die Motive seines Gesuches um Kapitalabfindung sind besonders durchsichtig. Welcher Schaden hier durch die Gewährung einer Kapitalabfindung angerichtet worden wäre, liegt auf der Hand.

Bemerkenswert ist aber auch hier, wo die plumpe Vortäuschung einer fast völligen beiderseitigen Taubheit einwandfrei erwiesen ist, dass seiner Zeit infolge Verschïttung ein beiderseitiger Trommelfellriss mit nachfolgender Mittelohreiterung bestanden hat, d. h. also auch hier die Täuschung anf bewusst-willkürlicher Reproduktion eines vor Jahr und Tag organisch begründet gewesenen Funktionsausfalls beruhte.

$\mathrm{Zu}$ den positiven Anzeichen der Vortäuschung gehörte in beiden Fällen die ausserordentliche Geschmeidigkeit und Promptheit, mit der sich die Störung durch straffe und überrumpelnde Psychotherapie ,wegblasen"* liess. Thre Unechtheit war schon an dem Mangel jeden psychologischen Feingefühls bei der Symptomenpreisgabe zu erkennen. Ganz anders als bei den echten Hysterien konnte aus dem Verhalten der Leute bei der Behandlung mit aller einfühlbaren Deutlichkeit verfolgt werden, wie sie ganz bewusst in Bausch und Bogen ihr Kunstprodukt preisgaben, als sie merkten, dass nichts mehr zu retten sei.

Es dürfte selbst dem Facharzt, der sich etwa vornehmen würde, eine Schwerhörigkeit vorzutäuschen, erst durch mühsame Eigendressur gelingen, seine Symptomdarstellung so zu sichern, dass sie auch überraschenden Aussenreizen gegenüber ihre psychologische Wahrheit und Geschlossenheit beibehält. Die Verkennung dieses psychologischen Zusammenhangs muss sich beim Ungebildeten daher besonders rächen gegenüber den Einwirkungen einer überrumpelnden Therapie. So ergibt sich gerade aus einer strengen Beobachtung der Art und Aufeinanderfolge der feineren psychologischen Signale im Verlauf solcher Eingriffe oft eine grössere subjektive Sicherheit über deren Echtheit oder Unechtheit wie aus manchen der neuerdings an- 
gegebenen Simulationsproben. Zudem eignen sich diese Proben jewei's nur zur Trennung von bewusster Simulation und organisch begründeter Hörstörung, versagen dagegen mehr minder alle, wenn es sich darum handelt, simulierte und hysterische Schwerhörigkeit oder Taubheit voneinander zu unterscheiden.

Was Lewandowsky bei Besprechung der hysterischen Amaurose hervorhebt, ,dass die Träger derselben ausnahmslos auf eine oder die andere der „Simulationsproben" (mit dem Stereoskop usw.) „hereinfallen“, gilt mutatis mutandis in vollem Umfang für die funktionellen Hörausfälle.

In einem lesenswerten Aufsatze hat jüngst $A$ u erbach ${ }^{1}$ ) einige wesentliche Unterschiede im Verhalten des "Simulanten und des Schwerhörigen“, will heissen, des organisch Schwerhörigen ,gegenüber einfacher Gehörprüfung" angegeben ${ }^{2}$ ). Es ist recht charakteristisch, dass er auf die Möglichkeit einer Auswertung seiner Merkmale für die Unterscheidung von Simulation und Hysterie der Schwerhörigkeit mit keinem Worte eingeht und vielleicht noch bemerkenswerter, dass Kümmel, der auf meine Bitte mir in liebenswürdigster Weise seine Ansicht über einzelne Punkte dieses Aufsatzes mitgeteilt hat, sie zwar im ganzen für zutreffend hält, dafür aber überall da, wo Auerbach von Simulation spricht, den Ausdruck, ,psychogene Schwerhörigkeit" gebraucht. Es scheint mir daraus auch mit aller Deutlichkeit hervorzugehen, dass eben alle angegebenen Unterschiede durch die Grundtatsache illasorisch gemacht werden, dass alles, was willkürlichbewusst darzustellen ist, gelegentlich von der Hysterie nachgeahme werden kann. $\mathrm{Zu}$ den wenigen hysterischen Symptomen, die willkürlich bewusst nicht produziert werden können, wie etwa eine isolierte Myopie, gehören nun leider die so wichtigen Hörausfälle nicht, vielmehr gilt, wenn irgendwo, hier, dass der Unterschied nur ein psychologisch erfassbarer ist und wie Babinski sagen würde, auf einen "d'ordre morale" hinausläuft. Entscheidend für die Beurteilung kommt hinzu, dass innerhalb des abgegrenzten und charakterisierten Gebiets der Simulation - wie in der Epikrise der Beobachtung auseinandergesetzt - die Hörstörungen „Unterlassungssimulationen" sind, d. h. nieht einer aktiven Produktion entspringen, sondern einer Unterdrückung von Reaktionen auf Sinnesreize, die in fliessenden Grenzen in die einfache Nachlässigkeit der Aufmerksamkeit und andererseits die Bewusstseinsenge für dies Sinnesgebiet hinüberführen. Zwischen dem schlechten Willen, dem Mangel des guten Willens und der - paradox

1) Deutsche med. Wochenschr. 1916. Nr. 52.

2) Inwieweit die von Auerbach für Simulation als charakteristisch angegebenen Merkmale auch bei sicher organisch Tauben oder Schwerbörigen gelegentlikh beobachtet werden, entzieht sich meiner Beurteilung. 
ausgedrückt - willkürlich nicht gewollten, d. h. nicht vorsätzlichen, aber aktiven Absperrung der Sinnesreaktionen finden wir alle Abstufungen. Für die höheren Simesgebiete komplizieren sich also die Verhältnisse noch erheblich durch die Einschaltung des psychologischen Faktors Aufmerksamkeit. Jede Hörprüfung stellt ja noch mehr als das ungezwungene Reagieren auf akustische Einwirkungen im freien Verkehr ein sehr kompliziertes System der Aufeinanderfolge und der wechselseitigen Beeinflussung einerseits von Lauterweckbarkeit, Einstellung und Deuten, andererseits von Wortbewegungsvorstellungen dar. Widersprechende Resultate im einzelnen können daher auch, ohne dass die Hauptzielvorstellung: Nichtwollen in Aktion tritt, durch ungleíche funktionelle Abwandlungen dieser einzelnen Faktoren- bedingt sein. Ein wissenschaftlich befriedigender Simulationsnachweis auf dem. Gebiete des Gehörs noch mehr als des Gesichts setzt daher eigentlich die Ausschliessung solcher Funktionsabwandlungen oder umgekehrt den Nachweis des Einflusses des Nichtwollens auf jeden einzelnen dieser Elementarvorgänge voraus. Die Unausführbarkeit dieses Nachweises in praxi ist der tiefere Grund, warum uns der Versuch einer eindeutigen Feststellung der Simulation von Hörstörung vielfach, und besonders dann geradezu zur Verzweiflung bringt, wemn im betreffenden Falle noch leichte Grade von Schwachsinn in wechselnden Masse diesen oder jenen Faktor störend beeinflussen. Und doch bietet sich in vielen Fällen keine Möglichkeit, die Funktion eines Gehörs und speziell seiner schallempfindenden Abschnitte anders festzustellen, als durch die Hörprüfung, also ein im Grunde genommen kompliziertes psychologisches Experiment. Es scheint wohl vorläufig auch keine Aussicht vorhanden zu sein, dass hierin ein Fortschritt eintritt, solange die Diagnose der Vestibularfunktion noch so wenig abgeschlossen ist, dass etwa nur im Falle des sicheren Ausfalles eines Vestubularis Rückschlüsse auf die Beschaffenheit des schallempfindenden Organs gezogen werden können. Von den Ohrenärzten wird ja der Mangel eines Apparates, der analog dem Augenspiegel den Zustand der Sinnesnerven diagnostisch wahrnehmbar macht, sehr lebhaft empfunden. Dementsprechend hat ja unsere gesamte Darstellung der Hysterie des Auges und Ohres die relative Unbrauchbarkeit bestimmter Tricks oder die „endogene“ Unzulässigkeit der „Simulationsproben" zur Unterscheidung der Hysterie von der Simulation zur Voraussetzung genommen und versucht diesen Mangel durch die Klärung der Entwicklung und des psychologischen Tatbestandes jeden Falles besonders auch der Hörprüfungen zu ersetzen.

$\mathrm{Zu}$ den wichtigen Kennzeichen des letzteren rechnen wir die, wenn man

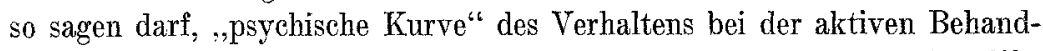
lung. Ihre Bedeutsamkeit ergibt sich u. a. ans dem Gegensatz zur Angriffsweise der direkten Simulationsproben. 
Während diese letzten Endes von der Voraussetzung ausgehen, dass Simulation vorliegt, so lange nicht das Gegenteil bewiesen ist und auf den unmerklichen Versuch einer primären Prüfung auf reelle Wahrnehmungen des verdächtigten Sinnesgebiets hinauslaufen, handelt es sich dort um eine mittelbare Probe, die aber deshalb wertvoller ist, weil sie mit souveräner Einseitigkeít von der (Schein-)Annahme der sicheren Krankhaftigkeit ausgeht und den Betreffenden daher gar nicht dazu kommen lässt, sich auf die Eventualität des Ueberführtwerdens einzustellen. Sie schiebt ihm umgekehrt. also die Beweislast zu, dass der Arzt sich in seiner (Schein-)Annahme der Krankhaftigkeit getäuscht hat. Und diesen Beweis führt der Simulant gerade durch sein Verhalten bei einer ,vorurteilslosen“ Heilkur. Die Art, wie der richtige Simulant sich voreilig an die Tatsache des Behandeltwerdens hält und die zäh bis dahin festgehaltene Symptomendarstellung preisgibt, weicht für den Kenner von dem Verhalten des echten Hysterikers bei gleicher Situation deutlich ab. Natürlich kommt auch diesem indirekten psychischen Merkmal nur ein relativer Wert zu. Zweifellos gibt es Simulanten, die darauf nicht "hereinfallen"; für diese Kategorie ist es aber dann wieder charakteristisch, dass sie überhaupt für jede wie immer geartete Psychotherapie mehr minder unzugänglich sind. Es ist andererseits die Möglichkeit zuzugeben, dass es "locker sitzende" Hysteriesymptome gibt, bei denen der Erwartungsaffekt vor der Behandlung so bedeutend ist, dass er in der Wirkung einem heilenden Affektchok beinahe gleichkommt und das Symptom sich durch die Kur scheinbar ,wegblasen" lässt. Soviel ich feststellen konnte (siehe z. B. Beob. 13), sind das keine monosymptomatischen Hysterien, sondern Fälle, in denen im übrigen Anzeichen sicherer Hysterie vorhanden sind oder aber solche, in denen Art und Stärke des Erwartungsaffekts bzw. seiner körperlichen Ausdrucksformen an sich schon abnorm sind.

Von allen bisher behandelten Arten psychogener Hörstörungen unterscheidet sich die doppelseitige Taubheit oder Taubstummheit, welche bei hörgesunden Menschen durch Explosion oder Verschüttung ausgelöst wird, in wesentlichen Zügen. Aus einer grösseren Reihe ziehe ich hier einige typische Vertreter heran.

Beobachtung 30. Sch., U.-Iehrer.

Mütterlicherseits nervöse Familie. Im Seminar unter den Besten; nie ohrenleidend. Soldat ab 1. 10. 1913; September 1914 Fussquetschrng. Jannar 1915 Rnssland, Mitte Februar Durchschuss rechten Oberarm. Ende Juni drittemal (freiw.!) ins Feld, diesmal, im Gegensatz zu früher, bei Schiesserei, selbst beim Schiessen des Nebenmannes, Erregtheit, Aengstlichkeit, Herzklopfen, univers. Tremor (konnte daher nicht schiessen); 17. 7. Granatverschüttung nach deutschem Angriff, Amnesie auch für unmittelbar Vorhergehendes. 4 Tage später in Ohrenstation Kiönigsberg: Macht die schriftliche Angabe: „Granate im Unterstand“, Kopfschmerz, Gefühl 
der Schädelzusammenpressung, beim Gehen Schwindel. Obj.: Völlig geistesabwesend, taubstumm; im rechten Ohr Blut. R. h. a. rundliche Perforation mitbräunlich-schwärzlichen Massen am Rand (früher nie Ohrenerkrankung). Weber nach links, Rinné beiderseits -; c 4 rechts -, links stark verkürzt. Harn: E +, Zylinder; Z +. Ende Juli mit Begleiter zum E. 1'. T'. zurück: Hier sah ich ihn zuerst: Es fehlte jegliche spontane Aeusserung der Mimik und der Gestik; er setzte sich, wohin er gesetzt wurde und blieb stundenlang aissolut regungslos sitzer. Auch visuell nahm er von den Vorgängen in der Umgebung nicnt die geringste Notiz. Schrieb man ihm Fragen auf, so nahm er das betreffende Blatt langsam in die Hand, betrachtete es erstaunten ratlosen Blicks und reagierte dann langsam mit Kopfbewegungen, die ein Verständnis der Frage bewiesen. Kam in die psychiatrische, von hier in die Ohrenklinik: Noch taubstumm. 8. 8. Rechts Ruptur; links Gehör für laute Sprache auf $10 \mathrm{~cm}$; maximal weite Pupillen; Stottern; Romberg 0 . Später Flüstersprache rechts 0,2 , links $1,2, \mathrm{c} \rightarrow$ links.

$$
\text { Tonstrecke } \frac{\mathrm{C}-\mathrm{g} 6}{\mathrm{c}-\mathrm{6} 6} \text {. }
$$

20. 11. Ohrenklinik: Sprachbörvermögen voll, normal. Subj.: Kopfspannung, Gefühl der Gleichgültigkeit, Erregbarkeit besonders für: Geräusche; müsse lange ïberlegen. Rückbildung vollzog sich so, dass erst Gehör, dann Sprache, zuletzt Wortfinden (Wortbesinnung) wiederkehrte. Lesekonzentrationssehwäche. Obj.: sens. ๖. B. Sprache abgehackt, zeitweise sucht er einzelne Worte; dabei kindliche Satzbildung mit Auslassungen. Später ganz schleichende, schrittweise Besserung der ungestörten Kon rersation (Angehörige!); Stockung fast nur unter psychischen Momenten (Arzt, Vorgesetzte), Ueberenipfindlichkeit universell. Fnde November Nervenbehandlungslazarett B.: Psychisch kindlich verklärtes, erstaunt-ratloses Wesen, weit aufgerissene Augen; verle gen beseeligtes Lächeln bei jedem Gespräch. Spontansprache fast 0. Antworten erfolgen so: Pause - Sprachinnervation - Impuls - Sprechexplosion -- Telegrammstil. Noch leicht stuporös. Ausser gegenüber Vorgesetzten Konversation flotter. Schlaffes Wesen. Sprechhemmungen bei der Beschältigung mit ihm zunehmend bis zur hochgradigen Verlegenheit, z. B. als er einmal Klavier vorspielen soll, flieht er, führt auf seinem Zimmer eine delirante, komödienhafte Szene mit seinem Säbel auf. Dezember wesentliche Besserung. Hörvermögen röllig intakt. Gibt über die Rückbildung der Störungen folgendes an: Nachdem die Spannung über der Stirn geschwunden war, kehrte das Sprachverständnis für laute Worte, später das Sprachvermögen zurück. Jetzt fehlte es nur noch im Zusammenhang zwischen der Auffassung und dem. Verstehen der Bedeutung der Sätze einerseits und dem Entwurf der Antwort andererseits (Schwerbesinnlichkeit), beim Nachspreehen muss or zwangmässig erst über Sinn and Bedeutung des Gehörten klar sein, ehe er das betreffende Wort aussprechen kann; daher Pause und Unfähigkeit zur Echolalie. Auch beim Lesen müsse er immer erst die Bedeutung suchen, und erst wenn er sie gefunden habe, könne er laut vor sich hin- oder vorlesen. Sei immer leicht verblüfft, auf Anrede leicht erschrocken usw. Obj.: Unfertig, knabenhaft, immer noch vor Sätzen und Perioden zwei- und mehrsekundige Pausen, dann Stacksen (Nachahmungs-Hy.?: Sch. wohnte jahrelang im Seminar nejen dem Taubstummeninstiut). 
10. 12. In seine frühere Schuldienststelle entlassen. Katamnese: Es gehe ganz gut; habe etliche 40 Kinder zu unterrichten; nur manchmal verliere er im Unterricht den Faden, so dass er sich lange besinnen müsse; es sei wie eine „Gedankenzwischenschiebung". So komme ihm die ganze Zeit seit seiner letzten Rückkehr aus der Front wie ein Traum vor; so verschwommen, unklar; er habe sich in diesem zwar Gedanken darüber gemacht, wie alles gekommen sei, habe es aber nicht genau herausgebracht. Ende Juli habe er zunächst überhaupt nicht gehört. Fr habe immer etwas sagen wollen, aber es nicht sagen können, weil auch das Denken schwer fiel. Einmal nachts sei es ihm so leicht geworden, dass er am folgenden Morgen Worte sprechen konnte, ohne zu hören, vielmehr habe er vom Mande abgelesen. In der Ohrenklinik habe er zum ersten Male überhaupt wieder gehört: den Klang einer Stimmgabel. In den nächsten Tagen sei auch das Sprachgehör und Verständnis wiedergekommen. Zur Zeit, als Sprechen und Hören schon ganz gut waren, fiel ihm das Donken noch schwer, und zwar das Denken geschlossener Sätze. Noch neulich, als er einmal Aushilfsunterricht hielt, ging ihm plötzlich der Faden aus, und es dauerte einige Sekunden, bis er ihn wieder hatte, oder aber er musste im. Buch nachsehen. Zurzeit rege ihn Musik noch stark auf; er habe dabei immer die Zwangsidee, der Betreffende bleibe stecken; ebenso gehe es, wenn einer etwas vortrage; er bekomme Herzklopfen und habe so ein drückendes Gefühl. Zeigt noch gelegentlich unter der Einwirkung nicht ganz durchsichtiger psychischer Momente Tachykardie, Puls 120-130 blasses, eingefallenes Aussehen, verstiärkte Herzaktion. Siprechen im Schlafe wird fast regelmïssig von Kameraden beobachtet.

Epikrise: Der von Haus aus ausgesprochen psychasthenische und dazu ,berufsnervöse" (Lehrer!) junge Mann, der früher nie an Ohrenleiden gelitten hat, war nach einer schweren Granatverschüttung mit Explosion, die rechts zum Trommelfellriss führte, völlig taubstumm und stuporös. In spontaner Rückbildung kehrte zuerst das Sprachhörvermögen, dann ganz allmählich die Sprechfähigkeit wieder. Ebenso allmählich klangen die sprachlichen und besonders die aussersprachlichen Zeichen des Stupors ab. Die für die meisten traumatischen Hysterien geltende Regel der umgekehrten Proportionalität zwischen der Schwere mechanischer Schädigung und der Massivität der Symptome zeigt sich hier beim gleichen Falle zweifach, d. $h$. bei jeder der beiden nebeneinander laufenden Symptomenreihen: nicht die Funktionsstörung, die allein auf eine der greifbaren materiellen Verletzungen zurückzuführen war, die Taubheit, erwies sich als die hartnäckigere und schwere, sondern umgekehrt die Stummheit. Die Folge der mechanischen Verletzung, die Hörstörung, war schon ganz verschwunden als die rein psychogenen Symptome erst anfingen abzuflauen. Ihre Rückbildung im einzelnen vollzog sich mit grösster Gleichmässigkeit, geradezu in Parallelität ihrer Kurven. Es liegt also sehr nahe, zwischen den psychischen Symptomen, dem Stupor, und den Sprechstörungen einen innigen Zusammenhang anzunehmen. Die sehr charakteristischen Aeusserungen des gebildeten Kranken über die retrospektive und derzeitige subjektive Auffassung über Krankheitsgefühl 
und -einsicht in seine psychogenen Störungen bestätigen dies in durchsichtigster Weise.

Die Deutung dieser Erscheinungen wird uns leichter, wenn wir uns 1. als Seitenstück den Fall des anderen Lehrers (Beob. 7) vergegenwärtigen, der nach Bruch des Hinterhauptes zu Hemianopie und Blickkrampf noch eine Choktaubstummheit bekam; 2. als Gegenstück die folgende Beobachtung heranziehen.

Beobachtung 31. K., stud. phil., Kriegsfreiwilliger 14. 8. 1914.

Mutter seit 12 Jahren gelähmt (Gicht), danernd bettlägerig. 4 Rrüder im Feld, 2 gefallen.

5. 10. 1914. Minenexplosion, 10 Mann getötet, er bewusstlos 2 Stunden; nachher taub (Blut am Ohr!!). Am 8. 11. ausser Verdickung beider Trommelfelle (r. $>1$.) nichts. Schallperzeptionsapparat intakt; Calor. Nystagmus normal. Hysterische Lähmung rechten Arm. Totale Anästhesie, auch der Nasenschleimhaut. 4. 3. 1915. Einmal nach Suggestion während Elektrisieren auf lauten Anruf gehört, danach Dämmerzustand (Ringkämpfe), später hysterische Anfälle. 31. 8. Bei Intention in allen möglichen Muskelgruppen Krampf, sehr schmerzhait. Mehr und mehr hysterischen Charakter, Beachtungskampf: .,Ist jemand zur Stelle, geht es ihm leidlich, ist niemand da, fällt er zum Bett heraus. Yuss entwöhnt werden, nur Flüssigkeiten essen zu können. Beine steif. Abwechselnd Delirien mit Krämpfen.

November 1915 ,Akinesia algera" (1). Jeiseste passive Bewegung führt zu schmerzhaften Paroxysmen mit Tachykardie, Zyanose, subj.: Beklenmung.

Dezember 1915 hysterische Canaille; bedrängt Personal, besticht es, Hetzsystem: gegen Arzt servil. Lähmung am rechten Arm fast weg, besteht noch an den Beinen.

Januar 1916 Nervenbehandlungslazarett B.: Totale Abasie-Astasie, hysterische Paraplegie beider Beine, auch in Liegen; rechts wie links völlig taub; Mundablesen. Therapie: Selbstausschaltung-Nichtbeachtung; nach einigen Wochen Gehenlernen an zwei Stöcken; dáoi stark theatralisch, kommt bis zu Spaziergängen. Heilung der Lähmung: Als ein Stubengenosse mit gleichstarker Abasie durch Gewaltexerzierkur geheilt und auf Urlaub geschickt wird, sagt er unter Zeichen starker Beschämtheit: „In 3 Tagen kann ich wohl auch ohne Stock gehev." Am 2. Tage ist er schon so weit. In der Niacht zum dritten wird er unruhig, ruft den Stubenkameraden. es rausche im Ohr, daranf, er höre das Rascheln der Taschenuhr mit dem Ohr, auf dem er liege, dann seine eigene Stimme. Danach restlose Heilung bis anf allerlei vage Klagen im Kopf, die aber ganz den Findruck hysteriscter Reminiszenzen machen.

Epikrise: Auch hier handelt es sich um einen gebildeten Mensehen. Es ist nicht mehr zu ermitteln, ob die 4 Wochen nach der Minenexplosion ermittelte Verdickung beider Trommelfelle auf die schädigende Wirkung derselben zurïckzuführen ist. Die nachfolgende Hysterie ist so plump und ausladend und mit degenerativen Zügen so rëichlich versehen, wie nur denkbar. Charakteristisch ist die Art der Heilung: aus einfacher Angst vor einer 
Gewaltkur und als Reaktion auf die ihm versagte Mitleidsbehandlung "fliegen" die Symptome über Nacht weg.

In jeder Beziehung hält sich hier das Bild der elementaren seelischen Erscheinungen und der feineren Züge des Charakters im Gegensatz zum vorhergehenden Falle. Die Analyse der seelischen Konstitution der beiden, wie sie sich nach der Heilung dargestellt hat, lässt uns die feineren psychischen Determinanten von Art und Verlauf des psychogenen Zustandsbildes nach dem Abklingen der ersten Chokwirkungen des Traumas erkennen. In den zahlreichen Innervationsstörungen der Sprache im ersten Falle finden wir den körperlichen Ausdruck komplizierter (psychomotorischer) Hemmungen und Sperrungen in der Verbindung zwischen Auffassung, Denken und Sprache, die dem Kranken mit einem sehr lebhaften Grundton von Unlust zum Bewusstsein kommen: im Kern also rein psychasthenische Mechanismen. Wir haben in diesen nur die pathologische Verzerrung individueller Eigentümlichkeiten der Charakteranlage, insbesondere seiner von Haus aus bestehenden Art der Reaktion auf die differenten Einwirkungen des menschlichen Verkehrs zu erblicken. Trotz mancher kleinen hysterischen Allüre und $\mathrm{K}_{0}$ ketterie bei besonderen Anlässen beherrscht doch die endogene psychasthenische Formel auch den posttraumatischen Ausnahmezustand. Im Gegensatz dazu setzt sich beim zweiten Kranken auch nach der Beseitigung der somatischen Symptome bis in alle Einzelheiten der nos ophile Grundzug durch. Die funktionelle Taubheit ergibt sich in einfachster Weise als Anreicherung und Fixierung der durch die traumatische Erschütterung des Gehörapparats bedingt gewesenen Funktionsstörung. Noch viel durchsichtiger und massiver sehen wir die psychogene Steigerung der konstitutionellen Züge sowohl auf körperlichem wie auf psychischem Gebiet in der folgenden Beobachtung verwirklicht.

Beobachtung 32. W., Wladislau, Armierungssoldat (Pole, Analphabet).

Eltern gesund, 3 Geschwister. Als Kind kräftig, keine Krämpfe. War 8 Jahre in der Schule, dann in der 3. Klasse abgegangen. Hierauf in der Landwirtsclaft seiner Eltern tätig.

1. 8. 1916. Eingezogen zum Armierungsbataillon in Hamel. 27. 8. Ins Feld nach Frankreich. Habe das Schiessen gehört, einen Einschlag aber nie gesehen. War 10 Tage bei der Truppe, dann vom Kompagnieführer wegen Unmöglichkeit einer Verständigung infolge hochgradiger Schwerhörigkeit und Imbezillität zur Lintersuchung auf seine Verwendungsfähigkeit fortgeschickt.

30. 8. Kriegslazarett J., Ohrenstation: Macht den Eindruck einer in der Jugend entstandenen schweren Erkrankung (Meningitis?). Sprache: Unverständliches Gestammel; hört nur laute Sprache direkt ins Ohr beiderseits. Als Armierungssoldat unbrauchbar. 9. 9. Lazarett F.: Starrer Gesichtsausdrack, funktioneller Verlust der Sprache und des Gehörs infolge einer nervösen Ersehütterung. 
Puls beschleunigt, Lidflattern bei Lidschluss, kein Romberg, erhöhte Reflexerregbarkeit. Verständigung nicht möglich, auch nicht schriftlich (Analphabet).

18. 9. Nervenbehandlungslazarett B.: Beschwerden: Habe des öfteren Schmerzen auf der Brust (zeigt auf die Magengegend!).

Befund: Kann bei seiner Ankunft weder sprechen noch hören; da er dentseh auch nicht lesen und schreiben kann, ist nahezu jede Verständigung ausgeschlossen. Bringt nur schwache, unartikulierte, tierische Laute heraus; dabei krampfhatte Mitbewegungen in Gesicht. Wird zunächst (20.9.) durch Ueberrumpelung von seiner Taubstummheit geheilt. Durch Schmerzreize an und vor dem Ohr mit Nadel und galvanischer Bürste werden erst das Gehör, dann durch endolaryngeale Galvanisation die Sprechfähigkeit wiederhergestellt.

21. 9. Sprache und Gehör befriedigend. Beim Sprechen erfolgen noch vereinzelte komplizierte Bewregungen im Gesicht, bald mebr im Sinne von innervatorischen Mitbewegungen, bald mehr solche von langsam ticartigem Charakter, besonders um den Mund herum. Beim Hören wird der Oberkörper vorgebeugt. Psychisch etwas ruhiger geworden, macht er weiter einen hochgradig imbezillen Lindruck. Kann nur seinen Namen schreiben.

9. 10. War 14 Tage auf Erholungsurlaub: Sprache ist noch schwer verständlich (Muttersprache polnisch), leicht spastisch, dabei Mitbewegungen des rechten Mundfacialis (Verziehen des Mundwinkels usw.), Verziehen der Stirn in Querfalten. Schein einer peripheren Schwerhörigkeit infolge hochgradiger, allgemeiner und sprachlich sensorischer Schwererregbarkeit. Psychisch: Stumpfsinnig, stieres Wesen, interesse-, ratlos. Auf einfachste, ruhig gestellte Fragen wie vor den Kopf geschlagen. Kann keine Antwort finden. Oertlich und zeitlich orientiert. $7+4=10$; $3+7=9$. Beim Lösen der einfachsten Rechenaufgaben zählt er angestrengt an den Fingèrn ab und findet schliesslich doch nur eine falsche Lösung. Intellektuelle Fähigkeiten grob geprüft sehr niedrig; nähere Prüfung nicht möglich, da ihm das Verstehen der einfachsten Begriffe anscheinend nur in seiner Muttersprache ausgedrückt möglich ist. Alle Bewegungen sind schlaff, unmilitärisch, zaghaft; schüchternes, mädchenhaftes, verlegenes Wesen.

Epikrise: Hochgradiger angeborener, allgemeiner, vorwiegend sensorischer Schwachsinn mit Entwicklungsstörung der Artikulation, Analphabetismus und sehr mangelhafter Sprachkenntnis (Muttersprache polnisch), rein durch negativ affektive Momente bis zur scheinbaren Taubstummheit verschlimmert. Hypermotilität der aussersprachlichen Ausdrucksbewegungen: unbewusste Innervationsvergeudung und Falsehschaltung bei der Sprechintention, Ableitung des Hauptinnervationsstroms auf die Sprachhilfsapparate. Auf den Kern einer hochgradigen Imbezillität mit Entwicklungshemmung des - sensorischen und motorischen - Sprachapparats hat sich also als Schreckwirkung ein Stupor aufgepfropit. Durch diese eigenartige Kombination wurde das Bild der Taubstummheit vorgetäuscht. Nach dessen Beseitigung hat er doch noch verschiedentlich den Eindruck eines wirklich Schwerhörigen hervorgerufen, obwohl nicht die geringste Störung des schall- 
leitenden oder schallempfindenden Apparats vorlag. In dem ganzen reaktiven Zustande findet sich nichts, was nicht restlos als pathologische Verzerrung seiner minderwertigen nervös-seelischen Veranlagung erklärbar wäre.

Aus der Reihe der Taubheiten oder Taubstummheiten habe ich diese 4 Fälle herausgegriffen, weil jeder in seiner Art mir ein typischer Vertreter der verschiedenen Kategorien von funktionellen Hör- bzw. Hörsprachstörungen darzustellen scheint, welche bei vorher sicher intaktem Mittel- oder Innenohr rein durch das mechanische oder psychische Trauma einer Granatexplosion oder Verschüttung ausgelöst werden.

Im Gegensatz zu den Formen der nicht simulierten psychogenen Hörschwäche, welche wir im ersten Abschnitte behandelt haben, besteht bei dieser Erschütterungs-Taubheit und noch viel mehr der -Taubstummheit zwischen der Art und Stärke des Hörausfalls und nachweisbaren Veränderungen am Hörapparat kein eindeutiger Kausalnexus. Das Vorliegen frischer Läsionen des Trommelfelles oder nicht unbedingt eindeutiger Funktionsstörungen des Labyrinths eines vorher nicht invaliden Hörapparates lässt sich nach allen Erfahrungen für die Erklärung dieser Taubheiten einzig und allein als unumstösslicher Beweis dafür verwerten, dass wirklich eine akustische oder mechanische Gewalteinwirkung anfs Gehör erfolgt ist. Bei der Schwierigkeit objektiver Ermittlungen über Granatexplosionen oder Verschüttungen bedeutet diese Feststellung schon sehr viel, aber die in dieser Beziehung negativen Fälle, d. h. die Fälle, mit in der Front erworbener Taubheit, die einen vollkommen normalen Trommelfellbefund aufweisen ${ }^{1}$ ), sind doch so zahlreich oder überwiegen gar prozentual so, dass man in solchen organischen Befunden keine wesentliche Bedingung für die Entstehung dieser Formen von Taubheit erblicken kann. Und dass, wie Pflug ${ }^{2}$ ) schon hervorhob, bei der Verschüttungs-Taubstummheit in weitaus den meisten Fällen die Gehörstörung früher verschwindet als die Sprachstörung weist in gleicher Richtung.

Diese Auffassung hält auch folgender Erwägung gegenüber stand: Entsprechend der Auffassung Kretschmann's ${ }^{3}$ ) dass die Gehörknöchelchenkette eine Art Schutzvorrichtung gegen zu starke Schallwirkungen darstellt, kann man sich vorstellen, dass die Ableitung der mechanischen Wirkung

1) Z. B. gibt Pflug (Inaug.-Diss. Heidelbg. 1916), welcher 12 Fälle von Verschüttungstanb- bzw. -taubstummheiten aus der Kümmel'schen Klinik zusammengefasst hat, normalen Trommelfellbefund als die Regel, Rupturen nur als Seltenheit an, wilhrend umgekehrt z. B. Westphal, Binswanger u. a. derartige Schädigungen des Hörapparats als bedeutungsvoll betrachten.

2) Ebenda.

3) Deutsche med. Wochenschr. 1917. S. 6 E. 
eines das Gehör treffenden Luftdruckstosses vom inneren Ohr gerade um so eher erfolgt, wenn das Trommelfell die Gewalt abfängt und infolgedessen zerreisst. Es ist umgekehrt theoretisch denkbar, dass die Gewalteinwirkung eines solchen Stosses das Trommelfell nicht zerreisst, dafür aber auf die dahinterliegenden Teile des inneren Ohres eine so schwere Erschütterung ausübt, dass es zu Störungen und Zerstörungen im feineren Bau des letzteren (Passow) kommt. Ohne Verletzung des Trommelfells kann also eine traumatische Schwerhörigkeit oder Taubheit durch Explosionswirkungen entstehen, die mikroorganisch bedingt ist. Von diesen mikroskopischen Veränderungen weiss man nun aber gerade, dass sie reparabel sind und vom dritten Tage ab anfangen, sich mehr minder völlig auszugleichen. Dass eine Steigerung der Gewalteinwirkung vom äusseren Ohr her Läsionen des inneren Ohres setzt, die eine nicht mehr ausgleichbare Taubheit nach sich ziehen, ist ohne Zerreissung des Trommelfelles völlig undenkbar.

Wir können also mit Sicherheit sagen, dass jede traumatische Taubheit ohne Trommelfellbefund, die bis nach 2 Monaten sich nicht allmählich ausgeglichen hat, als eine psychogene angesprochen werden muss - vorausgesetzt, dass es sich um einen früher völlig intakten Hörapparat handelt und andererseits das Vorliegen eines Bruches des Felsenbeins ausgeschlossen werden kann (s. Beobachtung 26).

Wie die Dinge anatomisch liegen, wenn derartige traumatische Schädigungen einen bereits in Degeneration begriffenen Akustikus treffen oder zu einer Sklerose des Trommelfells hinzutreten, darüber steht nichts fest. Andererseits dürfte es nicht ausgemacht sein, ob nicht geringfügige mikroorganische Veränderungen die - ohne Zerstörung des Trommelfells - ein bisher intaktes inneres $\mathrm{Ohr}$ treffen, doch auch einmal sich nicht ganz ausgleichen und zu geringfügiger Dauerschwerhörıgkeit führen. Wenn wir auch vorläufig noch nicht, wie es wünschenswert wäre, auf Grund eines ganz grossen und ohrenärztlich wie psychiatrisch genau untersuchten Materials eindeutige Beziehungen zwischen der Häufigkeit traumatisch friseher Veränderungen des Hörapparats einerseits bei Taubheiten, andererseits bei Taubstummheiten, die nach Explosion oder Verschüttung Ohrgesunder aufgetreten sind, herstellen können, so lässt uns doch die Erfahrung, dass wir durchschnittlich die vollere Symptomentfaltung Taubstummheit nach geringgradigeren Gewalteinwirkungen, die einfachere Taubheit nach stärkeren Gewalteinwirkungen - für die eben der Trommelfellbefund einen Massstab abgibt - antreffen, an sich schon nur den Ausweg, die sensorischpsychische Chokwirkung als die ausschlaggebende Ursache anzusehen. Dementsprechend zeigt nun die genauere Analyse des psychischen Verhaltens dieser Taubstummen, dass den Kern dieser Zustände komplizierte Seelenstörungen besonderer Art bilden, bei denen die Taub- 
stummheit nur das aufdringlichste Aussensymptom bildet. Intellegentere unter diesen Kranken (wie z. B. Fall 30) weisen ja retrospektiv geradezu auf den zentralen psychologischen Punkt hin, von dem aus wir ein Verständnis für alle Erscheinungen gewinnen können; nämlich die Verbindung zwischen Bedeutungserfassung der akustischen Eindrücke und sprachlichem Denken. Das einfühlende Nacherleben des Phänomens der Attonität oder des „,Betroffenseins" führt uns an das Wesen des seelischen Zustandes dieser Kranken heran, der sich stets nur ganz unvollkommen beschreiben lässt. Annähernd trifft es wohl das Richtige, wenn man von einer Auslöschung der Beziehungen zur Umwelt, dem Verlust der Ansprechbarkeit durch die Sinnesreize des menschlichen Verkehrs und der Aufhebung aller gedanklichen Verarbeitung der verschiedensten Aussen- und auch Innenreize spricht. Aus dieser zentraTen Störung, welche die Stiftung von Assoziationen verhindert und mehr nunder zur völligen Gedankenleere führt, ist es wohl zu erklären, dass nach der Heilung die Rückerinnerung den Zustand ganz summarisch als einen verschwommenen 'T'raumzustand charakterisiert. Und wenn wir sehen, dass auch die optische und die Ansprechbarkeit der übrigen nicht akustischen Sinnesgebiete hochgradig herabgesetzt ist, wird uns klar, dass die Taubstummheit nicht das Wesenhafte ist. Vielmehr tritt sie nur deshalb so hervor, weil sie sich in der Rückbildung am längsten konserviert und das Gehör die Eingangspforte des Schreckerlebnisses darstellte. Im Prinzip unterscheiden sie sich aber nicht wesentlich von den Erschütterung'sstuporen, die nach Katastrophen auftreten, bei welchen kein wesentliches oder ausschliessliches akustisches Trauma gesetzt wurde.

Wie ich oben hervorhob, haben wir in unseren Beobachtungen auch nach der Heilung der gröberen Erscheinungen Züge im psychischen Wesen vorgefunden, die uns zeigten, dass in dem Chokstupor die Elemente der psychisch-nervösen Persönlichkeitsanlage nicht ausgelöscht, sondern nur bis zur Unkenntlichkeit verzerrt oder überlagert waren.

Vom Standpunkt des Psychopathologen kann ich mich daher durchaus nicht der Auffassung ansehliessen, dass es sich in der weit überwiegenden Mehrzahl der Fälle um früher vollkommen gesunde Personen handelt. Die Mehrzahl derselben ist zwar nicht erheblich "belastet" oder im praktischen Sinne früher nervös krank gewesen. Nach der genauen Ermittelung ihres psychisch-nervösen Vorlebens und nach dem charakterologischen Befund ist es aber dennoch sicher, dass es sich um Individuen handelt, welche von Haus aus abnorm sensitiv oder in irgendeinem Sinne über den Durehschnitt reizbar schwach oder erregbar sind und dann infolge nervöser Erschöpfung oder reizbarer Schwäche, die sie meist in der Front erwarben, tatsächlich eine sensomotorische abnorme Bereitschaft hatten, als sie von dem Trauma betroffen wurden. 
Damit stimmt auch die auffällige Tatsache überein, dass im Gegensatz sowohl zu den übrigen schweren traumatischen Hysterien wie insbesondere zu den „Pfropfschwerhörigkeiten" die Vertreter des Bauernstandes unter den Trägern der traumatischen Taubstummheit kaum zu finden sind, vielmehr Angehörige städtischer oder ,gebildeter" Berufe, voran Lehrer und Kaufleute, weitaus überwiegen. Noch wichtiger ist in diesem Zusammenhang die andere Tatsache, dass in der Reihe der Gruppe A, d. h. der Schwerhörigen und Tauben, bei denen psychogene Hörausfälle auf Jahre bis Jahrzehnte lange bestehende organische Schwerhörigkeit aufgepfropft waren, sich kein Fall befindet, bei dem die Einwirkung einer Granatexplosion oder Verschüttung das Bild der Taubstumm heit hervorgerufen hat. Vielmehr boten auch sie nur eine quantitativ mehr minder erhebliche Verschlechterung der bestehenden Hörstörung. Es liegt die Vermutung nahe, dass derartig Hörschwache infolge der Invalidität ihres Gehörs durch die akustischen Granatwirkungen daneben aber auch durch die begleitenden seelischen Eindrücke der entsprechenden Frontereignisse an sich weniger betroffen werden und gegenüber gleichgearteten Ueberreizen geschützter sind als Leute mit gesundem Gehör, so dass sie durch solehe nur dann - und zwar relativ stärker betroffen werden kömnen, wenn der akustische Stoss die Kapazität des Trommelfell-Mittelohrs übersteigt oder durch die nicht-akustischen physikalischen Einwirkungen (Luftdruckstoss, Verbremnung od. dgl.) anatomische Läsionen gesetzt werden.

Beim

\section{Rückblick}

über die Erwägungen und Erfahrungen, die sich aus der Fülle unserer Beobachtungen ergeben haben, heben sich als wesentlich folgende Punkte heraus: Bei einer überraschend grossen Zahl von funktionell Schwerhörigen oder Ertaubten hat die eingehende psychopathologische Analyse Abweichungen des Seelenzustandes aufgedeckt, welehe für die Beurteilung des Mechanismus der psychogenen Hörausfälle von ausschlaggebender Bedeutung sind. Die tiefere Ursache für diese Tatsache, welche in schroffem Gegensatz zu der Erfahrung bei den psychogenen Sehstörungen steht, müssen wir wohl in der besonderen Bedeutung erblicken, die dem Gehör als dem Hauptverkehrssinn für das Seelenleben zukommt.

Besonders häufig findet sich ein inniger, meist auch durch den Erfolg der Psychotherapie zu erweisender Zusammenhang. mit Zuständen leichten Stupors von verschiedenartigster Färbung. Vornehmlich in Fällen, die der otriatrischen Beurteilungbesondere Schwierigkeiten boten, weil aus dem derzeitigen 
Ohrbefunde die körperliche Grundlage für die Art der wechselnden Hörausfälle nicht eindeutig ermittelt werden konnte, liess sich durch eine umfangreiche Erhebung der objektiven Anamnese und die psychologische Analyse nachweisen, dass es sich isoliert um psychogene Anreicherung oder Aufpfropfungen auf ,alteingesessene ${ }^{\prime \prime}$ organische Schwerhörigkeiten handelte (,Abrundung nach oben"). Bei eimer Reihe dieser Fälle liess es sich wahrscheinlich machen, dass schon vor ihrer militärischen Einstellung auf dem eigenartigen psychogenen Wege des apperzeptiven Mindergebrauchs ihres Gehörs die Hörfähigkeit nicht so ausgenützt wurde, als es dem organischen Zustande entsprach.

Besonders ron Haus aus schwachsinnige Vertreter des bäuerlichen Standes, die trotz Schwerhörigkeit und mangelhaftex Geistesanlage zur Einstellung kamen, zeigten reaktir nach Einwirkung akustischer Ceberreize oder situativ unter den dem Heeresdienst eigentümlichen Verhältnissen im Rahmen ihrer leichten Stuporzustände solche psychogene, nicht hysterische Verschlechterungen ihrer Hörfähigkeit. Regelmässig traten diese monosymptomatisch, d. h. ohne anderweitige psychogene körperliche Symptome auf. Nach ihrer psychologischen Struktur liessen sich verschiedene Unterformen der afiektiven Absperrungstanbheit (Verdrängung der Hörfähigkeit) und der apperzeptiven Untererregbarkeit herausheben. Neben dem Affekt des Misstrauens spielen hypochondrische Komplexe als Dauermotive eine Rolle.

Bei einzelnen war infolge der affektiven Einwirkung der Hörprüfungen, die regelmässig eigenartige Examensstuporen auslösten, ein objektiver Massstab der Hörfähigkeit nicht zu gewinnell.

Im engeren Sinne hysterische Schwerhörigkeiten oder Taubheiten traten quantitativ in den Hintergrund. Die Vorstellung des Nichthörenkönnems machte sich geltend in der psychischen Infektion eines Ohrs dureh das organisch kranke andere oder als Eigennachahmung (Automimesis) ausgeglichener früherer organischer Hörstörungen (ideogene Absperrungstaubheiten).

Daneben kam auch die bewusst willkürliche Nachahmung früher organisch, dann hysterisch bedingter Hörausfälle (,Simulationshysterie") zur Beobachtung. Bei dem Mangel brauchbarer Simulationsproben zur Unterscheidung von hysterischer und simulierter Taubheit verdient als indirektes Merk- 
532 Dr. A. Kehrer. Psychogene Störungen des Auges und des Gehörs.

mal die Art der psychischen Kurve bei der Psychotherapie Beachtung. Auch in dem einen Falle von reiner Simulation handelt es sich um den Rekurs auf eine ursprünglich organische Schwerhörigkeit nach Verschüttung.

Taubstummheit und häufig auch Taubheiten, die sich ohne Verletzung des Gehörapparates bei bis dahin Ohrgesunden nach Explosion oder Verschüttung etablieren, sind auf eigenartige abnorme Seelenzustände zurückzuführen und entwickeln sich regelmässig nur auf dem Boden irgendwie nachweisbarer psychasthenischer oder hysteriseher Anlage.

In allen Fällen psychogener Hörausfälle lässt sich also entweder eine körperliche Grundlage oder eine abnorme seelisch-nervöse Anlage oder beides nebeneinander nachweisen. 